\title{
Die Rolle des S1P-Rezeptors S1P5, des S1P-Transporters Spinster 2 und der kettenlängenspezifischen Ceramide bei Nierenfibrose
}

\author{
Dissertation \\ zur Erlangung des Doktorgrades \\ der Naturwissenschaften \\ vorgelegt beim Fachbereich Biochemie, Chemie und Pharmazie (14) \\ der Johann Wolfgang Goethe - Universität \\ in Frankfurt am Main
}

\author{
von \\ Timon Sebastian Eckes \\ aus Bad Soden (Taunus)
}

Frankfurt am Main (2021)

(D30) 
vom Fachbereich Biochemie, Chemie und Pharmazie (14) der Johann Wolfgang Goethe - Universität als Dissertation angenommen.

Dekan: Prof. Dr. Clemens Glaubitz

Gutachter: Prof. Dr. Dieter Steinhilber

Prof. Dr. Josef Pfeilschifter

Datum der Disputation: 


\section{Inhaltsverzeichnis}

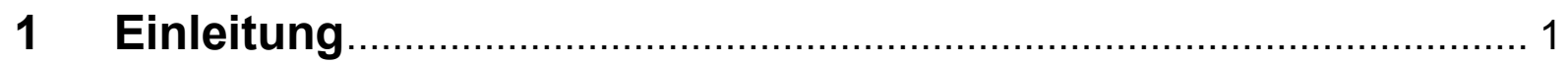

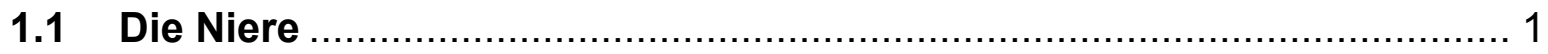

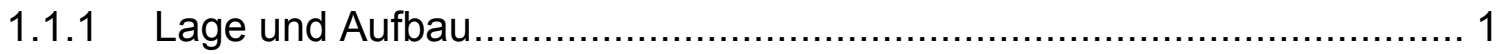

1.1.2 Aufbau und Funktion des Glomerulums und Tubulussystems .............. 2

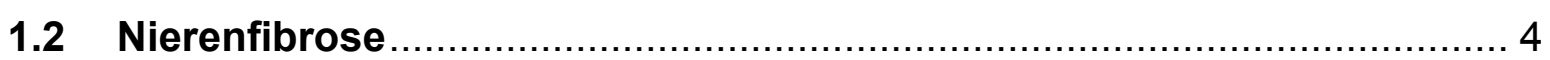

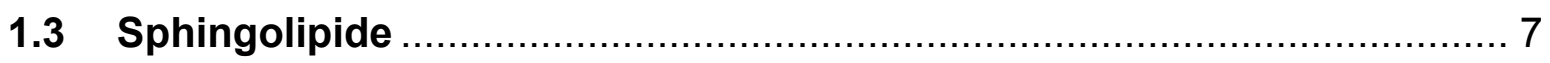

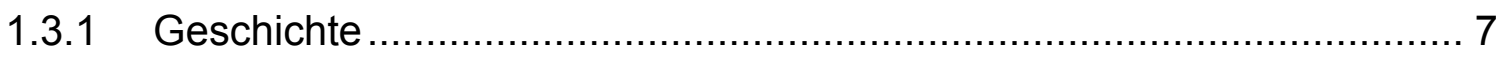

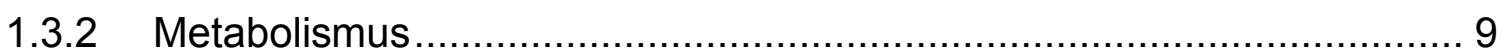

1.3.3 Sphingosinkinase-1 und Sphingosinkinase-2 ….............................. 11

1.3.4 Der S1P-Transporter Spinster Homolog 2 (Spns2) ............................ 13

1.3.5 Die S1P-Rezeptoren ................................................................ 16

1.3.6 Die Rolle der S1P-Rezeptoren bei renaler Fibrose ............................ 20

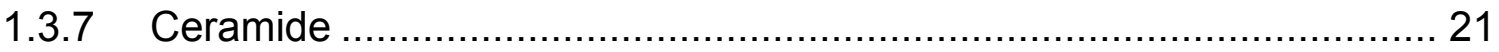

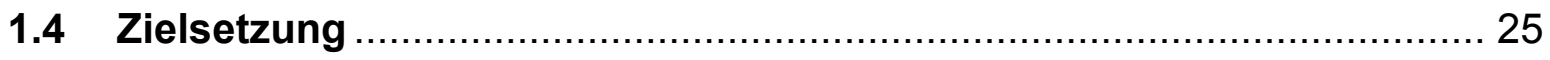

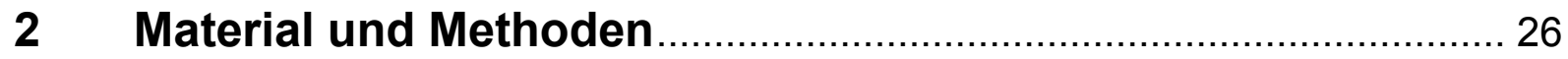

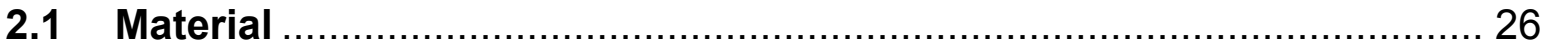

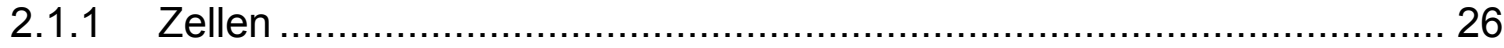

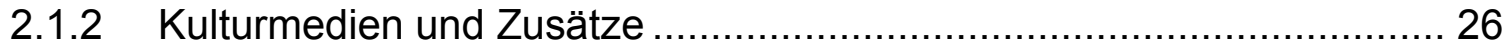

2.1.3 Zusammensetzung des Wachstumsmediums................................... 27

2.1.4 Zusammensetzung anderer Medien .............................................. 27

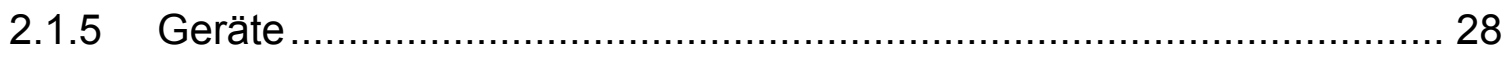

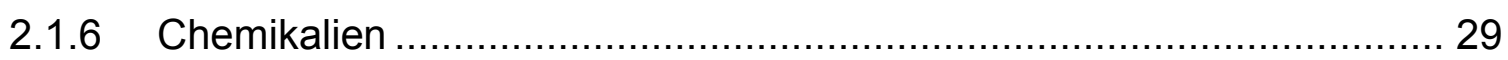

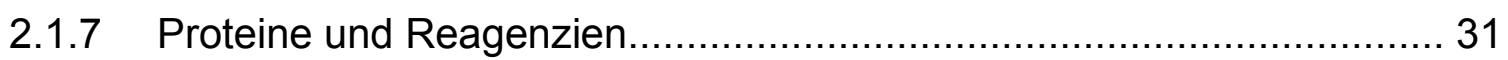

2.1.8 Antikörper für Western Blot ......................................................... 32

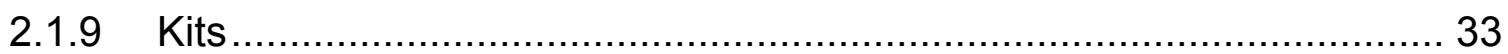

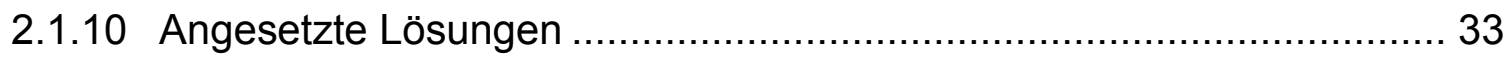




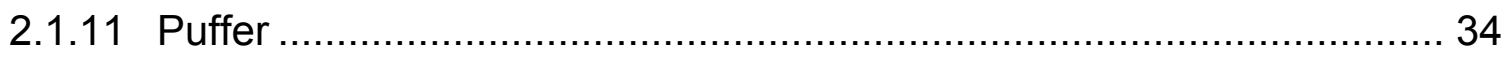

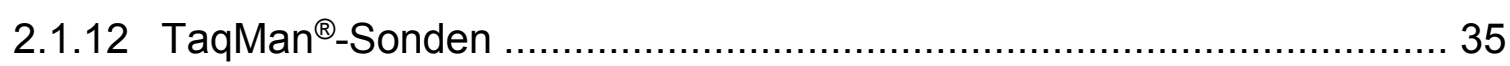

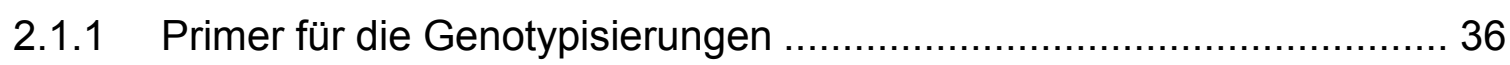

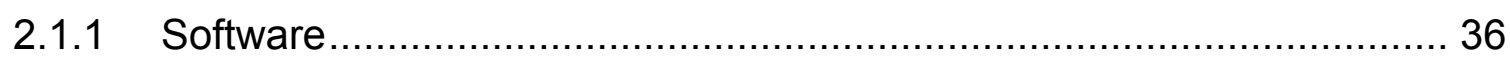

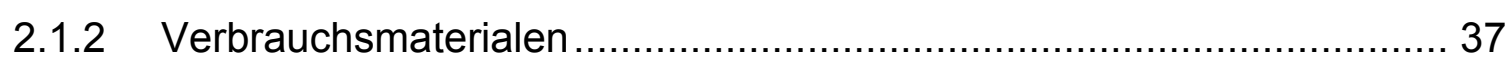

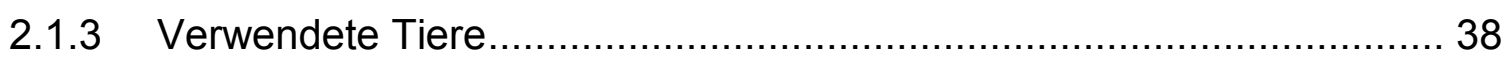

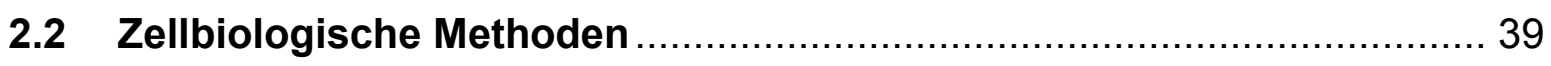

2.2.1 Isolation von Glomerula zur Kultivierung von Mesangiumzellen ..............

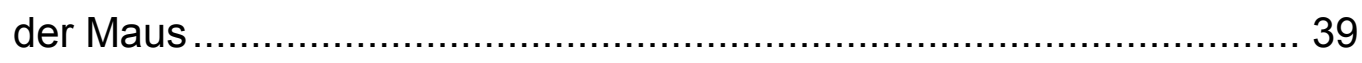

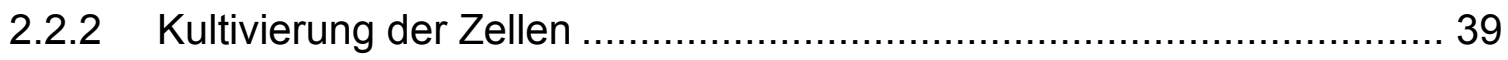

2.2.3 Stimulation adhärent wachsender Zellen ........................................... 40

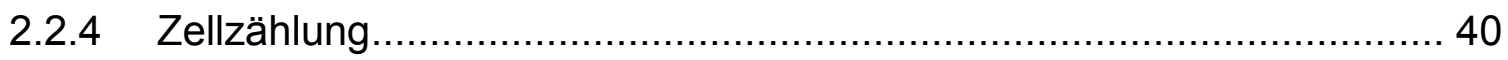

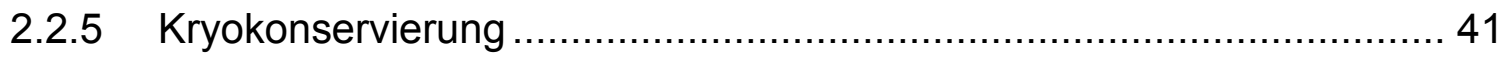

\subsection{Modell der Adenin-induzierten tubulointerstitiellen Nierenfibrose}

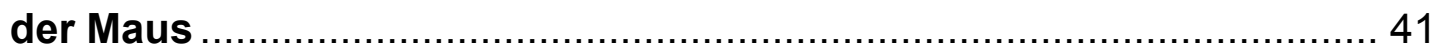

2.4 Lipid-Analyse mittels LC-ESI-MS/MS ….......................................... 43

2.4.1 Genotypisierung mittels Polymerase-Kettenreaktion .......................... 44

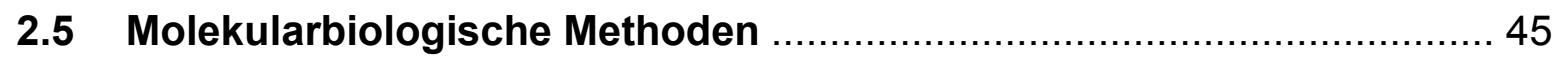

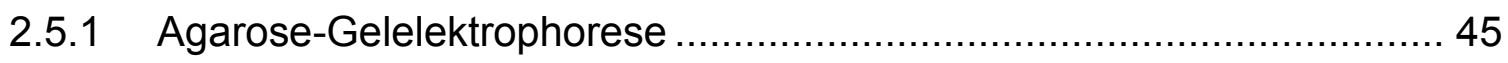

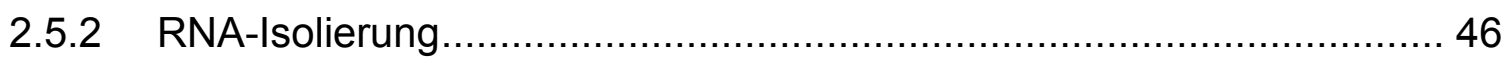

2.5.3 Konzentrations- und Reinheitsbestimmung isolierter RNA ................. 47

2.5.4 Reverse Transkriptase-PCR (RT-PCR) …........................................ 47

2.5.5 Quantitative Real-Time-PCR $\left(\operatorname{Taqman}^{\circledR}\right)$......................................... 48

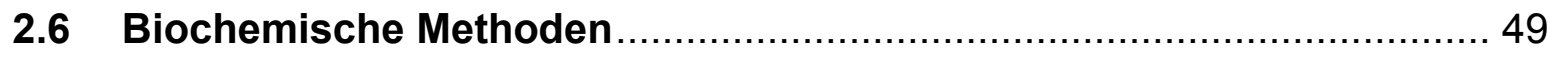

2.6.1 Präparation von Zelllysaten und Gewebehomogenisaten .................... 49

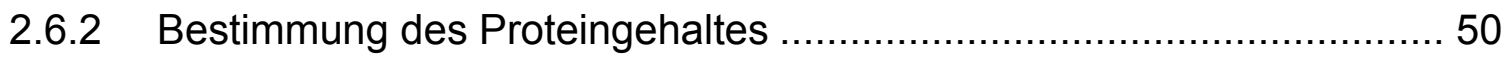

2.6.3 Trichloressigsäure-Proteinfällung aus Zellkulturüberständen ............... 50

2.6.4 SDS-Polyacrylamid-Gelelektrophorese (SDS-PAGE) ......................... 51 


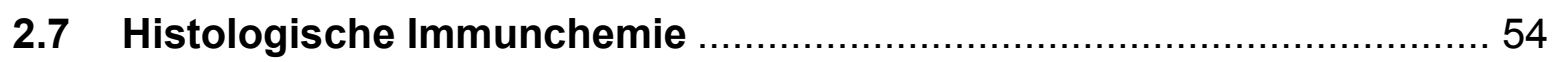

2.7.1 Vorbereitung der Paraffinblöcke........................................................... 54

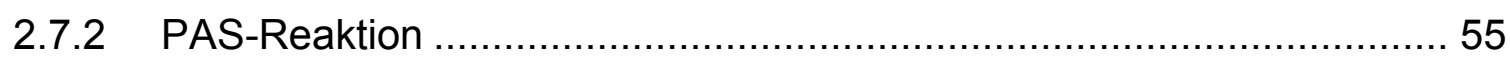

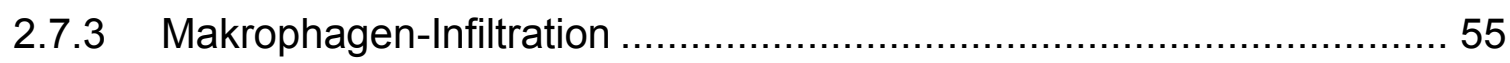

2.8 Datenanalyse und Präsentation .............................................................. 56

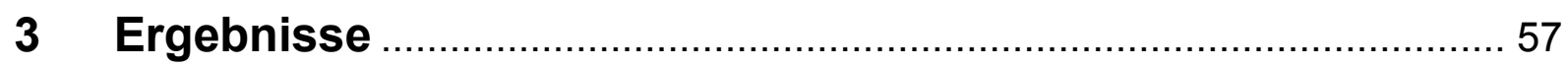

3.1 Untersuchung der Rolle des Sphingosin-1-Phosphat-Rezeptors 5

(S1P5) in fibrotischen Nierenerkrankungen ...................................... 57

3.1.1 S1P5-Expression ist erhöht in fibrotischem Nierengewebe .................. 57

3.1.2 S1 $\mathrm{P}^{-1-}$-Mäuse zeigen einen milderen Verlauf bei der .............................

Adenin-induzierten Nephropathie................................................... 58

3.1.3 Untersuchung des Gewebeschadens ............................................. 60

3.1.4 Untersuchung von Entzündungsmarkern ........................................... 63

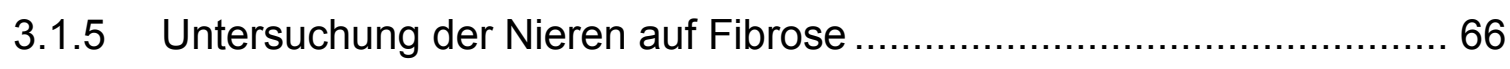

3.1.6 Untersuchung des Sphingolipidmetabolismus .................................. 68

3.2 Untersuchung der Veränderungen von kettenlängen-spezifischen ..........

Ceramiden in fibrotischen Nieren......................................................... 72

3.2.1 Veränderungen der Konzentrationen von Ceramiden in humanen ...........

Nierenrinden bei Fibrose .............................................................. 72

3.2.2 Veränderungen der Konzentrationen von Ceramiden in humanem ..........

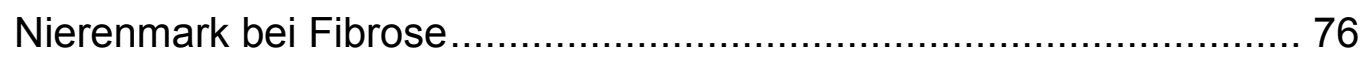

3.2.3 Unterschiede der Konzentrationen von kettenlängen-spezifischen.

Ceramiden zwischen Nierenrinde und Nierenmark in gesunden

Biopsien

3.2.4 Veränderungen der Konzentrationen von kettenlängen-spezifischen

Ceramiden in murinem Nierengewebe.

3.3 Die Rolle des Sphingosin-1-Phosphat-Transporters Spns2 im Kontext der Nierenfibrose 
3.3.1 Die Genexpression der SK-1 und S1P-Lyase ist unverändert in Spns2 $2^{-/-}$-Zellen im Vergleich zu Spns2 $2^{+/+}$-Zellen. 85

3.3.2 Spns2-/-Zellen bilden weniger CTGF nach Stimulation mit TFG- $\beta_{2} \ldots \ldots 87$

4 Diskussion. 88

4.1 Untersuchung der Rolle des Sphingosin-1-Phosphat Rezeptors 5 $\left(\mathrm{S}_{1} \mathrm{P}_{5}\right)$ in fibrotischen Nierenerkrankungen

4.2 Untersuchung der Veränderungen von kettenlängen-spezifischen Ceramiden in fibrotischen Nieren.

4.3 Die Rolle des Sphingosin-1-Phosphat-Transporters Spns2 im Kontext der Nierenfibrose. 98

5 Ausblick 100

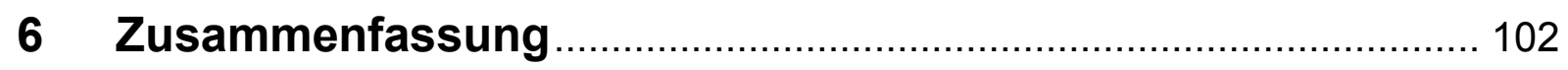

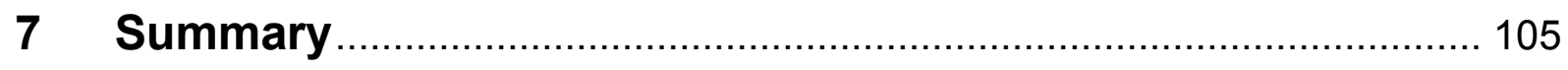

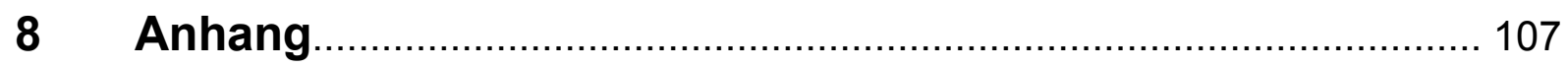

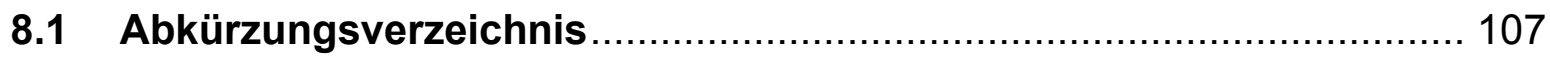

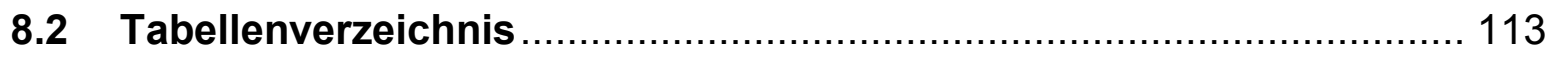

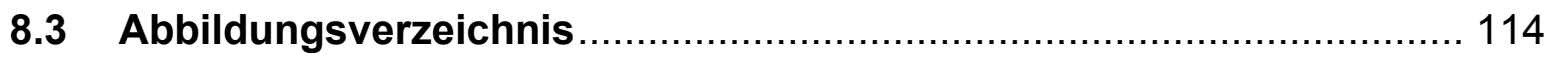

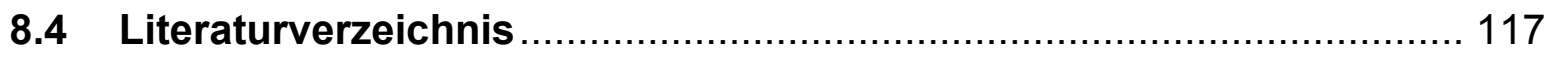

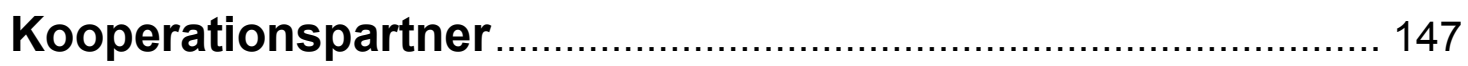

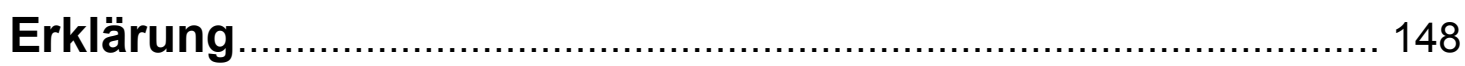




\section{Einleitung}

\subsection{Die Niere}

\subsubsection{Lage und Aufbau}

Die Nieren sind ein paarig angelegtes Organ, welches lebenswichtige Funktionen für den Organismus ausübt und seitlich im Retroperitonealraum liegt. Eine einzelne Niere eines ausgewachsenen Menschens ist in der Regel ca. $12 \mathrm{~cm}$ lang, $6 \mathrm{~cm}$ breit und wiegt etwa $150 \mathrm{~g}$ und wird von einer Kapsel aus Bindegewebe (Capsula fibrosa renis) und einer Fettkapsel (Capsula adiposa renis) umgeben. Grob wird die Niere in Nierenhilus und Nierenparenchym unterteilt (Klingele und Brodmann 2017).

Im Nierenhilus findet der Bluttransport über die Arteria renalis und Vena renalis als auch der Abtransport des Urins über den Harnleiter (Ureter) zur Blase statt. Das Nierenparenchym besteht aus der 1-1,5 cm dicken Rinde (Cortex renalis) und dem innenliegenden Mark (Medulla renalis) (Abbildung 1). Die Niere ist von einer Schicht aus Bindegewebe, der Nierenkapsel, umhüllt. Das Nierenmark ist in 10-12 kegelförmige Markpyramiden (Pyramides renales) unterteilt. Eine Markpyramide besitzt breit gefächerte Markstrahlen, die in Richtung Nierenrinde zeigen, und in entgegengesetzter Richtung spitz zulaufende Nierenpapillen (Papillae renales), welche in einen kleinen Nierenkelch (Calix renales) münden. Die kleinen und großen Nierenkelche (Calices minores renales et calices majores renales) vereinen sich zum Nierenbecken (Pelvis renalis), welches sich zum Harnleiter verjüngt.

Die Nephrone erstrecken sich über Rinde und Mark und bilden die funktionellen Einheiten der Niere, in denen unter anderem die Bildung des Urins stattfindet. Das Nephron besteht zum einen aus dem Glomerulum, welches im Bereich des Cortex liegt und als eine Art Filter den Primärharn aus dem Blut abpresst. Den anderen Teil des Nephrons bildet das tubuläre System, welches im Mark sitzt und für die Resorption von Wasser, Glucose und Salzen aus dem Primärharn verantwortlich ist, aber auch zur Sekretion von bestimmten Elektrolyten dient. Eine einzelne menschliche Niere enthält ca. 1-3 Millionen Nephrone (Klingele und Brodmann 2017). 


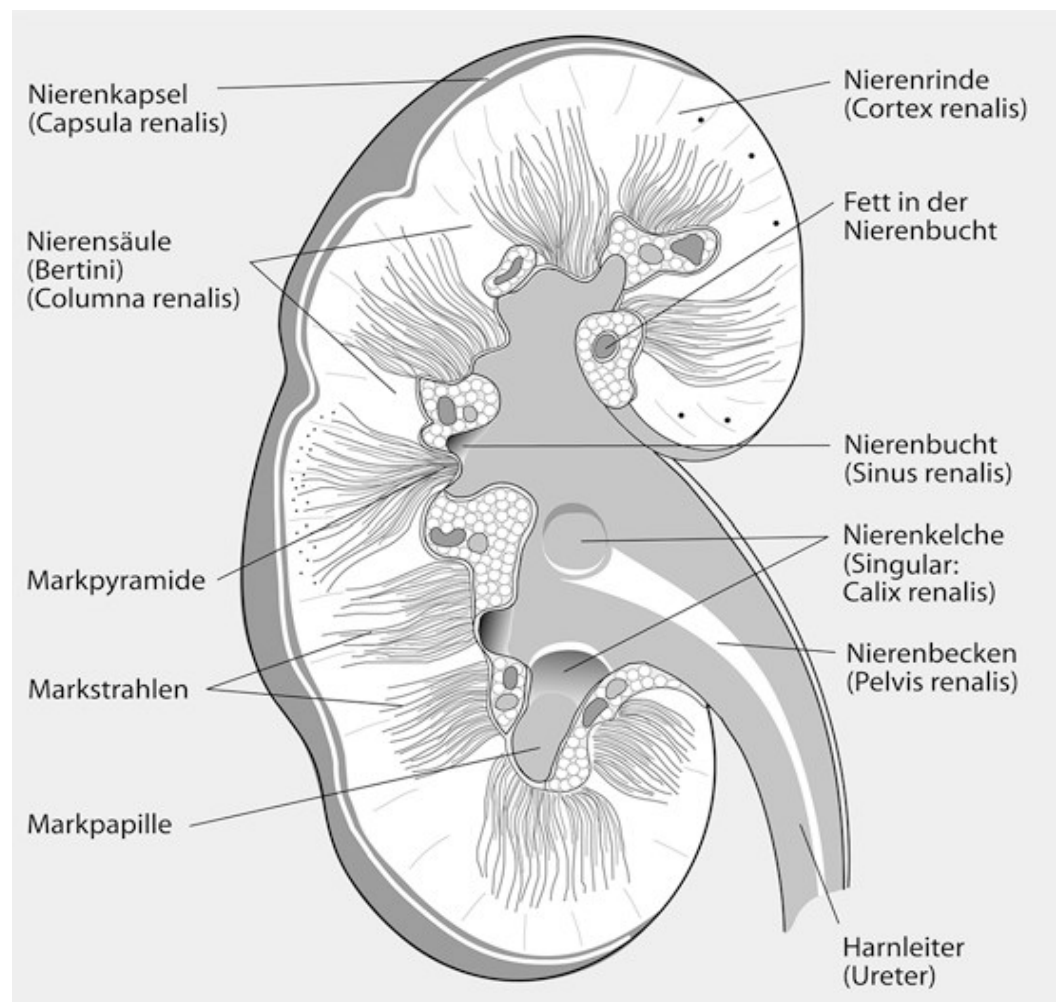

Abbildung 1: Schematischer Aufbau der Niere. Makroskopischer Längsschnitt durch die Niere mit Unterteilung in Nierenrinde und Nierenmark. Diese beherbergen die Nephrone, welche den Harn über Sammelrohre in das Nierenbecken und zu den abführenden Harnwegen leiten (Abb. von Nowack et al. 2009).

\subsubsection{Aufbau und Funktion des Glomerulums und Tubulussystems}

Das Glomerulum ist die kugelförmige Filtrationseinheit, die aus einer Hülle, der Bowman-Kapsel, und einem innenliegenden Gefäßknäuel besteht (Klingele und Brodmann 2017). Dieses Gefäßknäuel besteht aus feinen Kapillaren, aus deren Lücken Flüssigkeit aus dem Blut heraus in die Bowman-Kapsel gelangen kann. Die Kapillaren entstammen einer afferenten Arteriole und das gefilterte Blut verlässt das Glomerulum wieder in einer vereinten efferenten Arteriole (Abbildung 2). Podozyten, die ihren Namen durch ihre langen, ineinander verzahnten Fortsätze erhalten haben, bilden die Schlitzmembran als wichtigen Bestandteil der Blut-Harn-Schranke. Sie liegen auf den Endothelzellen der Kapillaren auf und sorgen dafür, dass Moleküle ab einer Größe von ca. 65.000 Dalton (wie zum Beispiel Albumin) nicht in den Primärharn gelangen. Des Weiteren sorgt die negative Ladung der Basalmembran dafür, dass insbesondere Proteine nicht aus dem Blut gefiltert werden. Im Laufe eines Tages 
werden ca. 180 Liter (60-faches Plasmavolumen) Primärharn abgepresst. Dieser Primärharn läuft anschließend durch das Tubulussystem und aufgrund von Rückresorption bleibt zum Schluss lediglich ein Volumen von 1,5-2 Liter übrig, welches als Urin ausgeschieden wird.

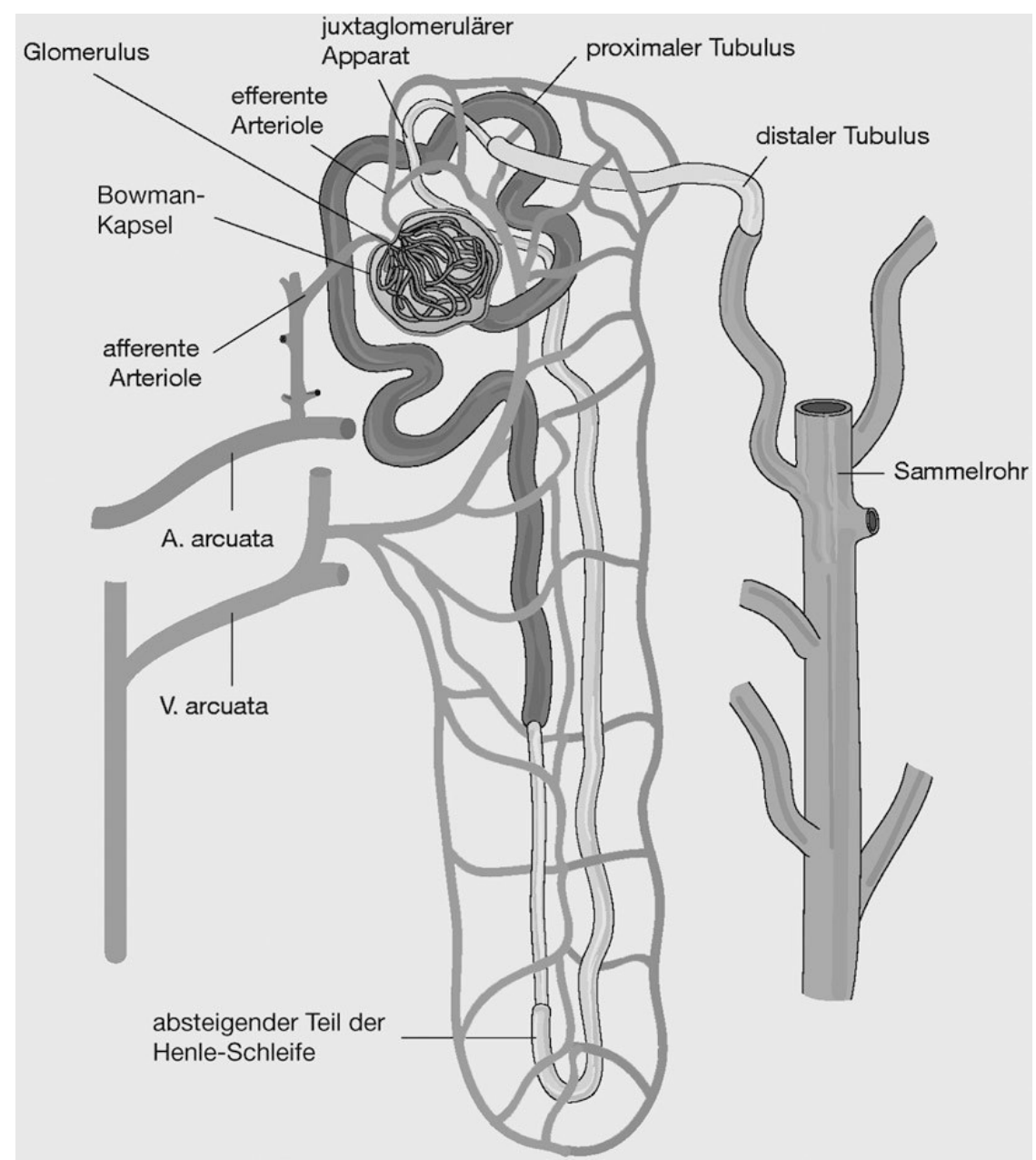

Abbildung 2: Schematischer Aufbau eines Nephrons. Das Nephron, als kleinste Funktionseinheit der Niere, bestehend aus Nierenkörperchen und Tubulussystem, filtriert den Primärharn, aus dem im Anschluss verschiedene Stoffe sowohl sezerniert als auch rückresorbiert werden. Das Tubulussystem konzentriert den Harn und mündet in das Sammelrohr. Der juxtaglomeruläre Apparat steuert den Filtrationsdruck zur Primärharnbildung und reguliert den Blutdruck (Abb. von Larsen 2016).

Neben Wasser und Elektrolyten werden auch nützliche Blutbestandteile wie Glucose, kleine Proteine und Aminosäuren rückresorbiert. In ihrer Aufgabe als exkretorisches Organ werden über die Niere harnpflichtige Endprodukte des Purin- und Stickstoffstoffwechsels (Kreatinin, Harnstoff, Harnsäure) sowie vom Körper aufgenommene Fremdstoffe über den gebildeten Harn ausgeschieden. Des Weiteren 
werden auch überschüssige Elektrolyte und Säuren aus dem Körper entfernt und somit reguliert die Niere den Elektrolythaushalt und das Säure-Basen-Gleichgewicht.

Die Niere übernimmt zusätzlich auch Aufgaben eines endokrines Organs und ist involviert in der Synthese und Metabolisierung von Hormonen wie Prostaglandinen und Erythropoetin (Klingele und Brodmann 2017). Über das Renin-AngiotensinSystem wird, ausgehend von der Niere, Einfluss auf den Blutdruck und Elektrolythaushalt genommen. Zusätzlich wird in den proximalen Tubuluszellen Calcitriol, die aktive Form von Vitamin $\mathrm{D}_{3}$, gebildet, wodurch der Kalzium- und Phosphathaushalt reguliert wird. Die Tubuli sind umgeben von Kapillaren, wodurch ein Austausch von Wasser und anderen Molekülen zwischen dem im Tubuluslumen befindlichem Urin und dem Blut stattfinden kann. Letztendlich mündet das Tubulussystem aus dem Nierenmark in das Nierenbecken und der Urin wird von dort aus über den Ureter zur Harnblase geführt.

\subsection{Nierenfibrose}

Eine Fibrose beschreibt die übermäßige, unkontrollierte Ablagerung von Bindegewebe nach Gewebeschädigung, welche zur Narbenbildung (Sklerose) im Gewebe führt. Die Filtration des Blutes in der Niere wird hierdurch gestört, was zu einem völligen Funktionsverlust des Organs führen kann. Die Fibrose ist ein wichtiges Charakteristikum von nahezu jeder Form der chronischen Niereninsuffizienz (chronic kidney disease, CKD) an der allein in den Vereinigten Staaten über 30 Millionen Menschen leiden (Saran et al. 2019). Es wird zudem vom US Zentrum für Krankheitskontrolle und Prävention befürchtet, dass $47 \%$ der über 30 Jahre alten Bürger in ihrem Leben an einer CKD erkranken werden (Hoerger et al. 2010). Dies liegt auch an der rasant steigenden Anzahl an Diabetikern, von denen $36 \%$ an einer CKD leiden und die als diabetische Nephropathie (DN) bezeichnet wird (Saran et al. 2019). Dieser hohe Anteil wirkt besonders dramatisch, da die Anzahl der Diabetiker im Jahr 2019 weltweit schon auf 463 Millionen Erwachsene (über 20 Jahre) gestiegen ist und im Jahr 2045 bei 700 Millionen liegen könnte (Saeedi et al. 2019). Über das Leiden der Menschen hinaus bedeutet dies auch eine große finanzielle Belastung für das Gesundheitssystem und verschlingt jetzt schon allein in den USA jährlich über 80 Milliarden USD für die Behandlung der CKD und über 30 Milliarden USD für die 
terminale Niereninsuffizienz (end-stage renal disease, ESRD), der letzten Stufe der CKD (Saran et al. 2020). Leider gibt es bisher nur wenige pharmakologische Therapiemöglichkeiten zur Verlangsamung der Progression der CKD wie die Inhibierung des Angiotensin-konvertierenden Enzyms (angiotensin converting enzyme, ACE), Blockade des Angiotensinrezeptors I, Blutdruckkontrolle und Natriumbikarbonat gegen metabolische Azidose ("KDOQI Clinical Practice Guideline for Diabetes and CKD: 2012 Update" 2012). Die Behandlungserfolge sind jedoch immer noch gering. Ungefähr $16 \%$ der Dialysepatienten versterben und die Zahl der Patienten, welche an einer CKD und später ESRD erkranken, steigt weiterhin an (Saran et al. 2020).

Die Fibrose ist ein Krankheitsbild, welches sich nicht nur in der Niere, sondern in vielen Organen in gleicher Weise finden lässt und es wird vermutet, dass fast die Hälfte aller Todesursachen in den entwickelten Ländern auf fibrotische Erkrankungen zurückzuführen sind (Wynn 2008). Unter anderem spielen fibrotische Prozesse auch bei Zirrhose, Kardiomyopathien und idiopathischer Lungenfibrose eine wichtige Rolle (Wynn 2011; Ke und Chen 2012; Weber et al. 2013; Kong et al. 2014).

Die Nierenfibrose kann durch einen Gewebeschaden, Entzündung oder auch hohe Glukosespiegel verursacht werden (Paradis et al. 2001; Li et al. 2003; Yang et al. 2011). Die extrazellulären Matrixproteine, welche das Bindegewebe bilden, lagern sich bei der Nierenfibrose besonders im Interstitium (tubulointerstitielle Fibrose) aber auch in den Glomeruli (Glomerulosklerose) und in den Blutgefäßen (Arteriosklerose) an (Abbildung 3). Kollagen I, das am häufigsten gebildete Matrixprotein, aber auch Kollagen III, V, VI, VII und XV und auch Fibronektin werden bei Fibrose verstärkt exprimiert (Genovese et al. 2014). Für die tubulointerstitielle Fibrose spielen vor allem aktivierte Fibroblasten eine Rolle, welche sich anhand der Expression von alphasmooth muscle actin (a-SMA), das Mikrofilamente für die Anheftung der Zellen an die ECM bildet, erkennen lassen (Zhou und Liu 2016). Für die Entstehung einer Glomerulosklerose sind vor allem Mesangiumzellen verantwortlich, welche durch Proliferation und exzessiver Bildung extrazellulärer Matrix für die Zerstörung der empfindlichen Filtrationseinheit sorgen können (Wahab et al. 1996; Lee 2011). 


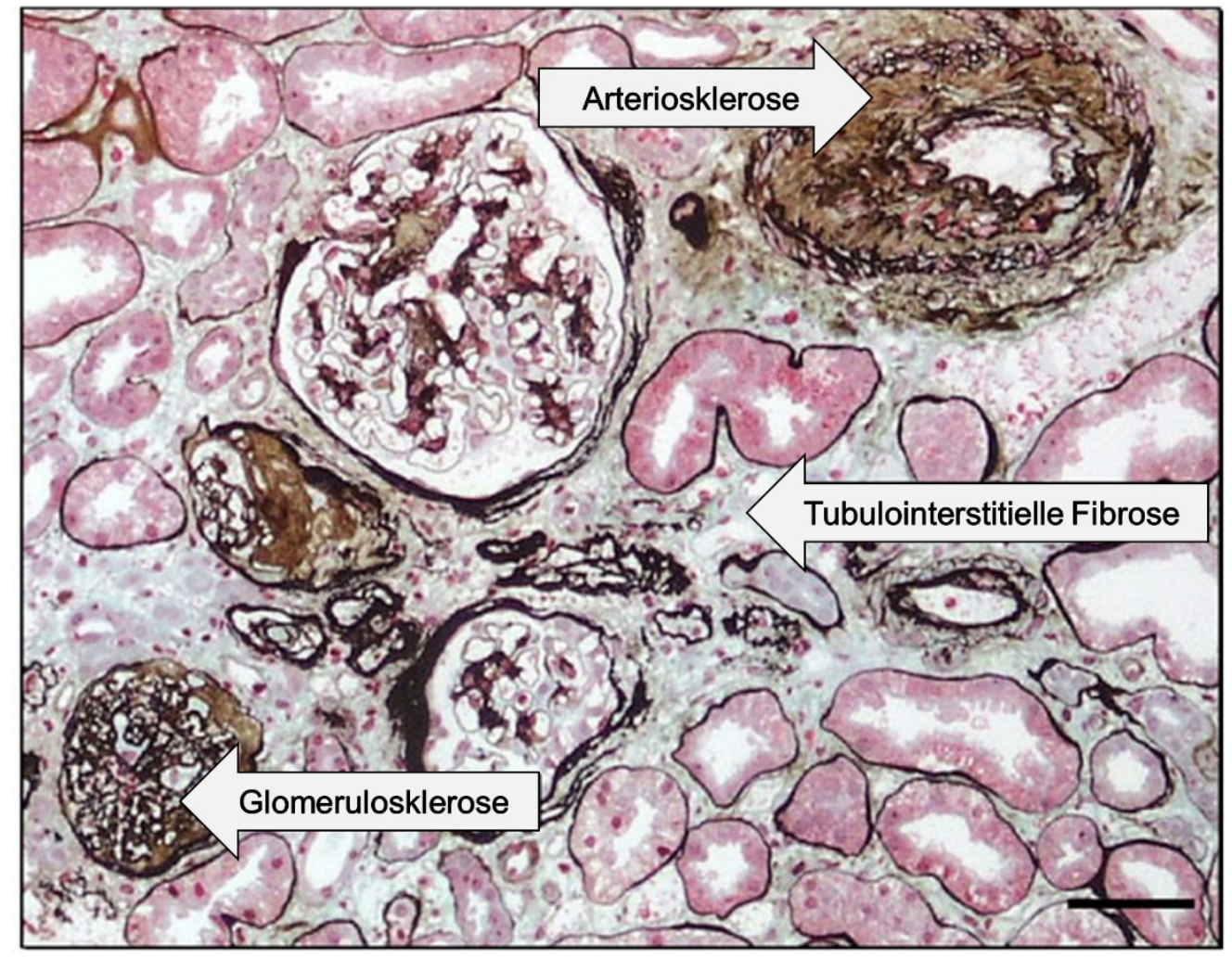

Abbildung 3: Histologischer Schnitt durch eine fibrotische Niere. Methenamin-basierte Silberfärbungen mit Masson-Trichrom-Gegenfärbung. Braune Färbung der Kollagenfasern der glomerulären Basalmembran und der Gefäßwände und leicht grüne Färbung des interstitiellen Bindegewebes. Der Balken entspricht 50 um (Abb. modifiziert von Hewitson 2012).

Eine entscheidende Rolle in der Entstehung von Fibrose und in der Steuerung der Myofibroblasten spielt das Zytokin transforming growth factor beta-1 (TGF- $\beta_{1}$ ) (Kanzler et al. 1999; Grupp et al. 2001). Es wird vermutet, dass Tubuluszellen in der Lage sind über die sogenannte Epitheliale-mesenchymale Transition (EMT) teilweise einen myofibroblastenartigen Phänotyp zu erlangen. In diesem Kontext wurden mehrere Modelle zur CKD wie Unilaterale Ureterobstruktion (UUO), Nephrotoxische Serumnephritis und Folsäure-induzierte Nephropathie mit konditionellen Snai1- oder Twist1-Knockout-Mäusen untersucht (Grande et al. 2015; Lovisa et al. 2015). Diese Studien zeigten, dass die Nierenfibrose durch die in den Knockout-Mäusen erreichte Inhibition des EMT-Programms reduziert und die Funktion und Regeneration der Tubuluszellen verbessert werden konnte. 
Des Weiteren führt auch eine gestörte Beta-Oxidation in den Tubuluszellen zu ATPMangel, Lipidakkumulation und Zelltod, wodurch eine Nierenfibrose begünstigt wird (Kang et al. 2015). Untersuchungen von Kang et al. (2015) zeigten, dass der stark profibrotische Wachstumsfaktor TGF- $\beta$ in der Lage ist, die Expression wichtiger Enzyme wie die Carnitin-Palmitoyltransferase 1, welche den geschwindigkeitsbestimmenden Schritt der Beta-Oxidation durchführt, zu unterdrücken. In einer anderen Studie wurde gezeigt, dass TGF- $\beta$ auch über microRNA-21 den Metabolismus in Tubuli stören und somit zur Fibrose beitragen kann (Gomez et al. 2015).

\subsection{Sphingolipide}

\subsubsection{Geschichte}

Sphingolipide sind essentielle Bestandteile von eukaryotischen Zellmembranen und wurden auch in manchen Prokaryoten nachgewiesen (LaBach und White 1969; Hannun und Bell 1989). Das strukturelle Rückgrat aller Sphingolipide bildet das Molekül Sphingosin. Sphingolipide werden vermehrt im Nervengewebe gefunden und haben verschiedene Funktionen inne.

Die Stoffklasse der Sphingolipide wurde erstmals 1884 vom hessischen Arzt Johann Ludwig Wilhelm Thudichum in seiner Arbeit „A Treatise on the Chemical Constitution of the Brain" beschrieben, nachdem er diese aus den Gehirnen von Ochsen und Menschen isoliert hatte. Da ihre Struktur und Funktion für inn ein Rätsel darstellte, benannte er sie nach der mythischen Figur Sphinx (Huwiler et al. 2000; Futerman und Hannun 2004). Zunächst wurde davon ausgegangen, dass Sphingolipide lediglich eine strukturelle Aufgabe für Zellmembranen haben und es dauerte etwa hundert Jahre bis gezeigt werden konnte, dass bestimmte Sphingolipide als Signalmoleküle wirken können.

So wurde 1991 herausgefunden, dass Sphingosin-1-Phosphat (S1P) in der Lage ist, Genexpression und Proliferation in Swiss 3T3-Fibroblasten zu induzieren und ihre Morphologie zu beeinflussen (Zhang et al. 1991). Darüber hinaus wurde in dieser Studie festgestellt, dass die Stimulation dieser Zellen mit S1P zur Freisetzung von intrazellulär gespeicherten Calciumionen führt. 
Anschließend wurde die Wirkung von S1P, welches in hoher Konzentration in fötalem Kälberserum (FKS) gefunden wurde, als proliferationsfördernder second messenger im Signalweg des platelet-derived growth factor (PDGF) beschrieben (Olivera und Spiegel 1993).

Zur selben Zeit wurde hingegen anhand des synthetischen, kurzkettigen C2-Ceramids auch gezeigt, dass andere Sphingolipide in der Lage sind, Apoptose zu induzieren (Obeid et al. 1993). Diese gegensätzlichen Effekte von bestimmten Ceramiden und S1P, die metabolisch nur durch zwei enzymatisch katalysierte Umwandlungen getrennt sind und über das Schicksal einer Zelle entscheiden können, wurden daraufhin in der Sphingolipid-Rheostat-Theorie zusammengefasst (Cuvillier et al. 1996).

Die besondere Rolle von S1P für die Medizin wurde schließlich durch die Entdeckung der S1P-Rezeptoren möglich. 1998 wurde beschrieben, dass S1P als Ligand eines GProtein-gekoppelter-Rezeptor fungiert (Lee et al. 1998). Dieser Rezeptor war bis dahin als endothelial differentiation gene 1 (EDG-1) bezeichnet worden, doch nach der Identifizierung des Liganden in S1P-Rezeptor-1 (S1P1) umbenannt worden (Wang et al. 2001). Zwei Jahre später wurde der fünfte und bisher letzte bekannte S1P-Rezeptor (EDG-8), jetzt als S1P 5 bekannt, beschrieben (Im et al. 2000). Eine Dekade später wurde auch die Kristallstruktur von S1P1 entschlüsselt (Parrill et al. 2012; Hanson und Peach 2014).

Die fünf S1P-Rezeptoren unterscheiden sich nicht nur in ihrem Expressionsmuster, welches abhängig von Gewebe und Zelltyp ist, sondern auch durch die Kopplung an unterschiedliche G-Proteine (Spiegel und Milstien 2003). Bis heute wurden in etlichen Arbeiten die Funktionen und Veränderungen von Sphingolipiden bei bestimmen Krankheiten untersucht und dennoch sind viele Fragen bisher ungeklärt. In meiner Arbeit wird nun konkret die Rolle von $\mathrm{S} \mathrm{P}_{5}$ und sehr langkettigen Ceramiden im Kontext von fibrotischen Veränderungen in der Niere untersucht. 


\subsubsection{Metabolismus}

Die de novo-Synthese von Sphingolipiden erfolgt aus der Kondensationsreaktion von Serin und Palmitoyl-CoA, welche von der Serin-Palmitoyltransferase katalysiert wird (Huwiler und Pfeilschifter 2018). Das entstandene 3-Keto-Dihydrosphingosin wird anschließend mit Hilfe der 3-Keto-Dihydrosphingosin-Reduktase zu Dihydrosphingosin (auch Sphinganin genannt) reduziert (Abbildung 4).

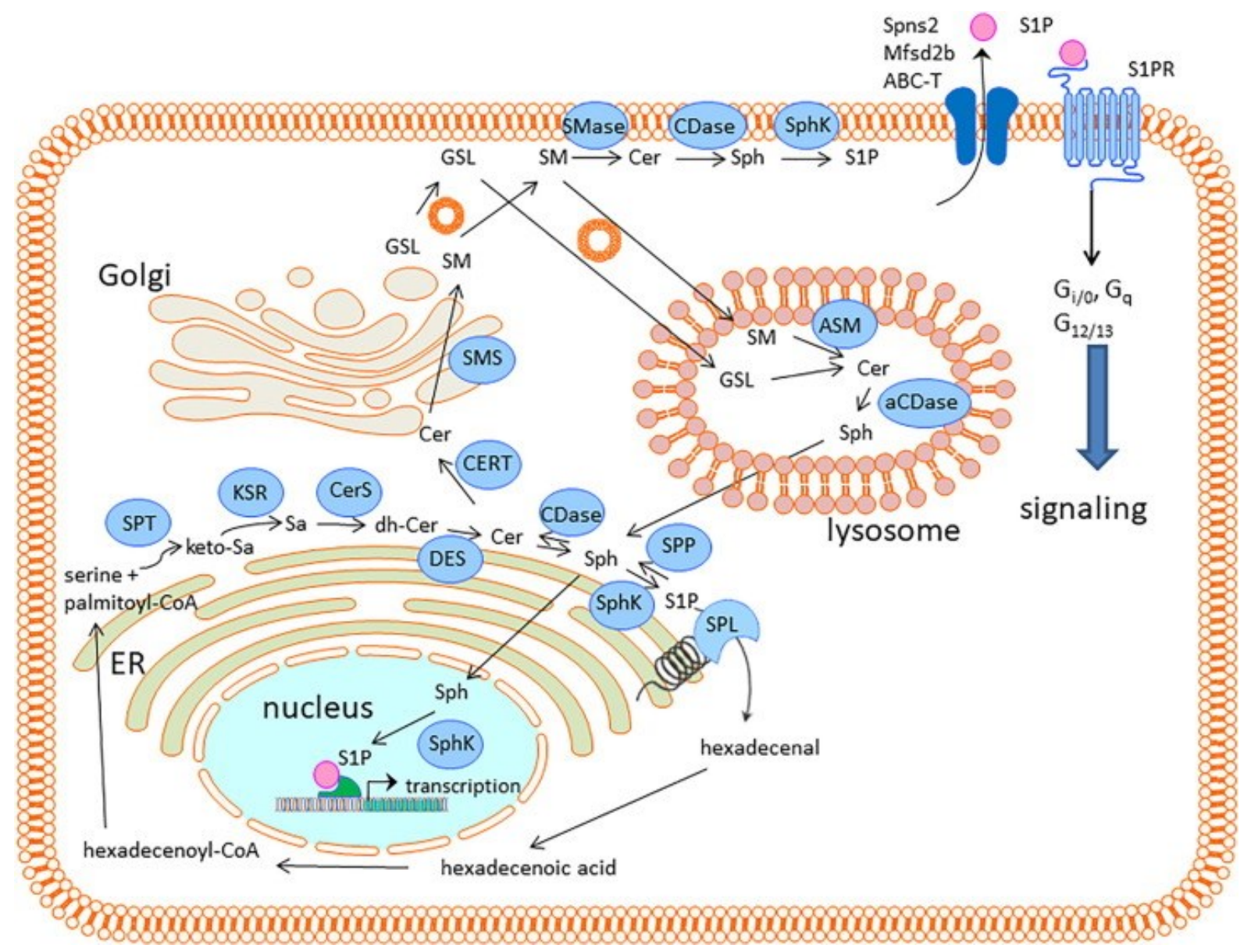

Abbildung 4: Übersicht über die Lokalisation und Stoffwechselwege der Sphingolipide inklusive der beteiligten Enzyme in den verschiedenen Zellkompartimenten. Die de novo-Synthese der Sphingolipide einschließlich der Verstoffwechslung hin zu Ceramiden (Cer) und S1P erfolgt im ER. S1P kann dort irreversibel degradiert werden oder aber in den Zellkern wandern und dort die Transkription beeinflussen. Cer werden zum Golgi-Apparat transportiert und dort in Sphingomyelin (SM) umgewandelt. SM erreicht über vesikulären Transport die Zellmembran und kann dort über Cer wieder zu Sphingosin (Sph) abgebaut werden. Sphingosinkinasen in der Plasmamembran (PM) können Sph zu S1P umwandeln, welches mittels aktiven Transports durch die PM aus der Zelle geschleust werden kann, um extrazelluläre S1P-Rezeptoren zu aktivieren. Über Endozytose sind Sphingolipide auch im Lysosom vertreten und können dort ebenfalls weiter verstoffwechselt werden (Abb. von Huwiler und Pfeilschifter 2018). 
Diese Katalyse findet auf der zytoplasmatischen Seite des endoplasmatischen Retikulums (ER) statt. An das Sphinganin kann nun ein Fettsäurerest mit einer Kettenlänge von 14 bis 26 Kohlenstoffatomen geknüpft werden. Die Wahl des AcylCoA-Substrats wird durch die Ceramidsynthasen vorgegeben. Die sechs verschiedenen Ceramidsynthasen unterscheiden sich in ihrer Präferenz für Substrate mit bestimmter Kettenlänge und in ihrem Expressionsmuster. Das entstandene Dihydroceramid kann entweder wieder zu Sphinganin und einem Fettsäurerest von einer Ceramidase gespalten werden oder aber durch die Desaturase zu Ceramid reduziert werden.

Vom ER aus können die Ceramide ohne Hilfe von Vesikeln über das Ceramidtransferprotein (CERT) zum Golgi-Apparat transportiert werden (Hanada et al. 2003). Dort angekommen können die Ceramide mit einem oder mehreren Zuckerresten verknüpft werden, um komplexe Sphingolipide wie Cerebroside und Ganglioside zu bilden (Abbildung 5). Ceramide können aber auch mit Hilfe der Sphingomyelinsynthase durch das Verestern mit Phosphocholin oder Phosphoethanolamin zu Sphingomyelinen metabolisiert werden (Abbildung 5). Die Rückreaktion kann durch die saure, alkalische oder neutrale Sphingomyelinase katalysiert werden. Diese Enzyme sind in bestimmten Zellkompartimenten, wie der Plasmamembran oder Lysosomen zu finden. Sphingomyelin und komplexe Sphingolipide können über vesikulären Transport die Plasmamembran und auch die Lysosomen erreichen. Sphingomyelin ist das am häufigsten vorkommende Sphingolipid und bildet einen großen Anteil an den Lipiden der Plasmamembran. Über den sogenannten salvage pathway kann Ceramid mit Hilfe der Ceramidase wieder zu einer Fettsäure und Sphingosin hydrolysiert werden. Darüber hinaus kann Sphingosin über die zwei Sphingosinkinasen 1 und 2 (SK-1 und SK-2) zu Sphingosin1-Phosphat phosphoryliert werden. Die Rückreaktion kann durch die S1PPhosphatasen 1 und 2 oder anderen Phosphatidat-Phosphatasen katalysiert werden. S1P kann jedoch auch irreversibel mit Hilfe der S1P-Lyase zu Hexadecenal und Phosphoethanolamin abgebaut werden. S1P ist ein bedeutendes Molekül der Sphingolipide und gilt als bioaktiver Lipidmediator, da es zahlreiche Signalwege aktivieren, Zellmigration steuern und die Genexpression beeinflussen kann. 

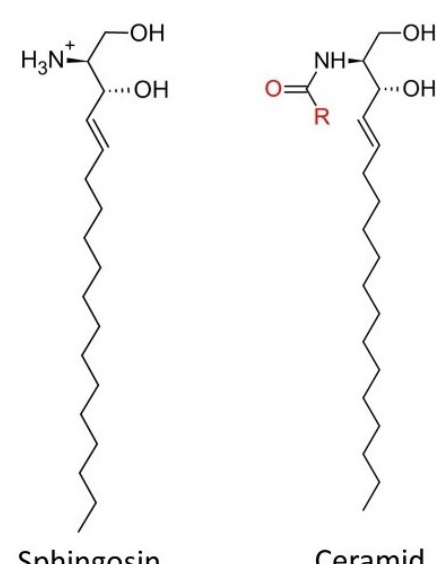

Ceramid

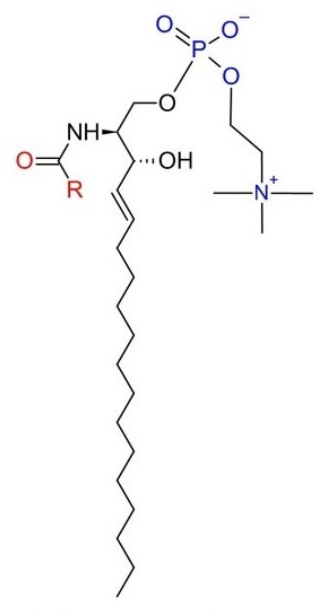

Sphingomyelin

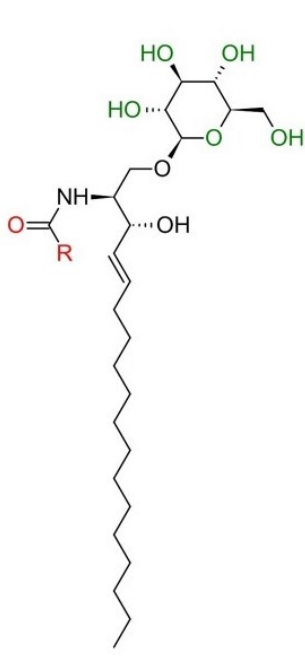

Cerebrosid

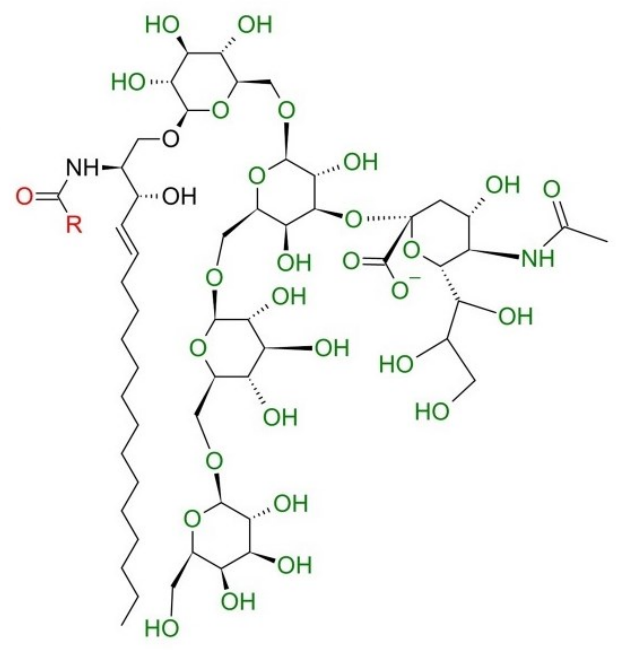

Gangliosid

Abbildung 5: Strukturformeln der wichtigsten Vertreter der Sphingolipide. Das Grundgerüst der Sphingolipide bildet der einfach ungesättigte Aminoalkohol Sphingosin, welcher aus einer langen Kohlenwasserstoffkette aus $18 \mathrm{C}$-Atomen und einem polaren Kopf, gebildet von einer Amino- und zwei Hydroxygruppen, besteht. Durch die Kondensation mit einer Fettsäure kann eine Carbonsäureamidbindung ausgebildet werden. Die entstandenen Moleküle werden Ceramide genannt. An die primäre Hydroxygruppe des Sphingosinrückgrats können eine Phosphocholin- oder Phosphoethanolamingruppe geknüpft werden, wodurch Sphingomyeline entstehen. Es finden sich aber auch Verbindungen mit einzelnen Zuckern oder Oligosacchariden zur Bildung von Cerebrosiden bzw. Gangliosiden.

\subsubsection{Sphingosinkinase-1 und Sphingosinkinase-2}

S1P wird aus Sphingosin durch eine enzymatisch katalysierte Phosphorylierung auf der zytosolischen Seite der Zellmembran gebildet und kann aufgrund des geladenen Phosphatrests nur mit Hilfe von Transportproteinen die Zellmembran passieren 
(Maceyka et al. 2012). Es gibt zwei verschiedene, ubiquitär exprimierte Isoformen der Sphingosinkinase, SK-1 und SK-2, die S1P bilden können und durch verschiedene Stimuli in ihrer Expression und Aktivierung gesteuert werden (Alemany et al. 2007). Die Synthese von S1P ist essentiell für die Entwicklung, weshalb der simultane Knockout beider Enzyme zu schweren Defekten in der Neurogenese und Angiogenese führt und bereits embryonal letal ist (Mizugishi et al. 2005). Wurde jedoch nur eine der beiden Sphingosinkinasen ausgeschaltet, zeigten Knockout-Mäuse keinen auffälligen Phänotyp. Trotz dieser Eigenschaft sich gegenseitig kompensieren zu können, weisen die beiden Isoformen jedoch Unterschiede auf, was die Gewebeexpression, zelluläre Lokalisation und Auswirkungen ihrer Aktivität auf die Zelle betrifft. So findet sich die SK-1 im Zytoplasma und transloziert nach Aktivierung zur Plasmamembran, wohingegen die SK-2 auch im Zellkern aktiv ist (Igarashi et al. 2003; Jarman et al. 2010). Es wurde beobachtet, dass die Aktivierung der SK-1 Zellproliferation und Migration bewirkt und Apoptose verhindert, wodurch Tumorzellen in ihrem Wachstum begünstigt wurden (Olivera et al. 1999; Xia et al. 2000; Edsall et al. 2001). Die Rolle der SK-2 ist hingegen nicht eindeutig geklärt. Einige Studien zeigten, dass die Aktivität der SK-2 die Zellproliferation inhibierte und über einen S1P-Rezeptor-unabhängigen Weg die Freisetzung von Cytochrom $\mathrm{C}$ aus den Mitochondrien und folglich Apoptose auslöste (Liu et al. 2003; Igarashi et al. 2003). Andere Studien fanden jedoch heraus, dass ein Knockdown von SK-2 Apoptose auch induzieren und das Wachstum von Tumorzellen sowohl in vitro als auch in vivo bremsen kann (Van Brocklyn et al. 2005; Weigert et al. 2009; Neubauer et al. 2016).

Beide Enzyme werden besonders stark in menschlichen Nieren exprimiert (Liu et al. 2000; Nava et al. 2000). Auch in der Niere wurden gegensätzliche Funktionen der beiden SKs in Bezug auf den Verlauf von renaler Fibrose in Mausmodellen beobachtet. So führte ein Knockout von SK-1 zu einem schwereren Krankheitsverlauf der Fibrose, wohingegen ein Knockout von SK-2 fibrotische Prozesse bremste (Ren et al. 2009; Du et al. 2017; Schwalm et al. 2017).

Da beide Enzyme dasselbe Substrat verwenden und das gleiche Produkt erzeugen, ist für die Funktion wohl entscheidend, an welchem Ort in der Zelle S1P gebildet wird. So wurde in mehreren Studien beobachtet, dass S1P nicht nur über die S1PRezeptoren auf der Außenseite der Plasmamembran sondern auch über intrazelluläre 
Zielstrukturen die Genexpression einer Zelle steuern kann (Spiegel und Milstien 2000; Takabe et al. 2008). Auch im Hinblick auf fibrotische Prozesse in renalen Zellen wurden gegensätzliche Effekte von S1P, abhängig davon, ob es extrazellulär oder intrazellulär aktiv war, beobachtet (Koch et al. 2013; Schwalm et al. 2013). So stellte sich heraus, dass extrazelluläres S1P über die Aktivierung von S1P-Rezeptoren die Expression von profibrotischen Zytokinen wie connective tissue growth factor (CTGF) und Proteinen der extrazellulären Matrix wie Kollagene induziert, aber intrazellulär gebildetes S1P deren Expression hemmt (Ren et al. 2009; Blanchard et al. 2018) (Abbildung 6).

\subsubsection{Der S1P-Transporter Spinster Homolog 2 (Spns2)}

Aufgrund der polaren Kopfgruppe des S1P kann dieses Molekül nur mit Hilfe eines aktiven Transporters die Plasmamembran überwinden. Für den Export von S1P aus Erythrozyten und Thrombozyten wurde der Transporter major facilitator superfamily transporter $2 b$ (Mfsd2b) identifiziert, dessen Knockout in Mäusen eine Reduktion von S1P im Plasma von ca. 50\% bewirkte (Vu et al. 2017). In mehreren Studien wurde auch bereits gezeigt, dass manche $\mathrm{ABC}$-Transporter wie multidrug resistanceassociated protein (MRP1/ABCC1) S1P transportieren und somit Einfluss auf S1Pvermittelte Prozesse nehmen können (Mitra et al. 2006; Nieuwenhuis et al. 2009; Cartwright et al. 2013; Yamada et al. 2018). Der prominenteste Vertreter der S1PTransporter ist Spinster homolog 2, kurz Spns2. Es wurde gezeigt, dass dieser S1PTransporter verantwortlich für den Export von S1P aus Endothelzellen ist, was aber nicht immer auch die Konzentrationen von S1P im Plasma und in der Lymphe veränderte, jedoch stets zu einer Lymphopenie führte (Hisano et al. 2011; Mendoza et al. 2012; Nagahashi et al. 2013; Donoviel et al. 2015).

Spns2 ist ein multitransmembrangängiges Transportprotein in Säugetieren, welches zur Familie der Spinster (Spns1 bis Spns3 in Wirbeltieren und Spinster in Drosophila) gehört (Osborne et al. 2008; Nishi et al. 2014). Entdeckt wurde Spinster in Drosophila melanogaster, wo seine Mutation in weiblichen Fliegen zum namensgebenden Desinteresse an Männchen führte (spinster = Jungfer) (Nakano et al. 2001). 
Die funktionelle Bedeutung von Spns2 für den Transport von S1P wurde durch Spns2defiziente Zebrafische bekannt, welche einen ähnlichen Phänotyp wie $\mathrm{S}_{1} \mathrm{P}_{2}$-defiziente Fische aufwiesen. In beiden Linien führte das Ausschalten des Gens zu einem gespaltenen Herzen, da die Migration von Herzvorläuferzellen inhibiert war (Osborne et al. 2008; Kawahara et al. 2009). Die Zugabe von exogenem S1P oder die Expression von humanem Spns2 konnte die Spns2-Defizienz kompensieren und eine normale Herzentwicklung sicherstellen (Kawahara et al. 2009). Neben S1P kann Spns2 auch dihydro-S1P und phosphoryliertes FTY720 (Fingolimod) transportieren (Hisano et al. 2011; Nagahashi et al. 2013). Spns2-/-Mäuse hingegen leiden nicht unter Defekten am Herz und entwickeln sich normal und sind fertil (Chen et al. 2014). Phänotypisch können diese Mäuse eine postnatale Hörschädigung und eine Fehlbildung der Augen entwickeln (Chen et al. 2014). Die Hörschädigung der Mäuse in der Studie von Chen et al. (2014) war unter anderem bedingt durch ein rapide abgesunkenes endocochleäres Potential und einer Degeneration der Haarsinneszellen aufgrund unzureichender Expression von Schlüsselproteinen wie Kcnj10, Kcnq1, Gjb2 und Gjb6. Die Defekte der Augen zeigten sich durch geöffnete Augenlieder bei der Geburt, einer Degeneration der Netzhaut, gestörter Vaskularisation der Netzhaut und einer getrübten Hornhaut. Sowohl der Effekt im Gehör als auch in den Augen war nicht durch eine systemische Spns2-Defizienz bedingt, sondern ein lokales Phänomen, wie durch gewebespezifische Spns2 ${ }^{-{ }^{-}}$-Mäuse gezeigt werden konnte. Die Defekte der Netzhaut konnten zudem auch in Spns2 $2^{-1}$ Sprague-Dawley-Ratten beobachtet werden und wurden einer fehlenden $\mathrm{S}_{1} \mathrm{P}_{3}$ Aktivierung zugeschrieben (Fang et al. 2018). 


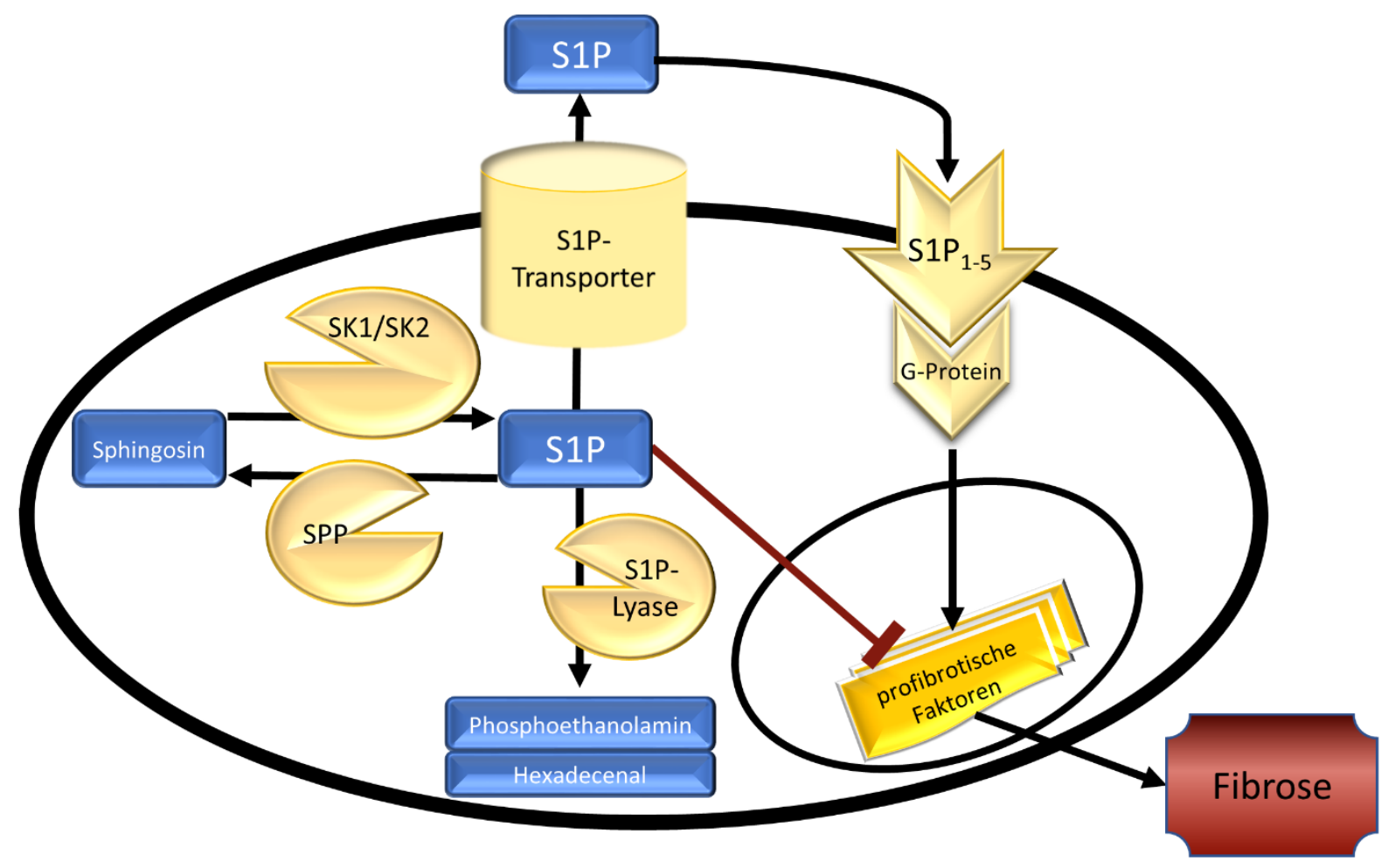

Abbildung 6: Schema des Metabolismus von S1P und der direkte Einfluss auf renale Fibrose. In den blauen Kästen stehen die Namen der Metabolite und in den gelben Kästen die der Enzyme, Transporter und Rezeptoren. Die Sphingosinkinasen (SK-1/SK-2) katalysieren die Phosphorylierung von Sphingosin auf cytosolischer Seite. Die Dephosphorylierung von S1P wird katalysiert von den S1P-Phosphatasen (SPP). S1P kann irreversibel von der S1P-Lyase zu Hexadecenal und Phosphoethanolamin abgebaut werden. Über S1P-Transporter wie Spns2 kann S1P aktiv über die Plasmamembran transportiert werden und autokrin und/oder parakrin S1P-Rezeptoren aktivieren. Die gekoppelten GProteine aktivieren unterschiedliche Signalkaskaden, die zur Expression von profibrotischen Faktoren führen können. Auf intrazellulärer Seite kann S1P jedoch die Expression von profibrotischen Faktoren blockieren.

Um die profibrotischen S1P-Rezeptor-vermittelten Effekte von S1P zu unterbinden, können zum einen die S1P-Transportproteine oder aber die S1P-Rezeptoren genetisch oder pharmakologisch manipuliert werden. So wurde bereits anhand eines Mausmodells zum Ischämie-Reperfusionsschaden in der Niere gezeigt, dass die Aktivierung von $\mathrm{S} \mathrm{P}_{2}$ Apoptose und Nekrose der Nierenzellen induzierte, die Inhibierung dieses Rezeptors mittels des S1P2-selektiven Antagonisten JTE-013 jedoch den Schaden in der Niere milderte (Won Park et al. 2012). 


\subsubsection{Die S1P-Rezeptoren}

Es sind insgesamt fünf S1P-Rezeptoren bekannt, die sich funktional vor allem in ihrer Gewebeexpression und auch teilweise durch die unterschiedlichen gekoppelten GProteine voneinander differenzieren lassen (Brinkmann 2007). Die Aktivierung der GProteine führt in den verschiedenen Geweben zur Aktivierung oder Inhibierung verschiedener Signalwege, welche sich letztlich auf zelluläre Schlüsselprozesse wie Proliferation, Migration und Überleben auswirken können und die Calciumhomöostase, die Vasokonstriktion und auch die Expression von Proteinen der extrazellulären Matrix steuern können (Abbildung 7) (Nagahashi et al. 2014).

$\mathrm{S}_{1} \mathrm{P}_{1}$ ist im Menschen ubiquitär exprimiert, was sowohl auf mRNA-Ebene als auch auf Proteinebene in etlichen Geweben nachgewiesen worden ist (Uhlén et al. 2015; Uhlén et al. 2019a; Uhlén et al. 2019b; Sjöstedt et al. 2020). S1P1 ist als einziger S1PRezeptor ausschließlich an $\mathrm{G}_{\mathrm{i} / \mathrm{og}}$ gekoppelt (Windh et al. 1999) (Abbildung 7). Es handelt sich hierbei um den am besten charakterisierten und bisher auch einzigen S1PRezeptor, dessen Aktivierung/Inhibition gezielt zur Behandlung bestimmter Patientengruppen therapeutisch genutzt wird. So sind zum einen der unspezifische Agonist FTY720 (Fingolimod, Gilenya ${ }^{\circledR}$, bindet alle S1P-Rezeptoren bis auf $\mathrm{S} \mathrm{P}_{2}$ ) und der S1P1- und S1P5-spezifische Agonist BAF312 (Siponimod, Mayzent ${ }^{\circledR}$ ) zur Behandlung der schubförmigen Multiplen Sklerose zugelassen (Sharma et al. 2011; Al-Salama 2019). Die beiden Agonisten sorgen für eine Internalisierung mit anschließendem proteasomalen Abbau von $\mathrm{S}_{1} \mathrm{P}_{1}$ und werden konstant in so hoher Dosis appliziert, dass sie funktionell als Antagonisten wirken, da der Rezeptor folglich nicht mehr in ausreichender Menge an der Zelloberfläche zur Bindung von S1P zur Verfügung steht (Brinkmann et al. 2004; Matloubian et al. 2004; Chun und Hartung 2010). Der Benefit der Inhibierung von S1P 1 liegt darin, dass T-Zellen über S1P 1 dem S1P-Gradienten zwischen Lymphe, Blut und Gewebe folgen und ohne den Rezeptor der Austritt dieser Immunzellen aus den Lymphknoten verhindert wird, was folglich in einer peripheren Lymphopenie mündet (Yanagawa et al. 1998). Ein Knockout von $\mathrm{S}_{1} \mathrm{P}_{1}$ in Mäusen führt zu embryonal letalen Blutungen, da er eine wichtige Rolle bei der Gefäßreifung und der Ummantelung der Gefäße mit glatten Muskelzellen im Rahmen der Vaskulogenese inne hat (Liu et al. 2000). 
S1P $P_{2}$ wird ebenfalls ubiquitär exprimiert und ist neben $\mathrm{G}_{\mathrm{i} / \mathrm{o}}$ auch noch an $\mathrm{G}_{12}$ und $\mathrm{G}_{\mathrm{q}}$ gekoppelt (Windh et al. 1999) (Abbildung 7). Die mRNA-Expression ist im Menschen besonders stark in den Geschlechtsorganen beider Geschlechter, im Blut, im Knochenmark, im lymphatischen System, im Fettgewebe und in der Lunge ausgeprägt und auf Proteinebene wurde die Expression in den Nieren, im Duodenum und im Dünndarm nachgewiesen (Uhlén et al. 2015; Uhlén et al. 2019a; Uhlén et al. 2019b; Sjöstedt et al. 2020). Knockout von $\mathrm{S} \mathrm{P}_{2}$ in Mäusen ist zunächst phänotypisch unauffällig, führt aber zu neuronalen Fehlfunktionen, die tödliche Krämpfe zur Folge haben können (MacLennan et al. 2001). Des Weiteren wurden bei 30 Tage alten Mäusen Läsionen in der Stria vascularis gefunden, die zur Taubheit führten (Kono et al. 2007). Auf zellulärer Ebene wurde festgestellt, dass die Aktivierung von $\mathrm{S}_{1} \mathrm{P}_{2}$ die Freisetzung von $\mathrm{Ca}^{2+}$ aus intrazellulären Speichern auslöst, was zur Kontraktion von glatten Muskelzellen führt (Ohmori et al. 2003; Kendig et al. 2013). Außerdem wurde bei der Untersuchung von malignen Gliazellen festgestellt, dass die Aktivierung von $\mathrm{S}_{1} \mathrm{P}_{2}$ die Zellmigration inhibiert (Lepley et al. 2005; Young und Van Brocklyn 2007; Malchinkhuu et al. 2008).

S1P3-mRNA wird ubiquitär im Menschen exprimiert und ist in besonders hohen Mengen in den Geschlechtsorganen beider Geschlechter, im Muskelgewebe und Organen des endokrinen Systems zu finden (Uhlén et al. 2015; Uhlén et al. 2019a; Uhlén et al. 2019b; Sjöstedt et al. 2020). S1P $P_{3}$ ist an $\mathrm{G}_{\mathrm{i} / \mathrm{o}}$, an $\mathrm{G}_{13}$ und $\mathrm{G}_{q}$ gekoppelt und Knockout-Mäuse weisen keinen auffälligen Phänotyp auf (Abbildung 7). Anhand isolierter Zellen konnte jedoch gezeigt werden, dass der S1P-induzierte $\mathrm{PLC} / \mathrm{IP}_{3} / \mathrm{Ca}^{2+}$ Signalweg gestört ist (Windh et al. 1999; Ishii et al. 2001). Die Aktivierung von S1P3 induziert in verschiedenen Zelltypen die Migration (Okamoto et al. 2000; Paik et al. 2001).

S1P4-mRNA wird im Menschen hauptsächlich im Blut (alle Zelltypen), im Knochenmark, im lymphatischen System, in der Lunge und dem Verdauungstrakt exprimiert (Uhlén et al. 2015; Uhlén et al. 2019a; Uhlén et al. 2019b; Sjöstedt et al. 2020). S1P $P_{4}$ ist an $\mathrm{G}_{\mathrm{i} / \mathrm{o}}$ und an $\mathrm{G}_{12 / 13}$ gekoppelt (Abbildung 7). Knockout-Mäuse zeigen keinen besonderen Phänotyp, weisen aber eine gestörte Ausbildung der Megakaryozyten auf (Gräler et al. 1998; Gräler et al. 2003; Golfier et al. 2010). 
S1P5-mRNA wird im Menschen am häufigsten im Blut, im Gehirn, im Knochenmark, im lymphatischen System und in der Haut exprimiert und konnte auf Proteinebene bereits im Gehirn, in der Haut, in der Lunge und in verschiedenen lymphatischen Geweben nachgewiesen werden (Uhlén et al. 2015; Uhlén et al 2019a; Uhlén et al. 2019b; Sjöstedt et al. 2020). S1P5 ist an $\mathrm{G}_{\mathrm{i} / \mathrm{o}}$ und an $\mathrm{G}_{12 / 13}$ gekoppelt (Im et al. 2000) (Abbildung 7). S1 $\mathrm{P}_{5}{ }^{-1-}$-Mäuse zeigen keinen auffälligen Phänotyp, besitzen jedoch weniger periphere natürliche Killerzellen und Ly6C-Monozyten (Jenne et al. 2009; Debien et al. 2013). Die essentielle Rolle von $\mathrm{S} \mathrm{P}_{5}$ für die Migration der natürlichen Killerzellen konnte in weiteren Studien sowohl in vitro als auch in vivo belegt werden (Walzer et al. 2007; Mayol et al. 2011; Drouillard et al. 2018). Des Weiteren wurde darüber berichtet, dass $\mathrm{S} \mathrm{P}_{5}$ eine Rolle bei der Phagozytose von alveolaren Makrophagen und bei der Autophagie der humanen Prostatakrebszellline PC-3 spielt (Chang et al. 2009; Barnawi et al. 2015). Alveolare Makrophagen von Patienten, die an chronisch obstruktiver Lungenerkrankung litten, zeigten eine signifikant erhöhte Genexpression von $\mathrm{S}_{1} \mathrm{P}_{5}$ und eine Antagonisierung von $\mathrm{S}_{1} \mathrm{P}_{5}$ über den $\mathrm{S}_{1} \mathrm{P}_{3}$ - und S1P5-spezifischen Rezeptorantagonisten Suramin führte zu einer Verbesserung der Phagozytose in alveolaren Makrophagen (Barnawi et al. 2015; 2017). In einer anderen Studie wurde eine weitere Rolle von S1P in Bezug auf die Migration und Proliferation von Tumorzellen entdeckt. Zhou et al. konnten in einem Mausmodell für Darmkrebs zeigen, dass die Herunterregulation von $\mathrm{S}_{1} \mathrm{P}_{5}$ die Tumorgröße reduzierte und eine Hochregulation von S1P5 das Tumorwachstum förderte (Zhou et al. 2020). Eine Untersuchung in vitro mit den kolorektalen Tumorzelllinien SW480 und SW620 ergab, dass die Herunterregulation von $\mathrm{S}_{1} \mathrm{P}_{5}$ die Migration und Proliferation der Zellen über die Inhibierung von NF-KB reduzierte (Zhou et al. 2020). 


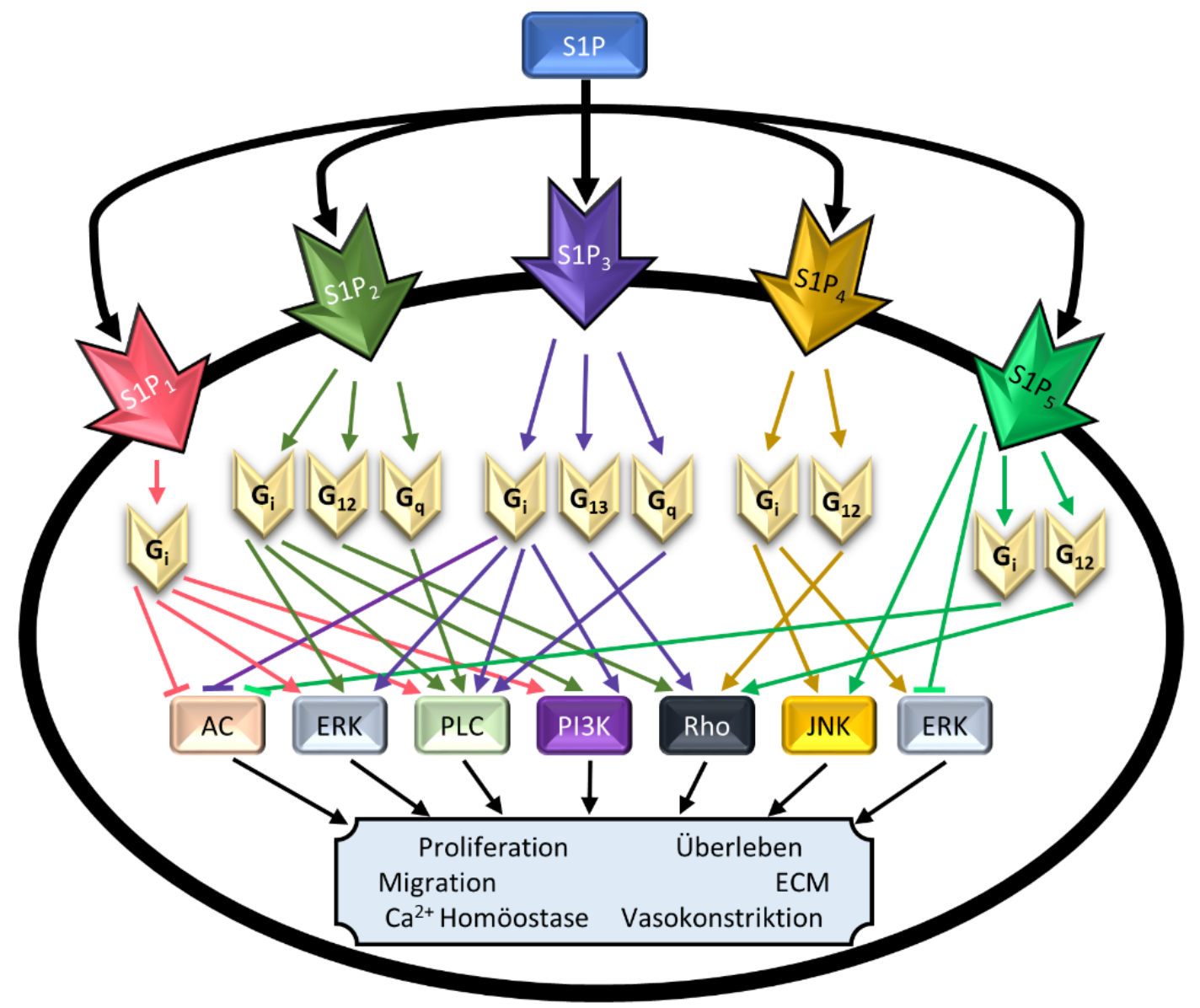

Abbildung 7: Schema der S1P-Rezeptoren und der gekoppelten G-Proteine sowie deren Einfluss auf nachgeschaltete Signalwege. S1P bindet die S1P-Rezeptoren in der Plasmamembran, was die Aktivierung der gekoppelten G-Proteine initiiert. Die S1PRezeptoren sind an unterschiedliche G-Proteine gekoppelt, was zur Aktivierung oder Inhibierung verschiedener Signalwege führen kann, von denen einige hier abgebildet sind. Die Signaltransduktionen lösen in der Zelle Schlüsselprozesse wie Proliferation, Migration, Überleben und auch die Expression von Proteinen des Bindegewebes aus. AC: Adenylylcyclase; ERK: extracellular signal-regulated kinase; PLC: Phospholipase C; PI3K: Phosphoinositid-3-Kinasen; Rho: Rho-GTPasen; JNK: c-Jun N-terminale Kinasen; ECM: extrazelluläre Matrix (Abb. nach Vorlage von Nagahashi et al. 2014). 


\subsubsection{Die Rolle der S1P-Rezeptoren bei renaler Fibrose}

Die Aktivierung von S1P-Rezeptoren kann in der Zelle eine Vielzahl verschiedener Effekte, wie zum Beispiel Proliferation, Synthese von extrazellulärer Matrix und Migration vermitteln und so den Krankheitsverlauf verschiedener Patientengruppen beeinflussen. Das prominenteste Beispiel eines solchen S1P-Rezeptormodulators ist das prodrug Fingolimod, welches bereits im Abschnitt 1.3.5 beschrieben wurde.

Neben Multipler Sklerose gibt es hingegen auch noch andere Autoimmunerkrankungen wie zum Beispiel den systemischen Lupus erythematodes (SLE) bei dem, abhängig vom ethnischen Hintergrund, $30-80 \%$ der Patienten eine Nephritis entwickeln (Imran et al. 2016; Rees et al. 2017). Diese sogenannte Lupus-Nephritis (LN) führt nicht selten zur CKD, welche in ESRD enden kann (Almaani et al. 2017). Anhand verschiedener Studien zur experimentellen SLE mit Hilfe von BXSB, NZB/W F1 und MRL-Ipr/Ipr Mäusen konnte eine Verbesserung des Krankheitsbildes, einschließlich einer verbesserten Nierenfunktion, durch die Behandlung mit Fingolimod bestätigt werden (Okazaki et al. 2002; Alperovich et al. 2007; Ando et al. 2010). Aktuell

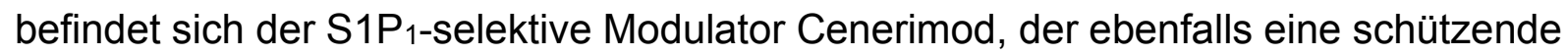
immunsupprimierende Wirkung ausübt, in Phase 2 einer klinischen Studie zur Behandlung von SLE-Patienten (Hermann et al. 2019; Lott et al. 2020).

Darüber hinaus wurden die Auswirkungen von Fingolimod auch in anderen Tiermodellen zu Nephropathien untersucht, welche nicht durch eine Autoimmunität verursacht werden. Es wurde herausgefunden, dass Fingolimod den Krankheitsverlauf bei Ratten mit einer Thy1.1-induzierten mesangioproliferativen Glomerulonephritis, mit antikörperinduzierter membranöser Glomerulonephritis, mit Adriamycin-induzierter Glomerulosklerose und interstitieller Fibrose, mit Albuminüberschuss-induzierter als auch mit 5/6-Nephrektomie-induzierter tubulointerstitieller Fibrose und mit Streptozotozin-induzierter DN verbessert (Peters et al. 2004; Martini et al. 2007; Awad et al. 2011; Sui et al. 2012; Ni et al. 2013; Xu et al. 2014; Yazdani et al. 2015). In Untersuchungen zur tubulointerstitiellen Fibrose, hervorgerufen durch UUO und auch bei akutem Nierenschaden induziert durch einen Ischämie-Reperfusionsschaden oder Cisplatin, konnte ebenso eine Milderung des Nierenschadens in Mäusen durch 
Behandlung mit Fingolimod erreicht werden (Bajwa et al. 2010; Shobha et al. 2014; Bajwa et al. 2015).

S1P 3 -defiziente Mäuse zeigten in zwei Studien einen milderen Krankheitsverlauf im Modell des Ischämie-Reperfusionsschadens, dessen Ursache Bajwa et al. in einer inhibierten Reifung von dendritischen Zellen und einer folgenden Hochregulation von regulatorischen T-Zellen sahen (Jo et al. 2009; Bajwa et al. 2016). In einem Modell zur Streptozotozin-induzierten DN zeigten S1P3-defiziente Mäuse jedoch keinen Unterschied in der Albuminurie im Vergleich zu Kontrollmäusen und die Behandlung von Fingolimod führte auch in S1P3-defizienten Mäusen zu einem Behandlungserfolg, was für einen $\mathrm{S}_{1} \mathrm{P}_{3}$-unabhängigen Mechanismus spricht (Awad et al. 2011).

Obwohl Fingolimod nicht an $\mathrm{S} \mathrm{P}_{2}$ bindet und die beschriebene protektive Wirkung

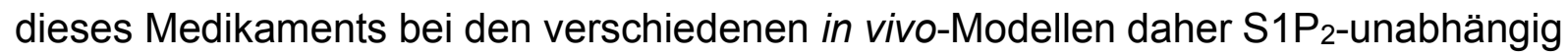
sein müsste, wurde dennoch in vitro unter Verwendung von renalen Zellen eine profibrotische Wirkung dieses Rezeptors entdeckt (Li et al. 2008; Ishizawa et al. 2014). In Tiermodellen zur Untersuchung von Leberfibrose wurde bestätigt, dass $\mathrm{S}_{1} \mathrm{P}_{2}$ die Entstehung einer Fibrose fördert, weshalb von einer ähnlichen Wirkung in einem Modell zur Nierenfibrose ausgegangen werden kann (Serriere-Lanneau et al. 2007; Ikeda et al. 2009).

Zusammengefasst wird deutlich, dass die den S1P-Rezeptoren nachgeschalteten Signalwege einen entscheidenden Einfluss auf den Krankheitsverlauf von verschiedenen Nierenerkrankungen ausüben. In der vorliegenden Arbeit wurde speziell der Einfluss von $\mathrm{S} \mathrm{P}_{5}$ auf die Entzündungsreaktionen und die Ausbildung einer Nierenfibrose durch eine Adenin-induzierte Nephropathie (AN) untersucht.

\subsubsection{Ceramide}

Ceramide sind ein Bestandteil der eukaryotischen Zellmembranen und zentrale Moleküle des Sphingolipidstoffwechsels. An der Synthese und der Degradation der Ceramide sind zahlreiche Enzyme involviert (Hannun und Obeid 2018). Ceramide können entweder de novo ausgehend von Serin und Palmityl-CoA, durch die Spaltung von Sphingomyelin oder über den salvage pathway aus Sphingosin und Acyl-CoA 
gebildet werden. Neben Sphingomyelin können Ceramide auch zu den komplexeren Cerebrosiden und Gangliosiden modifiziert, zu Sphingosin abgebaut oder zu Ceramid1-Phosphat metabolisiert werden (Hannun und Obeid 2018). Eine besondere Rolle spielen zudem die sechs Ceramidsynthasen (CerS1-6), die durch ihre unterschiedliche Substratspezifität zur Diversität der Ceramide beitragen. Die verschiedenen Isoformen der Ceramidsynthasen bevorzugen Acyl-CoA-Moleküle mit jeweils unterschiedlicher Kettenlänge, was zur Synthese von Ceramiden mit unterschiedlich langen Fettsäureresten führt (C14 bis C26) (Levy und Futerman 2010). Eine entscheidende Form der Steuerung dieses Prozesses geschieht schon durch die stark variable Expression der Ceramidsynthasen in den verschiedenen Geweben. So wird beispielsweise in der Niere hauptsächlich CerS2 exprimiert, im Herzen CerS4 und in den Hoden CerS3 (Grösch et al. 2012).

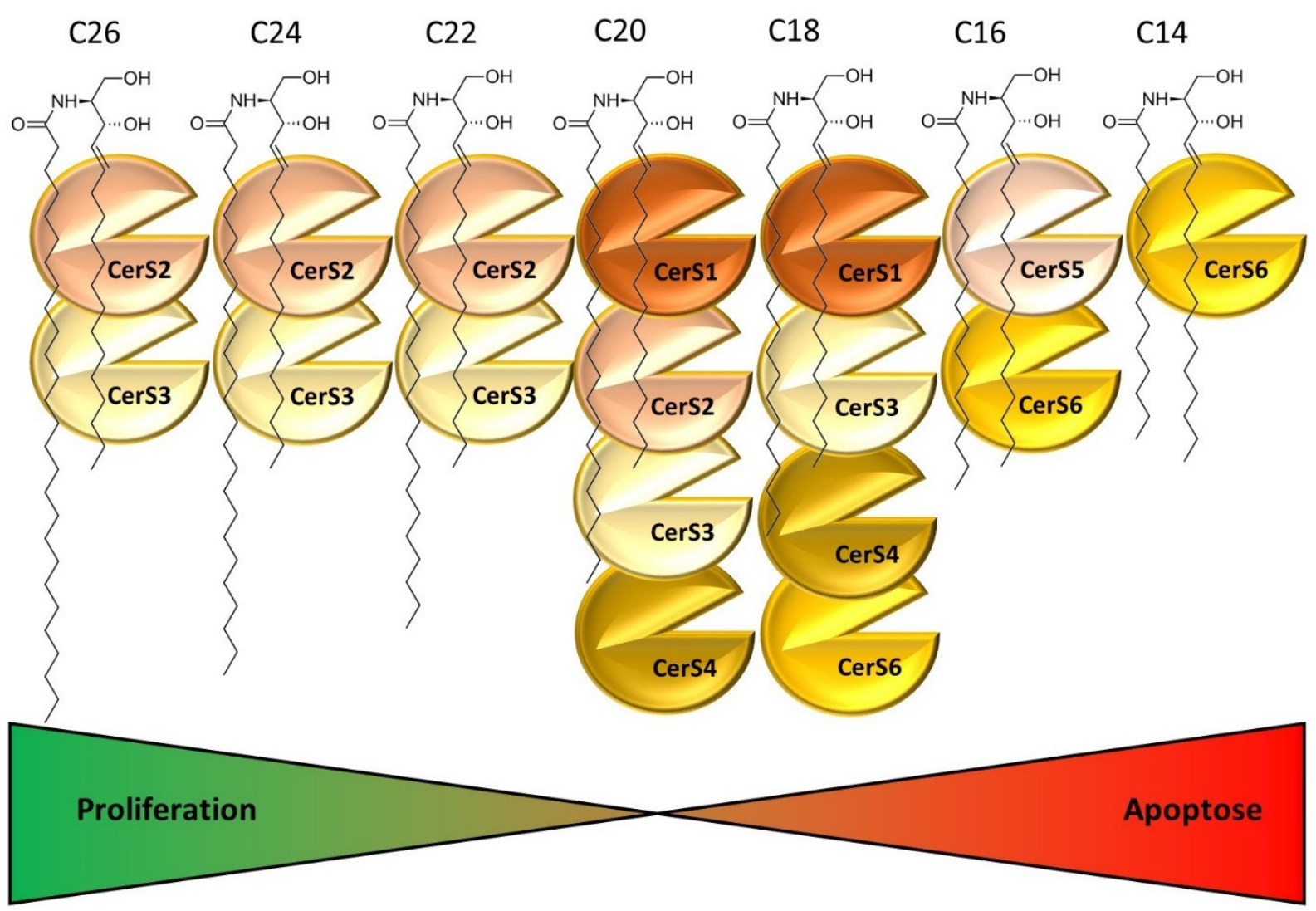

Abbildung 8: Die Substratspezifität der sechs bekannten Ceramidsynthasen. Die Ceramidsynthasen katalysieren die Acylierung von Sphingosin oder Sphinganin mit einer aktivierten Fettsäure unterschiedlicher Kettenlänge, aus denen die verschiedenen Ceramide bzw. Dihydroceramide gebildet werden (Levy und Futerman 2010a). Mehrheitlich wirken sehr langkettige Ceramide proproliferativ, wohingegen kurzkettige und langkettige Ceramide proapoptotisch Effekte zeigen (Mesicek et al. 2010; Siskind et al. 2010; Hartmann et al. 2013; Stiban und Perera 2015). 
Die unterschiedliche Kettenlänge der Ceramide wirkt sich biophysikalisch auf die Membranfluidität aus. Sie können sich zu Plattformen zusammenschließen und Einfluss auf die Proteine in der Zellmembran, wie zum Beispiel Rezeptoren, nehmen oder Ceramidkanäle in mitochondrieller Membran ausbilden und dadurch Apoptose induzieren (Bollinger et al. 2005; Siskind et al. 2006).

Unsere Arbeitsgruppe konnte zudem zeigen, dass Ceramide in massenspektrometrisch gut messbaren Mengen im Blutplasma vorhanden und resistent gegenüber klinischen Störfaktoren sind, weshalb kettenlängenspezifische Ceramide attraktive Kandidaten für Biomarker von Krankheiten sein können (Brunkhorst et al. 2018). Es wurde beispielsweise bereits gezeigt, dass, neben anderen Sphingolipiden, Ceramide im Plasma und Serum von Patienten, die an bestimmten Krankheiten wie zum Beispiel Leberzellkarzinom, Bluthochdruck und Typ 2 Diabetes leiden, erhöht sind (Haus et al. 2009; Grammatikos et al. 2016). Des Weiteren könnten Ceramide im Plasma auch bei der Diagnose von Herzkreislaufstörungen helfen, da gezeigt wurde, dass ein Anstieg von bestimmten Ceramiden mit einer höheren Wahrscheinlichkeit für ein unerwünschtes vaskuläres Ereignis wie ein Herzinfarkt oder Schlaganfall assoziiert war (Havulinna et al. 2016; Meeusen et al. 2018).

Auch im Zusammenhang mit verschiedenen Nierenerkrankungen wurden bereits Studien über Sphingolipide im Blut als Biomarker veröffentlicht. Im Fokus dieser Studien stand meistens die Veränderung von S1P im Plasma von Patienten, die an DN oder LN leiden (Watson et al. 2012; Bekpinar et al. 2015; Sun et al. 2017). Mittels LC-ESI-MS/MS Analyse konnte zuletzt durch Untersuchungen unserer Arbeitsgruppe gezeigt werden, dass bestimmte sehr langkettige Ceramide wie Cer d18:1/24:1 im Plasma und Serum von LN-Patienten im Vergleich zu gesunden Kontrollen und Patienten, die an SLE ohne Nierenbeteiligung leiden, erhöht sind (Patyna et al. 2019). Die Gruppe um Nowling et al. untersuchte zudem Nierengewebeproben von Patienten und Mäusen, die an LN litten und konnte zeigen, dass Glycosphingolipide, insbesondere Lactosylceramide, im Vergleich zu gesunden Gewebeproben verändert waren (Nowling et al. 2015). 
In der vorliegenden Arbeit haben wir nun die Veränderungen der Ceramide im Nierengewebe unter dem Einfluss der renalen Fibrose untersucht. Konkret haben wir Nierenbiopsien von Patienten, die an Hydronephrose und/oder Pyelonephritis als auch von Mäusen, die an AN litten, analysiert. Als gesunde Kontrollen dienten Biopsien von Patienten, die ein Nierentrauma erlitten haben oder an Nierenkrebs erkrankten, bzw. gesunde Mäuse. 


\subsection{Zielsetzung}

Im Rahmen dieser Arbeit soll die Rolle verschiedener Mediatoren des Sphingolipidstoffwechsels im Kontext fibrotischer Nierenerkrankungen untersucht werden. Insbesondere S1P spielt hierbei eine zentrale Rolle. Aus Voruntersuchungen unserer Arbeitsgruppe wissen wir, dass S1P über die Aktivierung der S1P-Rezeptoren die Expression des profibrotischen Zytokins CTGF induziert, während intrazelluläres S1P antifibrotische Effekte hervorruft. S1P 5 scheint hier, ausgehend von Vorarbeiten unserer Arbeitsgruppe, entscheidend an der Regulation der Expression von CTGF beteiligt zu sein. Neben S1P vermutet man, dass auch Ceramide eine wichtige Rolle bei der Progression fibrotischer Nierenerkrankungen spielen und zum Beispiel als Biomarker der LN eingesetzt werden könnten. Schließlich stellt sich auch die Frage, inwieweit die Regulation des Transports von S1P über die Zellmembran entscheidend für die Vermittlung der pro- und antifibrotischen Effekte von S1P ist.

Zur Beantwortung dieser Fragen wurden in einem ersten Teilprojekt die Auswirkungen des $\mathrm{S}_{1} \mathrm{P}_{5}$ in einem Modell zur tubulointerstitiellen Nierenfibrose bei der Maus auf entzündliche und fibrotische Prozesse untersucht. In einem zweiten Projekt wurde der Zusammenhang von Konzentrationsänderungen spezifischer Ceramide im Nierengewebe von Patienten und Mäusen mit fibrotischen Nieren im Vergleich zu gesunden Nierengeweben untersucht. Im dritten, hier vorgestellten, Projekt wurde die Rolle des S1P-Transporters Spns2 für die Expression von CTGF in Mesangiumzellen der Maus untersucht.

Insgesamt sollen die Ergebnisse dieser Arbeit dazu beitragen, unser Verständnis für die Funktion einzelner Bausteine des komplexen Sphingolipidstoffwechsels bei der Entstehung der Nierenfibrose besser zu verstehen und so den Weg für neuartige Diagnose- und Therapiemöglichkeiten zu ebnen. 


\section{Material und Methoden}

\subsection{Material}

\subsubsection{Zellen}

\begin{tabular}{|l|l|}
\hline \multicolumn{1}{|c|}{ Zellen } & \multicolumn{1}{c|}{ Herkunft } \\
\hline Mesangiumzellen (mMC) & primär isolierte Zellen \\
\hline
\end{tabular}

Tabelle 1: Zellen

\subsubsection{Kulturmedien und Zusätze}

\begin{tabular}{|c|c|}
\hline Kulturmedium oder Zusatz & Hersteller \\
\hline DMEM/F12 mit L-Glutamin & \multirow{5}{*}{ Life Technologies, Carlsbad } \\
\hline Dulbecco's PBS, $-\mathrm{CaCl}_{2},-\mathrm{MgCl}_{2}$ (DBPS) & \\
\hline Trypsin/EDTA 0,05\% & \\
\hline $\begin{array}{l}\text { DMEM, GlutaMAX'TM },+4,5 \text { g/L D-Glukose, } \\
\text { - Pyruvat (DMEM) }\end{array}$ & \\
\hline RPMI 1640, + GlutaMAX'TM & \\
\hline Natriumselenit & \multirow{6}{*}{ Sigma-Aldrich, Steinheim } \\
\hline Fetales Kälberserum (FKS) & \\
\hline Bovines Serumalbumin (BSA, fettsäurefrei) & \\
\hline Insulin & \\
\hline HEPES solution, $1 \mathrm{M}, \mathrm{pH}$ 7.0-7.6 & \\
\hline$\beta$-Mercaptoethanol & \\
\hline Transferrin & Roche Biochemicals, Mannheim \\
\hline
\end{tabular}

Tabelle 2: Kulturmedien und Zusätze 


\subsubsection{Zusammensetzung des Wachstumsmediums}

\begin{tabular}{|c|c|}
\hline Kulturmedium oder Zusatz & $\begin{array}{l}\text { Anteil/Konzentration für Mesangiumzellen } \\
\text { (Maus) }\end{array}$ \\
\hline RPMI $1640,+$ GlutaMAX ${ }^{\mathrm{TM}}$ & $500 \mathrm{~mL}$ \\
\hline Fetales Kälberserum (FKS) & $15 \%$ \\
\hline Penicillin-Streptomycin & $10000 \mathrm{U} / \mathrm{mL}$ \\
\hline HEPES solution (1 M) & $10 \mathrm{mM}$ \\
\hline$\beta$-Mercaptoethanol (10 mM) & $225 \mu \mathrm{L}$ \\
\hline Natriumselenit & $5 \mathrm{ng} / \mathrm{mL}$ \\
\hline Transferrin & $5 \mu \mathrm{g} / \mathrm{mL}$ \\
\hline Insulin & $6 \mu \mathrm{g} / \mathrm{mL}$ \\
\hline$\beta$-Mercaptoethanol & $4,5 \mu \mathrm{g} / \mathrm{mL}$ \\
\hline
\end{tabular}

Tabelle 3: Zusammensetzung des Wachstumsmediums

\subsubsection{Zusammensetzung anderer Medien}

\begin{tabular}{|l|l|l|}
\hline Kulturmedium oder Zusatz & \multicolumn{1}{|c|}{ Hungermedium } & \multicolumn{1}{|c|}{ Stimulationsmedium } \\
\hline DMEM, GlutaMAX ${ }^{\mathrm{TM}}$ & $500 \mathrm{~mL}$ & $500 \mathrm{~mL}$ \\
\hline Fetales Kälberserum (FKS) & $1 \%$ & \\
\hline $\begin{array}{l}\text { Bovines Serumalbumin } \\
\text { (fettsäurefrei) }\end{array}$ & & $0,1 \%$ \\
\hline
\end{tabular}

Tabelle 4: Zusammensetzung anderer Medien 
2.1.5 Geräte

\begin{tabular}{|c|c|}
\hline Gerät & Hersteller \\
\hline PowerPac 200 & \multirow{2}{*}{ BioRad, München, Deutschland } \\
\hline Elektrophoresekammer & \\
\hline Filmentwickler, CP 1000 & AGFA Healthcare, Bonn, Deutschland \\
\hline Herasafe Sterilbank & \multirow{4}{*}{ Heraeus, Hanau, Deutschland } \\
\hline Inkubator Heraeus BBD 6220 & \\
\hline Biofuge fresco & \\
\hline Megafuge 1.0 R & \\
\hline Lichtmikroskop Axiovert 25 & \multirow{2}{*}{ Zeiss, Göttingen, Deutschland } \\
\hline Lichtmikroskop Axiovert 135 TV & \\
\hline Microplate Reader Sunrise & Tecan, Neustadt, Deutschland \\
\hline Mikrozentrifuge (PerfectSpin Mini) & $\begin{array}{l}\text { Peqlab Biotechnologie } \mathrm{GmbH} \text {, } \\
\text { Erlangen, Deutschland }\end{array}$ \\
\hline NanoDrop® ND-1000 Spectrophotometer & $\begin{array}{l}\text { Thermo Fisher Scientific, Schwerte, } \\
\text { Deutschland }\end{array}$ \\
\hline Wippschüttler (Heidolph Duomax 1030) & $\begin{array}{l}\text { Geneo BioTechProducts GmbH, } \\
\text { Lübeck, Deutschland }\end{array}$ \\
\hline Thermocycler & BioRad, München, Deutschland \\
\hline Thermomixer compact & $\begin{array}{l}\text { Eppendorf } \mathrm{GmbH} \text {, Hamburg, } \\
\text { Deutschland }\end{array}$ \\
\hline Ultraschall-Desintegrator Sonifer W-450 & Branson Ultrasonics, Danbury, USA \\
\hline $\begin{array}{l}\text { Vectra } 3.0 \text { Automated Quantitative } \\
\text { Pathology Imaging System }\end{array}$ & $\begin{array}{l}\text { Akoya Biosciences, Massachusetts, } \\
\text { USA }\end{array}$ \\
\hline Vortexer (IKA ${ }^{\circledR}$ MS 3 digital) & IKA, Staufen im Breigau, Deutschland \\
\hline $\begin{array}{l}\text { Zellzähler (TC10 }{ }^{\mathrm{TM}} \text { Automates Cell } \\
\text { Counter) }\end{array}$ & BioRad, München, Deutschland \\
\hline 7500 Fast Real-Time PCR System & $\begin{array}{l}\text { Applied Biosystems, Darmstadt, } \\
\text { Deutschland }\end{array}$ \\
\hline
\end{tabular}

Tabelle 5: Geräte 
2.1.6 Chemikalien

\begin{tabular}{|c|c|}
\hline Chemikalie & Hersteller \\
\hline Agarose & $\begin{array}{l}\text { Sigma-Aldrich Chemie GmbH, } \\
\text { Steinheim }\end{array}$ \\
\hline 1,4 Dithiothreitol (DTT) & Roth, Karlsruhe \\
\hline Ammoniumperoxodisulfat (APS) & Merck, Darmstadt \\
\hline Bromphenolblau & AppliChem GmbH, Darmstadt \\
\hline Calciumchlorid $\left(\mathrm{CaCl}_{2}\right)$ & Carl Roth GmbH, Karlsruhe \\
\hline Chloroform $\geq 99,0 \%$ & $\begin{array}{l}\text { Sigma-Aldrich Chemie GmbH, } \\
\text { Steinheim }\end{array}$ \\
\hline D-erythro-Sphingosin C-18 & $\begin{array}{l}\text { Cayman Chemical Company, Ann } \\
\text { Arbor, USA }\end{array}$ \\
\hline Diethylpyrocarbonat (DEPC) & $\begin{array}{l}\text { Sigma-Aldrich Chemie } \mathrm{GmbH} \text {, } \\
\text { Steinheim }\end{array}$ \\
\hline $\begin{array}{l}\text { Dinatriumhydrogenphosphat Dihydrat } \\
\left(\mathrm{Na}_{2} \mathrm{HPO}_{4} \cdot 2 \mathrm{H}_{2} \mathrm{O}\right)\end{array}$ & VWR, Darmstadt \\
\hline DMSO $\geq 99 \%$ & \multirow{4}{*}{$\begin{array}{l}\text { Sigma-Aldrich Chemie GmbH, } \\
\text { Steinheim }\end{array}$} \\
\hline Entellan ${ }^{\circledR} \mathrm{Neu}$ & \\
\hline Essigsäure $\geq 99,8 \%$ & \\
\hline Ethanol $\geq 99,9 \%$ & \\
\hline Ethylendiamintetraessigsäure (EDTA) & \multirow{2}{*}{ AppliChem GmbH, Darmstadt } \\
\hline Ethylenglycoltetraacetat (EGTA) & \\
\hline $\begin{array}{l}\text { Forene } 100 \%(V / V) \text { Isofluran } \\
\text { Flüssigkeit zur Herstellung eines } \\
\text { Dampfes zur Inhalation PZN -10182054 }\end{array}$ & AbbVie, Wiesbaden \\
\hline Glycerin $\geq 99 \%$ & Sigma-Aldrich, Steinheim \\
\hline Glycin & Carl Roth GmbH, Karlsruhe \\
\hline HEPES $\left(\mathrm{C}_{8} \mathrm{H}_{18} \mathrm{~N}_{2} \mathrm{O}_{4} \mathrm{~S}\right)$ & Ponceau S \\
\hline $\begin{array}{l}\text { Heparin-Natrium } 25000 \text { I. E. } / 5 \mathrm{~mL} \\
\text { PZN -03029843 }\end{array}$ & Ratiopharm, Ulm \\
\hline Isopropanol $\geq 99,9 \%$ & Fisher Scientific UK, Leicestershire \\
\hline Kaliumchlorid (KCl) & $\begin{array}{l}\text { Sigma-Aldrich Chemie GmbH, } \\
\text { Steinheim }\end{array}$ \\
\hline Kaliumdihydrogenphosphat $\left(\mathrm{KH}_{2} \mathrm{PO}_{4}\right)$ & Carl Roth GmbH, Karlsruhe \\
\hline Magermilchpulver & AppliChem, Darmstadt \\
\hline $\begin{array}{l}\text { Magnesiumchlorid Hexahydrat }\left(\mathrm{MgCl}_{2}\right) \times \\
6 \mathrm{H}_{2} \mathrm{O}\end{array}$ & Merck, Darmstadt \\
\hline
\end{tabular}




\begin{tabular}{|c|c|}
\hline Chemikalie & Hersteller \\
\hline$\beta$-Mercaptoethanol & Sigma-Aldrich, Steinheim \\
\hline Methanol & Fisher Scientific UK, Leicestershire \\
\hline $\begin{array}{l}\text { N,N,N',N'-Tetramethylethylendiamin } \\
(\text { TEMED) } \geq 99,5 \%\end{array}$ & \multirow[t]{2}{*}{ Carl Roth GmbH, Karlsruhe } \\
\hline Natriumdodecylsulfat (SDS) & \\
\hline N,N-Dimethylformamid & \multirow{7}{*}{$\begin{array}{l}\text { Sigma-Aldrich Chemie GmbH, } \\
\text { Steinheim }\end{array}$} \\
\hline Natriumchlorid $(\mathrm{NaCl})$ & \\
\hline Natriumfluorid (NaF) & \\
\hline Natriumhydroxid $(\mathrm{NaOH})$ & \\
\hline Natriumorthovanadat $\left(\mathrm{Na}_{3} \mathrm{VO}_{4}\right)$ & \\
\hline Natriumpyrophosphat & \\
\hline Paraformaldeyd & \\
\hline $\begin{array}{l}\text { Narcoren } 16 \mathrm{~g} / 100 \mathrm{~mL} \text { Pentobarbital- } \\
\text { Natrium Injektionslösung PZN -11336163 }\end{array}$ & Merial GmbH, Lyon, Frankreich \\
\hline Perjodsäure & \multirow{2}{*}{ Carl Roth GmbH, Karlsruhe } \\
\hline Phenylmethylsulfonylfluorid (PMSF) & \\
\hline Ponceau S & AppliChem GmbH, Darmstadt \\
\hline Salzsäure $(\mathrm{HCl})$ & Fisher Scientific UK, Leicestershire \\
\hline Trichloressigsäure & \multirow{2}{*}{$\begin{array}{l}\text { Sigma-Aldrich Chemie GmbH, } \\
\text { Steinheim }\end{array}$} \\
\hline $\begin{array}{l}\text { Trizma }^{\circledR} \text { base [Tris(hydroxy-methyl)- } \\
\text { aminomethan] }\end{array}$ & \\
\hline Tris-HCl & AppliChem GmbH, Darmstadt \\
\hline Triton-X 100 & $\begin{array}{l}\text { Sigma-Aldrich Chemie GmbH, } \\
\text { Steinheim }\end{array}$ \\
\hline Tween ${ }^{\circledR} 20$ & AppliChem GmbH, Darmstadt \\
\hline Wasserstoffperoxid 30 wt \% in $\mathrm{H}_{2} \mathrm{O}$ & $\begin{array}{l}\text { Sigma-Aldrich Chemie GmbH, } \\
\text { Steinheim }\end{array}$ \\
\hline Xylol & Thermo Fisher Scientific, Schwerte \\
\hline
\end{tabular}

Tabelle 6: Chemikalien 
2.1.7 Proteine und Reagenzien

\begin{tabular}{|c|c|}
\hline Enzym/Reagenz/Größenstandard & Hersteller \\
\hline ABsolute $^{\text {TM }}$ Blue QPCR LowROX Mix & Thermo Fisher Scientific, Schwerte \\
\hline $\begin{array}{l}\text { cOmplete Protease Inhibitor Cocktail } \\
\text { (PIC) }\end{array}$ & Roche Diagnostics $\mathrm{GmbH}$, Mannheim \\
\hline $\begin{array}{l}\text { Dako Antibody Diluent with Background- } \\
\text { Reducing Components S3022 }\end{array}$ & \multirow{3}{*}{ Agilent, Ratingen } \\
\hline Dako Goat Serum & \\
\hline $\begin{array}{l}\text { Dako Real Target Retrieval Solution 10x } \\
\text { Citrate pH } 6 \text { Concentrate } 2031\end{array}$ & \\
\hline $\begin{array}{l}\text { Immobilion }{ }^{\mathrm{TM}} \text { Western Blot } \\
\text { Chemiluminescent HRP Substrate }\end{array}$ & Merck, Schwalbach \\
\hline Mayer's Hematoxilin & AppliChem GmbH, Darmstadt \\
\hline Molekulargewichtsstandard (Protein) & Biomol, Hamburg \\
\hline Pferdeserum & $\begin{array}{l}\text { Perbio Science Deutschland GmbH, } \\
\text { Bonn }\end{array}$ \\
\hline Schiff'sches Reagenz & Carl Roth $\mathrm{GmbH}$, Karlsruhe \\
\hline TRIReagent ${ }^{\circledR}$ RNA Isolation Reagent & $\begin{array}{l}\text { Sigma-Aldrich Chemie } \mathrm{GmbH} \text {, } \\
\text { Steinheim }\end{array}$ \\
\hline GelRed $^{\circledR}$ Nucleic Acid Gel Stain & Biotium, CA, USA \\
\hline 100 bp DNA-Leiter & \multirow{9}{*}{ Thermo Fisher Scientific, Schwerte } \\
\hline 6x DNA loading dye & \\
\hline dNTP Mix (10 mM) & \\
\hline $\mathrm{MgCl}_{2}(25 \mathrm{mM})$ & \\
\hline Random Hexamer Primer & \\
\hline RevertAid $^{\mathrm{TM}}$ Reverse Transcriptase & \\
\hline Reaction Buffer, $5 x$ & \\
\hline PCR Reaction Buffer 10x & \\
\hline RiboLock $^{\mathrm{TM}}$ Ribonuclease Inhibitor & \\
\hline $\begin{array}{l}\text { Roti }^{\circledR} \text {-Histofix ( } 4 \% \text { phosphatgepufferte } \\
\text { Formaldehydlösung) }\end{array}$ & \multirow{3}{*}{ Carl Roth GmbH, Karlsruhe } \\
\hline Rotiphorese $^{\circledR}$-Gel $30(37,5: 1)$ & \\
\hline Roti $^{\circledR}$-Quant & \\
\hline
\end{tabular}

Tabelle 7: Proteine und Reagenzien 


\subsubsection{Antikörper für Western Blot}

\begin{tabular}{|c|c|}
\hline Antikörper & Hersteller \\
\hline \multicolumn{2}{|l|}{ Primärantikörper } \\
\hline $\begin{array}{l}\text { Anti-a-SMA Klon 1A4 } \\
\text { (Maus, monoklonal, 1:5000, A2527) }\end{array}$ & $\begin{array}{l}\text { Sigma-Aldrich Chemie } \mathrm{GmbH} \text {, } \\
\text { Steinheim }\end{array}$ \\
\hline $\begin{array}{l}\text { Anti-ß-Aktin } \\
\text { (Ziege, polyklonal, 1:3000, sc-1616) }\end{array}$ & \multirow{3}{*}{ Santa Cruz, Heidelberg } \\
\hline $\begin{array}{l}\text { Anti-CTGF } \\
\text { (Ziege, polyklonal, 1:1000, sc-14939) }\end{array}$ & \\
\hline $\begin{array}{l}\text { Anti-GAPDH } \\
\text { (Ziege, polyklonal, 1:1000, sc-20357) }\end{array}$ & \\
\hline $\begin{array}{l}\text { Anti-GAPDH (Maus, monoklonal, 1:3000, } \\
\text { GTX627408) }\end{array}$ & GeneTex (CA, USA) \\
\hline $\begin{array}{l}\text { Anti-Fibronectin-IgG } \\
\text { (Kaninchen, polyklonal, ab2413) }\end{array}$ & abcam, Cambridge, UK \\
\hline $\begin{array}{l}\text { Anti-F4/80 Klon Cl:A3-1 } \\
\text { (Maus, monoklonal, 1:200, MCA497R) }\end{array}$ & Bio-Rad, München \\
\hline $\begin{array}{l}\text { Anti-CerS2 (Kaninchen, polyklonal, } \\
\text { 1:1000) HPA027262 }\end{array}$ & $\begin{array}{l}\text { Sigma-Aldrich Chemie GmbH, } \\
\text { Steinheim }\end{array}$ \\
\hline Lipocalin-2 (Ziege, polyklonal, AF1857) & \multirow[b]{2}{*}{ R\&D Systems (Minneapolis, USA) } \\
\hline $\begin{array}{l}\text { HAVCR/KIM-1 (Ziege, polyklonal, } \\
\text { AF1817) }\end{array}$ & \\
\hline \multicolumn{2}{|l|}{ Sekundärantikörper } \\
\hline $\begin{array}{l}\text { Anti-Maus-Immunglobulin G (IgG) } \\
\text { (Schaf, HRP-gekoppelt, 1:5000, \#NA934) }\end{array}$ & GE Healthcare, München \\
\hline $\begin{array}{l}\text { Anti-Ziege-lgG } \\
\text { (Esel, HRP-gekoppelt, 1:5000, AP180P) }\end{array}$ & EMD Millipore (CA, USA) \\
\hline $\begin{array}{l}\text { Anti-Kaninchen-lgG } \\
\text { (Esel, HRP-gekoppelt, 1:5000, \#NA934) }\end{array}$ & GE Healthcare, München \\
\hline $\begin{array}{l}\text { Alkaline Phosphatase-Anti-Alkaline } \\
\text { Phosphatase (Kaninchen, 1:5) }\end{array}$ & $\begin{array}{l}\text { Sigma-Aldrich Chemie GmbH, } \\
\text { Steinheim }\end{array}$ \\
\hline $\begin{array}{l}\text { N-Histofine Simple Stain Mouse Max PO } \\
\text { Rat } 414311 \mathrm{~F}\end{array}$ & Nichirei Biosciences Inc., Tokyo, Japan \\
\hline
\end{tabular}

Tabelle 8: Antikörper für Western Blot 
2.1.9 Kits

\begin{tabular}{|l|l|}
\hline \multicolumn{1}{|c|}{ Kit } & \multicolumn{1}{c|}{ Hersteller } \\
\hline $\begin{array}{l}\text { Alkaline Phosphatase Permanent AP Red } \\
\text { Kit }\end{array}$ & Zytomed Systems GmbH, Berlin \\
\hline DAB Peroxidase Substrat Kit SK-4100 & $\begin{array}{l}\text { Vector Laboratories, Burlingame, CA, } \\
\text { USA }\end{array}$ \\
\hline $\begin{array}{l}\text { Mouse on mouse (M.O.M.TM) Elite } \\
\text { Peroxidase Kit }\end{array}$ & $\begin{array}{l}\text { Vector Laboratories, Burlingame, CA, } \\
\text { USA }\end{array}$ \\
\hline $\begin{array}{l}\text { StressXpress } \\
\text { Creatinine Serum Detection Kit }\end{array}$ & $\begin{array}{l}\text { StressMarq Biosciences Inc., Victoria, } \\
\text { BC Canada }\end{array}$ \\
\hline
\end{tabular}

Tabelle 9: Kits

\subsubsection{Angesetzte Lösungen}

\begin{tabular}{|c|c|c|c|}
\hline \multicolumn{4}{|c|}{ Wässrige Lösungen } \\
\hline $\begin{array}{l}\text { Ponceau S-Lösung } \\
\text { Ponceau S } \\
\text { Trichloressigsäure }\end{array}$ & $\begin{array}{r}0,2 \% \\
3 \%\end{array}$ & $\begin{array}{l}\text { Trichloressigsäurelösung } \\
\text { Trichloressigsäure }\end{array}$ & $70 \%$ \\
\hline $\begin{array}{l}\text { Tris-gepufferte Salir } \\
\text { Tris } \\
\mathrm{NaCl} \\
\mathrm{pH} 7,6\end{array}$ & $\begin{array}{l}\text { 3S) } \\
0,61 \% \\
0,87 \%\end{array}$ & $\begin{array}{l}\text { Sammelgelpuffer } \\
\text { Tris - HCl } \\
\mathrm{pH} 6,8\end{array}$ & $0,5 \mathrm{M}$ \\
\hline $\begin{array}{l}\text { Lysereagenz (5x) } \\
\mathrm{NaOH} \\
\text { EDTA.Na2 } \\
\text { pH } 12\end{array}$ & $\begin{array}{r}125 \mathrm{mM} \\
1 \mathrm{mM}\end{array}$ & $\begin{array}{l}\text { MOPS-Lösung (5x) } \\
\text { MOPS }\end{array}$ & $250 \mathrm{mM}$ \\
\hline
\end{tabular}

Tabelle 10: Angesetzte Lösungen 
2.1.11 Puffer

\begin{tabular}{|c|c|c|}
\hline \multicolumn{3}{|c|}{ Verwendete Puffersysteme in VE- $\mathrm{H}_{2} \mathrm{O}$} \\
\hline $\begin{array}{l}\text { Trenngelpuffer } \\
\text { Tris - } \mathrm{HCl} \\
\mathrm{pH} 8,8\end{array}$ & $\begin{array}{l}\text { Sammelgelpuffer } \\
\text { Tris - } \mathrm{HCl} \\
\mathrm{pH} 6,8\end{array}$ & $0,5 \mathrm{M}$ \\
\hline $\begin{array}{lr}\text { Lysepuffer } & \\
\text { Tris-HCl } & 50 \mathrm{mM} \\
\mathrm{NaCl} & 150 \mathrm{mM} \\
\text { Glycerol } & 10 \% \\
\text { EDTA } & 2 \mathrm{mM} \\
\text { EGTA } & 2 \mathrm{mM} \\
\mathrm{NaF} & 50 \mathrm{mM} \\
\mathrm{Na}_{4} \mathrm{P}_{2} \mathrm{O}_{7} & 10 \mathrm{mM} \\
\mathrm{DTT} & 2 \mathrm{mM} \\
\mathrm{Na}_{3} \mathrm{VO}_{4} & 200 \mu \mathrm{\mu M} \\
\text { Triton X-100 } & 1 \% \\
\beta-G l y c e r o l p h o s p h a t & 40 \mathrm{mM} \\
\text { pH 7,4 } & \\
\text { Vor Verwendung wurden } 1 \times \text { PIC und } \\
1 \text { mM PMSF zugegeben. }\end{array}$ & $\begin{array}{l}\text { 4x Laemmli-Puffer } \\
\text { Glycerol } \\
\text { SDS } \\
\text { Tris-HCl } \\
\text { Dithiothreitol (DTT) } \\
\text { Bromphenolblau } \\
\text { pH 6,5 }\end{array}$ & $\begin{array}{r}40 \% \\
10 \% \\
125 \mathrm{mM} \\
50 \mathrm{mM} \\
0,01 \%\end{array}$ \\
\hline $\begin{array}{l}\text { 10x SDS-Puffer } \\
\text { Tris-Base } \\
\text { Glycin } \\
\text { SDS } \\
\text { pH } 8,3\end{array}$ & $\begin{array}{l}\text { Transferpuffer } \\
\text { Tris-Base } \\
\text { Glycin } \\
\text { Isopropanol } \\
\text { pH 8,3 }\end{array}$ & $\begin{array}{r}25 \mathrm{mM} \\
200 \mathrm{mM} \\
10 \%\end{array}$ \\
\hline $\begin{array}{lr}\text { Phosphatgepufferte } & \text { Saline } \\
\mathrm{NaCl} & \text { (PBS) } \\
\mathrm{KCl} & 237 \mathrm{mM} \\
\mathrm{KH}_{2} \mathrm{PO}_{4} & 2,7 \mathrm{mM} \\
\mathrm{Na}_{2} \mathrm{HPO}_{4} & 1,4 \mathrm{mM} \\
& 10 \mathrm{mM}\end{array}$ & $\begin{array}{l}\text { PBS mit Tween (PBST) } \\
\mathrm{NaCl} \\
\mathrm{KCl} \\
\mathrm{KH}_{2} \mathrm{PO}_{4} \\
\mathrm{Na}_{2} \mathrm{HPO}_{4} \\
\text { Tween - } 20(\mathrm{~V} / \mathrm{N})\end{array}$ & $\begin{array}{c}137 \mathrm{mM} \\
2,7 \mathrm{mM} \\
1,4 \mathrm{mM} \\
10 \mathrm{mM} \\
0,1 \%\end{array}$ \\
\hline $\begin{array}{l}\text { Sekundärantikörperverdünnung und } \\
\text { Blockierungspuffer } \\
\text { PBST mit } 5 \% \text { Magermilchpulver }\end{array}$ & $\begin{array}{l}\text { Primärantikörperverdünnung } \\
\text { Tris- } \mathrm{HCl} \\
\mathrm{NaCl} \\
\text { Triton-X } 100 \\
\mathrm{BSA} \\
\text { Pferdeserum }\end{array}$ & $\begin{array}{r}50 \mathrm{mM} \\
150 \mathrm{mM} \\
2 \% \\
3 \% \\
10 \%\end{array}$ \\
\hline $\begin{array}{lr}\text { 50x Tris-Acetat-EDTA-Puffer (TAE) } \\
\text { EDTA.Na } 2 & 50 \mathrm{mM} \\
\text { Tris } & 2 \mathrm{mM} \\
\text { Essigsäure } & 1 \mathrm{M}\end{array}$ & & \\
\hline
\end{tabular}

Tabelle 11: Puffer 


\subsubsection{TaqMan $^{\circledR}$-Sonden}

\begin{tabular}{|c|c|}
\hline Sonde & Ziel mRNA \\
\hline \multicolumn{2}{|l|}{ Gene Mensch } \\
\hline Hs00426853_g1 & smooth muscle actin alpha 2 \\
\hline Hs00164004_m1 & Collagen type I alpha 1 \\
\hline Hs00943809_m1 & Collagen type III alpha 1 \\
\hline \multicolumn{2}{|l|}{ Gene Maus } \\
\hline Mm00725412_s1 & smooth muscle actin alpha 2 \\
\hline Mm00801666_g1 & Collagen type I alpha 1 \\
\hline Mm01254476_m1 & Collagen type III alpha 1 \\
\hline Mm01258345_g1 & Ceramide synthase 2 \\
\hline Mm00510998_m1 & Ceramide synthase 5 \\
\hline Mm00556165_m1 & Ceramide synthase 6 \\
\hline Mm01252547_g1 & SK-1 \\
\hline Mm00445021_g1 & SK-2 \\
\hline Mm00514644_m1 & $\mathrm{S}_{1} \mathrm{P}_{1}$ \\
\hline Mm02620208_s1 & $\mathrm{S}_{1} \mathrm{P}_{2}$ \\
\hline Mm02620181_s1 & $\mathrm{S}_{1} \mathrm{P}_{3}$ \\
\hline Mm02620565_s1 & $\mathrm{S}_{1} \mathrm{P}_{5}$ \\
\hline Mm00461932_g1 & Spns2 \\
\hline Mm01192933_g1 & CTGF \\
\hline Mm01256744_m1 & Fn-1 \\
\hline Mm00506686_m1 & Kim-1 \\
\hline Mm01324470_m1 & Lcn2 \\
\hline Mm00435858_m1 & Pai-1 \\
\hline Mm00446190_m1 & IL-6 \\
\hline Mm00441242_m1 & $\mathrm{Ccl} 2$ \\
\hline Mm00840904_m1 & NIrp3 \\
\hline Mm00443258_m1 & Tnf- $\alpha$ \\
\hline Mm00434228_m1 & IL-1 $\beta$ \\
\hline Mm00802529_m1 & Adgre1 \\
\hline
\end{tabular}

Tabelle 12: TaqMan $^{\circledR}$-Sonden 
2.1.1 Primer für die Genotypisierungen

\begin{tabular}{|l|l|}
\hline \multicolumn{1}{|c|}{ Primer } & \multicolumn{1}{c|}{ Sequenz $\left(\mathbf{5}^{`}-\mathbf{3}^{`}\right)$} \\
\hline Spns2 (vorwärts) & CAAAACAATATGGGCTGGGG \\
\hline Spns2 (revers) & GATGAAGGCAGGACTCAGGG \\
\hline Spns2 (Kassette) & TCGTGGTATCGTTATGCGCC \\
\hline S1P5 (vorwärts) TCCTCGGTTCTAAACCTTCTC \\
\hline S1P5 (revers) & CTCTAAAGCAATGGCCAAGAG \\
\hline DsRed (revers) & TTGGTCACCTTCAGCTTCACG \\
\hline
\end{tabular}

Tabelle 13: Primer für die Genotypisierungen

Die verwendeten Primer für die Genotypisierungen und die TaqMan ${ }^{\circledR}$-Sonden wurden bei Thermo Fisher Scientific (Schwerte) erstanden.

\subsubsection{Software}

\begin{tabular}{|c|c|}
\hline Software & Hersteller \\
\hline GraphPad Prism - V. 5.02 & Graphpad Software, San Diego, USA \\
\hline ImageJ - V. 1.51j8 & $\begin{array}{l}\text { National Institutes of Health, Bethesda, } \\
\text { USA }\end{array}$ \\
\hline inForm ${ }^{\circledR}$ Tissue Finder ${ }^{\mathrm{TM}}$ & \multirow{3}{*}{$\begin{array}{l}\text { Akoya Biosciences, Massachusetts, } \\
\text { USA }\end{array}$} \\
\hline Phenochart $^{\circledR}$ & \\
\hline Vectra $^{\circledR}$ & \\
\hline TaqMan $^{\circledR}$ - 7500 Fast - V. 1.4 .0 & AppliChem GmbH, Darmstadt \\
\hline ZEISS ZEN Imaging Software - V. 2008 & Carl Zeiss, Jena \\
\hline ChemSketch V. 2020.1.2 & ACD/Labs \\
\hline
\end{tabular}

Tabelle 14: Software 
2.1.2 Verbrauchsmaterialen

\begin{tabular}{|c|c|}
\hline Verbrauchsmaterialen & Hersteller \\
\hline Amersham Hyperfilm ${ }^{\mathrm{TM}} \mathrm{ECL}$ & GE Healthcare, München, Deutschland \\
\hline $\begin{array}{l}\text { CELLSTAR }{ }^{\circledR} \text { Polypropylen Röhrchen } \\
15 \mathrm{~mL} \text { und } 50 \mathrm{~mL}\end{array}$ & $\begin{array}{l}\text { Greiner Bio-One, Frickenhausen, } \\
\text { Deutschland }\end{array}$ \\
\hline Corning ${ }^{\circledR} 500$ mL Filter System & Corning, New York, USA \\
\hline $\begin{array}{l}\text { Eppendorf Reaktionsgefäß } \\
(0,5 \mathrm{~mL}, 1,5 \mathrm{~mL}, 2 \mathrm{~mL})\end{array}$ & $\begin{array}{l}\text { Eppendorf } \mathrm{GmbH} \text {, Hamburg, } \\
\text { Deutschland }\end{array}$ \\
\hline Kryoröhrchen CELLSTAR ${ }^{\circledR}(2 \mathrm{~mL})$ & $\begin{array}{l}\text { Greiner Bio-One, Frickenhausen, } \\
\text { Deutschland }\end{array}$ \\
\hline $\begin{array}{l}\text { Lumi-Film Chemiluminescent Detection } \\
\text { Film }\end{array}$ & $\begin{array}{l}\text { Roche Diagnostics, Mannheim, } \\
\text { Deutschland }\end{array}$ \\
\hline $\begin{array}{l}\text { MicroAmp }{ }^{\circledR} \text { Fast Optical 96-Well reaction } \\
\text { plate }\end{array}$ & Life Technologies, Darmstadt \\
\hline Kryoröhrchen Cellstar (2 mL) & $\begin{array}{l}\text { Greiner Bio-One, Frickenhausen, } \\
\text { Deutschland }\end{array}$ \\
\hline Nitrozellulosemembran, $0,45 \mu \mathrm{m}$ & BioRad, München, Deutschland \\
\hline Pasteur Capillary Pipettes, 230 mm & WU Mainz, Bamberg, Deutschland \\
\hline PCR SoftTubes, 0,2 mL & Biozym Biotech, Wien, Österreich \\
\hline Steriflip $^{\circledR}($ Sterilfiltersystem $)$ & Merck Millipore, Darmstadtt \\
\hline Stripette ${ }^{\circledR}$ (Zellkulturpipetten) & Corning Incorporated, New York, USA \\
\hline Whatman ${ }^{\circledR}$ Filterpapier (3 MM) & $\begin{array}{l}\text { Whatman International Ltd., Maidstone, } \\
\text { GB }\end{array}$ \\
\hline $\begin{array}{l}\text { Zählkammer TC10 } 10^{\mathrm{TM}} \text { System Counting } \\
\text { Slides, Counting Slides Dual Chamber } \\
\text { for Cell Counter }\end{array}$ & BioRad, München, Deutschland \\
\hline Zellkulturflaschen & $\begin{array}{l}\text { Greiner Bio-One, Frickenhausen, } \\
\text { Deutschland }\end{array}$ \\
\hline Zellkulturplatten (6- und 24-Well) & $\begin{array}{l}\text { Greiner Bio-One, Frickenhausen, } \\
\text { Deutschland }\end{array}$ \\
\hline Zellkulturschalen & $\begin{array}{l}\text { Greiner Bio-One, Frickenhausen, } \\
\text { Deutschland }\end{array}$ \\
\hline Zellschaber, $25 \mathrm{~cm}$ & Sarstedt, Newton, USA \\
\hline
\end{tabular}

Tabelle 15: Verbrauchsmaterialien 


\subsubsection{Verwendete Tiere}

Spns2 ${ }^{+/}$-Mäuse (Mus musculus Spns2tm1a(KOMP)Wtsi) wurden wie bereits beschrieben generiert (Chen et al. 2014) und von Prof. Paul van Veldhoven (Katholieke Universiteit Leuven, Belgien) erhalten. Es wurde eine L1L2_Bact_PKassette an Position 72464268 des Chromosoms 11 per Kassettenaustauschverfahren eingefügt (Abbildung 9). Für die Isolation der Primärzellen wurden Spns2 $2^{-1-}$ Mäuse und korrespondierende Wildtypen (Spns2 $2^{++}$-Mäuse) verwendet.

\section{Spns $2^{\text {tm1a }}$}

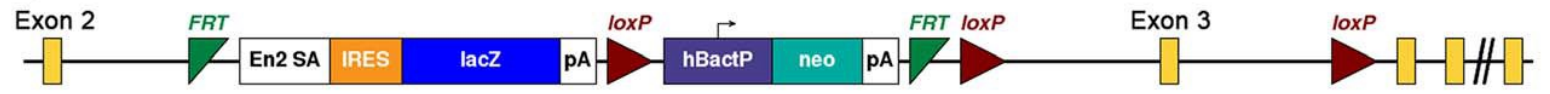

Abbildung 9: Schema der Herstellung des Spns2 ${ }^{-/-}$mittels des Kassettenaustauschverfahrens. Abgebildet sind eine promotorgesteuerte Genkassette, welche eine SpleißAkzeptorseite, eine interne ribosomale Eintrittsstelle (IRES) und einen $\beta$-Galaktosidase Reporter (lacZ) enthält. Anschließend folgt ein Neomycinresistenzmarker (neo), welcher unter der Kontrolle eines unabhängigen $\beta$-Aktin-Promotors steht. Diese Kassette wurde in das Intron 2 von Spns2 eingeschleust. FRT (flippase recognition target)-Sequenzen flankieren die Kassette und LoxP (locus of X-over P1)-Sequenzen flankieren das Exon 3 (Chen et al. 2014).

Die S1P $5^{-1-}$-Mäuse wurden im The Scripps Research Institute (La Jolla, CA, USA) generiert und uns von Prof. Dr. Jerold Chun zur Verfügung gestellt (Jenne et al. 2009). Die gesamten kodierenden Gensequenzen von $\mathrm{S}_{1} \mathrm{P}_{5}$ wurden, bis auf die Sequenz, welche für die ersten sieben Aminosäuren kodiert, mit herkömmlichen molekularbiologischen Methoden deletiert. Hierfür wurde der Vektor pBluescript (Agilent Technologies) verwendet. Es wurde zudem die Sequenz für DsRed von DsRed-N1 (Takara Bio Inc.) eingefügt. Die Orientierung der Neomycinkassette unter Kontrolle des Phosphoglyceratkinase-Promotors liegt umgekehrt zu der des S1P5Lokus. 


\subsection{Zellbiologische Methoden}

\subsubsection{Isolation von Glomerula zur Kultivierung von Mesangiumzellen der Maus}

Nach der schmerzfreien Tötung der Maus wurde der Bauchraum geöffnet und eine der beiden Niere mit einer Pinzette fixiert. Anschließend wurde mit einer Schere das Fettgewebe und die Nierenarterie abgetrennt. Mit Hilfe von Pinzetten wurde die Nierenkapsel abgezogen und die Niere in ein $15 \mathrm{~mL}$ Reaktionsgefäß, gefüllt mit sterilem PBS, gelegt. Der Vorgang wurde mit der verbliebenen Niere wiederholt. Die Glomeruli wurden mit Hilfe eines Siebsystems isoliert. Die Maschenweite der Siebe betrug $180 \mu \mathrm{m}$ oben, $106 \mu \mathrm{m}$ in der Mitte und $53 \mu \mathrm{m}$ unten. Die Nieren wurden auf das oberste Sieb gelegt, mit einem Skalpell zunächst zerhackt und schließlich mit Daumen oder Fingern in sterilen Handschuhen durch das Sieb gerieben. Es wurde mit sterilem PBS nachgespült, sodass sich möglichst viel Gewebe auf dem mittleren Sieb ansammeln konnte. Hier wurde auch wieder Gewebe durch das Sieb gedrückt und mit PBS nachgespült. Die glomerulären Kapseln und tubuläre Bruchstücke blieben auf dem oberen und mittleren Sieb hängen. Auf dem unteren Sieb sammelten sich somit die Glomerula, welche aufgrund ihrer Größe nicht mehr passieren konnten. Einzelne, aus dem Blut stammende Zellen und das PBS wurden in das Auffangbecken gespült. Das unterste Sieb wurde aus dem Siebsystem herausgenommen, um $180^{\circ}$ gedreht und über eine Zellkulturschale mit $150 \mathrm{~mm}$ Durchmesser gelegt. So konnten die Glomerula nun mit PBS von dem Sieb in die Zellkulturschale gespült werden. Die Glomerula wurde mit Hilfe eines Zellkulturschabers und Pipette in $50 \mathrm{~mL}$ Reaktionsgefäßen überführt und bei 1000 Upm für 10 Minuten zentrifugiert. Das PBS wurde abgesaugt und die Glomerula in $3 \mathrm{~mL}$ Wachstumsmedium resuspendiert und in $25 \mathrm{~cm}^{2}$ Zellkulturflaschen überführt. Die Glomerula wurden zunächst für 3 Wochen im Brutschrank inkubiert, da die Mesangiumzellen diese Zeit benötigen, um die anderen Zellen des Glomerulums zu überwachsen.

\subsubsection{Kultivierung der Zellen}

Die Kultivierung aller Zellen erfolgte in Kulturflaschen im Brutschrank bei $37^{\circ} \mathrm{C}, 5 \%$ $\mathrm{CO}_{2}$ und $95 \%$ Luftfeuchtigkeit unter Verwendung des jeweiligen Wachstumsmediums. Alle Zellkulturarbeiten wurden unter sterilen Bedingungen durchgeführt. 


\subsubsection{Stimulation adhärent wachsender Zellen}

Um die Zellen für ein Experiment verwenden zu können, wurden sie von den Kulturflaschen in Zellkulturschalen oder Zellkulturplatten überführt. Hierfür wurde zunächst das verbrauchte Medium abgesaugt und die Zellen mit DPBS gewaschen. Anschließend wurde Trypsin/EDTA Lösung auf die Zellen gegeben und die Zellkulturflasche zurück in den Brutschrank gestellt. Nach ein paar Minuten hatten sich die Zellen vom Boden der Zellkulturflasche gelöst oder wurden gegebenenfalls noch durch leichte Schläge gegen die Wand der Flasche abgelöst. Die Zellen wurden im stets vorgewärmten Wachstumsmedium resuspendiert, in sterile Cellstar ${ }^{\mathrm{TM}}$ Röhrchen überführt, pelletiert und die Flüssigkeit abgesaugt. Zum Aussäen wurden die Zellen in frischem Wachstumsmedium verdünnt. Für Experimente wurden die Zellen in Zellkulturschalen oder Zellkulturplatten ausgelegt und bis zu einer Konfluenz von ca. $70 \%$ kultiviert. Anschließend wurde das Wachstumsmedium der Zellen für $24 \mathrm{~h}$ gegen Hungermedium getauscht, um die Zellen in die Ruhephase zu versetzen. Für die Stimulation der Zellen wurden die verwendeten Substanzen in Stimulationsmedium in Cellstar ${ }^{\mathrm{TM}}$ Röhrchen angesetzt.

\subsubsection{Zellzählung}

Adhärente Zellen wurden wie im vorigen Abschnitt beschrieben in Suspension gebracht. $20 \mu \mathrm{L}$ der Zellsuspension wurden 1:1 mit einer Trypanblau-Lösung behutsam vermischt und etwa $20 \mu \mathrm{L}$ des Gemischs auf eine Neubauer-Zählkammer pipettetiert und die Zellen mit Hilfe eines Lichtmikroskops untersucht. Das Trypanblau konnte nur die toten Zellen blau anfärben, wohingegen lebende Zellen mit intakter Zellmembran farblos blieben. Zur Bestimmung der Anzahl lebender Zellen in der Zellsuspension wurden diese in den eingeschliffenen Quadranten mit definiertem Volumen gezählt. 


\subsubsection{Kryokonservierung}

Zur Kryokonservierung wurden die Zellen mit DPBS gewaschen, trypsiniert, in Wachstumsmedium aufgenommen und für 5 Minuten bei $800 \mathrm{Upm}$ zentrifugiert. Der Überstand wurde abgesaugt und das Zellpellet in Einfriermedium, bestehend aus 45\% Wachstumsmedium, 45\% FKS und 10\% DMSO resuspendiert und in sterile Kryoröhrchen überführt. Diese wurden anschließend in einem mit Isopropanol gefüllten Gefrierbehälter (Mr. Frosty ${ }^{\mathrm{TM}}$ ) langsam auf $-80^{\circ} \mathrm{C}$ abgekühlt und zur Langzeitlagerung in flüssigem Stickstoff eingefroren.

Zum Auftauen der Zellen wurden die Kryoröhrchen unverzüglich in ein $37^{\circ} \mathrm{C}$ warmes Wasserbad gestellt und die Zellsuspension mit Wachstumsmedium in ein Cellstar ${ }^{\mathrm{TM}}$ Röhrchen überführt. Die Röhrchen wurden zentrifugiert, der Überstand abgesaugt und die Zellen in frischem Wachstumsmedium resuspendiert und zur Kultivierung in Zellkulturflaschen überführt.

\subsection{Modell der Adenin-induzierten tubulointerstitiellen Nierenfibrose der Maus}

Durch eine Übersättigung der Adeninphosphoribosyltransferase (APRT) wird Adenin über die Xanthindehydrogenase $(\mathrm{XDH})$ zu 2,8-Dihydroxyadenin (2,8-DHA) anstatt zu Adenosinmonophosphat (AMP) verstoffwechselt (Abbildung 10) (Zaidan et al. 2014). 2,8-DHA ist wasserunlöslich und präzipitiert unter der Bildung von Kristallen im Gewebe, wenn es nicht über den Urin vorher ausgeschieden werden kann. Hierdurch wird das Gewebe geschädigt und eine Entzündungsreaktion hervorgerufen. Sowohl im Menschen wie auch in Mäusen lagern sich die Kristalle vor allem im Lumen der Tubuli und im Zytosol von Tubulusepithelzellen an und führen zu einer tubulointerstitiellen Fibrose (Zaidan et al. 2014; Jia et al. 2013). 


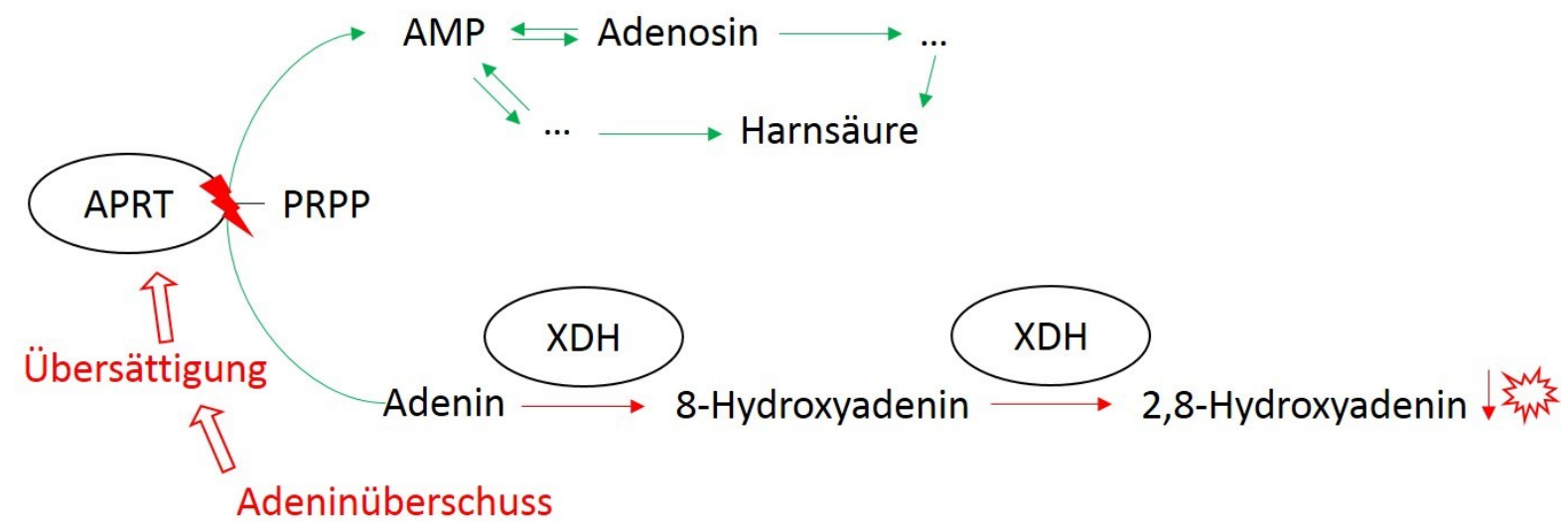

Abbildung 10: Stoffwechselweg für den Abbau von Adenin und die Folgen einer Übersättigung für die Niere (Zaidan et al. 2014).

Durch eine Übersättigung des Enzyms Adeninphosphoribosyltransferase (APRT) mit Adenin, kann dieses nicht mehr vollständig unter Verbrauch von 5-Phosphoribosyl-1-pyrophosphat (PRPP) über Adenosinmonophosphat (AMP) bis zur Ausscheidung als Harnsäure verstoffwechselt werden. Stattdessen wird das überschüssige Adenin mit Hilfe der Xanthindehydrogenase (XDH) zu 2,8-Dihydroxyadenin umgewandelt, welches im Gewebe auskristallisiert und zur Nephropathie führt.

Die Haltung der Mäuse erfolgte in der zentralen Forschungseinrichtung (ZFE) der Universitätsklinik Frankfurt am Main. Alle Mäuse hatten freien Zugang zu Futter und Wasser und wurden in einem Haltungsraum mit einem $12 \mathrm{~h}$ Tag-Nacht-Rhythmus und einer konstanten Raumtemperatur von $22 \pm 2^{\circ} \mathrm{C}$ gehalten. Die Durchführung des Tiermodells der Adenin-induzierten tubulointerstitiellen Nierenfibrose, fortan ANModell genannt, erfolgte unter Berücksichtigung der Richtlinien des deutschen Tierschutzgesetzes und nach einem zuvor vom zuständigen Regierungspräsidium bewilligten Tierversuchsantrag. Für den Versuch wurden männliche $\mathrm{S}_{1 \mathrm{P}^{-1}-\text { Mäuse }}$ bzw. deren korrespondierende Wildtyp-Mäuse (C57BL/6J-Mäuse) verwendet. Das Standardfutter wurde durch eine adeninhaltige Diät ersetzt und den Versuchstieren ad libitum zur Verfügung gestellt. Am Ende der jeweiligen Versuchsdauer wurden die Tiere schmerzfrei getötet und anschließend die Nieren, Leber, Milz und Blut für weitere Untersuchungen entnommen.

Die Organe wurden kurz in Zellkulturschalen mit PBS gewaschen. Bei einer Niere wurde die Nierenkapsel entfernt und das Organ der Länge nach halbiert. Die Milz und der Leberlappen wurden ebenfalls halbiert. Die beiden Hälften der einen Niere und eine Hälfte der Milz und des Leberlappens wurden jeweils in eine Einbettkassette 
gefasst und in eisgekühltes Formalin gelegt, um sie später für histologische Untersuchungen verwenden zu können. Die andere Niere und die verbliebenen Hälften der Milz und des Leberlappens wurden trocken getupft, in 1,5 mL Reaktionsgefäße überführt, in flüssigem Stickstoff schockgefroren und anschließend bei $-80^{\circ} \mathrm{C}$ gelagert.

Die tiefgefrorenen Organe bzw. Teile davon wurden in flüssigen Stickstoff überführt und mit Hilfe eines Dismembrators (B. Braun, Melsungen) pulverisiert. Hierfür wurden die Zylinder und Kugeln des Dismembrators ebenfalls in flüssigem Stickstoff vorgekühlt. Das Organ wurde zusammen mit der Kugel in einen Zylinder gesteckt und dieser in das Gerät eingespannt. Bei 3000 Upm für eine Dauer 20 Sekunden wurden die Organteile zu einem Pulver verarbeitet. Die Homogenisate wurden mit vorgekühlten Spateln auf mehrere Reaktionsgefäße verteilt. Für die Lipidanalytik musste das Gewicht der Homogenisate gemessen werden. Hierfür wurde zuvor das Leergewicht der 1,5 mL Reaktionsgefäße ermittelt und anschließend nach Augenmaß eine Menge von ca. $15 \mathrm{mg}$ überführt, unmittelbar das Gewicht bestimmt und die Proben in flüssigen Stickstoff geworfen, bevor sie bei $-80^{\circ} \mathrm{C}$ gelagert wurden. Um die RNA isolieren zu können, wurde $1 \mathrm{~mL}$ TR ${ }^{\circledR}$ Reagenz zu einer Menge von 20 bis 30 $\mathrm{mg}$ Homogenisat gegeben und die Proben bei $-80^{\circ} \mathrm{C}$ gelagert. Für die Proteinanalytik wurde eine Menge von ca. $40 \mathrm{mg}$ Homogenisat mit $500 \mu \mathrm{L}$ Lysispuffer auf Eis vermischt und anschließend bei $-20^{\circ} \mathrm{C}$ gelagert.

\subsection{Lipid-Analyse mittels LC-ESI-MS/MS}

Die Organe, Plasma und Zellkulturproben wurden zur Bestimmung und Quantifizierung der Sphingolipide mit Hilfe von Flüssigchromatographie mit ElektrosprayionisationMassenspektrometrie-Kopplung und anschließender Tandem Massenspektrometrie (LC-ESI-MS/MS) durch das Institut für Klinische Pharmakologie unter der Leitung von Prof. Dr. med. Dr. rer. nat. Gerd Geißlinger aufgearbeitet, gemessen und ausgewertet. Die Gewebeproben wurden mit einem Gemisch aus Ethanol in Wasser (1:3 V/V) versetzt und mittels einer Scheibenschwing-Mühle (Retsch, Haan) mit vier Zirconiumoxid-Kugeln für 2,5 Minuten bei $25 \mathrm{~Hz}$ aufgearbeitet und auf eine Konzentration von $0,02 \mu \mathrm{g} / \mathrm{mL}$ gebracht. $50 \mu \mathrm{L}$ der Gewebesuspension wurden mit 20 
$\mu \mathrm{L}$ eines internen Standards und mit $150 \mu \mathrm{L}$ eines Extraktionspuffers $(30 \mathrm{mM}$ Citronensäure und $40 \mathrm{mM}$ Dinatriumhydrogenphosphat) vermischt.

Die Mischung wurde mit $600 \mu \mathrm{L}$ Methanol/Chloroform/Salzsäure (15:83:2, V/V/N) extrahiert. Die untere, organische Phase wurde bei $45^{\circ} \mathrm{C}$ und unter einem sanften Stickstofffluss verdampft und in $50 \mu \mathrm{L}$ Tetrahydrofuran/Wasser (9:1 V/V) mit 0,2\% Ameisensäure und $10 \mathrm{mM}$ Ammoniumformiat wieder gelöst. Von den Standards zur Kalibrierung und von den Proben für die Qualitätskontrolle wurden im Gegensatz zu den $50 \mu \mathrm{L}$ von den zu untersuchenden Homogenisaten nur stets $20 \mu \mathrm{L}$ verwendet. $\mathrm{Zu}$ Beginn und am Ende jedes Laufes wurden drei verschiedene Konzentrationen der Qualitätskontrollproben (niedrig, mittel, hoch) gemessen.

Für die chromatographische Auftrennung der Sphingolipide wurde ein Agilent 1290 HPLC System bestückt mit einer Zorbax C18 Eclipse Plus UHPLC Säule $\left(2,1^{*} 50 \mathrm{~mm}\right.$, 1,8 $\mu \mathrm{m}$, Agilent Technologies, Waldbronn) verwendet. Die Tandem-Massenspektrometrie-Analyse wurde mit einem hybriden Tripel-Quadrupol-Ionenfallen Massenspektrometer QTRAP 5500 (Sciex, Darmstadt) durchgeführt, welches mit einer Turbo $\mathrm{V}$ Ionenquelle, die im positiven Elektrospray-lonisierungsmodus betrieben wurde, ausgestattet war. Die Daten wurden mit Analyst Software Version 1.6 und MultiQuant Software Version 3.0 (beides von Sciex, Toronto Kanada) anhand des Isotop-spezifischen, internen Standards analysiert. Die Abweichungen vom internen Standard betrugen nicht mehr als 15\%, außer für das untere Limit der Quantifizierung, wo eine Abweichung von $20 \%$ akzeptiert wurde.

\subsubsection{Genotypisierung mittels Polymerase-Kettenreaktion}

Für die Genotypisierung der Mäuse wurde die Polymerasekettenreaktion (polymerase chain reaction, PCR) verwendet. Schwanzbiopsien oder Ohrstanzen der Mäuse wurden hierfür in 0,5 mL Eppendorf Reaktionsgefäße überführt und für 1 Stunde bei $95^{\circ} \mathrm{C}$ in $50 \mu \mathrm{L}$ eines basischen Lysereagenz gekocht, um die Zellen aufzuschließen und die DNA zugänglich zu machen. Anschließend wurde das Gewebeextrakt mit 50 $\mu \mathrm{L}$ einer MOPS-Lösung ( $50 \mathrm{mM})$ neutralisiert und die Proben kurz abzentrifugiert, um grobe Gewebestücke zu pelletieren. 
Für die PCR wurde folgender Ansatz verwendet (Volumen pro Probe):

\begin{tabular}{|c|c|}
\hline $5 \mu \mathrm{L}$ & 10x PCR Reaction Buffer \\
\hline $3 \mu \mathrm{L}$ & $25 \mathrm{mM} \mathrm{MgCl}_{2}$ \\
\hline $2 \mu \mathrm{L}$ & 10 mM dNTP Mix (dATP, dCTP, dGTP, dTTP) \\
\hline $2 \mu \mathrm{L}$ & $10 \mu \mathrm{M}$ Primer (forward) \\
\hline $2 \mu \mathrm{L}$ & $10 \mu \mathrm{M}$ Primer (reverse) \\
\hline $0,3 \mu \mathrm{L}$ & Taq Polymerase $(5 \mathrm{U} / \mu \mathrm{L})$ \\
\hline $5 \mu \mathrm{L}$ & Gewebeextrakt \\
\hline $30,7 \mu \mathrm{L}$ & $\mathrm{ddH}_{2} \mathrm{O}$ \\
\hline
\end{tabular}

Temperaturprogramm des Thermocyclers:

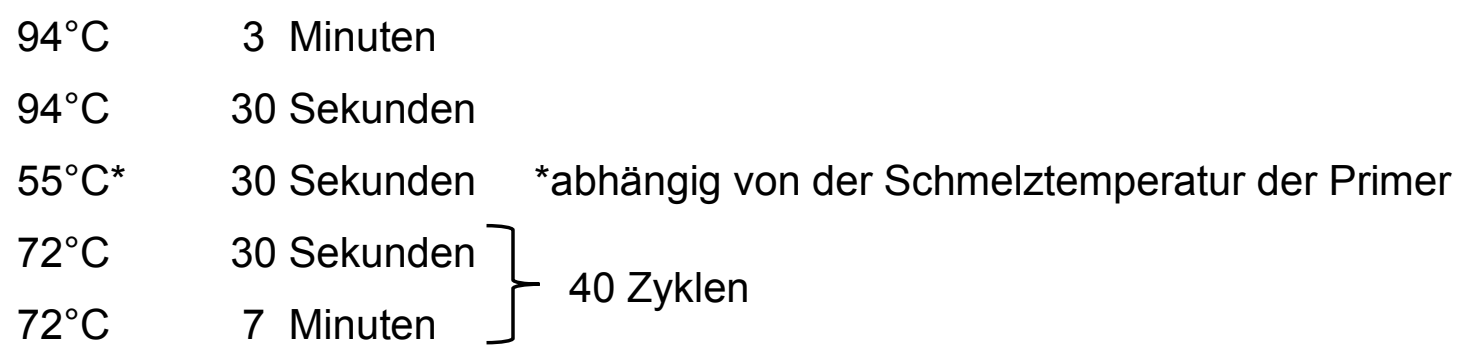

Die Proben wurden anschließend mittels Gelelektrophorese und UV-Licht analysiert.

\subsection{Molekularbiologische Methoden}

\subsubsection{Agarose-Gelelektrophorese}

PCR-Proben wurden mittels Gelelektrophorese nach ihrer Größe aufgetrennt und anschließend mit Hilfe von UV-Licht sichtbar gemacht. Für die Analyse der PCRProdukte aus den Genotypisierungsreaktionen wurden Gele aus $15 \mathrm{~g} / \mathrm{L}$ Agarose in TAE-Puffer verwendet, die mit GelRed $^{\circledR}$ nach Anleitung des Herstellers gefärbt wurden, um die DNA unter UV-Licht sichtbar zu machen. Die Proben und die $100 \mathrm{bp}$ DNA-Leiter wurden mit 6x DNA-Ladepuffer (Thermo Scientific) angesetzt, auf das Gel aufgetragen und die Elektrophorese wurde für 100 Minuten bei $90 \mathrm{~V}$ in einer Elektrophoresekammer, betrieben durch den Power Pac 200 (BioRad), durchgeführt. Abschließend wurden die DNA-Banden unter UV-Licht (300 nm) sichtbar gemacht. 


\subsubsection{RNA-Isolierung}

Um die Zersetzung der RNA durch omnipräsente RNasen zu vermeiden, wurde für die RNA-Isolierung stets DEPC- $\mathrm{H}_{2} \mathrm{O}$ verwendet. Hierfür wurde eine $0,1 \%$ ige-Lösung von DEPC- $\mathrm{H}_{2} \mathrm{O}$ hergestellt, welche bei $37^{\circ} \mathrm{C}$ über Nacht inkubiert und am nächsten Tag autoklaviert wurde. Durch diesen Prozess werden vorhandene RNasen inaktiviert und DEPC zerfällt zu Ethanol und Kohlendioxid.

Die Isolierung der mRNA aus den Zellen wurde mit Hilfe von TR ${ }^{\circledR}$ Reagenz nach Angaben des Herstellers durchgeführt. Das Stimulationsmedium der Zellen wurde abgesaugt oder gegebenenfalls in $2 \mathrm{~mL}$ Eppendorf Reaktionsgefäße überführt und je $1 \mathrm{~mL} \mathrm{TRI}{ }^{\circledR}$ Reagenz auf den Zellrasen in der Zellkulturplatte gegeben. Nach Zugabe von $200 \mu \mathrm{L}$ Chloroform und 20-fachem Invertieren der Reaktionsgefäße wurde über eine Zentrifugation von 15 Minuten bei $13.000 \mathrm{Upm}$ und $4^{\circ} \mathrm{C}$ eine Phasentrennung des Gemisches erzielt. Die RNA-haltige obere Phase wurde vorsichtig abgenommen, in ein frisches $1,5 \mathrm{~mL}$ Eppendorf Reaktionsgefäß überführt und mit $500 \mu \mathrm{L}$ Isopropanol versetzt. Die Gefäße wurden erneut $20 \mathrm{Mal}$ invertiert und anschließend für 5 Minuten bei $13.000 \mathrm{Upm}$ und $4^{\circ} \mathrm{C}$ zentrifugiert. Im Anschluss wurde das Isopropanol verworfen, die präzipitierte RNA mit 75\%iger Ethanol-Lösung (V/V) gewaschen und nach dem Verwerfen des Ethanols für 10 bis 30 Minuten bis zur Verdunstung jeglicher Flüssigkeit bei $55^{\circ} \mathrm{C}$ im Thermomixer getrocknet. Das Pellet wurde entsprechend seiner Masse mit 20-50 $\mu \mathrm{L}$ DEPC- $\mathrm{H}_{2} \mathrm{O}$ unter zur Hilfenahme des Thermomixers gelöst (10 Minuten, $\left.1000 \mathrm{Upm}, 55^{\circ} \mathrm{C}\right)$. Die Proben wurden bei $-80^{\circ} \mathrm{C}$ gelagert. 


\subsubsection{Konzentrations- und Reinheitsbestimmung isolierter RNA}

Die Konzentration isolierter RNA wurde mit Hilfe des NanoDrop ${ }^{\mathrm{TM}}$ ND-1000 Spektrophotometers bestimmt. Die Konzentration errechnete sich aus der OD bei 260 nm, der Verdünnung sowie dem für RNA spezifischen Multiplikationsfaktor 40.

$c[n g / \mu L]=O D 260 \times V \times F$

$c=$ Konzentration der Probe

$V=$ Verdünnungsfaktor

$F=$ Multiplikationsfaktor (40 für RNA)

Durch das Verhältnis aus der OD260 und OD280 kann eine Aussage über die Phenolund Proteinverunreinigung der RNA getroffen werden. Bei geringer Kontamination liegt der Quotient bei ca. 2,0.

\subsubsection{Reverse Transkriptase-PCR (RT-PCR)}

Mit Hilfe der Reversen Transkriptase, einer RNA-abhängigen DNA-Polymerase, wurde die messenger-RNA (mRNA) in komplementäre DNA (cDNA) umgeschrieben. Als Primer diente eine Mischung aus zufälligen Hexanukleotiden (Random Hexamer Primer) mit 5'- und 3'- Hydroxylgruppenende.

Folgender Ansatz wurde je Probe verwendet und in $0,5 \mathrm{~mL}$ Eppendorf Reaktionsgefäße pipettiert:
$1,2 \mu \mathrm{g}$
RNA
$1 \mu \mathrm{L}$
Random Hexamer Primer
ad $12,5 \mu \mathrm{L}$
DEPC- $\mathrm{H}_{2} \mathrm{O}$ 
Die Anlagerung der Random Hexamer Primer an die mRNA (Primerhybridisierung) wurde durch fünfminütiges Erhitzen auf $70^{\circ} \mathrm{C}$ ermöglicht. Anschließend wurden die Proben wieder auf Raumtemperatur gebracht und folgender Mastermix hinzugefügt (Volumen pro Probe):
$4 \mu \mathrm{L}$
5x Reaction Buffer
$0,5 \mu \mathrm{L}$
RiboLock ${ }^{\mathrm{TM}}$ Ribonuclease Inhibitor (40 $\mathrm{U} / \mathrm{\mu L}$ )
$2 \mu \mathrm{L}$ 10 mM dNTP Mix (dATP, dCTP, dGTP, dTTP)
$1 \mu \mathrm{L}$ RevertAid $^{\mathrm{TM}}$ Reverse Transcriptase $(200 \mathrm{U} / \mu \mathrm{L})$

Danach wurden die Proben für 60 Minuten bei $42^{\circ} \mathrm{C}$ im Thermocycler inkubiert für die Synthese des cDNA-Strangs. Zum Schluss wurde die Reverse Transkriptase inaktiviert, indem die Temperatur für 10 Minuten auf $70^{\circ} \mathrm{C}$ erhöht wurde. Die Proben wurden im Verhältnis von 1:5 mit DEPC- $\mathrm{H}_{2} \mathrm{O}$ verdünnt und bis zur weiteren Verwendung bei $-20^{\circ} \mathrm{C}$ gelagert.

\subsubsection{Quantitative Real-Time-PCR (Taqman ${ }^{\circledR}$ )}

Die quantitative Real-Time-PCR (RT-qPCR) wurde für die Quantifizierung der mRNA ausgewählter Gene in den Proben eingesetzt. Das Verfahren basiert auf dem klassischen PCR-Verfahren zur Vermehrung der CDNA, bei der zusätzlich die Menge der amplifizierten DNA-Stränge je Zyklus über Fluoreszenz in Echtzeit gemessen wird. Um die gemessene Genexpression in den Proben in Relation setzen zu können, wurde in jeder Probe die Menge der transkriptionell kaum regulierten 18S rRNA bestimmt (sogenanntes Haushaltsgen). Für die RT-qPCR wurden cDNA-haltige Proben verwendet, die wie im Abschnitt 2.5.4 hergestellt wurden. Folgende Reagenzien wurden in $0,5 \mathrm{~mL}$ Eppendorf Reaktionsgefäß pipettiert:

$\begin{array}{lll}\text { Haushaltsgen (18S) } & \text { Zielgen } & \text { Reagenz } \\ 1 \mu \mathrm{L} & 5 \mu \mathrm{L} & \text { cDNA } \\ 0,3 \mu \mathrm{L} & 1 \mu \mathrm{L} & \text { Sonde inklusive Primer } \\ 9 \mu \mathrm{L} & 9 \mu \mathrm{L} & \text { LowRox Mix } \\ 9,7 \mu \mathrm{L} & 5 \mu \mathrm{L} & \mathrm{ddH}_{2} \mathrm{O}\end{array}$


Die verwendeten Sonden sind in Abschnitt 2.1.12 (Tabelle 14) aufgeführt. Der beschriebene Reaktionsansatz wurde für die Möglichkeit einer Doppelbestimmung auf jeweils zwei wells einer 96-well-Platte verteilt und nach Versiegelung der Platte mittels einer durchsichtigen Folie in dem „7500 Fast Real-Time PCR System“ unter Verwendung von folgendem Temperaturprogramm analysiert:

\begin{tabular}{|c|c|}
\hline $50^{\circ} \mathrm{C}$ & 5 Sekunden \\
\hline $94^{\circ} \mathrm{C}$ & 15 Minuten \\
\hline $60^{\circ} \mathrm{C}$ & 60 Sekunden \\
\hline $94^{\circ} \mathrm{C}$ & 15 Sekunden \\
\hline $94^{\circ} \mathrm{C}$ & 15 Sekunden 7 \\
\hline${ }^{\circ} \mathrm{C}$ & 60 Sekunden \\
\hline
\end{tabular}

Für die Auswertung mittels der 7500 Fast System SDS Software Version 1.4 wurde Cycle threshold-Wert ( $\mathrm{C}_{\mathrm{t}}$-Wert) herangezogen. Er bildet den Schnittpunkt zwischen der Amplifikationskurve und dem Schwellenwert. Der Schwellenwert wurde hierbei so gesetzt, dass der $\mathrm{C}_{\mathrm{t}}$-Wert an einer Position auf der Amplifikationskurve ausgelesen wird, an der das Fluoreszenzsignal exponentiell pro Zyklus ansteigt und sich deutlich von der Hintergrundsfluoreszenz abhebt. Die relative Quantifizierung der Genexpression erfolgte anschließend nach der $\Delta \Delta \mathrm{C}_{\mathrm{t}}$-Methode.

\subsection{Biochemische Methoden}

\subsubsection{Präparation von Zelllysaten und Gewebehomogenisaten}

Für die Untersuchung der Proteinexpression wurden die Zellen zunächst, wie in den Abschnitten 2.2.2 und 2.2.3 beschrieben, kultiviert, stimuliert und am Ende mit DPBS gewaschen. Die nachfolgenden Schritte wurden stets auf Eis durchgeführt. Auf den Zellrasen wurde, je nach Größe der verwendeten Zellkulturschalen, 100-200 $\mu \mathrm{L}$ Lysepuffer gegeben, die Zellen mit einem Zellschaber abgekratzt und in ein 1,5 mL Reaktionsgefäß überführt. Anschließend wurden die Zellen der Zellsuspensionen bzw. der Gewebehomogenisate mit Hilfe eines Ultraschallstabs (Branson Sonifer W-450) aufgeschlossen und das Gemisch zentrifugiert (10 Minuten, $13.000 \mathrm{Upm}, 4^{\circ} \mathrm{C}$ ). Der 
Überstand wurde in ein neues $1,5 \mathrm{~mL}$ Reaktionsgefäß überführt und bis zur weiteren Verwendung bei $-20^{\circ} \mathrm{C}$ gelagert.

\subsubsection{Bestimmung des Proteingehaltes}

Die Bestimmung des Proteingehalts der Zelllysate oder Gewebehomogenisate erfolgte nach der Methode von Bradford (Bradford 1976). Es wurde für jede Messung eine neue BSA-Standardreihe in VE- $\mathrm{H}_{2} \mathrm{O}$ mit einem Konzentrationsbereich zwischen 0 (blank) und $30 \mu \mathrm{g} / \mathrm{mL}$ und $800 \mu \mathrm{L}$ Gesamtvolumen in 1,5 $\mathrm{mL}$ Reaktionsgefäßen angesetzt. Für die zu untersuchenden Proben wurden je $795 \mu \mathrm{L}$ VE- $\mathrm{H}_{2} \mathrm{O}$ in $1,5 \mathrm{~mL}$ Reaktionsgefäßen vorgelegt und $5 \mu \mathrm{L}$ der Probe hinzugegeben. Alle Proben der Standardreihe und die Probenverdünnungen wurden mit $200 \mu \mathrm{L}$ Bradford Protein Assay-Reagenz (Roti ${ }^{{ }^{-}}$-Quant) auf $1 \mathrm{~mL}$ aufgefüllt und gut vermischt. Nach 10 Minuten Inkubation im Dunkeln wurden jeweils $100 \mu \mathrm{L}$ in einer Doppelbestimmung luftblasenfrei in eine 96-Well-Mikrotiterplatte pipettiert und die Absorption bei $595 \mathrm{~nm}$ mit Hilfe des Mikroplatten-Lesegeräts Sunrise (Tecan, Neustadt) gemessen. Die Umrechnung auf die Proteinmenge in den Proben wurde mit Hilfe von Magellan3 (Tecan, Neustadt) und Excel durchgeführt.

\subsubsection{Trichloressigsäure-Proteinfällung aus Zellkulturüberständen}

Der zu untersuchende Zellkulturüberstand wurde nach dem Experiment in ein Reaktionsgefäß überführt und anschließend schonend zentrifugiert, um Zellen zu pelletieren (2000 rpm, $4^{\circ} \mathrm{C}, 5$ Minuten). 90\% (V/V) des Überstands wurde in neue Reaktionsgefäße überführt. Die Proben wurden ggf. bis zur weiteren Verwendung bei $-20^{\circ} \mathrm{C}$ gelagert. Um den Überstand von Zellresten zu befreien, wurden die Proben bei 13000 Upm und $4^{\circ} \mathrm{C}$ für 10 Minuten zentrifugiert und wiederum $90 \%$ (V/V) des Überstands in ein neues Reaktionsgefäß überführt. Zur Fällung der Proteine wurde eine Trichloressigsäure-Lösung (70\%) im Verhältnis 1:10 hinzugegeben und durch Invertieren gemischt. Die Proben wurden für 30 Minuten auf Eis inkubiert und anschließend für weitere 30 Minuten bei $13000 \mathrm{Upm}$ und $4^{\circ} \mathrm{C}$ zentrifugiert. Jegliche Flüssigkeit wurde sorgfältig und restlos entfernt. Zu den Proben wurde je nach Größe 
des Pellets 30-75 $\mu \mathrm{L}$ Tris/ $\mathrm{HCl}(\mathrm{pH} \mathrm{8,5)} \mathrm{hinzugegeben} \mathrm{und} \mathrm{das} \mathrm{Pellet} \mathrm{mittels} \mathrm{einer}$ Inkubation im Thermomixer bei $50^{\circ} \mathrm{C}$ und $1400 \mathrm{Upm}$ für eine Dauer von 20 Minuten gelöst. Die Proben wurden kurz mit einer Tischzentrifuge abzentrifugiert und $4 \mathrm{x}$ Laemmli-Puffer im Verhältnis 1:4 hinzugegeben und vermischt. Die Proben wurden bei $95^{\circ} \mathrm{C}$ für 10 Minuten zur Denaturierung der Proteine erhitzt, kurz abzentrifugiert und bis zur weiteren Analyse mittels SDS-PAGE bei $-20^{\circ} \mathrm{C}$ gelagert.

\subsubsection{SDS-Polyacrylamid-Gelelektrophorese (SDS-PAGE)}

Zur Identifizierung und Quantifizierung von Proteinen mittels Western Blot wurde zunächst die sodium dodecyl sulfate polyacrylamide gel electrophoresis (SDS-PAGE) nach Laemmli zur Auftrennung der Proteine anhand ihrer Größe durchgeführt (Laemmli 1970). Hierfür wurden jeweils entsprechende Volumina der Lysatproben für $30 \mu \mathrm{g}$ Protein entnommen und mit Lysispuffer auf ein Volumen von $30 \mu \mathrm{L}$ aufgefüllt. Diese Verdünnungen wurden mit je $10 \mu \mathrm{L} 4 \mathrm{x}$ Laemmli-Puffer vermischt und die Proteine für 10 Minuten bei $95^{\circ} \mathrm{C}$ denaturiert. Die fertigen Proben aus den Zelllysaten, Gewebehomogenisaten oder Zellkulturüberständen sowie $6 \mu \mathrm{L}$ eines Molekulargewichtsstandards wurden in die Geltaschen eines diskontinuierlichen Systems aus einem oben liegenden Sammelgel, welches die Taschen für die Proben bildet, und einem Trenngel zur Separation der Proteine gefüllt. Die Gelelektrophorese wurde für die Aufenthaltszeit der Proben im Sammelgel bei $70 \mathrm{~V}$ und für die Auftrennung im unten liegenden Trenngel bei $100 \mathrm{~V}$ in einer mit Laufpuffer gefüllten Elektrophoresekammer durchgeführt. Die Zusammensetzung des Trenngels (Tabelle 16) richtete sich nach der Größe des Zielproteins, um eine optimale Auflösung zu erreichen.

\subsubsection{Herstellung der Gele}

Für die SDS-PAGE wurden die Polyacrylamidgele mit Hilfe von speziellen Gelapparaturen gegossen. Ca. $10 \mathrm{~mL}$ einer Trenngellösung wurde zwischen die Glasplatten der Apparatur gegossen und anschließend mit Isopropanol überschichtet, um eine glatte Schicht, die frei von Luftblasen ist, zu erhalten. Nachdem das Trenngel auspolymerisiert war, wurde das Isopropanol abgeschüttet, das Trenngel mit ca. 2,5 $\mathrm{mL}$ Sammelgellösung überschichtet und sogleich die Taschenkämme eingesetzt. Die 
auspolymerisierten Gele wurden aus der Apparatur entfernt und entweder sofort verwendet oder für kurze Zeit in feuchte Tücher gewickelt, in Plastiktüten verstaut und im Kühlschrank gelagert.

\begin{tabular}{|l|c|c|c|c|}
\hline Trenngellösungen & $\mathbf{6 \%}$ & $\mathbf{1 0 \%}$ & $\mathbf{1 2 \%}$ & $\mathbf{1 5 \%}$ \\
\hline Rotiphorese $^{\circledR}$ & $4,1 \mathrm{~mL}$ & $6,7 \mathrm{~mL}$ & $8 \mathrm{~mL}$ & $10 \mathrm{~mL}$ \\
\hline Trenngelpuffer $^{2}$ & $5 \mathrm{~mL}$ & $5 \mathrm{~mL}$ & $5 \mathrm{~mL}$ & $5 \mathrm{~mL}$ \\
\hline $\mathrm{H}_{2} \mathrm{O}$ & $10 \mathrm{~mL}$ & $8 \mathrm{~mL}$ & $6,7 \mathrm{~mL}$ & $4,6 \mathrm{~mL}$ \\
\hline SDS $10 \%$ & $0,2 \mathrm{~mL}$ & $0,2 \mathrm{~mL}$ & $0,2 \mathrm{~mL}$ & $0,2 \mathrm{~mL}$ \\
\hline APS $10 \%$ & $0,2 \mathrm{~mL}$ & $0,2 \mathrm{~mL}$ & $0,2 \mathrm{~mL}$ & $0,2 \mathrm{~mL}$ \\
\hline TEMED & $10 \mu \mathrm{L}$ & $10 \mu \mathrm{L}$ & $10 \mu \mathrm{L}$ & $10 \mu \mathrm{L}$ \\
\hline
\end{tabular}

Tabelle 16: Zusammensetzung der Trenngellösungen für 2 Gele

\begin{tabular}{|l|c|}
\hline \multicolumn{2}{|c|}{ Sammelgellösung } \\
\hline Rotiphorese $^{\circledR}$ & $1,3 \mathrm{~mL}$ \\
\hline Sammelgelpuffer & $2,5 \mathrm{~mL}$ \\
\hline $\mathrm{H}_{2} \mathrm{O}$ & $6 \mathrm{~mL}$ \\
\hline SDS $10 \%$ & $100 \mu \mathrm{L}$ \\
\hline APS $10 \%$ & $60 \mu \mathrm{L}$ \\
\hline TEMED & $20 \mu \mathrm{L}$ \\
\hline
\end{tabular}

Tabelle 17: Zusammensetzung der Sammelgellösung für 2 Gele

\subsubsection{Western Blot-Analyse}

Die mittels SDS-PAGE nach ihrem Molekulargewicht aufgetrennten Proteine wurden nach dem Western Blot-Verfahren auf eine Nitrozellulosemembran übertragen, auf der anschließend der immunchemische Nachweis bestimmter Proteine erfolgen konnte. 


\subsubsection{Elektrotransfer nach dem Wet-Blot-Verfahren}

Die in der SDS-PAGE aufgetrennten Proteine wurden nun senkrecht zur vorangehenden Laufrichtung über ein weiteres elektrisches Feld auf eine Nitrozellulosemembran übertragen („Blotten“). Für den Transfer der Proteine wurde folgendes „Sandwich“ in einer Schale gefüllt mit Transferpuffer zusammengelegt: Elektrodenschwamm, zwei Whatman-Papiere, Nitrozellulosemembran, PolyacrylamidGel, zwei Whatman-Papiere, Elektrodenschwamm. Um Luftblasen zwischen Membran und Gel zu entfernen, wurden unter leichtem Druck mit einem Glasstab über das Sandwich gerollt. Das fertige Sandwich wurde in einen Schlitten gespannt und so in die Transferkammer (Mini Trans-Blot ${ }^{\circledR}$ Electrophoretic Transfer Cell) gestellt, dass die Membran zur Anode und das Gel zur Kathode zeigt. Die Transferkammer wurde mit Transferpuffer aufgefüllt und auf Eis gestellt. Das „Blotten“ erfolgte für 75 Minuten bei $70 \mathrm{~V}$ und wurde zum Schluss durch reversible Anfärbung aller Proteine auf der Membran überprüft. Hierfür wurde die Membran kurz in eine Ponseau-S-Lösung gelegt und nach optischer Kontrolle mittels PBST wieder vom Farbstoff befreit.

\subsubsection{Immunchemischer Nachweis von Proteinen}

Die Zielproteine wurden immunchemisch durch die Bindung von Antikörpern und mittels Chemilumineszenz detektiert. Damit die Antikörper sich nicht wie beim „Blotten“ unspezifisch an die Membran anlagern, wurde die Membran für eine Stunde bei Raumtemperatur in eine mit Milchpulverlösung (5\%) gefüllte Schale auf einen Schüttler gestellt. Anschließend wurde die Milchlösung weggeschüttet, die Schale mit PBST gefüllt und für 10 Minuten auf einen Schüttler gestellt, bevor die Lösung verworfen wurde. Dieser Schritt wurde dreimal durchgeführt und folgend als „PBST-Waschschritt“ zusammengefasst. Die Membran wurde anschließend mit einer entsprechenden Lösung des Erstantikörpers, welcher an das Zielprotein bindet, über Nacht bei $4^{\circ} \mathrm{C}$ auf einem Schüttler inkubiert. Danach folgte ein PBST-Waschschritt und die Membran wurde daraufhin mit einer entsprechenden Lösung des Zweitantikörpers, welcher an den Erstantikörper bindet und an eine Meerrettichperoxidase gekoppelt ist, für 90 Minuten bei Raumtemperatur auf einem Schüttler inkubiert. Ein weiterer PBSTWaschschritt erfolgte, die feuchte Membran wurde auf eine Glasplatte gelegt und für eine Minute mit dem Substrat für Chemilumineszenzreaktion der Peroxidase benetzt. 
Zur Visualisierung und Dokumentation des Zielproteins wurde die Membran in eine Klarsichtfolie gesteckt, diese in eine Filmkassette gelegt und in eine Dunkelkammer gebracht. Dort wurde ein Autoradiographiefilm für wenige Sekunden bis Minuten auf die Membran gelegt und dieser mit Hilfe einer Entwicklermaschine entwickelt.

Die entwickelten Filme wurden nach Abpausen des Molekulargewichtsstandards eingescannt und die Banden des Zielproteins mit Hilfe des Bildbearbeitungsprogramms ImageJ 1.51j8 (National Institutes of Health, Bethesda, MD, USA) quantifiziert. Dazu wurde die optische Dichte und Größe der Proteinbanden des Zielproteins und des Referenzproteins bestimmt. Somit konnte die Expression des Zielgens in Relation zur Expression eines Haushaltsgens semiquantitativ bestimmt werden. Mit der Membran wurde erneut ein PBST-Waschschritt durchgeführt und diese direkt für einen weiteren immunchemischen Nachweis verwendet oder aber zur Lagerung getrocknet.

\subsection{Histologische Immunchemie \\ 2.7.1 Vorbereitung der Paraffinblöcke}

Die Organe wurden über Nacht bei $4^{\circ} \mathrm{C}$ in $4 \%$ Formalin fixiert. In einer automatischen Gewebeinfiltrationsmaschine wurden die Organe nacheinander in 50\%, 75\%, 90\%, $96 \%$ und $100 \%$ Ethanol, Isopropanol und Xylol dehydriert und zuletzt mit Paraffin infiltriert. Die getrockneten Organe wurde in Einbettformen aus Edelstahl gelegt und in flüssigem Paraffin eingebettet. Zur Aushärtung wurden die Blöcke auf eine Kühlplatte gelegt. Zur histologischen Untersuchung wurden $3 \mu \mathrm{m}$ dünne Schnitte der Organe abgeschnitten, in einem warmen Wasserbecken ausgelegt, auf Objektträger übertragen und bei $37^{\circ} \mathrm{C}$ auf einer Heizplatte über Nacht getrocknet. Auf den fertigen Schnitten konnten nachfolgend spezifische Proteine oder Organelle mit Antikörpern oder Farblösungen angefärbt werden. 


\subsubsection{PAS-Reaktion}

Mit der periodic acid-Schiff reaction (PAS-Reaktion) werden Bindegewebe, Membranen und Zellwände durch eine rosa bis magentafarbene Färbung sichtbar gemacht. Für die Deparaffinisierung wurden die Schnitte nacheinander in Schalen mit folgendem Inhalt getaucht:

10 Minuten Xylol, 10 Minuten Xylol, 5 Minuten 100\% Ethanol, 5 Minuten 90\% Ethanol, 5 Minuten 70\% Ethanol, 5 Minuten 50\% Ethanol, 5 Minuten VE-Wasser.

Die Schnitte wurden für 5 Minuten in 0,8\% Perjodsäure gelegt und mit destilliertem Wasser gewaschen. Im Anschluss wurde Schiff'sches Reagenz für 20 Minuten auf die Schnitte pipettiert, sodass das Gewebe komplett bedeckt war. Das Reagenz wurde mit Leitungswasser abgespült und die Schnitte anschließend für zehn Sekunden in Hematoxylin getaucht, um die Zellkerne anzufärben. Das Hematoxylin wurde mit Leitungswasser abgewaschen und die Schnitte für 3 Minuten in destilliertes Wasser gegeben. Zuletzt wurden die Schnitte wieder entwässert, indem die oben aufgeführte Reihe zur Deparaffinisierung rückwärts durchlaufen wurde. Direkt im Anschluss wurde zum Eindecken ein Deckglas mit Hilfe von Entellan ${ }^{\circledR}$ auf die Schnitte unter Ausübung von Druck geklebt. Die gefärbten Schnitte wurden unter dem Mikroskop (Axiovert 200 Vergrößerung x100, Zeiss) betrachtet und repräsentative Aufnahmen (Leica DFC310 FX Kamera, Leica Camera AG) gespeichert.

\subsubsection{Makrophagen-Infiltration}

Zum Nachweis der Infiltration des Gewebes mit Makrophagen wurde ein Antikörper gegen das EGF-ähnliche modulhaltige Mucin-ähnliche Hormonrezeptor-ähnliche 1 Protein (EMR 1 ) auch bekannt als F4/80 verwendet. Für die Deparaffinisierung wurden die Schnitte nacheinander in Schalen mit folgendem Inhalt getaucht:

10 Minuten Xylol, 10 Minuten Xylol, 5 Minuten 100\% Ethanol, 5 Minuten 90\% Ethanol, 5 Minuten 70\% Ethanol, 5 Minuten 50\% Ethanol, 5 Minuten VE-Wasser.

Citratpuffer von Dako wurde 1:10 mit Wasser verdünnt, ein Gefäß, in welches die Schnitte gestellt wurden, mit diesem Puffer gefüllt und für 10 Minuten bei 800 Watt in einer Mikrowelle erhitzt. Der Puffer wurde auf Raumtemperatur abgekühlt und zwei 
Mal mit TBS gewaschen. Der Antikörper gegen F4/80 wurde in Dako Antibody Diluent 1:200 verdünnt. $100 \mu \mathrm{L}$ dieser Verdünnung wurden auf einen Schnitt pipettiert und bei $4^{\circ} \mathrm{C}$ über Nacht inkubiert. Die Schnitte wurden zwei Mal mit TBS gewaschen und anschließend für 30 Minuten mit ein bis zwei Tropfen des Zweitantikörpers N-Histofine Simple Stain Mouse Max PO Rat bei Raumtemperatur inkubiert. Die Schnitte wurden erneut zwei Mal mit TBS gewaschen und $100 \mu \mathrm{L}$ des Peroxidase-Substrats wurde auf

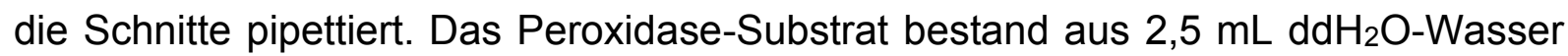
vermischt mit einem Tropfen Puffer, zwei Tropfen DAB und einem Tropfen Peroxide Solution. Der Färbeprozess wurde durch Spülen in Leitungswasser gestoppt. Die Schnitte wurden anschließend für zehn Sekunden in eine Hematoxylinlösung getaucht, um die Zellkerne anzufärben. Überschüssiger Farbstoff wurde nachfolgend in Leitungswasser abgewaschen. Zuletzt wurden die Schnitte wieder entwässert, indem die oben aufgeführte Reihe zur Deparaffinisierung rückwärts durchlaufen wurde. Direkt im Anschluss wurde zum Eindecken ein Deckglas mit Hilfe von Entellan ${ }^{\circledR}$ auf die Schnitte unter Ausübung von Druck geklebt. Die gefärbten Schnitte wurden unter dem Vectra 3.0 Automated Quantitative Pathology Imaging System (Akoya Biosciences, Massachusetts, USA) betrachtet und repräsentative Aufnahmen mit Vectra ${ }^{\circledR}$ (Akoya Biosciences, Massachusetts, USA) gespeichert. Mit Hilfe des lernfähigen, automatisierten Algorithmus von inForm ${ }^{\circledR}$ Tissue Finder ${ }^{\mathrm{TM}}$ (Akoya Biosciences, Massachusetts, USA) und dem Bildauswertungsprogramm Phenochart ${ }^{\circledR}$ (Akoya Biosciences, Massachusetts, USA) wurden alle Zellen des Schnittes, welche positiv für F4/80 waren, gezählt und in Relation zur Gesamtzellzahl gesetzt.

\subsection{Datenanalyse und Präsentation}

Die präsentierten Messdaten zeigen jeweils den errechneten Mittelwert sowie den dazugehörigen Standardfehler des Mittelwerts $( \pm$ SEM) von der gegebenen Anzahl $(n)$ an unabhängigen Experimenten. Die Western Blot-Banden wurden quantitativ mit dem Programm Image $J^{\circledR}$ ausgewertet, auf die Haushaltsgene $\beta$-Aktin oder GAPDH normalisiert und in Relation zur Kontrolle gesetzt. Die graphische Präsentation und statistische Auswertung wurden mit GraphPad Prism 5 durchgeführt. Ergebnisse von ELISA Versuchen wurden nach den Angaben der Hersteller ausgewertet. 


\section{Ergebnisse}

\subsection{Untersuchung der Rolle des Sphingosin-1-Phosphat- Rezeptors $5\left(\mathrm{~S}_{1} \mathrm{P}_{5}\right)$ in fibrotischen Nierenerkrankungen}

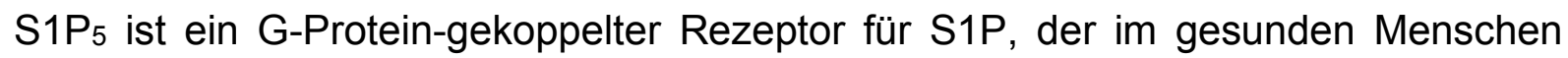
hauptsächlich im Gehirn, im Knochenmark, in der Haut und in der Milz exprimiert wird (Im et al. 2000; Fagerberg et al. 2014). Die Aktivierung des Rezeptors erzeugt über die G-Proteine verschiedene Signale in der Zelle, welche die Proliferation, Migration, Gefäßtonus, Barrierefunktion und Zellkommunikation steuern können (Brinkmann 2007).

\subsection{1 $\mathrm{S} \mathrm{P}_{5}$-Expression ist erhöht in fibrotischem Nierengewebe}

Es wurde bereits gezeigt, dass der profibrotische Faktor TGF- $\beta_{2}$ in der Lage ist, die Expression von $\mathrm{S}_{1} \mathrm{P}_{5}$ in humanen Mesangiumzellen zu erhöhen (Wünsche et al. 2015). Des Weiteren wurde gezeigt, dass die TGF- $\beta_{2}$-induzierte Expression des profibrotischen Zytokins CTGF durch eine vorhergehende Herunterregulation von $\mathrm{S}_{1} \mathrm{P}_{5}$ verhindert werden kann (Wünsche et al. 2015). Mit Hilfe von RT-qPCR konnte nun auch eine erhöhte Expression von $\mathrm{S}_{1} \mathrm{P}_{5}$ in fibrotischem gegenüber nichtfibrotischem Gewebe aus der Niere von Patienten, die an einer Hydronephrose leiden, gemessen werden (Abbildung 11A). Zudem konnten Mitarbeiter von Prof. Dr. H. J. Gröne, dem Leiter der Abteilung für Zelluläre und Molekulare Pathologie am DKFZ in Heidelberg, mit Hilfe einer semi-quantitativen RT-PCR die Expression von $\mathrm{S}_{1} \mathrm{P}_{5}$ in der humanen Niere auf mRNA-Ebene nachweisen. Die höchste Expression wurde hierbei im Tubulussystem gemessen (Abbildung 11B). 


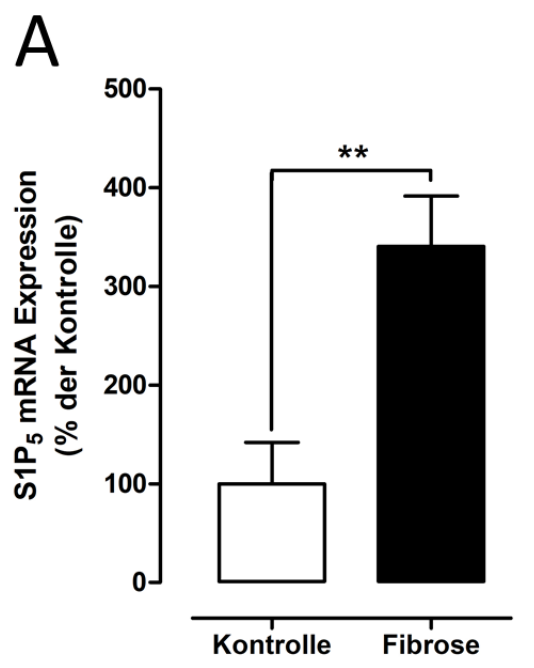

B

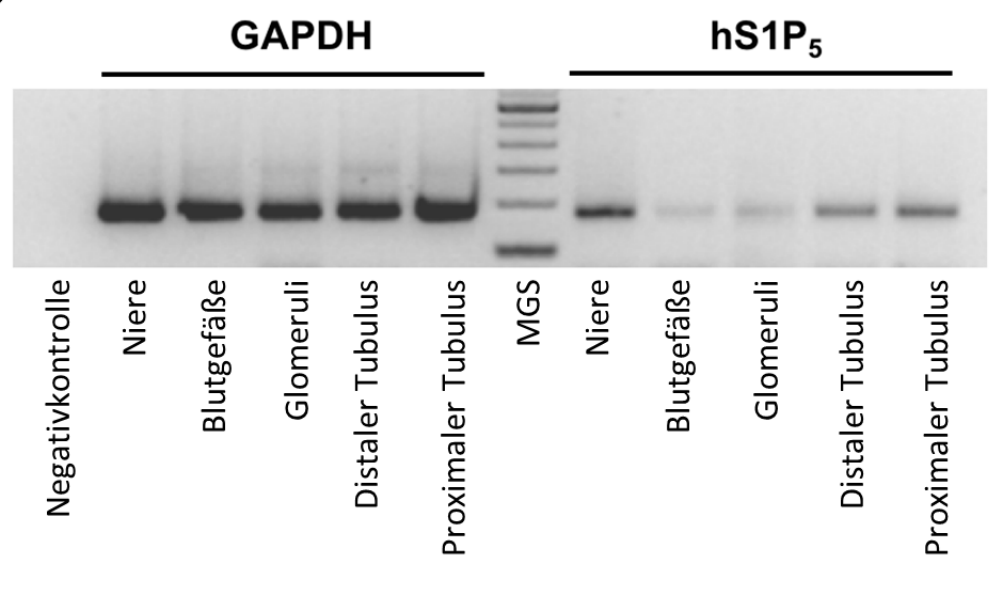

Abbildung 11: Genexpression von $\mathrm{S1P}_{5}$ in humanen Nierenbiopsien. A: RT-qPCR von

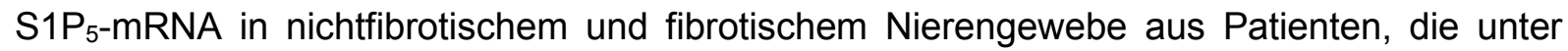
einer Hydronephrose litten. Abgebildet sind Mittelwerte \pm Standardfehler (standard error of the mean, SEM); ${ }^{* *} p<0,01 ; n=5$ (Kontrolle), $n=10$ (Fibrose). B: Vergleich der mRNA-Expression von humanem $\mathrm{S}_{1} \mathrm{P}_{5}$ gegenüber der Referenz-mRNA GAPDH in verschiedenen Sektionen von humanem Nierengewebe. Die Abb. wurde von Prof. Dr. H. J. Gröne, dem Leiter der Abteilung für Zelluläre und Molekulare Pathologie am DKFZ, zur Verfügung gestellt.

\subsection{2 $\mathrm{S} \mathrm{P}_{5}{ }^{-1-}$-Mäuse zeigen einen milderen Verlauf bei der Adenin-induzierten Nephropathie}

Um die Rolle von $\mathrm{S}_{1} \mathrm{P}_{5}$ in der Nierenfibrose weiter zu untersuchen, wurden $\mathrm{S}_{1} \mathrm{P}_{5}{ }^{-1}$ Mäuse und Wildtypmäuse der Linie C57BL/6J in dem Modell der Adenin-induzierten Nephropathie (AN) eingesetzt.

Wildtyp- und S1 $\mathrm{P}_{5}^{-/-}$-Mäuse wurden für 7 und 14 Tage mit einer adeninreichen (0,25\% Adenin) Nahrung gefüttert. Anschließend wurden die Mäuse schmerzfrei getötet, um Blut und Organe zu entnehmen. Mit Hilfe des aus dem Blut gewonnenen Plasmas wurde die Funktionalität der Nieren untersucht. Hierfür wurde mittels eines ELISAs die Kreatininkonzentration im Plasma bestimmt und davon die Nierenfunktion abgeleitet (Kuć et al. 2010). Die Kreatininkonzentrationen in den gesunden Tieren waren bei beiden Genotypen im Mittel bei 0,6 mg/dL (Wildtyp) und 0,5 mg/dL (S1P ${ }^{--}$) (Abbildung 12). Nach 7 Tagen im AN-Modell verdoppelte sich die Kreatininkonzentration in den Wildtypmäusen auf einen Wert von $1 \mathrm{mg} / \mathrm{dL}$ wohingegen die Konzentration im Plasma der $\mathrm{S}_{1} \mathrm{P}_{5}{ }^{-1}$-Mäusen nicht signifikant anstieg und einen Mittelwert von $0,7 \mathrm{mg} / \mathrm{dL}$ 
erreichte. Nach 14 Tagen im AN-Modell stieg die Kreatininkonzentration auf 2,2 mg/dL in den Wildtypmäusen an, in den $\mathrm{S}_{15^{-1}}$-Mäusen lag der Wert hingegen bei $0,9 \mathrm{mg} / \mathrm{dL}$ (Abbildung 12).

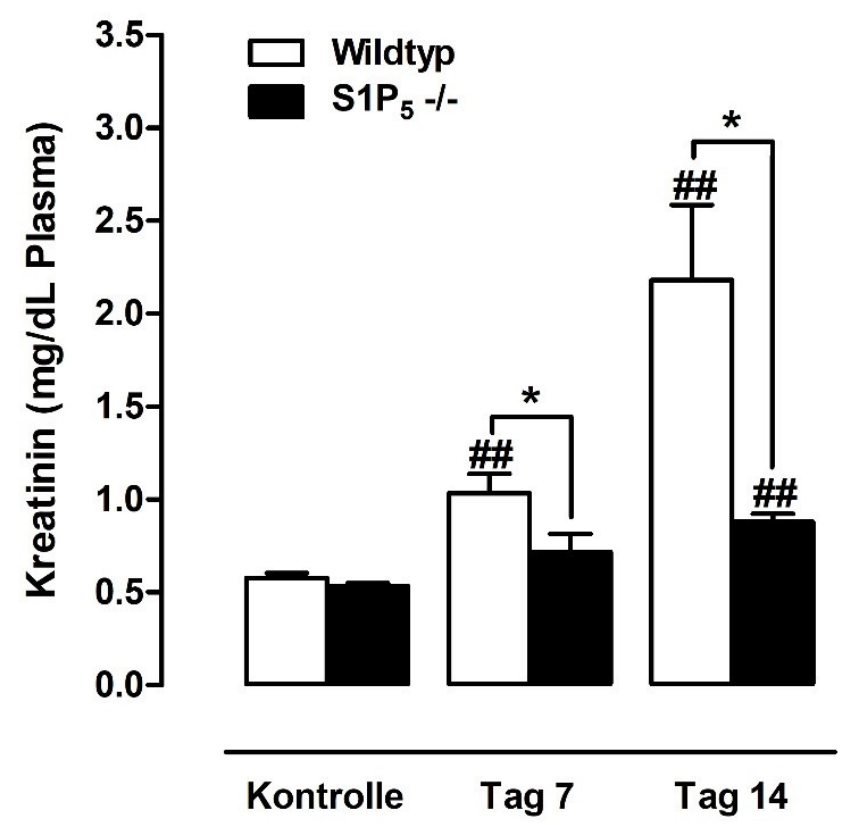

Abbildung 12: Kreatininkonzentrationen im Plasma der Mäuse. Die Nierenfunktion von Wildtyp und $\mathrm{S} \mathrm{P}_{5}{ }^{-1}$-Mäusen wurde über die Kreatininkonzentration im Plasma überprüft. Verglichen wurden Proben von unbehandelten Mäusen (Kontrolle) und von Tieren, die 7 Tage oder 14 Tage mit adeninreicher Diät gefüttert wurden. Abgebildet sind Mittelwerte \pm SEM; ${ }^{*} p$ $<0,01 ;$ \# $\mathrm{p}<0,01$ verglichen mit der gesunden Kontrolle; $\mathrm{n}=7-9$ (Kontrolle), $\mathrm{n}=7$ (Tag 7), $\mathrm{n}$ $=5(\operatorname{Tag} 14)$. 


\subsubsection{Untersuchung des Gewebeschadens}

In den Nierenschnitten wurden mit Hilfe der PAS-Reaktion Kohlenhydrate der Zellbestandteile rosa bis magentafarben und die Zellkerne blau gefärbt, um die Zellen im Gewebe besser zu erkennen. In den Sektionen des Nierenkortex beider Genotypen wurden deutliche Schädigungen des Gewebes durch die Behandlung mit Adenin sichtbar (Abbildung 13). Zu sehen sind nekrotische Tubuluszellen und Tubulusdilatationen, welche zur Perforation des Gewebes führten. Im kranken Gewebe der Wildtypmäuse sind zudem auch die Glomeruli kleiner und verdichteter im Gegensatz zum gesunden Gewebe. An manchen Stellen sind die bernsteinfarbenen Dihydroxyadenin-Kristalle zu erkennen, welche meist von vielen Zellen umgeben sind, bei denen es sich um Makrophagen handeln könnte.
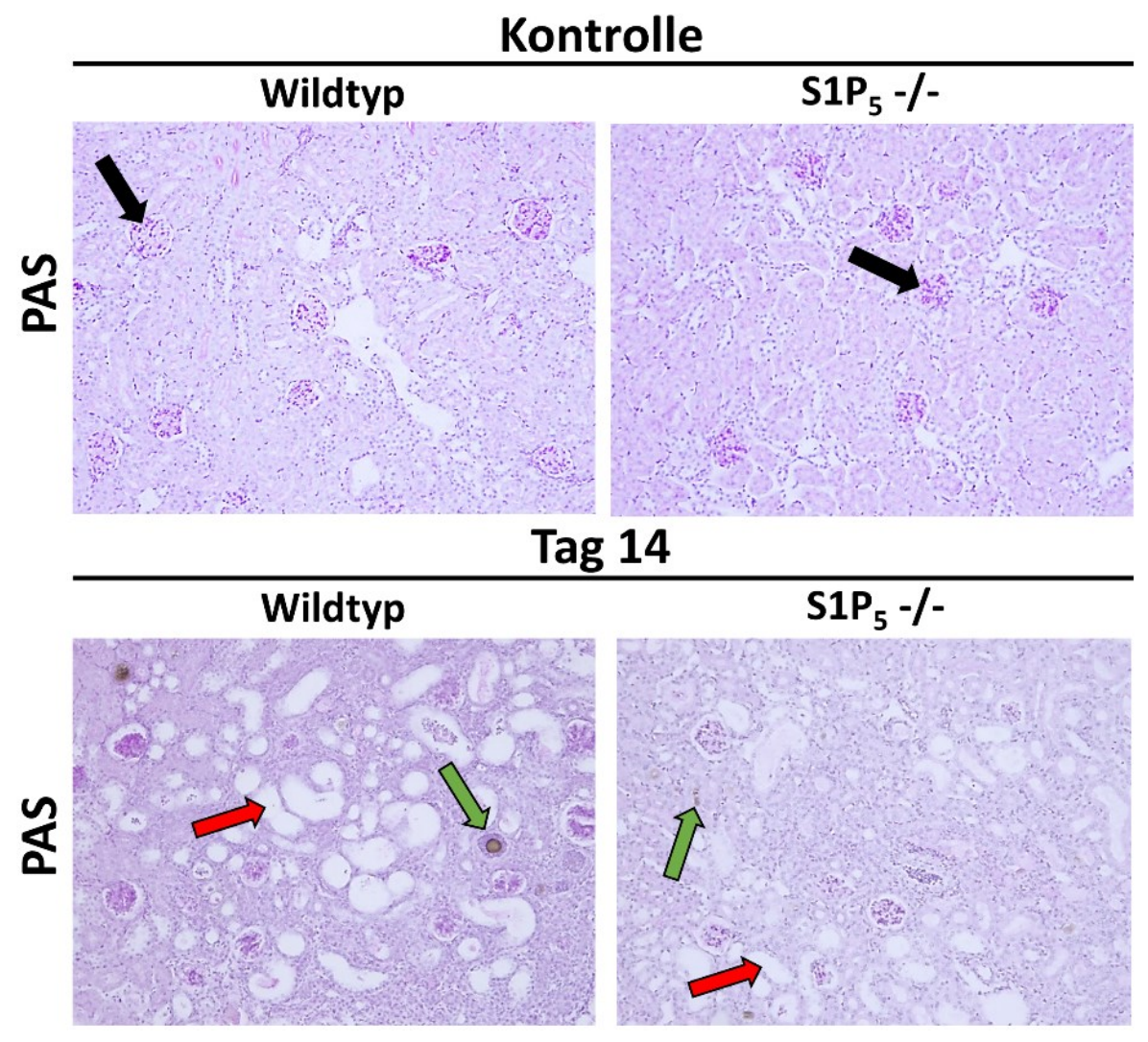

Abbildung 13: Untersuchung auf Gewebeschäden in den Nieren. Repräsentatives Bild der Färbung der Gewebeschnitte aus dem Nierenkortex mit PAS von Kontrollmäusen und Mäusen nach 14 Tagen im AN-Modell. Die Zellkerne sind blauviolett und die kreisförmig erscheinenden Glomeruli (schwarze Pfeile) sind zu erkennen. Nach 14 Tagen im AN-Modell ist das Gewebe von großen Löchern (rote Pfeile), Dilatationen der Tubuli, durchzogen und es werden an manchen Stellen die bernsteinfarbenen Kristalle aus 2,8-Dihydroxyadenin sichtbar (grüne Pfeile). 
Die Schädigung des Gewebes wurde auch auf molekularer Ebene über eine Bestimmung der Expression von Kidney injury molecule-1 (KIM-1) und Neutrophil gelatinase-associated lipocalin (NGAL) auf mRNA- und Protein-Ebene untersucht. Diese Biomarker können einen akuten Nierenschaden anzeigen und sind bereits vor einem Anstieg des Serumkreatinins im Urin von Patienten nachweisbar (Han et al. 2002; Bolignano et al. 2008; Han et al. 2008; Nickolas et al. 2008; Lei et al. 2018). Es wird vermutet, dass die Expression von KIM-1 in Reaktion auf den Verlust von ZellZell-Kontakten, welche dem Zelltod vorangehen, stattfindet (Prozialeck et al. 2009). NGAL wird ebenfalls bei einem Nierenschaden exprimiert und soll verhindern, dass Zellen des Tubulussystems in Apoptose gehen (Mishra et al. 2004; An et al. 2013; Han et al. 2018).

Die mRNA-Expression in der Niere wurde mittels RT-qPCR (TaqMan ${ }^{\circledR}$ ) quantifiziert und die Proteinexpression per Western Blot bestimmt. Die Expression der beiden Proteine, wie auch die der jeweilgen korrespondierenden mRNA, wurde durch die AN nach 7 und auch nach 14 Tagen induziert, wohingegen in den gesunden Tieren keine Expression detektiert werden konnte (Abbildung 14). In Relation zu den Wildtypen war die Expression von Kim-1 sowohl nach 7 als auch nach 14 Tagen signifikant geringer in den $\mathrm{S}_{1} \mathrm{P}_{5}^{-1}$-Mäusenieren. Die Genexpression von NGAL war hingegen nur nach 7 Tagen im AN-Modell signifikant geringer in den Nieren der S1 $\mathrm{P}_{5}^{-1-}$-Mäuse gegenüber den Wildtypen. Mittels Western Blot wurde gezeigt, dass die Expression von KIM-1 nach 7 Tagen aber nicht nach 14 Tagen im AN-Modell signifikant geringer war in den S1 $\mathrm{P}_{5}^{-1-}$-Mäusenieren gegenüber den Wildtypen. Umgekehrt war die Expression von NGAL erst nach 14 Tagen im AN-Modell signifikant geringer in den Nieren der S1 $\mathrm{P}_{5}^{-1-}$ -Mäuse gegenüber den Wildtypen. 

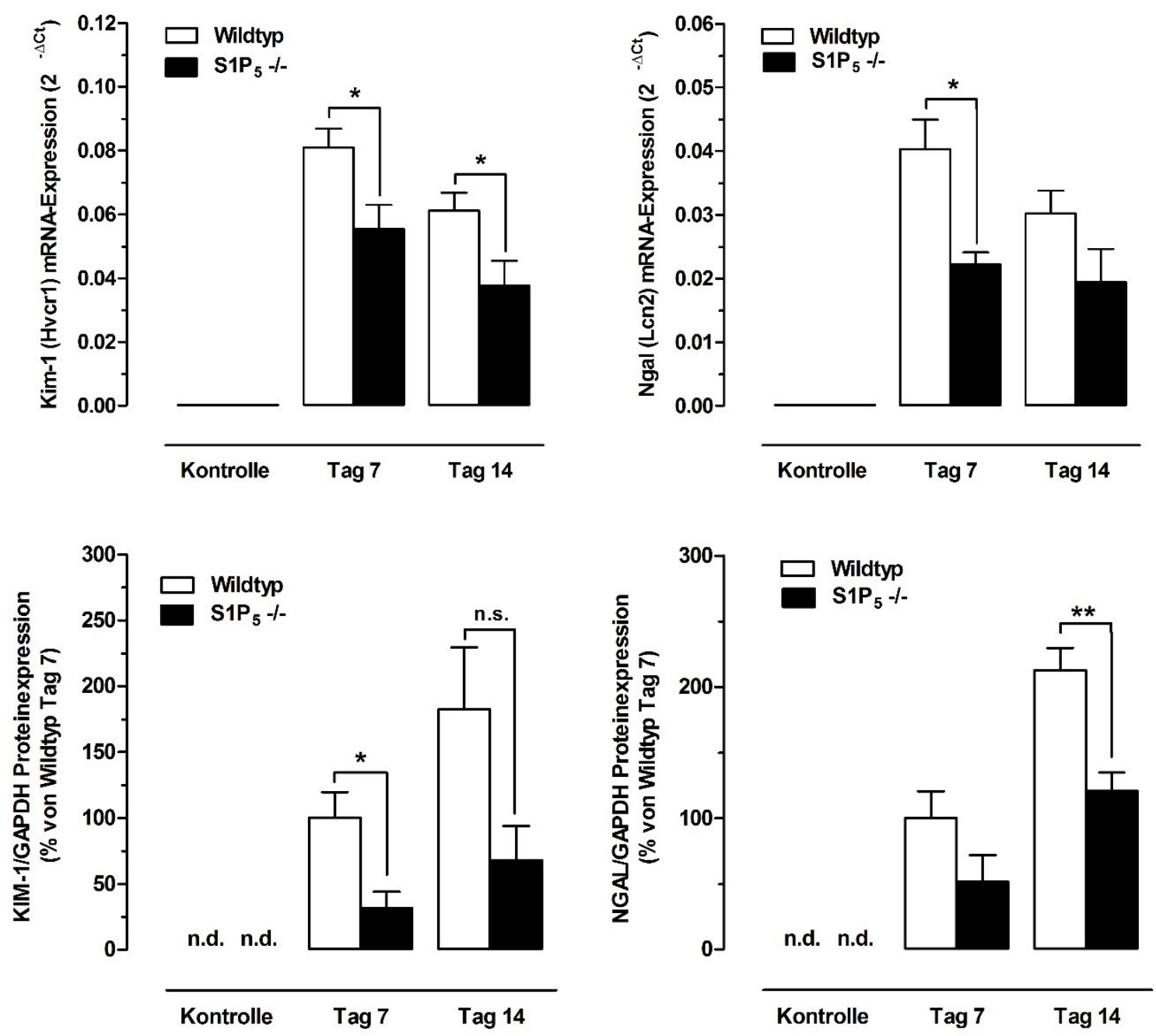

Abbildung 14: Expression von Nierenschädigungsmarkern. Die mRNA-Level und ProteinLevel von Nierenschädigungsmarkern wurde in Nierenproben von gesunden Kontrollmäusen und Mäusen nach 7 und 14 Tagen im AN-Modell gemessen und ausgewertet. Oben: Analyse der RT-qPCR zur Bestimmung der Genexpression von Kim-1 und Ngal. Unten: Quantitative Auswertung der Western Blots von KIM1 und NGAL im Verhältnis zum Haushaltsprotein GAPDH zur Bestimmung der Proteinmengen. Abgebildet sind Mittelwerte der berechneten Konzentrationen \pm SEM. Genexpression: $n=7-9$ (Kontrolle), $n=7$ (Tag 7), $n=5$ (Tag 14). Proteinexpression: alle $n=5$; n.d. $=$ nicht detektiert; $n . s$. $=$ nicht signifikant ${ }^{*} p<0,05 ;{ }^{* *} p<$ 0,01 . 


\subsubsection{Untersuchung von Entzündungsmarkern}

Durch die Bildung von Kristallen im Nierengewebe wird eine Entzündungsreaktion hervorgerufen. Aus diesem Grund wurde die Genexpression von verschiedenen proinflammatorischen Zytokinen in den Nieren untersucht. Die mRNA-Konzentrationen Ccl2, II-6, Tnfa und II-1 $\beta$ wurden durch die AN in allen Mäusen induziert. Die Expression der genannten Zytokine war in den $\mathrm{S}_{1} \mathrm{P}_{5}^{-{ }^{-l}}$-Mäusen jedoch signifikant geringer im Vergleich zu den Wildtypen sowohl nach 7 Tagen als auch nach 14 Tagen mit AN, mit der Ausnahme von II-1 $\beta$ nach 7 Tagen (Abbildung 15).

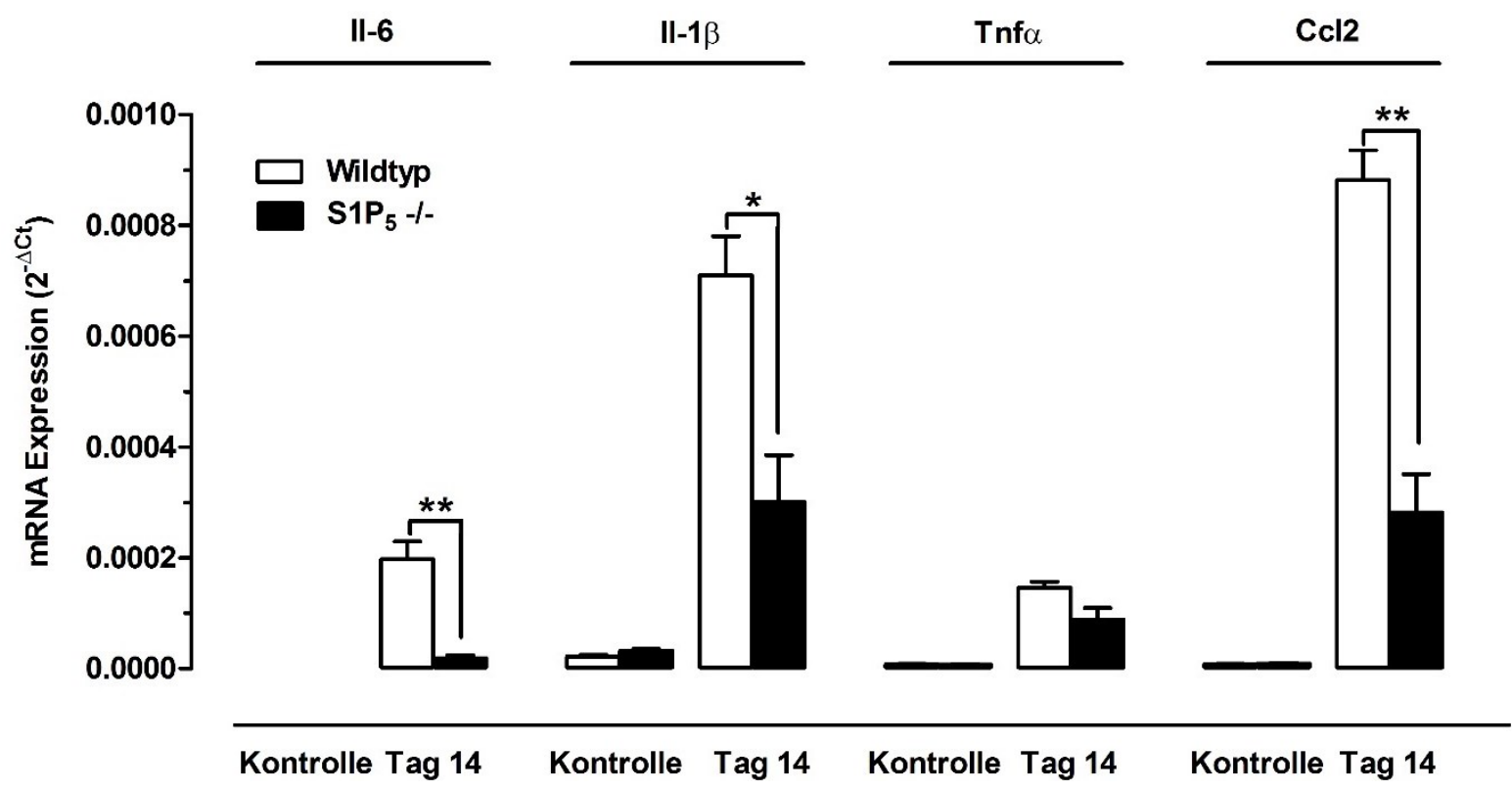

Abbildung 15: Genexpression proinflammatorischer Zytokine. Mittels RT-qPCR wurden die mRNA-Level von II-6, II-1 $\beta$, Tnfa und Ccl2 in den Nierenproben von gesunden Mäusen und Mäusen nach 14 Tagen im Modell der AN gemessen und ausgewertet. Abgebildet sind Mittelwerte der berechneten Konzentrationen \pm SEM; ${ }^{*} p<0,05 ;{ }^{* *} p<0,01 ; n=7-9$ (Kontrolle), $\mathrm{n}=5$ (Tag 14).

Zusätzlich wurde auch die Infiltration bzw. Proliferation von renalen mononukleären Phagozyten (Makrophagen und dendritische Zellen) in Folge der Expression der proinflammatorischen Zytokine überprüft. Gewebeschnitte der Niere wurden mit einem Antikörper gegen das Oberflächenprotein F4/80 (auch bekannt als EMR1), welches exklusiv auf mononukleären Phagozyten exprimiert wird, gefärbt (Abbildung 16D). Nach der Färbung wurden von den Nierenschnitten alle Kortexregionen mit Hilfe von 
Vectra $^{\circledR}$ als Einzelbilder gesichert. Die positive Färbung für $F 4 / 80$ (braun) in Kombination mit Nachweis des Zellkerns durch DAPI (blau) wurde mit Hilfe des Programms inForm ${ }^{\circledR}$ Tissue Finder ${ }^{\mathrm{TM}}$ als „ein mononukleärer Phagozyt" definiert und dem Algorithmus antrainiert. Daraufhin konnten die mononukleären Phagozyten in der kompletten Nierenrinde aller gefärbten Schnitte automatisch gezählt und in Relation zur Gesamtzellzahl gesetzt werden (Abbildung 16C). Es konnte eine starke Infiltration der Gewebe bzw. Proliferation im Gewebe von mononukleären Phagozyten bei AN festgestellt werden, welche aber in ihrer Ausprägung unabhängig vom Genotyp der Mäuse waren. Diese Beobachtung wurde gestützt durch die Messung der Genexpression von adhesion $G$ protein-coupled receptor E1 (Adgre1), ein Gen, welches für den Rezeptor EMR1 kodiert und ebenfalls in beiden Genotypen gleichermaßen stark durch die AN nach 14 Tagen induziert wurde (Abbildung 16B). An Tag 7 war die Genexpression von Adgre1 in den Wildtypen schon auf dem maximalen Niveau angekommen, wohingegen in den $\mathrm{S}_{1} \mathrm{P}_{5}{ }^{-l}$-Mäusen zu diesem Zeitpunkt die Expression nur halb so stark war, was zu einem signifikanten Unterschied führte. Die Aktivität der Makrophagen kann zusätzlich noch über Aktivierung des Inflammasoms bestimmt werden. Hierfür wurde die Genexpression der Inflammasomkomponente nucleotide-binding oligomerization domain, leucine-rich repeat and pyrin domain-containing 3 gene (Nlrp3) gemessen (Abbildung 16A). Auch hier konnten keine Unterschiede in der Expression in den erkrankten Mäusen zwischen den S1 $\mathrm{P}_{5}^{-1-}$-Mäusen und Wildtypmäusen festgestellt werden. 


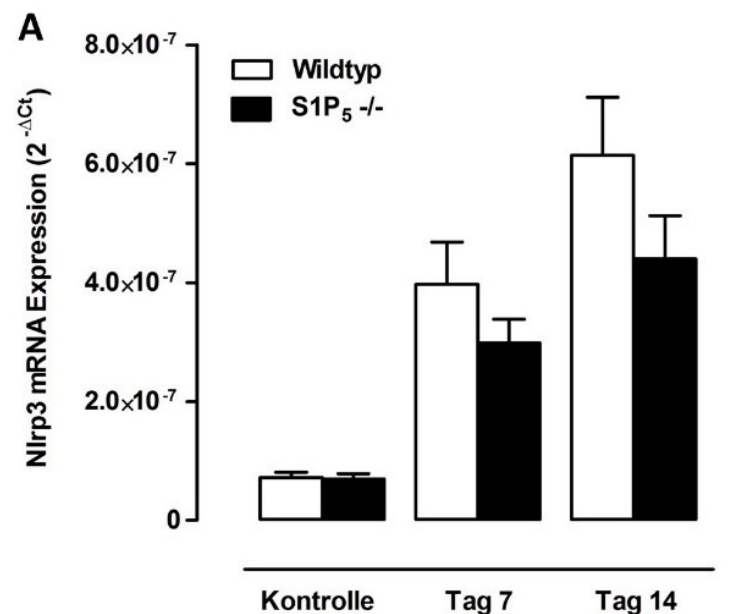

C

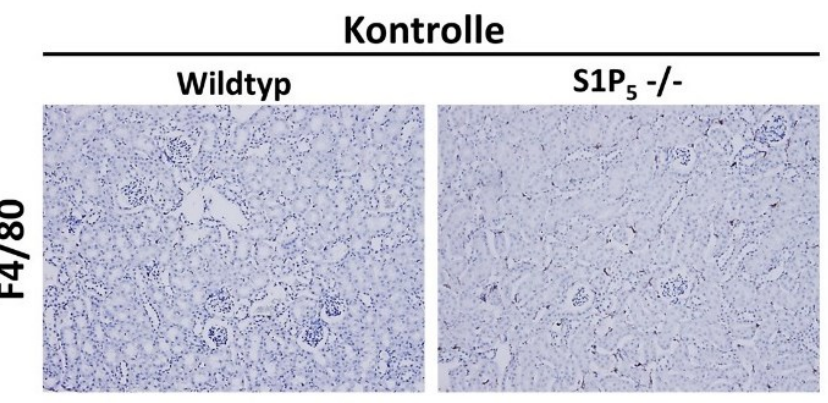

Tag 14

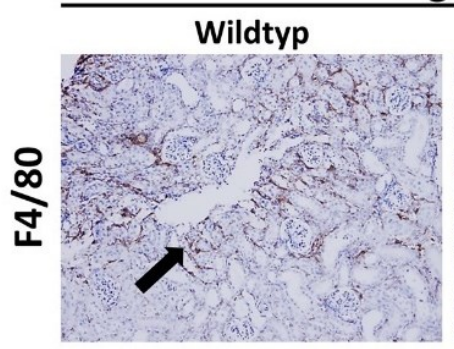

$\mathrm{S} \mathrm{P}_{5}-\%$

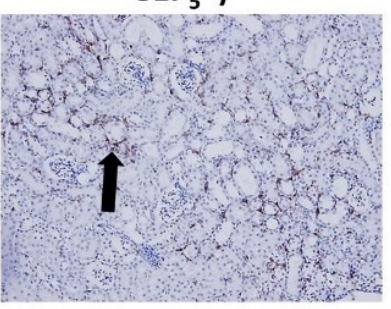

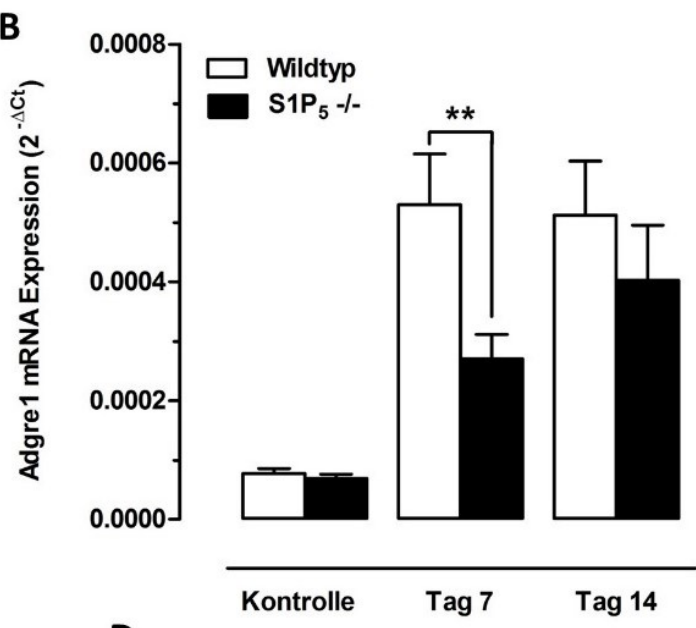

D

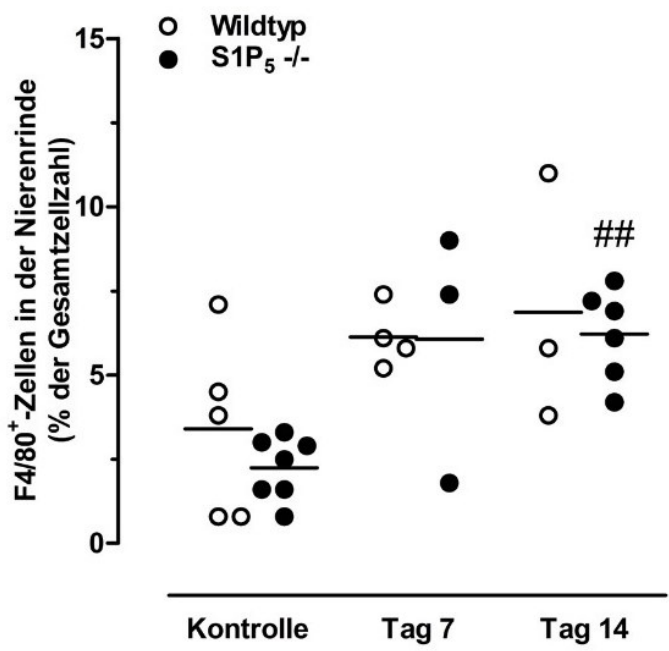

Abbildung 16: Untersuchung der Nieren auf mononukleäre Phagozyten. A+B: Genexpression von Nlrp3 und Adgre1 in den Nierenproben von gesunden Mäusen und Mäusen nach 7 und 14 Tage im Modell der AN; $n=7-9$ (Kontrolle), $n=7$ (Tag 7), $n=5$ (Tag 14). C: Repräsentatives Bild der immunhistochemischen Färbung gegen das Epitop F4/80 (braun, schwarze Pfeile) im Gewebeschnitt aus dem Nierenkortex von Kontrollmäusen und Mäusen nach 14 Tagen im AN-Modell. D: Auswertung der F4/80-Färbungen im Nierenkortex. $\mathrm{n}=5-7$ (Kontrolle), $\mathrm{n}=3-4$ (Tag 7), $\mathrm{n}=3-6$ (Tag 14). Abgebildet sind die Mittelwerte als Datenpunkte aus den Messungen von mehreren gefärbten Nierenschnitten; ${ }^{* *} p<0,01$; ${ }^{*} p<$ 0,01 verglichen mit der gesunden Kontrolle des gleichen Genotyps. 


\subsubsection{Untersuchung der Nieren auf Fibrose}

Durch die AN wurde die Genexpression von einigen Fibrosemarkern induziert. Ähnlich wie bei den Ergebnissen zur Entzündung war auch die Expression der Fibrosemarker in den $\mathrm{S}_{1} \mathrm{P}_{5}{ }^{-/}-$-Mäusen im Vergleich zu den Wildtypen verringert. Aus der RT-qPCRAnalyse ging hervor, dass die Konzentrationen von Ctgf, Fn1, Col1a1, Col3a1, Pai1/Serpine1 und Acta-2/aSMA nach 14 Tagen im AN-Modell signifikant niedriger waren (Abbildung 17A). Die Expression des profibrotischen Wachstumsfaktors CTGF und des Matrixproteins FN1 wurde zusätzlich noch auf Proteinebene mittels Western Blot untersucht (Abbildung 17B). Nach densitometrischer Quantifikation der Proteinbanden wurde festgestellt, dass die Proteinexpression von CTGF und FN1 in den S1P $5^{-1-}$ Mäusen nach 14 Tagen im AN-Modell im Vergleich zu den unbehandelten Kontrollen signifikant niedriger war (Abbildung 17C).

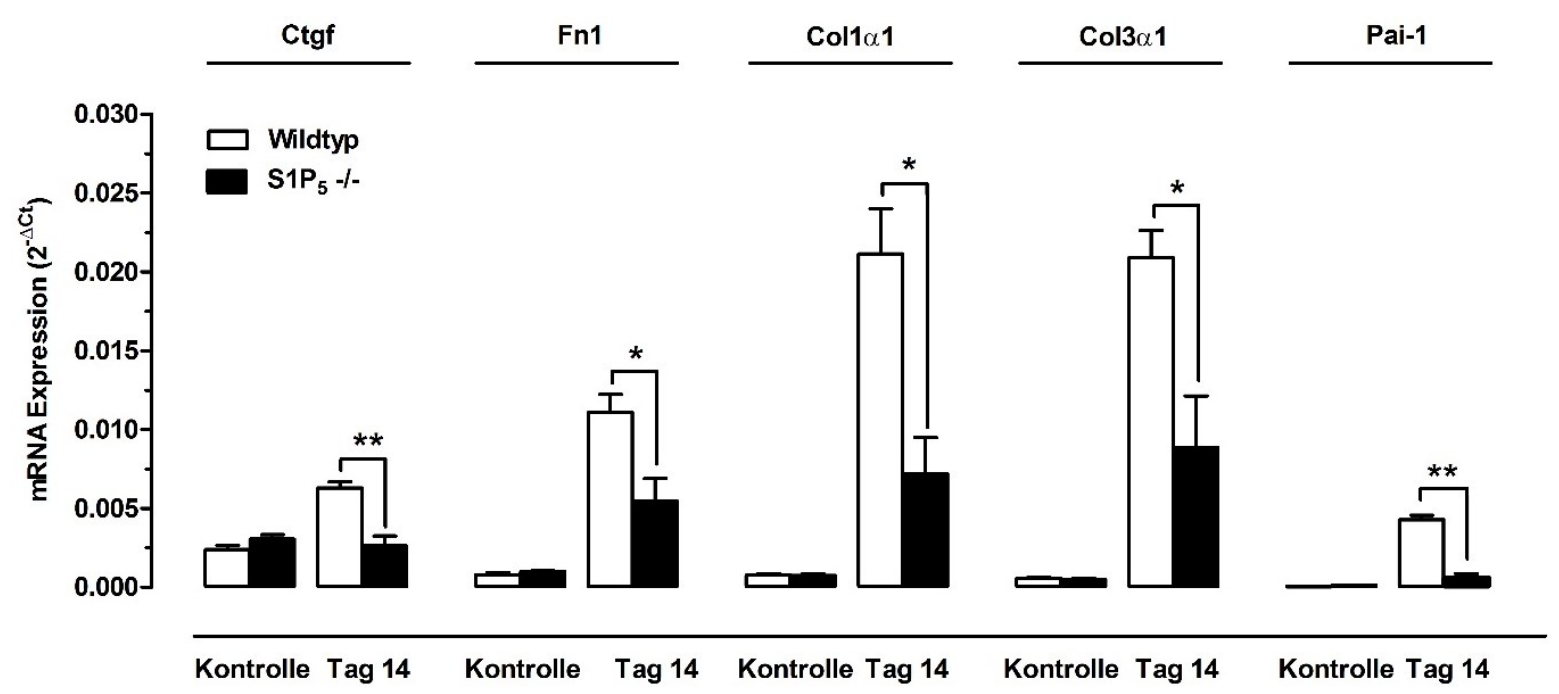

Abbildung 17: Genexpression von Fibrosemarkern in den Nieren. Genexpression von Ctgf, Fn1, Col1a1, Col3a1 und Pai-1 ermittelt via RT-qPCR in den Nierenproben von gesunden Mäusen und Mäusen, die 14 Tage im AN-Modell waren. Wildtyp: Kontrolle: $n=9$, Tag 14: $\mathrm{n}=5 ; \mathrm{S}_{1} \mathrm{P}_{5}^{--}:$Kontrolle: $\mathrm{n}=7, \operatorname{Tag} 14: \mathrm{n}=5$. 
A

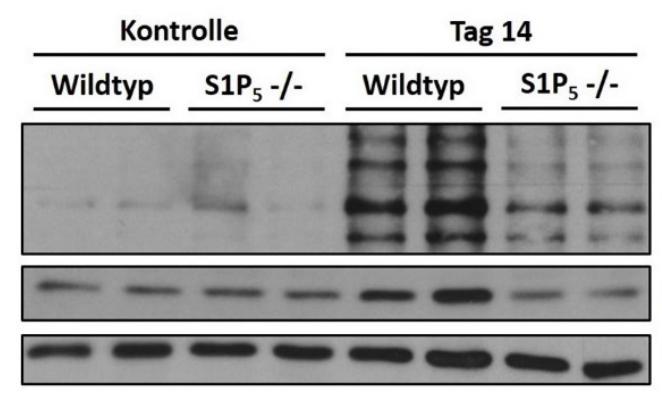

(9)

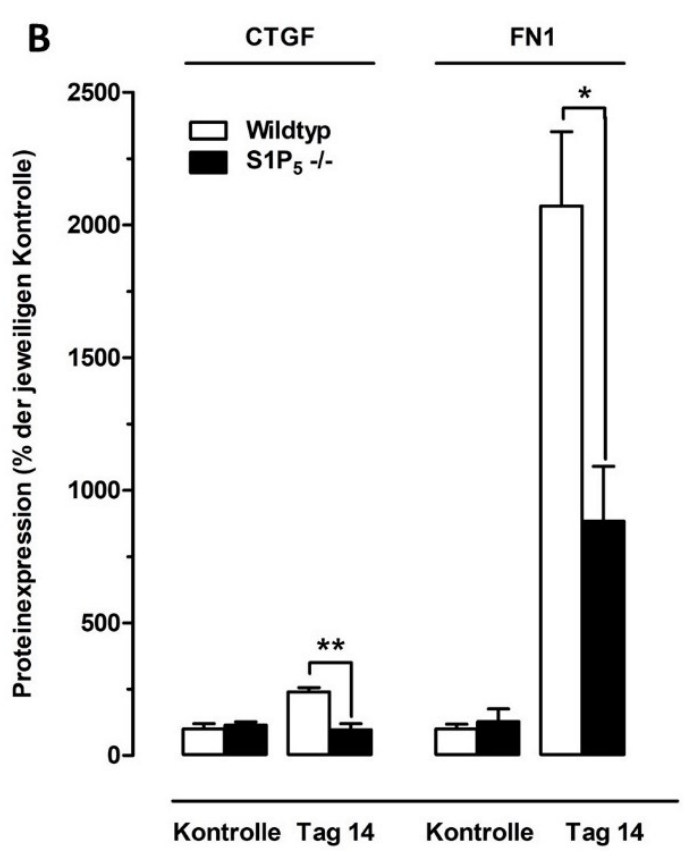

Abbildung 18: Proteinexpression von Fibrosemarkern in den Nieren. A: Repräsentativer Western Blot von FN1 und CTGF und dem Referenzprotein GAPDH. B: Quantitative Auswertung der Western Blot Analyse von CTGF und FN1. Abgebildet sind Mittelwerte der berechneten Konzentrationen \pm SEM; ${ }^{*} p<0,05 ;{ }^{* *} p<0,01 ; n=7-9$ (Kontrolle), $n=5$ (Tag 14).

Des Weiteren wurden Gewebeschnitte aus der Niere auf die Expression von fibrotischen Markern untersucht. Es wurde sowohl ein immunchemischer Nachweis von Fibronektin als auch eine Färbung des Bindegewebes mittels AZAN durchgeführt (Abbildung 19). Die Färbungen dieser Fibrosemarker waren in S1 $\mathrm{P}_{5}^{-{ }^{-1}}$-Mäusen nach 14 Tagen im AN-Modell weniger stark ausgeprägt im Vergleich zu den Wildtypen. 


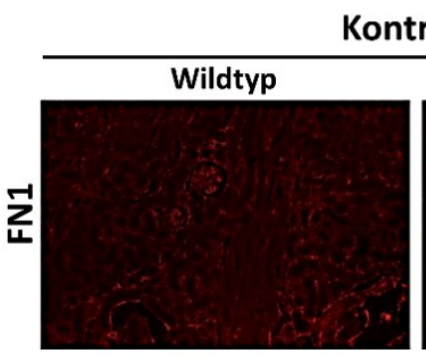

Kontrolle

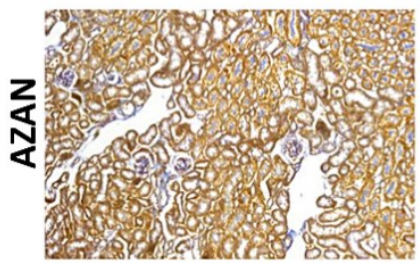

Tag 14

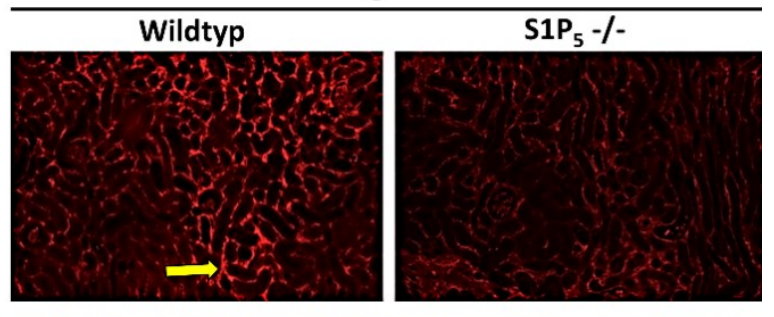

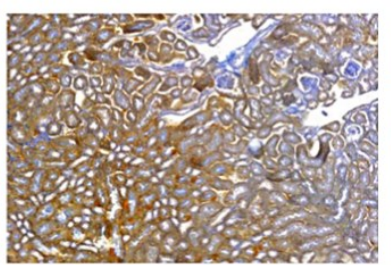

$\mathrm{S}_{1 \mathrm{P}_{5}-/-}$
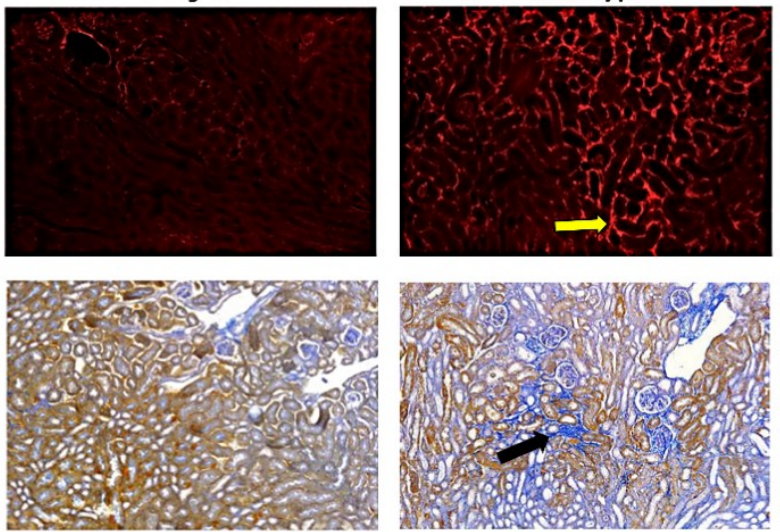

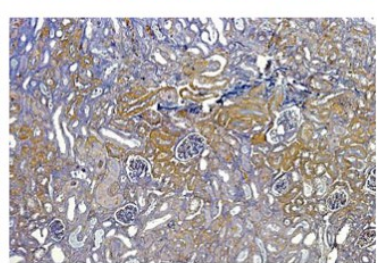

Abbildung 19: Fibrose im Nierengewebe von Kontrollmäusen und AN-Mäusen. Repräsentatives Bild der immunhistochemischen Färbung von Fibronektin (leuchtend rot, gelber Pfeil) und der Färbung von Bindegewebe (dunkel blau, schwarzer Pfeil) mittels AZAN in Gewebeschnitten aus dem Nierenkortex von Kontrollmäusen und Mäusen nach 14 Tagen im AN-Modell. Das Bild wurde zur Verfügung gestellt von Dr. Stefan Gauer vom Universitätsklinikum Frankfurt am Main.

\subsubsection{Untersuchung des Sphingolipidmetabolismus}

Die Genexpression der SK-1 war nach 14 Tagen im AN-Modell sowohl in den S1P $5^{-1-}$ Mäusen als auch in den Wildtypmäusen gegenüber den jeweiligen gesunden Kontrollen signifikant erhöht (Abbildung 20). Die Genexpression der SK-2 war höher im Vergleich zur SK-1 in den S1 $\mathrm{P}_{5}{ }^{-/}-$Mäusen und Wildtypmäusen und wurde durch die AN nicht signifikant verändert. Die mRNA-Menge des S1P-Transporters Spns2 war in kranken Mäusen beider Genotypen gegenüber den gesunden Kontrollen signifikant erhöht. Die Expression von SK-1 und Spns2 ist wichtig für die Synthese und den Export von S1P und begünstigt folglich die Aktivierung der S1P-Rezeptoren, wodurch diese einen Einfluss auf den Verlauf der Krankheit ausüben können. 

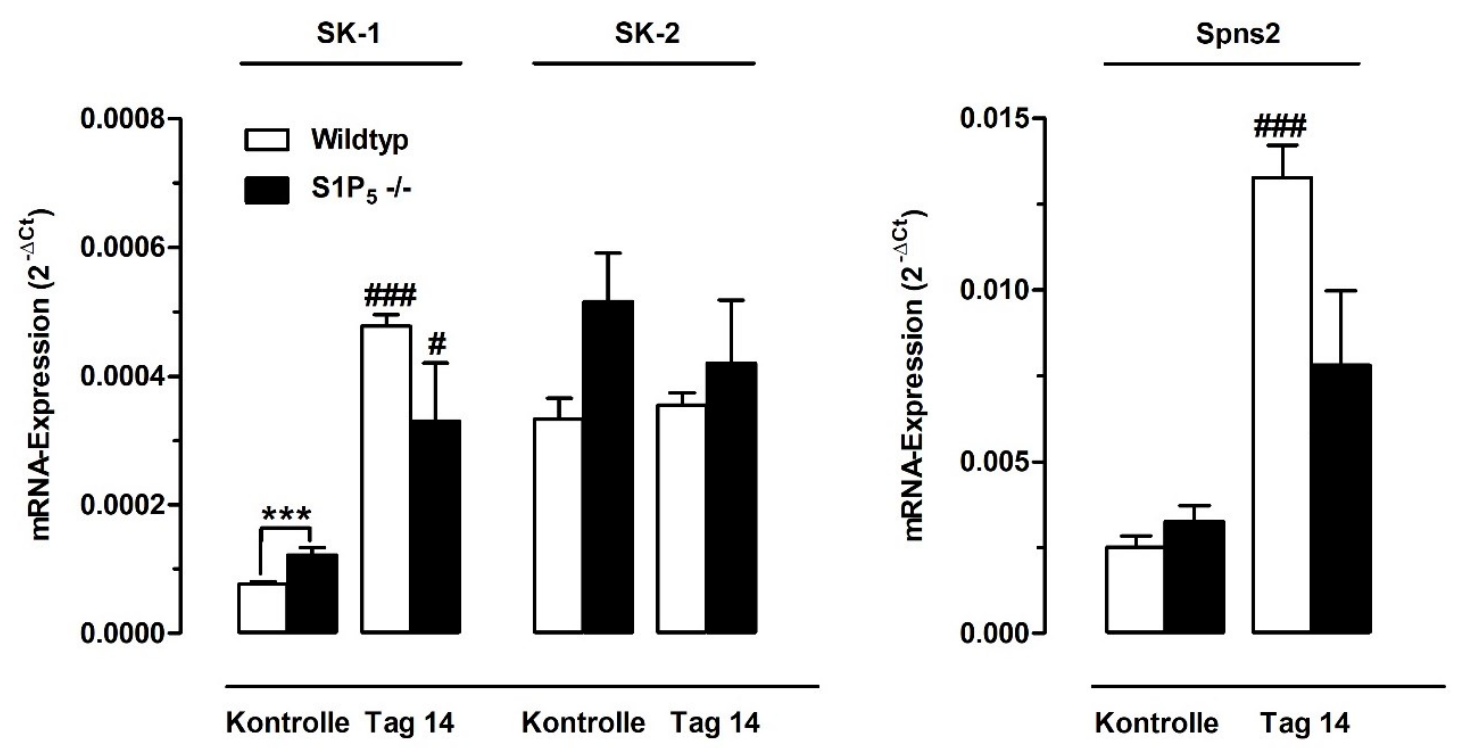

Abbildung 20: Genexpression der Sphingosinkinasen 1 und 2 und des S1PTransporters Spns2 in den Nieren der gesunden und nierenkranken Mäuse. Mittels RTqPCR wurden die mRNA-Level von SK-1, SK-2 und Spns2 in den Nierenproben von gesunden Mäusen und Mäusen nach 14 Tagen im Modell der AN gemessen und ausgewertet. Abgebildet sind Mittelwerte der berechneten Konzentrationen \pm SEM. Wildtyp: $n=9$ (Kontrolle), $n=5$ (Tag 14); $\mathrm{S}^{\mathrm{P}}{ }^{-{ }^{-}:}: \mathrm{n}=7$ (Kontrolle), $\mathrm{n}=5$ (Tag 14); ${ }^{* *} \mathrm{p}<0,001 ;{ }^{\#} \mathrm{p}<0,05$ und ${ }^{\# \#} \mathrm{p}<0,001$ verglichen mit der jeweiligen gesunden Kontrollgruppe.

Die Expression der S1P-Rezeptoren war bei den gesunden S1P5 ${ }^{-/-}$-Mäusen etwas niedriger als bei den Wildtypen (Abbildung 21). Nach 14 Tagen im AN-Modell wurden jedoch keine Unterschiede in der Genexpression der Rezeptoren zwischen den Genotypen gefunden. Durch die AN wurden insbesondere die Konzentrationen von $\mathrm{S}_{1} \mathrm{P}_{2}$ in den Nieren verändert und es wurden im Durchschnitt 6-fach höhere Level dieses Rezeptors im Vergleich $\mathrm{zu}$ den gesunden Kontrollen gemessen. Die Expressionslevel von $\mathrm{S}_{1} \mathrm{P}_{1}, \mathrm{~S}_{1} \mathrm{P}_{3}$ und $\mathrm{S}_{1} \mathrm{P}_{5}$ weisen ein ähnliches Muster auf, sind jedoch insgesamt im Krankheitsverlauf kaum verändert. Auffällig ist, dass auch in den Nieren der $\mathrm{S}_{1} \mathrm{P}_{5}{ }^{-/}-$Mäusen ein Anstieg des Signals für $\mathrm{S}_{1} \mathrm{P}_{5}$ gemessen wurde, welches sogar höher ist als die Expression der anderen S1P-Rezeptoren in den gesunden Kontrollen. Die Unterscheidung des Genotyps scheint also über RT-qPCR mit der verwendeten Sonde nicht möglich und zeigt falschpositive Ergebnisse. 


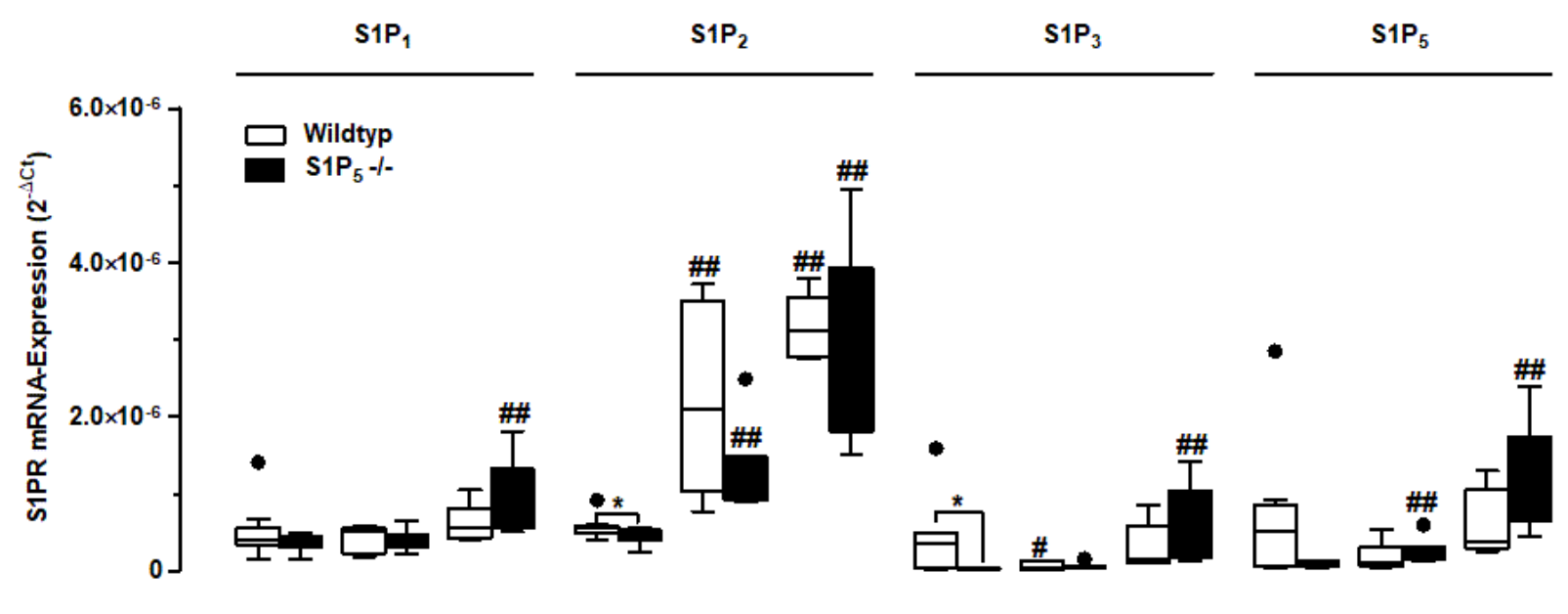

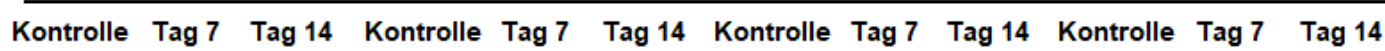

Abbildung 21: Genexpression der S1P-Rezeptoren. Mittels RT-qPCR wurden die mRNALevel von $\mathrm{S}_{1} \mathrm{P}_{1}, \mathrm{~S}_{1} \mathrm{P}_{2}$ und $\mathrm{S}_{1} \mathrm{P}_{3}$ in den Nierenproben von gesunden Mäusen und Mäusen nach 14 Tagen im Modell der AN gemessen und ausgewertet. Die Daten sind dargestellt als BoxPlots nach Tukey mit Ausreißern (Punkte). Wildtyp: $n=9$ (Kontrolle), $n=5$ (Tag 14); S1P ${ }_{5}^{-1 /}: n$ $=7$ (Kontrolle), $n=5$ (Tag 14); ${ }^{*} p<0,05 ;{ }^{\#} p<0,01$ verglichen mit der gesunden Kontrolle.

Mittels Massenspektrometrie wurde gemessen, dass S1P- und SphingosinKonzentrationen im Plasma von Wildtypmäusen nach 7 und 14 Tagen signifikant gegenüber gesunden Kontrollen sanken (Abbildung 22). Im Gegensatz dazu wurden keine Veränderungen der Konzentration von Sphingosin im Plasma von S1 $\mathrm{P}_{5}^{-1-}$ Mäusen gemessen. Die Konzentration von S1P im Plasma von S1P $5^{-1-}$-Mäusen war erst nach 14 Tagen verringert. Generell waren die S1P-Level von gesunden S1 $\mathrm{P}_{5}^{-1-}$ Mäusen niedriger als in gesunden Wildtypmäusen. Dieses Verhältnis wurde durch das starke Abfallen der S1P-Konzentrationen in Wildtypen nach 14 Tagen im AN-Modell umgekehrt 

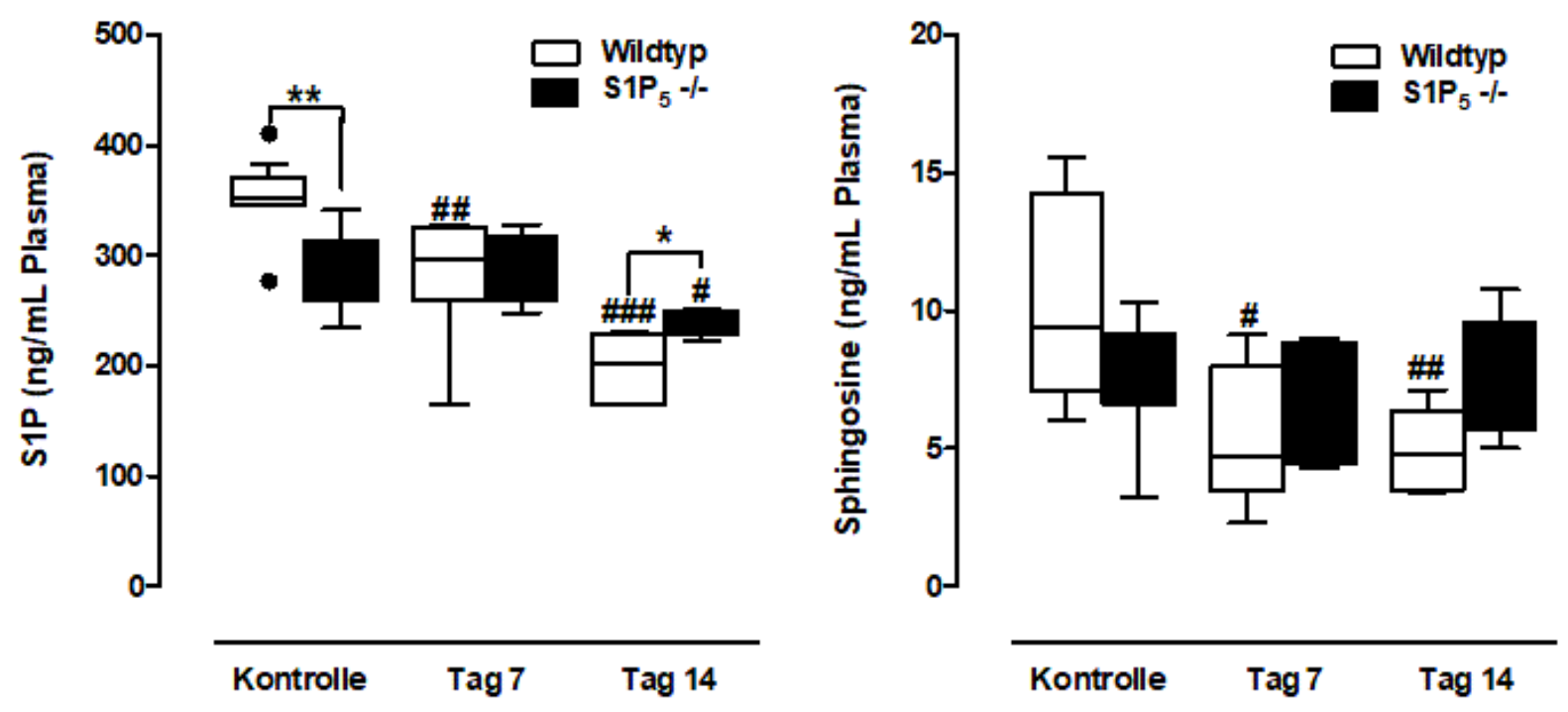

Abbildung 22: Plasmaspiegel von S1P und Sphingosin in gesunden und nierenkranken Mäusen. S1P- und Sphingosin-Plasmaspiegel wurden mit Hilfe von Massenspektrometrie, wie im Kapitel Material und Methoden beschrieben, ermittelt. Die Daten sind dargestellt als BoxPlots nach Tukey mit Ausreißern (Punkte). ( $n=5-9$ ); ${ }^{*} p<0,05 ;{ }^{* *} p<0,01 ;{ }^{\#} p<0,05 ;{ }^{\#} p<0,01$ und ${ }^{\# \#} p<0,001$ verglichen mit der gesunden Kontrolle. 


\subsection{Untersuchung der Veränderungen von kettenlängen- spezifischen Ceramiden in fibrotischen Nieren}

\subsubsection{Veränderungen der Konzentrationen von Ceramiden in humanen Nierenrinden bei Fibrose}

Zu Beginn wurden alle Nierenbiopsien auf die Ausprägung einer Fibrose anhand der Expression von klassischen Fibrosemarkern untersucht. Mittels Real-Time PCR wurde in den Nierenrindenbiopsien der Hydronephrose- bzw. Pyelonephritispatienten eine 10- bis 15-fache Erhöhung der mRNA-Expression von Kollagen Typ I, alpha 1 (COL1a1), Kollagen Typ III, alpha 1 (COL3a1) und alpha smooth muscle actin (aSMA) gemessen (Abbildung 23).

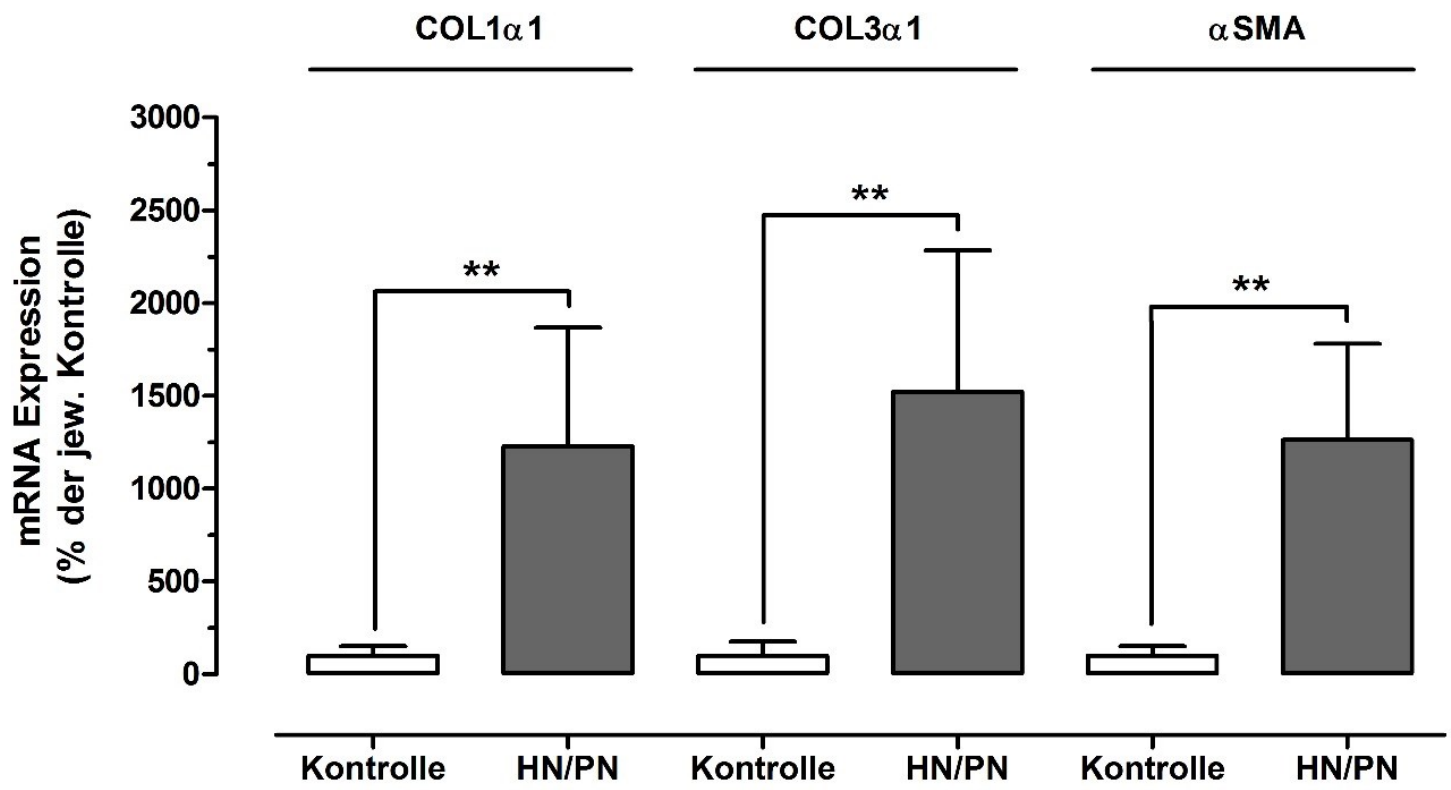

Abbildung 23: Ergebnis der Real-Time PCR zur Bestimmung der mRNA-Expression in den fibrotischen und gesunden Kortexgewebeproben. Es wurde die Expression von Kollagen Typ 1, alpha I (COL1a1), Kollagen Typ III, alpha 1 (COL3a1), alpha smooth muscle cctin (aSMA) gemessen. Die Expression in den Proben der Hydronephrose-/Pyelonephritis(HN/PN) Patienten wurde in Relation zu den Kontrollproben gesetzt und der Mittelwert mit Standardfehler ( \pm SEM) in \% abgebildet; ${ }^{* *} \mathrm{p}<0,01 ; n=6$ (Kontrolle), $n=8$ (HN/PN).

Zusätzlich wurden auch mittels immunhistochemischer Analyse die Expression des extrazellulären Matrixproteins Kollagen III und des Fibroblastenmarkers aSMA in den Biopsien von den Kooperationspartnern Dr. Sonja Djudjaj und Prof. Dr. Peter Boor vom Universitätsklinikum der RWTH Aachen untersucht (Abbildung 24). Auch hier wurde 
eine deutlich stärkere Färbung aufgrund einer erhöhten Expression von Kollagen III und aSMA und somit sowohl eine Nierenfibrose als auch eine erhöhte Myofibroblasten-Aktivierung bei den Schnitten der Patienten mit Hydronephrose bzw. Pyelonephritis detektiert.

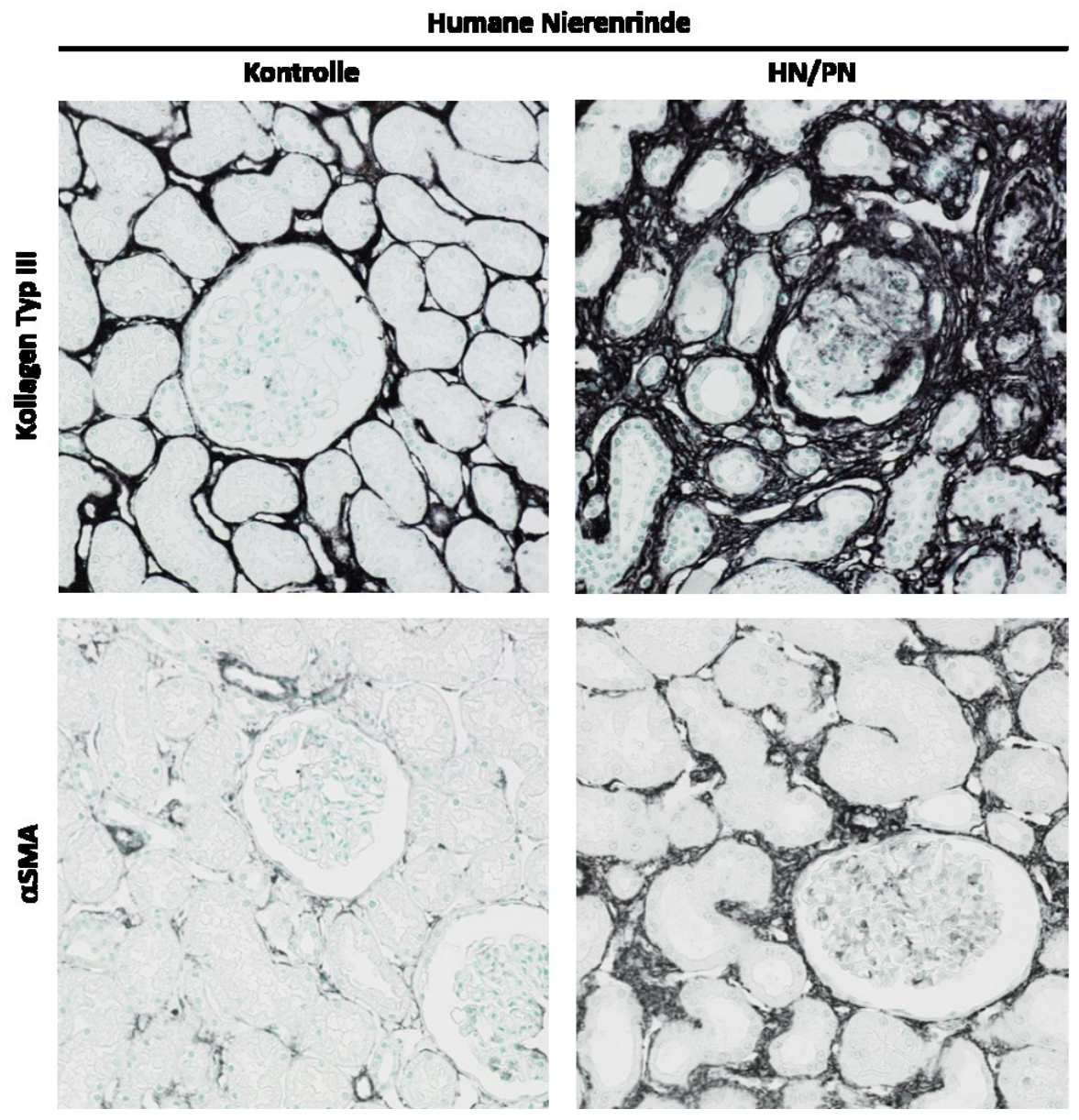

Abbildung 24: Immunhistochemische Färbungen des humanen Nierenkortex. Antikörperbasierte Färbungen von Kollagen III und aSMA in Biopsien aus dem Nierenkortex von Patienten, die zum Zeitpunkt der Entnahme an Hydronephrose oder Pyelonephritis (HN/PN) litten und in tumorfreien Nierenkortexproben von Patienten, an denen eine Tumornephrektomie durchgeführt worden war (Kontrolle). Die gefärbten Proteine sind dargestellt in schwarz und die Zellkerne in blau. Das Bild wurde zur Verfügung gestellt von Dr. Sonja Djudjaj vom Universitätsklinikum der RWTH Aachen. 
Als Nächstes wurden die Ceramidkonzentrationen in den Gewebeproben mit Hilfe von LC-ESI-MS/MS gemessen (Abbildung 25). Dabei wurde deutlich, dass die sehr langkettigen Ceramide Cer d18:1/20:0, Cer d18:1/24:0 und Cer d18:1/24:1 in den Hydronephrose-/Pyelonephritis-Proben gegenüber den gesunden Gewebeproben aus dem Nierenkortex signifikant niedriger konzentriert waren. Der Median von Cer d18:1/20:0 war im fibrotischen Nierenkortex um etwa 50\% niedriger im Vergleich zum gesunden Gewebe. Die Werte von Cer d18:1/24:0 und Cer d18:1/24:1 waren ebenfalls um ca. $30 \%$ niedriger. Die Konzentrationen der langkettigen Ceramide Cer d18:1/16:0 und Cer d18:1/18:0 sowie die der sehr langkettigen Dihydroceramide Cer d18:0/24:0 und Cer d18:0/24:1 waren hingegen nicht signifikant verändert.
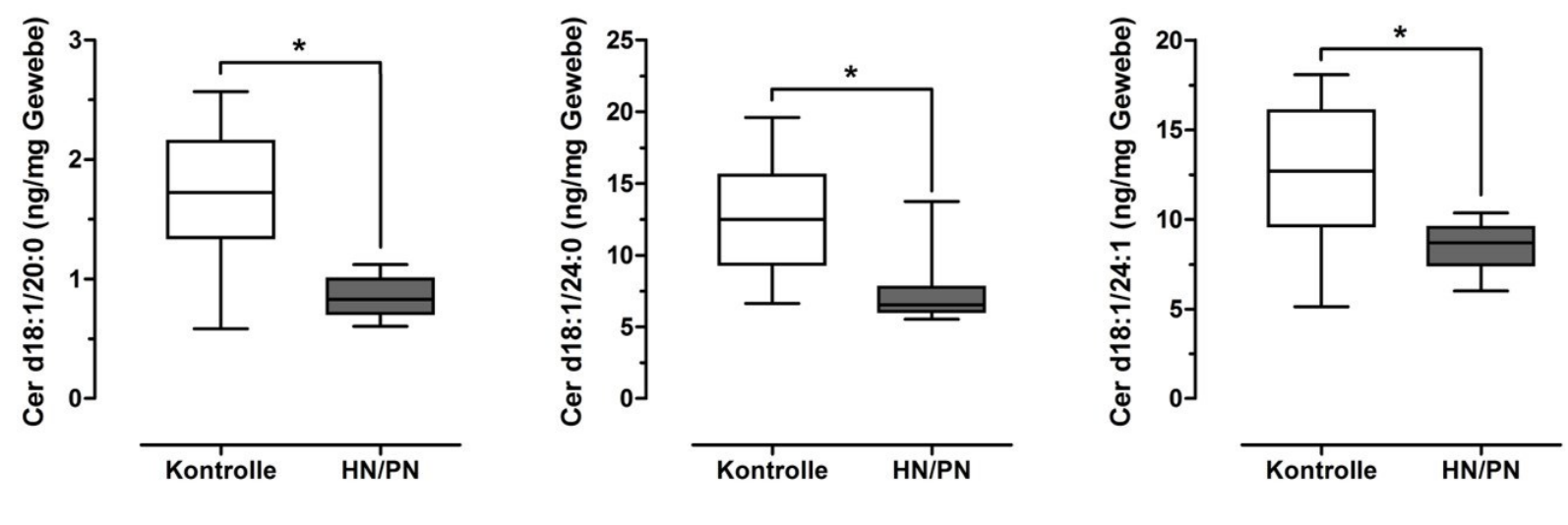

\begin{tabular}{cccc}
\hline Ceramide (Cer) & Kontrolle & HN/PN & p-Wert \\
\hline Cer d18:1/16:0 & $2,8(2,3-4,0)$ & $3,3(2,3-3,9)$ & 0,755 \\
Cer d18:1/18:0 & $1,1(0,7-1,5)$ & $0,7(0,6-1,0)$ & 0,108 \\
Cer d18:0/24:0 & $0,6(0,4-0,7)$ & $0,5(0,5-0,5)$ & 0,108 \\
Cer d18:0/24:1 & $0,8(0,6-0,9)$ & $0,6(0,6-0,8)$ & 0,284 \\
\hline
\end{tabular}

Abbildung 25: Konzentration von Ceramiden bestimmter Kettenlänge im menschlichen Nierenkortex. In Biopsien aus dem Nierenkortex von Patienten, die zum Zeitpunkt der Entnahme an Hydronephrose oder Pyelonephritis (HN/PN) litten und in tumorfreien Nierenkortexproben von Patienten, an denen eine Tumornephrektomie durchgeführt worden war (Kontrolle), wurden mittels LC-ESI-MS/MS, wie im Methodenteil beschrieben, Ceramide gemessen. Abgebildet sind die Interquartilsabstände sowie Median mit Minimum und Maximum in $\mathrm{ng} / \mathrm{mg}$ Gewebe; * $\mathrm{p}<0,05 ; \mathrm{n}=6$ (Kontrolle), $\mathrm{n}=8$ (HN/PN). 
Im nächsten Schritt wurde die Genexpression der drei in den Nieren relevanten Ceramidsynthasen CerS2, CerS5 und CerS6 mittels Real-Time PCR gemessen (Abbildung 26). Die Genexpression von allen drei Ceramidsynthasen war in den Gewebeproben der HN/PN-Patienten höher im Vergleich zur Expression in gesunden Gewebeproben. Die Genexpression von CerS2 war 8-mal höher als die von CerS5 und 38-mal höher als die von CerS6 in den gesunden Gewebeproben.

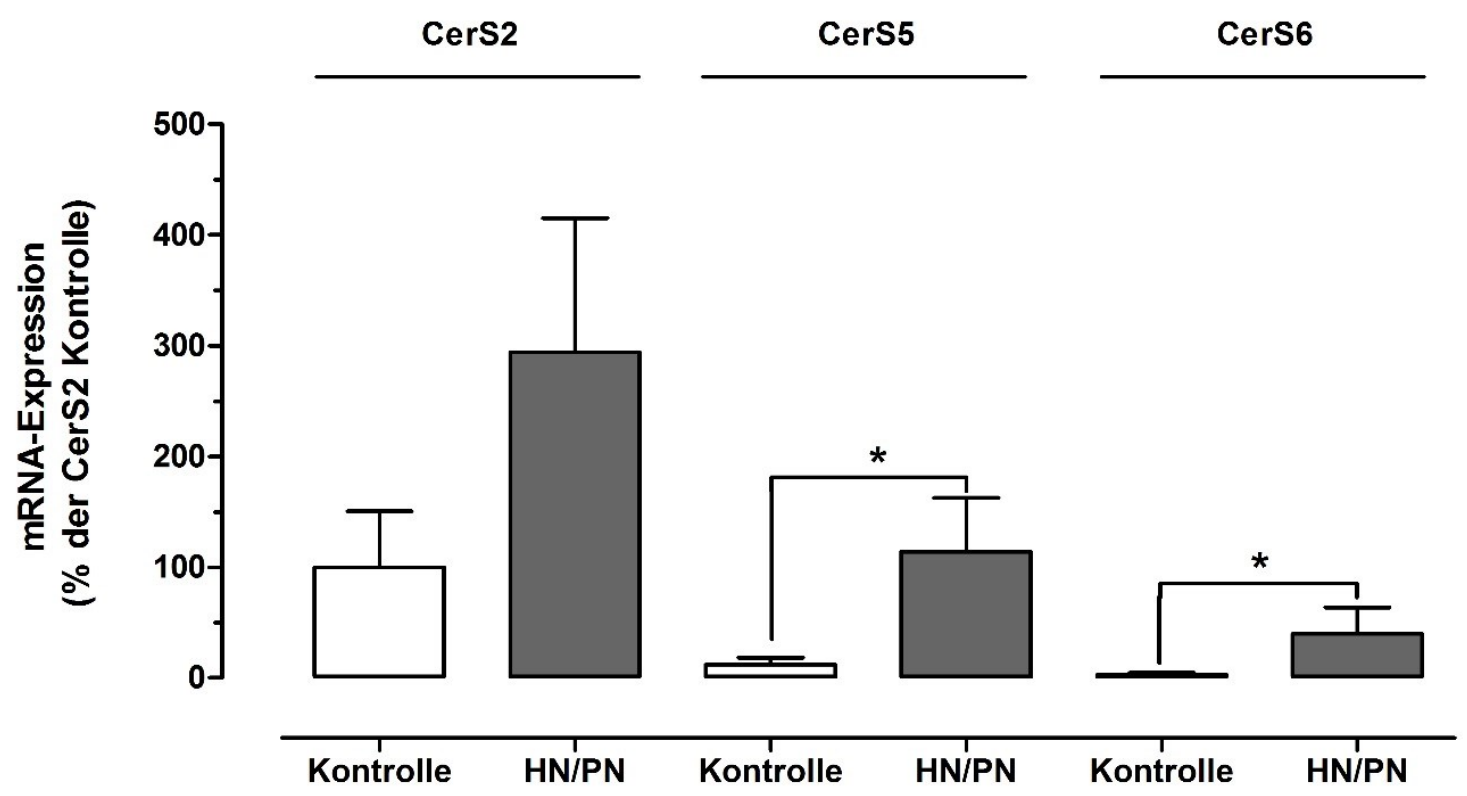

Abbildung 26: Ergebnis der Real-Time PCR zur Bestimmung der mRNA-Expression in den fibrotischen und gesunden Kortexgewebeproben. Es wurde die Expression von Ceramidsynthase 2 (CerS2), Ceramidsynthase 5 (CerS5) und Ceramidsynthase 6 (CerS6) gemessen. Die Expression in den Proben der HN/PN-Patienten wurde in Relation zu den Kontrollproben gesetzt und der Mittelwert \pm SEM abgebildet; ${ }^{*} p<0,05 ; n=6$ (Kontrolle), $n=8$ (HN/PN). 


\subsubsection{Veränderungen der Konzentrationen von Ceramiden in humanem Nierenmark bei Fibrose}

Im Gegensatz zur Nierenrinde wurde im Nierenmark der Hydronephrose- bzw. Pyelonephritispatienten kein signifikanter Anstieg von COL1a1, COL3a1 und aSMA auf mRNA-Ebene gegenüber den Kontrollen gemessen (Abbildung 27).

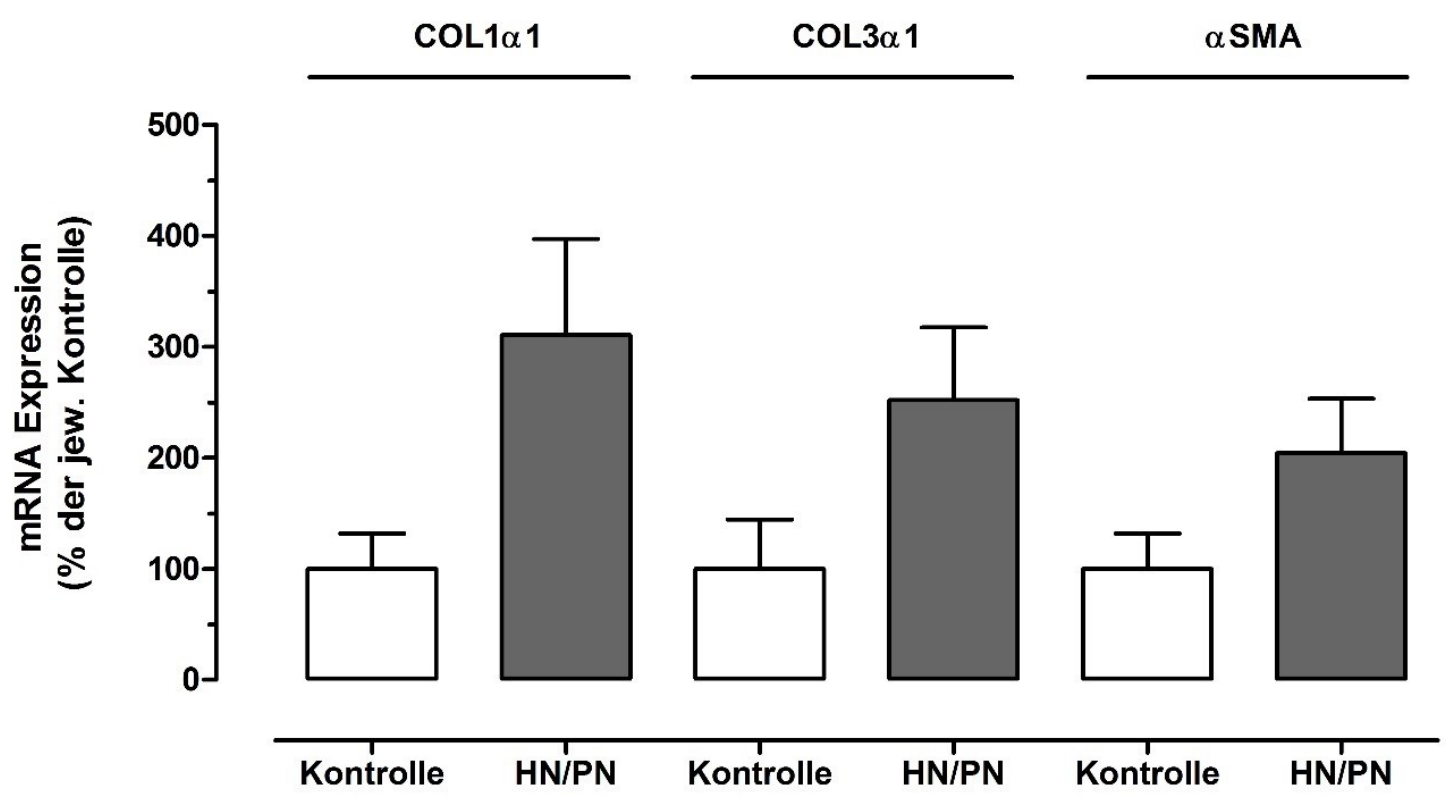

Abbildung 27: Ergebnis der Real-Time PCR zur Bestimmung der mRNA-Expression in den fibrotischen und gesunden Nierenmarkgewebeproben. Es wurde die Expression von Kollagen Typ I, alpha 1 (COL1a1), Kollagen Typ III, alpha 1 (COL3a1), alpha smooth muscle actin (aSMA) gemessen. Die Expression in den Proben der HN/PN Patienten wurde in Relation zu den Kontrollproben gesetzt und der Mittelwert \pm SEM in \% abgebildet; $n=5$ (Kontrolle), $n$ $=9(\mathrm{HN} / \mathrm{PN})$.

Bei der Färbung von Kollagen III und aSMA in den Gewebeschnitten fielen die Unterschiede zwischen den Schnitten der gesunden Kontrollen und den HN/PNSchnitten im Vergleich zum Nierenkortex geringer aus (Abbildung 28). Dennoch konnte festgestellt werden, dass die kollagenhaltige Schicht im Interstitium stärker ausgeprägt war. Zusätzlich zeigte die Färbung, dass die Expression von aSMA in den gesunden Geweben nur in den Gefäßen zu sehen ist, wohingegen sie in den HN/PNSchnitten auch tubulointerstitiell zu erkennen ist. 


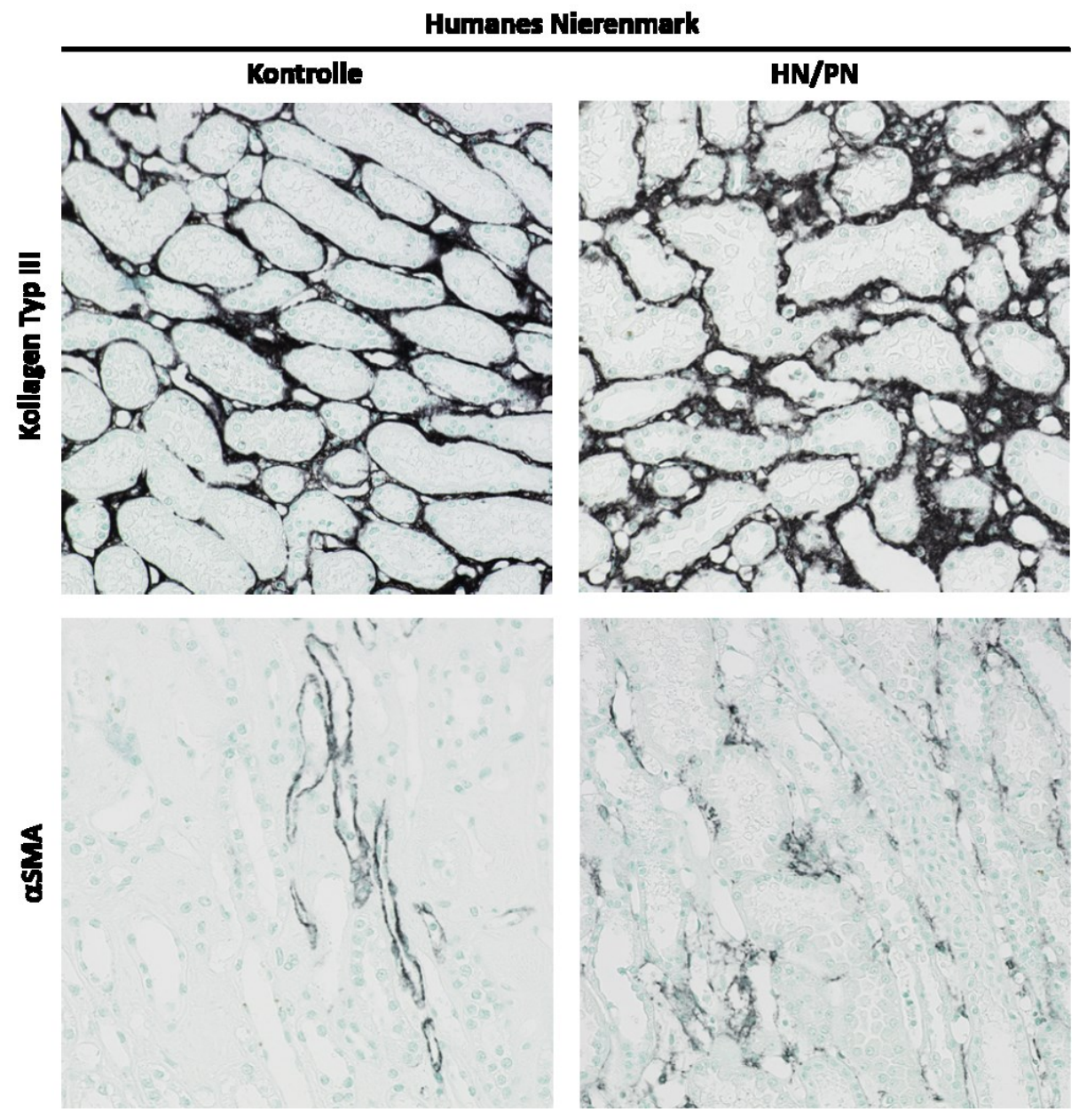

Abbildung 28: Immunhistochemische Färbungen des humanen Nierenmarks. Antikörperbasierte Färbungen von Kollagen Typ III und aSMA in Biopsien aus der medulla renalis von Patienten, die zum Zeitpunkt der Entnahme an Hydronephrose oder Pyelonephritis (HN/PN) litten und in tumorfreien Nierenmarkproben von Patienten, an denen eine Tumornephrektomie durchgeführt worden war (Kontrolle). Die gefärbten Proteine sind dargestellt in schwarz und die Zellkerne in blau. Das Bild wurde zur Verfügung gestellt von Dr. Sonja Djudjaj vom Universitätsklinikum der RWTH Aachen.

Im Hinblick auf Ceramid- und Dihydroceramidspiegel im Gewebe wurde im Nierenmark kein signifikanter Unterschied zwischen den Proben aus den HN/PN-Patienten und den gesunden Kontrollen gemessen (Abbildung 29). 

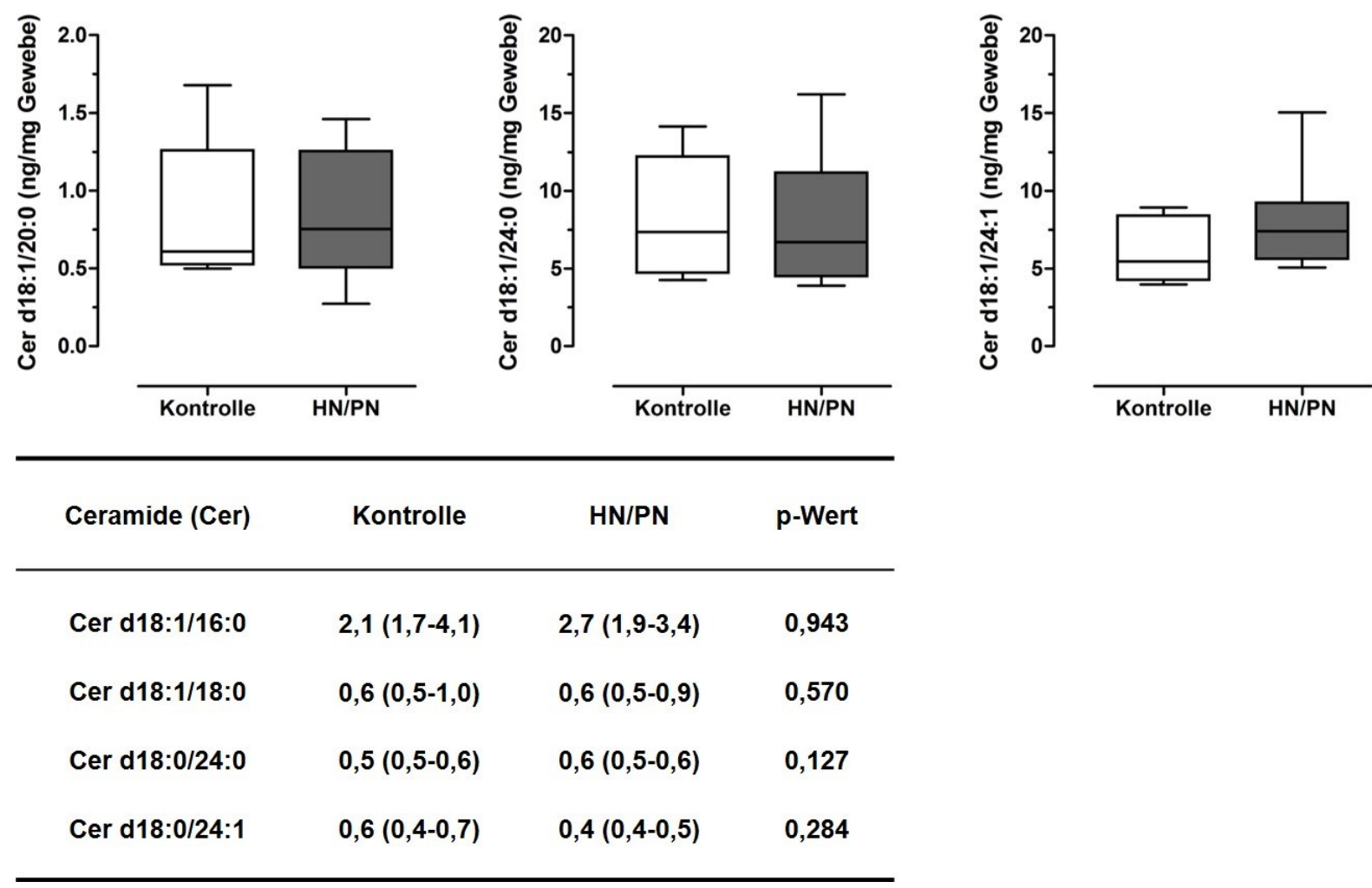

Abbildung 29: Konzentration von Ceramiden bestimmter Kettenlänge im menschlichen Nierenmark. In Biopsien aus dem Nierenmark von Patienten, die zum Zeitpunkt der Entnahme an Hydronephrose oder Pyelonephritis (HN/PN) litten und in tumorfreien Nierenmarkproben von Patienten, an denen eine Tumornephrektomie durchgeführt worden war (Kontrolle), wurden mittels LC-ESI-MS/MS, wie im Methodenteil beschrieben, Ceramide gemessen. Abgebildet sind die Interquartilsabstände sowie Median mit Minimum und Maximum in $\mathrm{ng} / \mathrm{mg}$ Gewebe; $n=5$ (Kontrolle), $n=9$ (HN/PN).

Es wurde als Nächstes die Genexpression der drei in den Nieren relevanten Ceramidsynthasen CerS2, CerS5 und CerS6 mittels Real-Time PCR gemessen (Abbildung 30). Wie auch im Nierenkortex wurde CerS2 am stärksten exprimiert, gefolgt von CerS5. Im Gegensatz zu den Proben aus dem Nierenkortex wurde im Nierenmark hingegen kein Anstieg, sondern eine Reduktion der Expression der Ceramidsynthasen gemessen. 


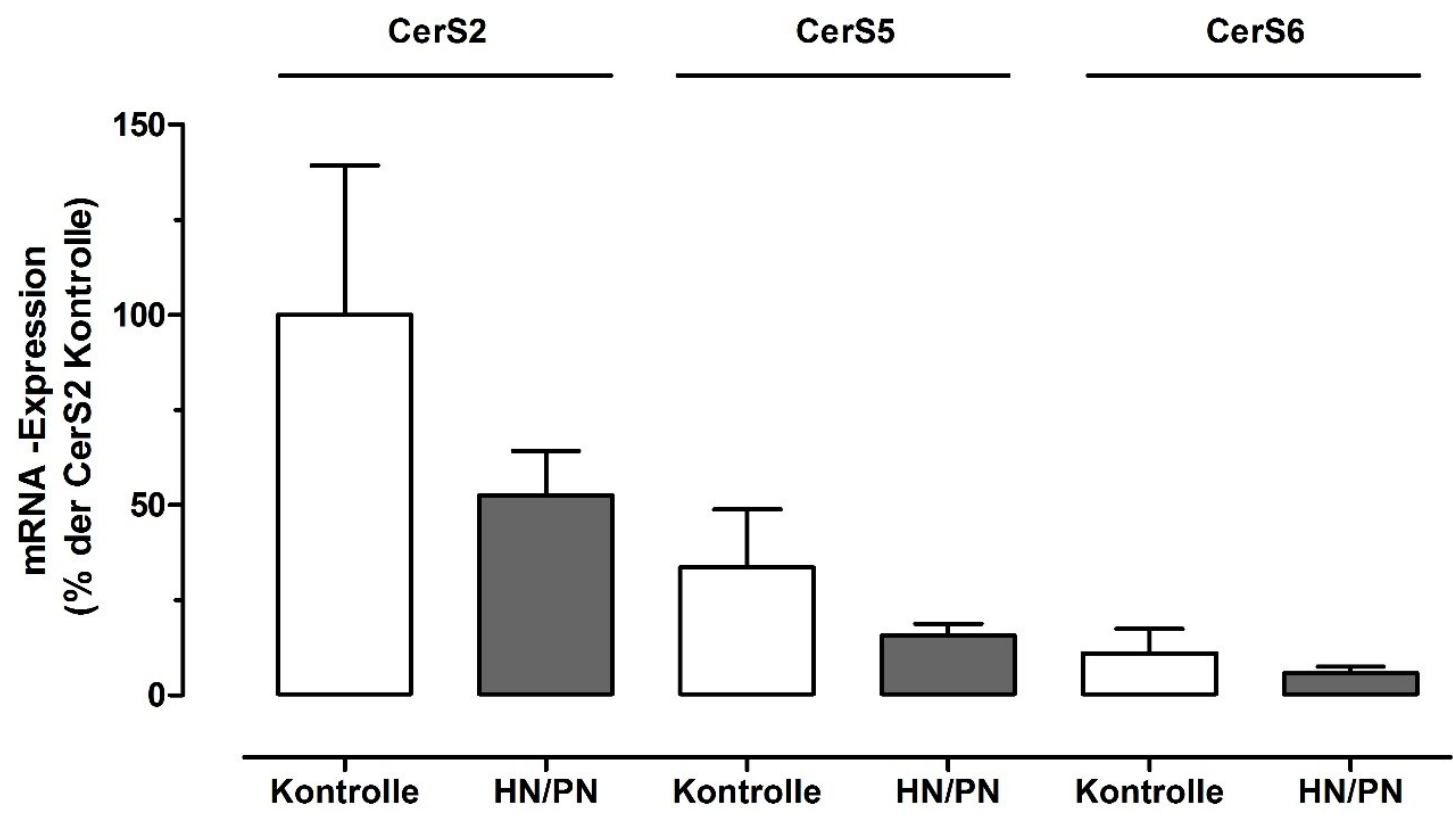

Abbildung 30: Ergebnis der Real-Time PCR zur Bestimmung der mRNA-Expression in den fibrotischen und gesunden Nierenmarkgewebeproben. Es wurde die Expression von Ceramidsynthase 2 (CerS2), Ceramidsynthase 5 (CerS5) und Ceramidsynthase 6 (CerS6) gemessen. Die Expression in den Proben der HN/PN-Patienten wurde in Relation zu den Kontrollproben gesetzt und der Mittelwert mit \pm SEM abgebildet; $n=5$ (Kontrolle), $n=9$ (HN/PN).

\subsubsection{Unterschiede der Konzentrationen von kettenlängen- spezifischen Ceramiden zwischen Nierenrinde und Nierenmark in gesunden Biopsien}

Die sehr langkettigen Ceramide Cer d18:1/24:0 und Cer d18:1/24:1 wiesen die höchsten Konzentrationen unter den hier gemessen Ceramiden in allen Nierenbiopsien auf (Abbildung 31). Im gesunden Nierenkortex wurden Mittelwerte von $12,5 \mathrm{ng} / \mathrm{mg}$ und 12,6 ng/mg von Cer d18:1/24:0 bzw. Cer d18:1/24:1 bezogen auf das Gewicht der analysierten Gewebeproben bestimmt. Im gesunden Nierenmark wurden hingegen geringere Mittelwerte von lediglich 6,1 ng/mg und 8,2 ng/mg von Cer d18:1/24:0 bzw. Cer d18:1/24:1 berechnet, wobei der Unterschied zum Nierenkortex nur im Falle des Cer d18:1/24:1 statistisch signifikant war ( $p$-Wert: 0,03). Die ermittelten Mittelwerte von Cer d18:1/20:0 von $1,7 \mathrm{ng} / \mathrm{mg}$ und $0,84 \mathrm{ng} / \mathrm{mg}$ in der Nierenrinde bzw. im Nierenmark wiesen ebenfalls keine signifikanten Unterschiede ( $p$-Wert: 0,052) auf. 


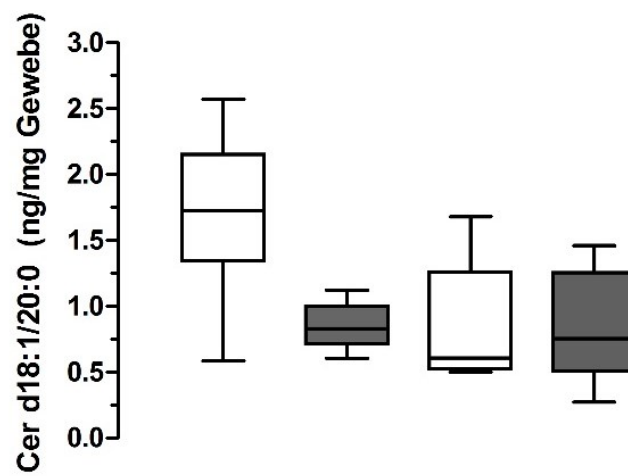

Kontrolle HN/PN Kontrolle HN/PN
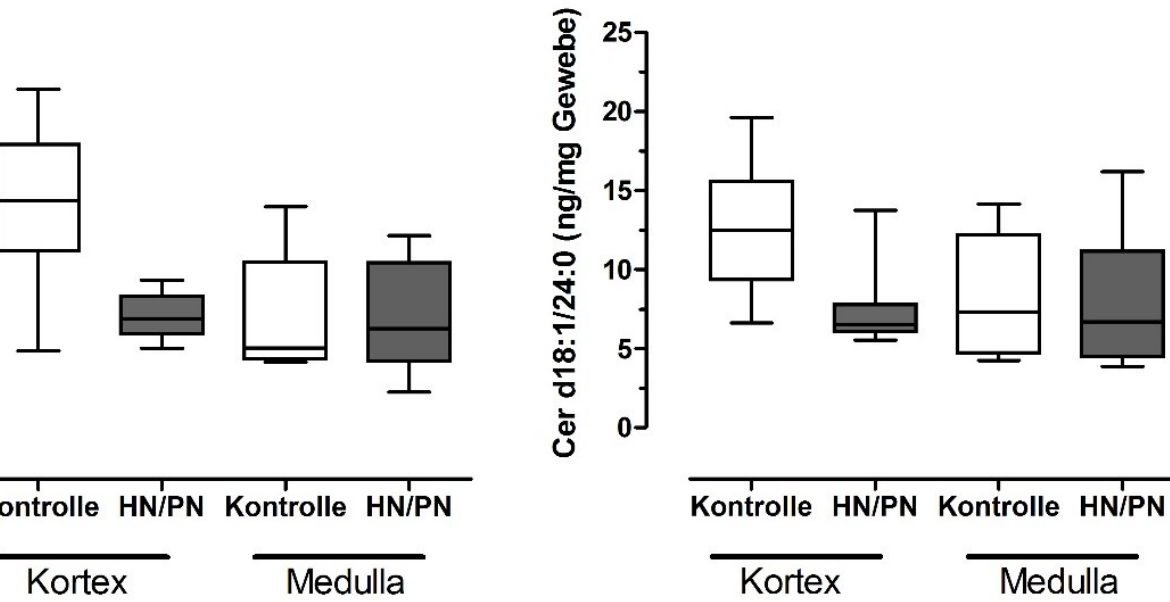

Kontrolle HN/PN Kontrolle HN/PN
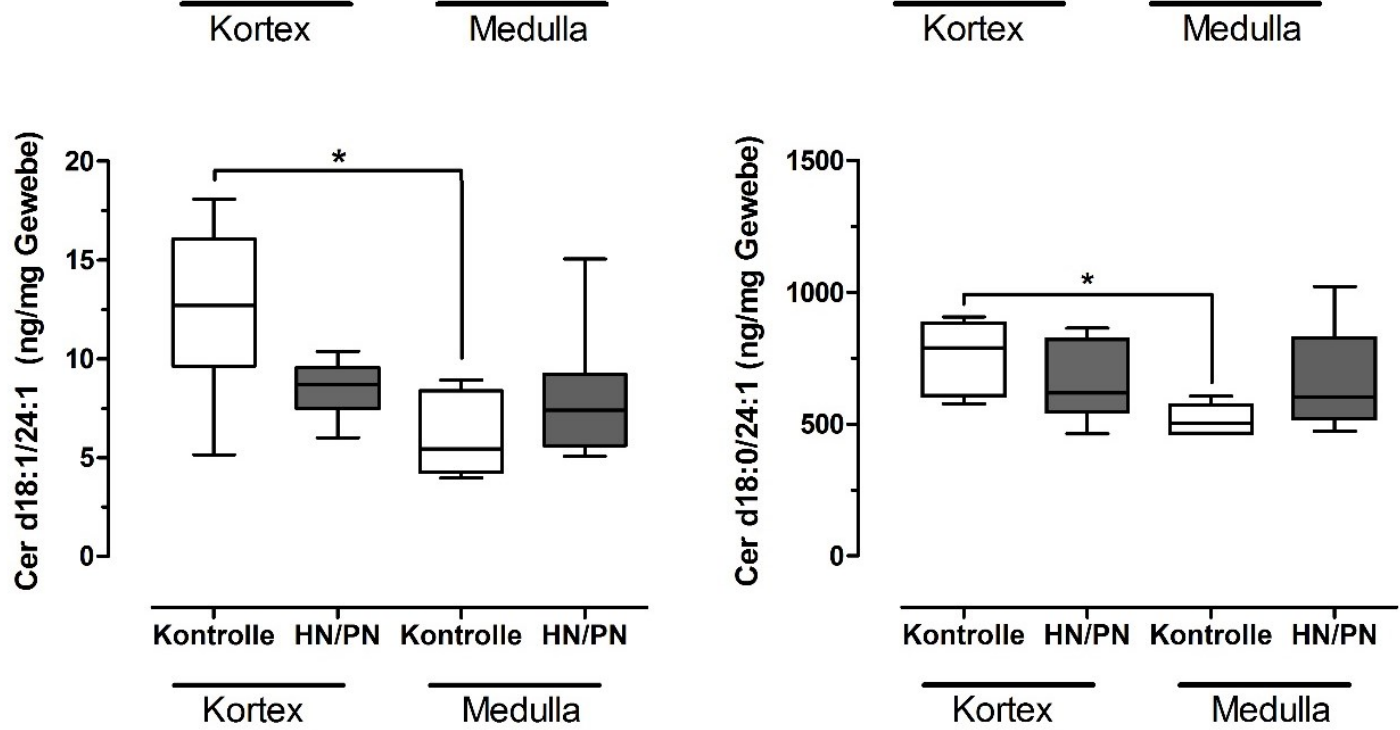

Abbildung 31: Konzentration von Ceramiden bestimmter Kettenlänge im menschlichen Nierenkortex und in der Nierenrinde. In Biopsien aus der Niere von Patienten, die zum Zeitpunkt der Entnahme an Hydronephrose oder Pyelonephritis (HN/PN) litten und in tumorfreien Nierenproben von Patienten, an denen eine Tumornephrektomie durchgeführt worden war (Kontrolle) wurden mittels LC-ESI-MS/MS, wie im Methodenteil beschrieben, Ceramide gemessen. Abgebildet sind die Interquartilsabstände sowie Median mit Minimum und Maximum in ng/mg Gewebe; ${ }^{*} p<0,05$; Kortex: $n=6$ (Kontrolle), $n=8$ (HN/PN), Medulla: $n=5$ (Kontrolle), $n=9$ (HN/PN).

Alle weiteren Werte der gemessenen Ceramide und Dihydroceramide sind in den Tabellen von Abbildung 25 und Abbildung 29 aufgeführt. Es wurden bei diesen Lipiden keine signifikanten Konzentrationsunterschiede zwischen den Proben aus der gesunden Nierenrinde und dem gesunden Nierenmark gemessen. 


\subsubsection{Veränderungen der Konzentrationen von kettenlängen- spezifischen Ceramiden in murinem Nierengewebe}

Zum Vergleich der Befunde in den humanen Proben haben wir die Ceramidspiegel in Nierenhomogenisaten von Mäusen, die aufgrund einer 14-tägigen adeninreichen Diät an einer milden Nierenfibrose litten, sowie gesunden Kontrollmäusen gemessen (Abbildung 32). In Anlehnung an die Untersuchungen der humanen Proben haben wir auch in den Mausnieren die mRNA-Expression der Fibrosemarker COL1a1, COL3a1 und von aSMA als Myofibroblastenmarker mittels Real-Time PCR gemessen.

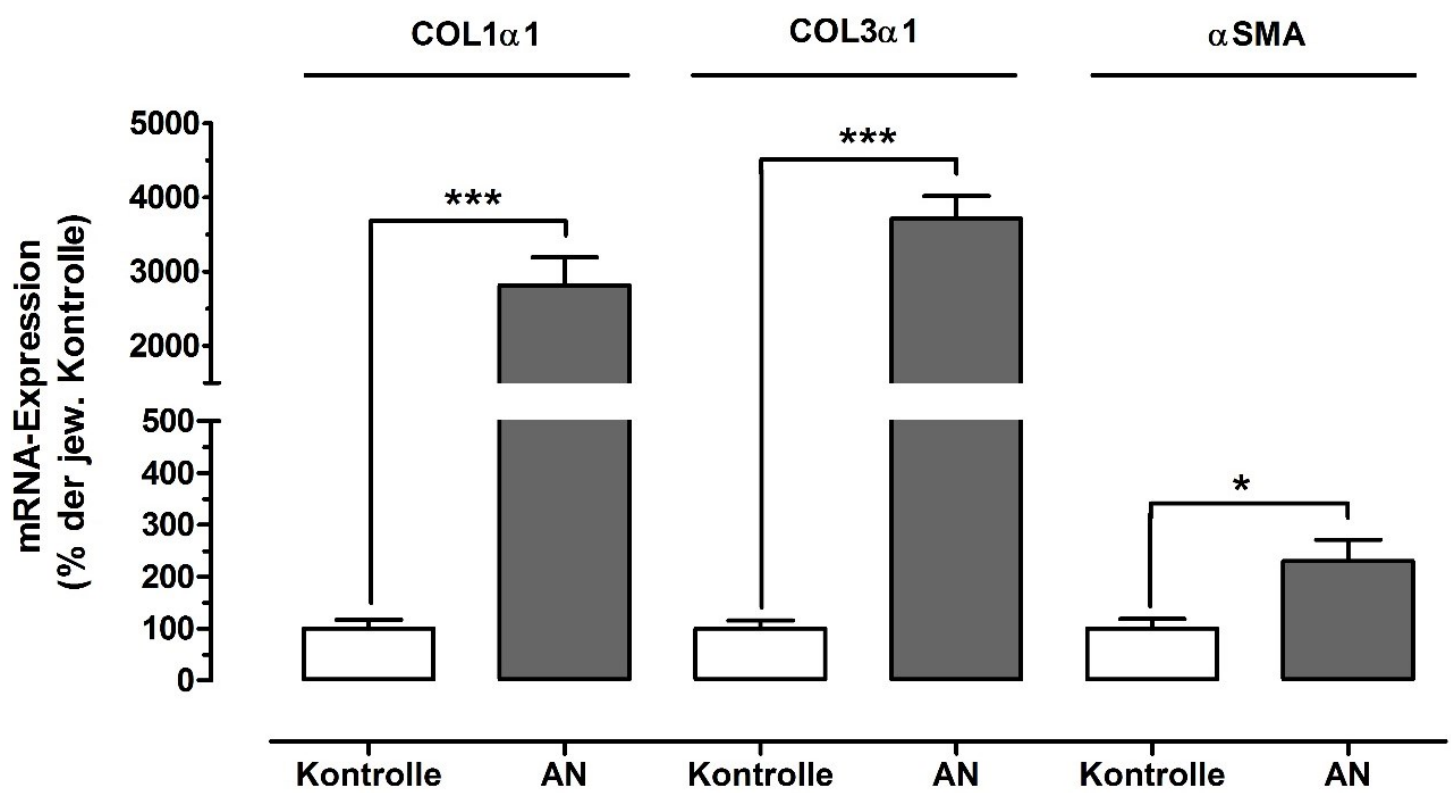

Abbildung 32: Ergebnis der Real-Time PCR zur Bestimmung der mRNA-Expression von Fibrosemarkern in den fibrotischen und gesunden Kortexgewebeproben von Mäusen. Es wurde die Expression von Kollagen Typ I, alpha 1 (COL1a1), Kollagen Typ III, alpha 1 (COL3a1), alpha smooth muscle actin (aSMA) gemessen. Die Expression in den Proben der Mäuse aus dem AN-Modell wurde in Relation zu den Kontrollproben gesetzt und der Mittelwert \pm SEM in \% abgebildet; ${ }^{*} p<0,05 ;{ }^{* * *} p<0,001 ; n=9$ (Kontrolle), $n=5$ (AN).

Mäuse mit einer AN wiesen eine ca. 30-fach höhere mRNA-Expression von COL1a1 und COL3a1 im Vergleich zu den Kontrolltieren auf. Die mRNA-Expression von aSMA war ebenfalls signifikant höher in den kranken Tieren. Eine histologische Überprüfung der Fibrose in den Nieren erfolgte mittels einer AZAN-Färbung (Abbildung 33). Nur die Nieren der AN-Mäuse wiesen hierbei Areale mit starker Ausprägung der extrazellulären Matrix im Interstitium des Tubulussystems auf. 


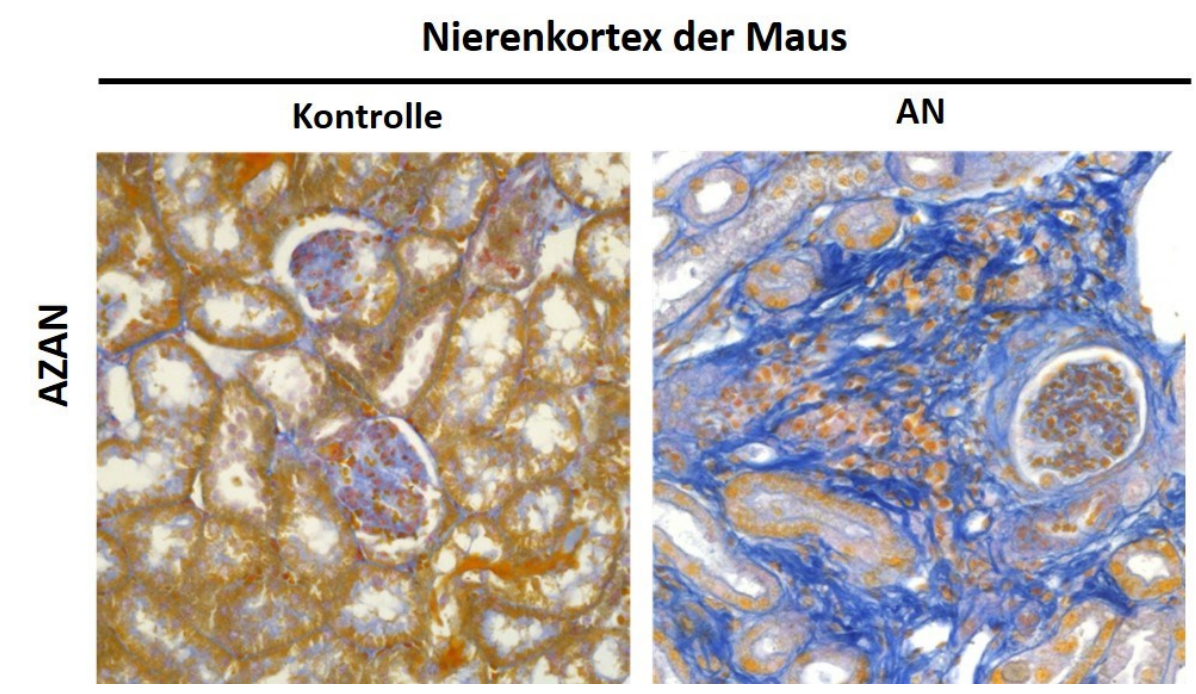

Abbildung 33: Histochemische Färbungen von Nierenschnitten aus der Maus. AZANFärbung, durchgeführt von Dr. Stefan Gauer (Klinik für Nephrologie, UKF), von Nierenschnitten aus Mäusen, die an einer Adenin-induzierten Nephropathie litten (AN) und von gesunden Kontrollmäusen (Kontrolle). Kollagenfasern, Bindegewebe erscheinen tiefblau, Mucine blau, Zellkerne orange und Zytoplasma sandfarben.

In den Nierenhomogenisaten der kranken Mäuse waren die Konzentrationen von den sehr langkettigen Ceramiden Cer d18:1/24:0 und Cer d18:1/24:1 signifikant niedriger im Vergleich zu denen aus den gesunden Mäusen (Abbildung 34). Der Median von Cer d18:1/24:0 war um 17\% und der von Cer d18:1/24:1 war um 43\% niedriger im Vergleich zur Kontrollgruppe. Auch das langkettige Ceramid Cer d18:1/16:0 war in den fibrotischen Nieren signifikant reduziert mit einem Median der Konzentration, der im Vergleich zur Kontrolle um 69\% niedriger ausfiel. Die Konzentrationen von Cer d18:1/18:0 und Cer d18:1/20:0 und den Dihydroceramiden Cer d18:0/24:0 und Cer d18:0/24:1 waren hingegen nicht unterschiedlich. 

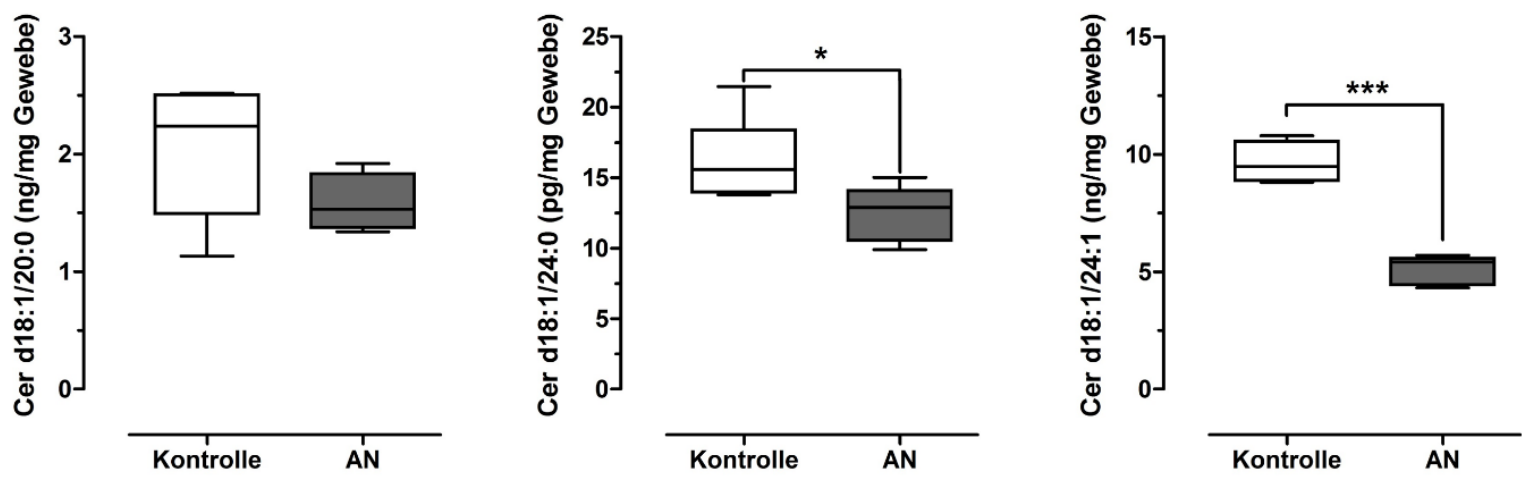

\begin{tabular}{cccc}
\hline Ceramide (Cer) & Kontrolle & AN & p-Wert \\
\hline Cer d18:1/18:0 & $0,6(0,4-0,7)$ & $0,4(0,3-0,5)$ & 0,083 \\
Cer d18:1/20:0 & $2,2(1,5-2,5)$ & $1,5(1,4-1,8)$ & 0,240 \\
Cer d18:0/24:0 & $0,3(0,3-0,3)$ & $0,4(0,3-0,5)$ & 0,065 \\
Cer d18:0/24:1 & $0,2(0,2-0,3)$ & $0,2(0,2-0,2)$ & 0,240 \\
\hline
\end{tabular}

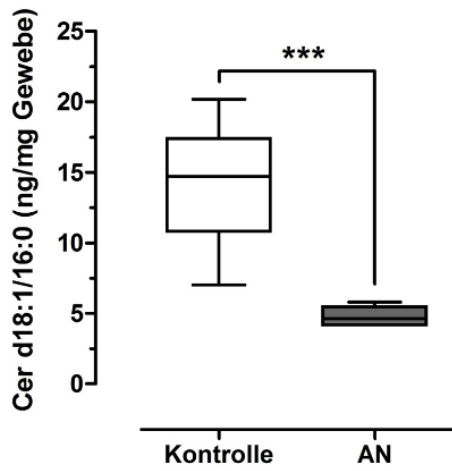

Abbildung 34: Konzentration von Ceramiden bestimmter Kettenlänge in Mausnieren. In Homogenisaten aus der Niere von Mäusen, die an einer Adenin-induzierten Nephropathie litten (AN) und von gesunden Kontrollmäusen (Kontrolle) wurden mittels LC-ESI-MS/MS, wie im Methodenteil beschrieben, Ceramide gemessen. Abgebildet sind die Interquartilsabstände sowie Median mit Minimum und Maximum in ng/mg Gewebe; ${ }^{*} p<0,05 ;{ }^{* * *} p<0,001 ; n=9$ (Kontrolle), $n=5$ (AN).

Die renale mRNA-Expression der Ceramidsynthasen CerS2, CerS5 und CerS6 wurde durch das Krankheitsmodell nicht verändert (Abbildung 35A). Die Proteinexpression von CerS2 wurde zudem mittels Western Blot untersucht, wodurch festgestellt werden konnte, dass CerS2 in den fibrotischen Proben stärker exprimiert wird (Abbildung 35B). 


\section{A}

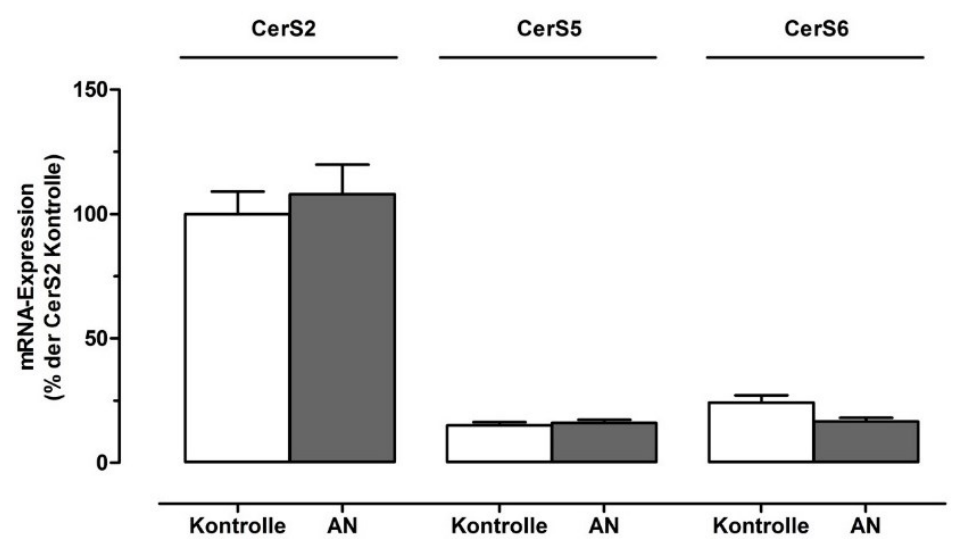

B

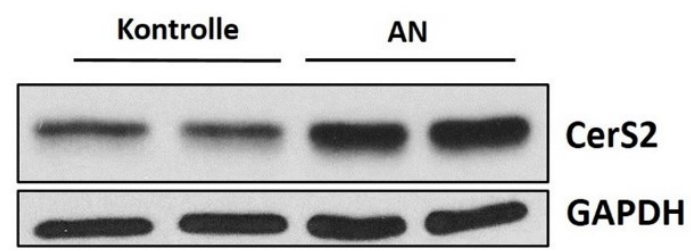

Abbildung 35: Ergebnis der Real-Time PCR und des Western Blots zur Bestimmung der Expression der Ceramidsynthasen in den fibrotischen und gesunden Nierenproben. $A$ : Es wurde die Expression von Ceramidsynthase 2 (CerS2), Ceramidsynthase 5 (CerS5) und Ceramidsynthase 6 (CerS6) gemessen. Die Expression in den Proben der Mäuse mit AN wurde in Relation zu der Expression in den Proben der Mäuse aus der Kontrollgruppe gesetzt und der Mittelwert \pm SEM abgebildet; $n=9$ (Kontrolle), $n=5$ (AN). B: Repräsentativer Western Blot zur Detektion der Proteinexpression von CerS2 (Bande bei ca. $38 \mathrm{kDa}$ ) und GAPDH als Referenzprotein.

\subsection{Die Rolle des Sphingosin-1-Phosphat-Transporters Spns2 im Kontext der Nierenfibrose}

In verschiedenen Arbeiten konnte bereits gezeigt werden, dass es Unterschiede zwischen der intra- und extrazellulären Wirkung von S1P gibt. Intrazellulär hemmt S1P die CTGF-Expression in renalen Zellen (Ren et al. 2009; Blanchard et al. 2018). Über eine Aktivierung der S1P-Rezeptoren hingegen fördert extrazelluläres S1P die Bildung von profibrotischem CTGF (Xin et al. 2004). Da S1P im Zytosol gebildet wird, ist ein aktiver Transport über die Plasmamembran zur Aktivierung der extrazellulären S1P. Rezeptoren notwendig. Neben dem möglichen Einfluss verschiedener ABCTransporter ist aus der Literatur bekannt, dass insbesondere Spns2 eine zentrale Rolle 
für den Transport und somit für die Lokalisation von S1P spielt (Mitra et al. 2006; Hisano et al. 2012; Liu et al. 2016).

\subsubsection{Die Genexpression der SK-1 und S1P-Lyase ist unverändert in Spns2 ${ }^{-/}$-Zellen im Vergleich zu Spns2 $2^{+/+}$ Zellen}

Zunächst wurde überprüft, ob der Knockout von Spns2 zu Veränderungen der Genexpression wichtiger Enzyme des Sphingolipidstoffwechsels unter fibrotischen Bedingungen führt. Die Expression der SK-1 wurde in Spns2---Zellen durch TFG- $\beta_{2}$ genauso stark induziert wie in den Spns $2^{+/+}$-Zellen (Abbildung 36). Die Genexpression der S1P-Lyase war ebenfalls in beiden Genotypen, unabhängig von der Stimulation mit TFG- $\beta_{2}$, nicht signifikant verändert. Die Expression von Spns2 war nach 16 Stunden Stimulation mit TFG- $\beta_{2}$ in den Spns $2^{+/+}$-Zellen unverändert im Vergleich zur unstimulierten Kontrolle. Die Spns2 $2^{-/}$-Zellen zeigten wie erwartet nur ein schwaches Hintergrundsignal in der RT-qPCR mit der Spns2-Sonde.
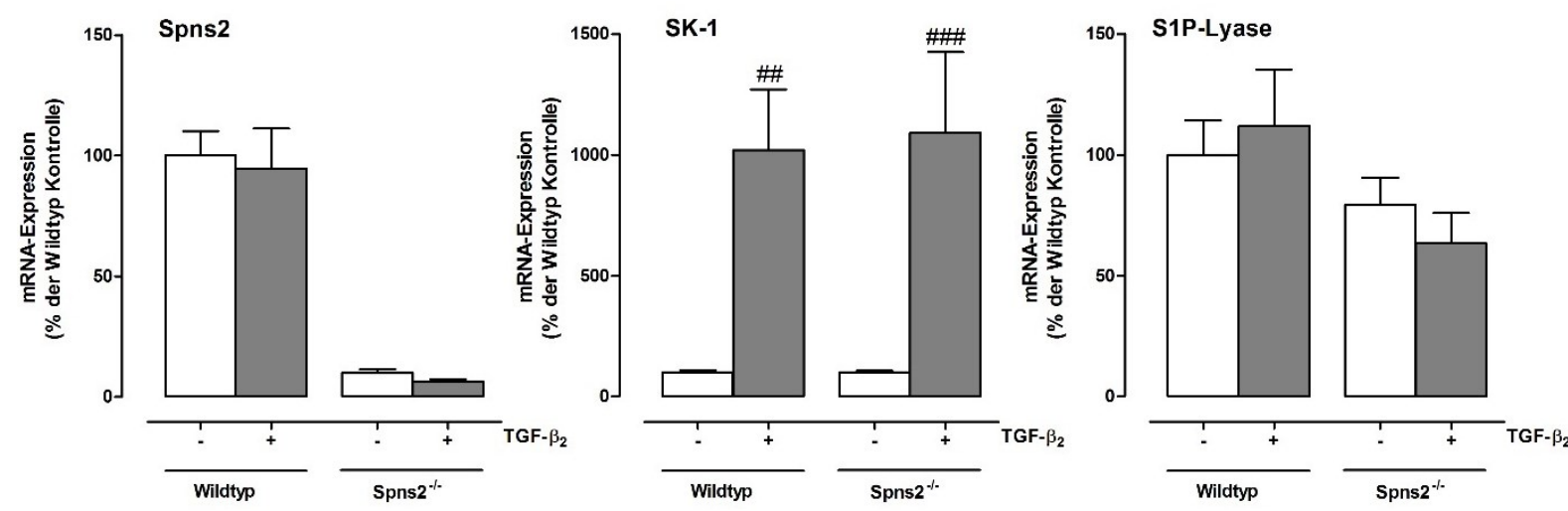

Abbildung 36: Genexpression von SK-1, Spns2 und S1P-Lyase in Mesangiumzellen der Maus. Die Zellen wurden für $16 \mathrm{~h}$ mit $5 \mathrm{ng} / \mathrm{ml}$ TFG- $\beta_{2}$ stimuliert. Mittels RT-qPCR wurden die mRNA-Level von SK-1, Spns2 und S1P-Lyase in Spns2 ${ }^{-{ }^{-}}$- und Spns $2^{+/+}$-mMC gemessen und ausgewertet. Abgebildet sind die Mittelwerte in Prozent der berechneten Konzentrationen \pm SEM; ${ }^{\#} p<0,01 ;{ }^{\# \#} p<0,001$ verglichen mit der unbehandelten Kontrolle; $n=10-12$ aus 3 unabhängigen Versuchen. 
In einem weiteren Schritt wurde untersucht, ob das Fehlen des S1P-Transporters Spns2 nach einer Stimulation mit TFG- $\beta_{2}$ zu einer Akkumulation von S1P in der Zelle führt. Die Auswertung der Ergebnisse aus den LC-ESI-MS/MS-Messungen zeigt, dass S1P in Spns2 $2^{-1-Z e l l e n ~ i m ~ V e r g l e i c h ~ z u ~ S p n s 2 ~}{ }^{+/+}$-Zellen nicht akkumuliert. Die relativen Mengen an Sphingosin pro Protein waren ebenfalls nicht unterschiedlich. Im Zellkulturüberstand konnte S1P nicht nachgewiesen werden, da die Konzentrationen unter dem Detektionslimit der LC-ESI-MS/MS-Messung lagen.
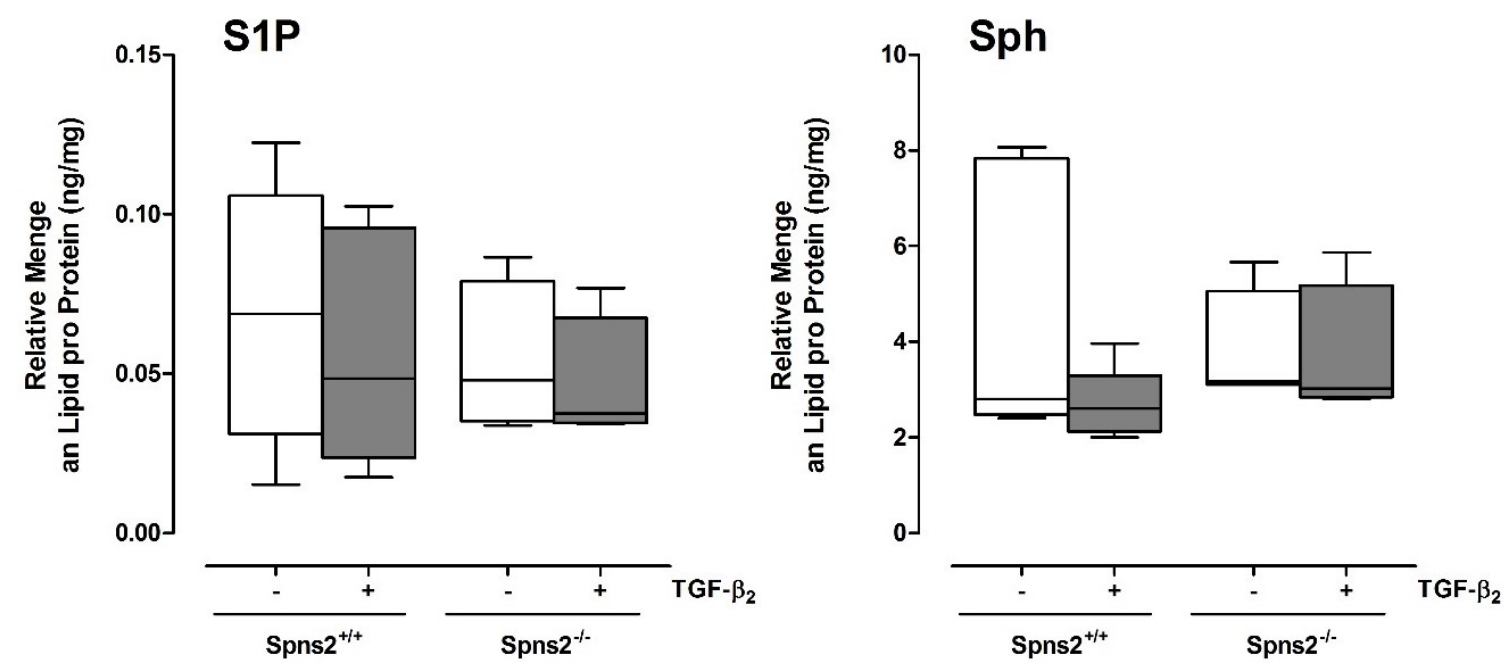

Abbildung 37: S1P und Sphingosinkonzentration in Mesangiumzellen der Maus. Mit Hilfe von Massenspektrometrie wurden die Konzentrationen der Sphingolipide in den Zellpellets ermittelt. Als Referenz wurde die Proteinmenge in Zelllysaten aus dem gleichen Versuch per Bradford bestimmt. Die Daten sind dargestellt als Box-Plots nach Tukey. Spns2 ${ }^{++}: n=6$; Spns2---: $n=4$. 


\subsubsection{Spns $2^{-1-}$-Zellen bilden weniger CTGF nach Stimulation mit TFG- $\beta_{2}$}

Ob sich das Fehlen des S1P-Transporters Spns2 auf die TFG- $\beta_{2}$-induzierte CTGFExpression auswirkt, wurde in Mesangiumzellen aus den Nieren von Spns2 ${ }^{-1-}$ und Spns $2^{+/+}$-Mäusen der Linie Swiss Webster untersucht. Die Zellen wurden in serumfreiem Medium mit $5 \mathrm{ng} / \mathrm{ml}$ TFG- $\beta_{2}$ stimuliert und die Proteinexpression von CTGF nach 24 und 48 Stunden sowohl im Zellkulturüberstand als auch in den Zelllysaten per Western Blot analysiert (Abbildung 38). Die CTGF-Expression stieg durch die Stimulation mit TFG- $\beta_{2}$ an und war sowohl in den Zelllysaten (CTGF Lysat) als auch im Zellkulturüberstand (CTGF ÜS) nachweisbar. Die gebildete Menge an CTGF war im Zelllysat und Zellkulturüberstand der Spns $2^{+/+}-\mathrm{mMC}$ sowohl nach 24 Stunden als auch nach 48 Stunden stets höher im Vergleich zu den Spns2-/--mMC.

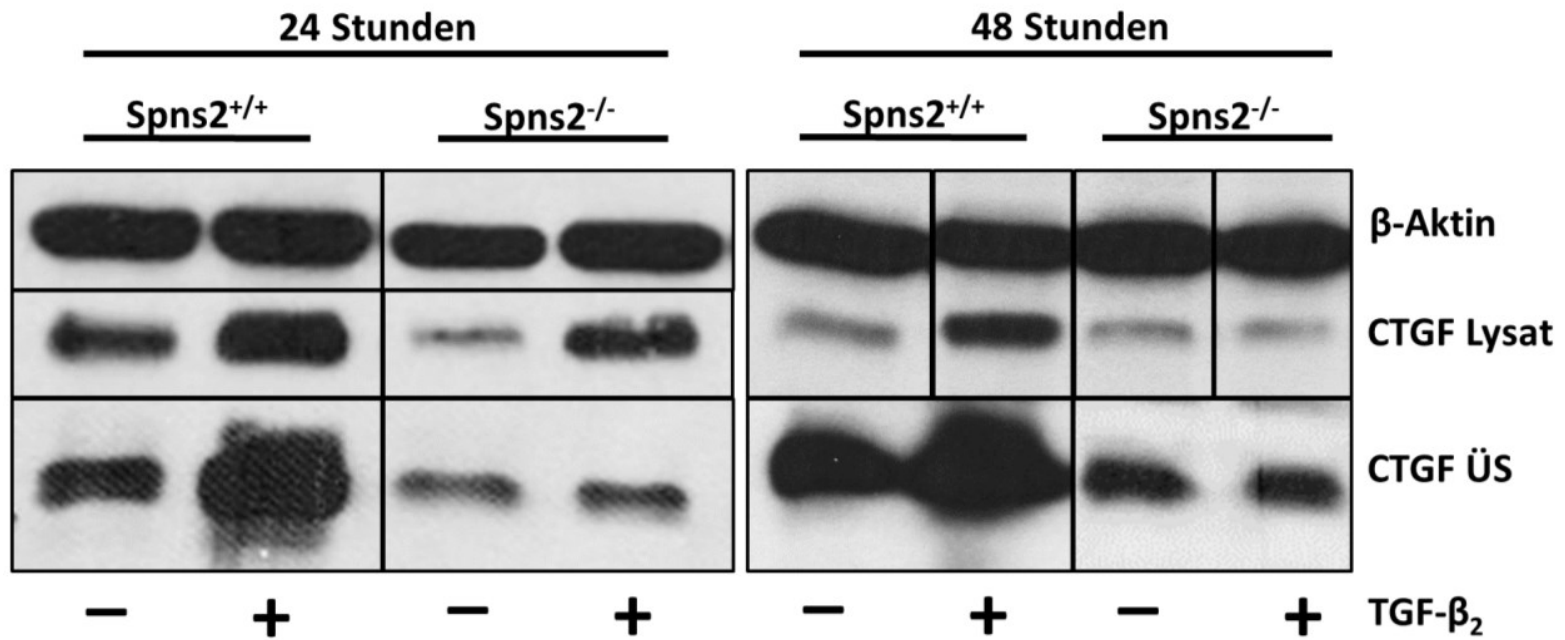

Abbildung 38: CTGF-Expression in Mesangiumzellen der Maus. Ruhende Mesangiumzellen aus Spns2 ${ }^{-/}-$und Spns2 ${ }^{+/+}$-Mäusen wurden für die angegebenen Zeiten mit $5 \mathrm{ng} / \mathrm{ml}$ TFG- $\beta_{2}$ stimuliert. Die Expressionen von CTGF und des Haushaltsgens $\beta$-Aktin wurden mittels Western Blot nachgewiesen. 


\section{Diskussion}

\subsection{Untersuchung der Rolle des Sphingosin-1-Phosphat Rezeptors $5\left(\mathrm{~S}_{1} \mathrm{P}_{5}\right)$ in fibrotischen Nierenerkrankungen}

In der vorliegenden Arbeit wurde ein Mausmodell zur tubulointerstitiellen Fibrose angewendet, um eine mögliche Rolle von $\mathrm{S} \mathrm{P}_{5}$ in Nierenerkrankungen zu untersuchen, da $\mathrm{S}_{1} \mathrm{P}_{5}$ bereits in vitro eine profibrotische Wirkung in humanen Mesangiumzellen zeigte (Wünsche et al. 2015). Zudem konnten mehrere Studien durch die Verwendung von funktionellen S1P-Rezeptorantagonisten und auch mittels S1P ${ }_{3}$-defizienten Mäusen einen schützenden Effekt in fibrotischen Nierenmodellen erreichen. So zeigte beispielsweise die Verwendung von Fingolimod, welches an alle S1P-Rezeptoren außer $\mathrm{S}_{1} \mathrm{P}_{2}$ bindet, bei der Thy1.1-induzierten mesangioproliferativen Glomerulonephritis, bei Antikörper-induzierter membranöser Glomerulonephritis, bei Adriamycin-induzierter Glomerulosklerose und interstitieller Fibrose, bei Albuminüberschuss-induzierter als auch bei 5/6-Nephrektomie-induzierter tubulointerstitieller Fibrose und bei Streptozotozin-induzierter DN bei Ratten einen milderen Krankheitsverlauf (Peters et al. 2004; Martini et al. 2007; Awad et al. 2011; Sui et al. 2012; Ni et al. 2013; Xu et al. 2014; Yazdani et al. 2015). Doch auch in Mausmodellen zur Untersuchungen von tubulointerstitiellen Fibrose hervorgerufen durch UUO und auch bei akutem Nierenschaden, induziert durch einen Ischämie-Reperfusionsschaden oder Cisplatin, konnte ein geringerer Nierenschaden durch die Behandlung mit Fingolimod erreicht werden (Bajwa et al. 2010; Shobha et al. 2014; Bajwa et al. 2015).

Als Nächstes wurden Entzündungsgeschehen im Gewebe untersucht und festgestellt, dass die Genexpression von proinflammatorischen Zytokinen in den Nieren aus den S1 $\mathrm{P}_{5}^{-1-}$-Mäusen im AN-Modell signifikant geringer war als in den Wildtypmäusen. Da diese Zytokine von infiltrierten oder lokal proliferierten Immunzellen gebildet werden können, wurden die Nieren auf mononukleäre Phagozyten, ein Sammelbegriff für Makrophagen und dendritische Zellen, untersucht (Gottschalk und Kurts 2015). Es wurde bereits in mehreren Studien gezeigt, dass mononukleäre Phagozyten in großer Zahl in entzündeten Nieren auftreten und innen eine wichtige Rolle für den Krankheitsverlauf zukommt (Yang et al. 1998; Eardley et al. 2006; Duffield 2010; Weisheit et al. 2015; Klessens et al. 2017). Zusätzlich wurde beobachtet, dass S1P5 $5^{-1-}$ 
-Mäusen periphere Ly6C--Monozyten fehlen, welche Vorgänger von bestimmten Populationen geweberesidenter Makrophagen sein können (Geissmann et al. 2003; Debien et al. 2013). Die proinflammatorischen Ly6C+-Monozyten hingegen

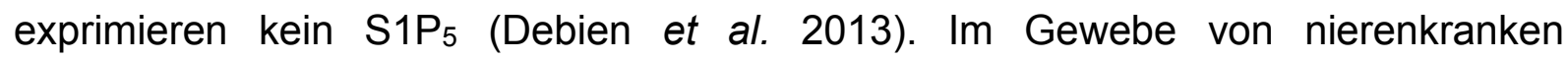
Wildtypmäusen und $\mathrm{S}_{15_{5}}{ }^{-/}$-Mäusen wurde eine große Anzahl von $\mathrm{F} 4 / 80^{+}$-Zellen gefunden. F4/80 ist ein vielfach verwendeter Marker für mononukleäre Phagozyten (Cao et al. 2015; Gottschalk und Kurts 2015; Anjos Cassado et al. 2017). Mit Hilfe eines Antikörper-basierten Nachweises wurde ein signifikanter Anstieg von F4/80+Zellen nach 14 Tagen im AN-Modell bei S1 F $^{-1-}$-Mäusen, jedoch nicht bei Wildtypmäusen, festgestellt, was vermutlich durch die geringe Probenzahl bedingt war. Auf mRNA-Ebene wurde hingegen ein 6-facher Anstieg von Adgre1, dem Gen von F4/80, nach 14 Tagen im AN-Modell sowohl bei S1 $\mathrm{P}_{5}^{-1-}$-Mäusen als auch bei Wildtypmäusen gemessen.

Obwohl die Anzahl der Immunzellen in den kranken Geweben der S1 $\mathrm{P}_{5}^{-1-}$-Mäuse nicht niedriger war als in den Wildtypen, wurden jedoch signifikant geringere mRNA-Mengen von proentzündlichen Zytokinen wie Interleukin-6 (IL-6) und Tumornekrosefaktor- $\alpha$ (TNFa) gemessen. Diese Zytokine können unter anderem von Makrophagen in Reaktion auf entzündliche Prozesse sezerniert werden (Arango Duque und Descoteaux 2014). Hinzu kommt, dass auch die mRNA-Mengen von Mcp-1 (Ccl2), ein Chemokin, das Monozyten anlockt, signifikant niedriger in den Nieren von S1 $\mathrm{P}_{5}^{-1-}$ Mäusen gegenüber Wildtypen waren (Leonard und Yoshimura 1990). Die mengenmäßigen Unterschiede von Zytokinen zwischen S1P-1--Mäusen und Wildtypmäusen könnte durch geringe Aktivierung von Immunzellen oder auch durch Zellen des tubulären Systems bedingt sein, welche ebenfalls in der Lage sind, proentzündliche Zytokine freizusetzen (Daha und van Kooten 2000). So wurde bereits in einer Studie gezeigt, dass die Verwendung des S1P1-spezifischen Agonisten SEW2871 zu einer Verringerung der Expression von proinflammatorischen Zytokinen im Mausmodell der DN führte, obwohl die Anzahl der Lymphozyten in der Niere genauso hoch war, wie in den unbehandelten diabetischen Mäusen (Awad et al. 2011).

Über die Rolle von $\mathrm{S} \mathrm{P}_{5}$ in (differenzierten) Monozyten ist bisher kaum etwas bekannt, doch konnte seine Expression auf einigen Subtypen nachgewiesen werden (Duong et al. 2004; Debien et al. 2013; Barnawi et al. 2015). Es wurde berichtet, dass eine 
Antagonisierung von $\mathrm{S} \mathrm{P}_{5}$ durch Suramin, ein Antiprotozoikum, das zur Behandlung der Schlafkrankheit eingesetzt wird, die Phagozytose von alveolaren Makrophagen verbessert werden konnte (Barnawi et al. 2015). Übertragen auf unser Modell könnte das Fehlen von ${\mathrm{S} 1 \mathrm{P}_{5}}_{5}$ die Aktivierung des Inflammasoms, ausgelöst durch Phagozytose von Kristallen im Nierengewebe, unterbunden haben, weshalb die Entzündungsreaktion schwächer ausfiel (Kim et al. 2015). Die mRNA-Expression von NLRP3, einer Komponente des Inflammasoms, war genauso hoch in den S1P $5^{-1}$ Mäusen wie in den Wildtypmäusen, weshalb die Aktivierung des Inflammasoms daraufhin anhand der Sekretion von IL-1 $\beta$ untersucht wurde (Rajamäki et al. 2010). Die mRNA-Expression von IL-1 $\beta$ war mehr als doppelt so hoch in Wildtypmäusen nach 14 Tagen im AN-Modell im Vergleich $z u$ den S1 $\mathrm{P}_{5}^{-/-}$-Mäusen. Dass eine pharmakologische Inhibierung der Aktivierung von NLRP3 in Mäusen oder die Verwendung von NLRP3 ${ }^{-/}$-Mäusen zu einer milderen Ausprägung der Fibrose im ANModell führt, wurde bereits gezeigt (Ludwig-Portugall et al. 2016).

Dass S1P eine wichtige Rolle für die Infiltration von Immunzellen in das Gewebe spielt, wurde bereits intensiv erforscht und es wurde eine immunsupprimierende Wirkung der Blockade der S1P-Rezeptoren festgestellt (Brinkmann et al. 2004; Lai et al. 2007; Chun und Hartung 2010; Imeri et al. 2015; Glaenzel et al. 2018). Bis heute sind bereits zwei Medikamente, Fingolimod und Siponimod für die Behandlung der schubförmig verlaufenden Multiplen Sklerose auf dem Markt (Sharma et al. 2011; Al-Salama 2019). Obwohl die immunsupprimierende Wirkung hauptsächlich der Internalisierung und dem Abbau von S1P1 zugeschrieben wird, ist es interessant zu beobachten, dass beide Medikamente auch $\mathrm{S}_{1} \mathrm{P}_{5}$ antagonisieren (Brinkmann et al. 2004; Lai et al. 2007; Allende et al. 2010). Eine verminderte Infiltrierung des Nierengewebes durch Immunzellen konnten wir in den Nierengeweben der $\mathrm{S}_{15_{5}}{ }^{-/}$-Mäuse nicht feststellen, was zu den zuvor beschrieben Ergebnissen aus der Literatur passt, wonach S1P 1 für die chemotaktische Wirkung von S1P verantwortlich ist. Zudem wurde auch kein signifikanter Unterschied in der Genexpression der anderen S1P-Rezeptoren zwischen den S1 $\mathrm{P}_{5}{ }^{-1-}$-Mäusen und den Wildtypmäusen festgestellt. 
Es wurde herausgefunden, dass ${\mathrm{S} 1 \mathrm{P}_{5}}_{5}$ sowohl in vitro als auch in vivo eine entscheidende Rolle für die Wanderung der natürlichen Killerzellen einnimmt (Walzer et al. 2007; Mayol et al. 2011; Drouillard et al. 2018). In dem von uns verwendeten Tiermodell wurde jedoch keine Infiltration von natürlichen Killerzellen sowohl in Nierengeweben aus Wildtypen als auch aus $\mathrm{S} \mathrm{P}_{5^{-1}}$-Mäusen festgestellt. Auch die Ergebnisse zu mRNA-Spiegeln von Oberflächenmarkern anderer Immunzellen zeigten in dem AN-Modell keine Unterschiede zwischen Wildtypen und S1P $5^{-1-}$-Mäusen.

Im Plasma der kranken Wildtypmäuse haben wir geringere Konzentrationen von S1P und Sphingosin im Vergleich zu den gesunden Kontrollen gemessen. Dieser Abfall war in den kranken S1 $\mathrm{P}_{5}^{-1-}$-Mäusen nicht zu beobachten. Die mRNA-Expression der SK-1 war hingegen in Mäusen beider Genotypen durch das AN-Modell in den Nieren stark erhöht und es konnte auch eine Analyse von anderen Enzymen des Sphingolipidstoffwechsels kein Befund erhoben werden, der diesen Unterschied erklären könnte. Geringere S1P-Konzentrationen im Plasma wurden aber auch bei Patienten mit Makroalbuminurie gegenüber Patienten mit normaler Nierenfunktion gemessen (Bekpinar et al. 2015). Bei Kindern, die unter chronischer Niereninsuffizienz litten, wurden hingegen höhere S1P-Spiele gemessen (Benito et al. 2018).

Die Expression verschiedener Fibrosemarker war in den Nieren der S1 $\mathrm{P}_{5^{-1}}$-Mäuse im AN-Modell signifikant niedriger gegenüber den Wildtypen. Ein Grund für die unterschiedliche Expression von profibrotischen Genen könnte der unterschiedliche Gewebeschaden in den Nieren sein, der in den S1 $\mathrm{P}_{5}^{-{ }^{-}}$-Mäusen milder ausfiel als in den Wildtypen. Doch in humanen Mesangiumzellen ist $\mathrm{S}_{1} \mathrm{P}_{5}$ notwendig für eine TGF$\beta_{2}$-induzierte CTGF-Expression, was auch in den Mäusenieren der Grund für die mildere Fibrose sein könnte (Wünsche et al. 2015). Welche Zellen in der Niere für die antifibrotische Wirkung von $\mathrm{S}_{1} \mathrm{P}_{5}$ verantwortlich waren, konnte hier jedoch nicht abschließend geklärt werden, da S1P 5 auf mRNA-Ebene nur in geringen Mengen in der Niere exprimiert wurde und keine verlässlichen Antikörper für eine Detektion mittels Western Blot zur Verfügung standen.

Eine kürzlich veröffentlichte Studie zeigte, dass eine Herunterregulation von S1 $\mathrm{P}_{5}$ die Migration und Proliferation einer Tumorzelllinie aus dem Kolon über die Inhibierung von NF-KB reduzierte (Zhou et al. 2020). Dass die Inhibierung von NF-KB zur Linderung 
von Entzündungen und Fibrose in der Niere führt, wurde bereits in mehreren Studien gezeigt (Tashiro et al. 2003; Esteban et al. 2004; Panzer et al. 2009; Wang et al. 2015). Mit Hilfe eines Mausmodells konnte die Gruppe um Zhou zudem belegen, dass die Herunterregulation von $\mathrm{S}_{1} \mathrm{P}_{5}$ die Tumorgröße reduziert und eine Hochregulation von $\mathrm{S}_{1} \mathrm{P}_{5}$ das Tumorwachstum fördert (Zhou et al. 2020). In diesem Zusammenhang wäre es daher interessant, auch die Rolle von NF-KB in dem AN-Modell mit S1 $\mathrm{P}^{-{ }^{-1}-\text { Mäusen }}$ zu untersuchen.

Diese neuen Ergebnisse zeigen, dass $\mathrm{S}_{1} \mathrm{P}_{5}$ ein interessanter Rezeptor ist, der weiter erforscht werden muss. Die Inhibierung des S1P5-Signalwegs scheint ein vielversprechendes Ziel für die Behandlung von Entzündungen und Fibrose in der Niere zu sein. Besonders greifbar wird diese Vision dadurch, dass mit Siponimod bereits ein S1P5-Antagonist auf dem Markt ist. Mit dem von AbbVie entwickelten S1P F- $_{5}$ spezifischen Antagonisten A-971432 können hierzu spezifische Studien durchgeführt werden (Di Pardo et al. 2018).

\subsection{Untersuchung der Veränderungen von kettenlängen- spezifischen Ceramiden in fibrotischen Nieren}

Veränderungen in den Konzentrationen von bestimmten Ceramiden wurden bereits bei Patienten mit verschiedenen Krankheiten beobachtet. Aufgrund der schlechten Verfügbarkeit von geeigneten Gewebeproben wurde in den meisten Studien lediglich die Veränderungen im Plasma und Serum analysiert (Cutler et al. 2004; Haus et al. 2009; Kajander et al. 2009; Brodlie et al. 2010; Brunkhorst et al. 2015; Patyna et al. 2019).

Eine Studie, die den Zusammenhang zwischen Ceramiden im Plasma und dem Risiko für Herzversagen untersuchte, zeigte eine positive Korrelation von langkettigen Ceramiden, aber eine negative Korrelation von sehr langkettigen Ceramiden mit dem Risiko von Herzversagen (Lemaitre et al. 2019). In einer anderen Studie konnte gezeigt werden, dass die Unterbindung der Synthese von sehr langkettigen Ceramiden durch Genknockout der Serin-Palmitoyl-Transferase 2 zu kardialen Dysfunktionen führte (Lee et al. 2012). 
Eine Studie zu cystischer Fibrose veranschaulichte, welche Veränderungen in den Konzentrationen der Ceramide im Plasma von Patienten gegenüber gesunden Probanden stattfinden und welche Rolle die Ceramide in einem Mausmodell für cystische Fibrose spielen (Guilbault et al. 2008). Patienten, die an cystischer Fibrose litten, hatten signifikant niedrigere Konzentrationen von sehr langkettigen Ceramiden im Plasma. Zusätzlich konnte die Gruppe zeigen, dass $\mathrm{Cftr}^{-1}$-Mäuse (cystic fibrosis transmembrane conductance regulator gene), die für das Mausmodell einer cystischen Fibrose eingesetzt wurden, ebenfalls geringere Konzentrationen an Ceramiden als Wildtypen aufwiesen und auch schon vor einer Infektion eine höhere Immunzellinfiltration und Fibrose zeigten. Wurden die Mäuse mit Pseudomonas infiziert und zusätzlich mit Fenritinid, ein Retinoidderivat zur Behandlung von Tumoren und cystischer Fibrose, das zur Akkumulation von Ceramiden im Gewebe führt, behandelt, konnte die Anzahl der Bakterien in den $\mathrm{Cftr}^{-}$-Mäusen auf das Niveau in den Wildtypen reduziert werden (Wu et al. 2001; Guilbault et al. 2008). Eine weitere Studie belegte, dass $\mathrm{Cftr}^{-}-$-Mäuse weniger sehr langkettige Ceramide aber mehr langkettige Ceramide in der Lunge und im Plasma akkumulieren (Garić et al. 2017). CerS2-1-Mäuse, welche ebenfalls weniger der sehr langkettigen Ceramide Cer d18:1/24:0 und Cer d18:1/24:1 und dafür mehr des langkettigen Ceramids Cer d18:1/16:0 aufwiesen, hatten entzündete und vergrößerte Lungen (Petrache et al. 2013).

In Colitis ulcerosa-Patienten wurden ebenfalls Veränderungen von bestimmten Sphingolipiden im Darmgewebe festgestellt, die mit einer verminderten de novo Synthese, bedingt durch posttranslationale Modifikationen der Serin-Palmitoyl-Transferase und Ceramidsynthasen, begründet wurden (Bazarganipour et al. 2019). So waren in den Patientenproben, die sehr langkettigen Dihydroceramide signifikant niedriger im Vergleich zu den Kontrollgeweben.

In einigen der Studien wurde ein Anstieg von langkettigen und sehr langkettigen Ceramiden im Plasma von Patienten gemessen, die an Nierenerkrankungen wie LN oder DN litten (Haus et al. 2009; Galadari et al. 2013; Mitsnefes et al. 2014; Checa et al. 2017; Patyna et al. 2019). So konnten wir bereits zeigen, dass Cer d18:1/24:1 im Plasma und Serum von Patienten mit LN signifikant erhöht war, sowohl im Vergleich zu gesunden Kontrollen als auch im Vergleich zu Patienten, die an SLE ohne Nierenbeteiligung litten (Patyna et al. 2019). 
Eine altersbedingt veränderte Ceramidkonzentration demonstrierte eine andere Studie und fand erhöhte Konzentrationen von Cer d18:1/24:1 im Serum von 75-90 Jahre alten Frauen gegenüber 24-40 Jahre alten Frauen, sowie im Serum von alten gegenüber jungen Affen (Khayrullin et al. 2019). Jedoch ist bekannt, dass die Nierenfunktion mit dem Alter stetig abnimmt (Shlipak et al. 2009; Denic et al. 2016).

Es stellt sich dennoch die Frage, ob Ceramide als Biomarker für bestimmte Krankheiten geeignet sind. Da offensichtlich verschiedene Erkrankungen in unterschiedlichen Organen eine Veränderung von Ceramiden im Plasma und Serum hervorrufen können, erscheint eine eindeutige Zuordnung ausschließlich anhand der Analyse von Ceramiden im Plasma unrealistisch. Jedoch könnte das Ceramidprofil im Plasma eines Patienten mit bisherigen Daten verglichen und dadurch weitere spezifische diagnostische Verfahren durchgeführt werden. Über die genaue Funktion und Ursachen für die Veränderungen von bestimmten Ceramiden im Blut und den Geweben ist bisher wenig bekannt, weshalb Untersuchungen, wie sie in dieser Arbeit vorliegen, wichtig sind, um die Zusammenhänge zu entschlüsseln. Im Gegensatz zu dem bioaktiven Lipidmediator S1P, welcher von Erythrozyten und Thrombozyten aktiv über spezifische Transporter sezerniert werden kann, gelangen Ceramide wohl hauptsächlich durch extrazelluläre Vesikel wie Exosomen ins Blut (Hänel et al. 2007; Vu et al. 2017; Khayrullin et al. 2019). Aus diesem Grund ist es notwendig, die Veränderungen von Ceramiden in erkrankten Geweben zu untersuchen, um den Wissensstand von Korrelationen hin zu Kausalitäten voranzubringen. Somit können auch Mechanismen identifiziert werden, die als Ziele für pharmakologische Modulationen zur Verbesserung des Krankheitsbildes genutzt werden können.

Veränderungen der Sphingolipide im Nierengewebe von Patienten mit Nierenerkrankungen waren bisher jedoch kaum Gegenstand der Forschung. Deshalb wurde in dieser Studie untersucht, ob sich die Ceramidspiegel im Nierengewebe in Gegenwart einer Fibrose, dem wichtigen Kennzeichen nahezu aller chronischen Nierenerkrankungen, im Vergleich zu gesunden Kontrollen verändern. 
Tatsächlich wurden Unterschiede bei bestimmten Ceramiden zwischen gesundem und fibrotischem Nierengewebe von Patienten gefunden. Diese Effekte konnten auch in zwei Mausmodellen, wie dem hier beschriebenem Modell zur AN und im Modell der UUO, welche von den Kolleginnen Dr. Stephanie Schwalm und Dr. Sandra Beyer durchgeführt wurden, reproduziert werden. Die Konzentrationsspiegel der sehr langkettigen Ceramide Cer d18:1/24:0 und Cer d18:1/24:1 waren signifikant niedriger im fibrotischen Nierenkortex der Patienten im Vergleich zu den gesunden Kontrollgeweben. Andere Ceramidspezies, wie die langkettigen Ceramide und sehr langkettigen Dihydroceramide, waren hingegen nicht in ihrer Konzentration im fibrotischen Nierenkortex gegenüber dem gesunden Gewebe verändert. Die spezifische Reduktion der sehr langkettigen Ceramide wurde ebenfalls im entzündeten und fibrotischem Nierengewebe der Mäuse, die an einer AN litten, nachgewiesen. Dies spricht dafür, dass es sich nicht um eine allgemeine Reduktion aller Ceramide im Gewebe handelt.

Die Ursache für diese konsistenten Veränderungen der Ceramide im Nierengewebe aus Menschen und Mäusen kann an dieser Stelle nicht abschließend geklärt werden. Ein Einfluss des Alters auf die Ceramidkonzentrationen scheint zumindest ausgeschlossen. So haben Eum et al. (2020) keine Unterschiede in den Ceramidspiegeln im Nierengewebe von 4 und 25 Monate alten Mäusen festgestellt. Interessant wäre zudem auch, die Zusammensetzung der Sphingomyeline in Bezug auf kettenlängenspezifische Unterschiede zu messen, denn Ceramide werden auch aus der Spaltung von Sphingomyelin mittels Sphingomyelinasen gebildet, wodurch ein Einfluss denkbar ist.

Unter den vielen Enzymen des Sphingolipidstoffwechsels wurde eine Substratspezifizität bezüglich unterschiedlicher Kettenlänge der Fettsäurereste bisher jedoch nur bei den Ceramidsynthasen bestätigt (Levy und Futerman 2010b). Die sechs verschiedenen Ceramidsynthasen der Säugetiere sind unterschiedlich stark exprimiert in den verschiedenen Geweben. In den Nieren der Mäuse wird vor allem die CerS2 und in geringeren Mengen noch CerS5 und CerS6 exprimiert (Laviad et al. 2008). Diese Befunde konnten wir durch Messung von 5- bis 6-fach höheren mRNA-Spiegeln von CerS2 gegenüber CerS5 und CerS6 bestätigen, welche die Synthese von Cer d18:1/16:0 katalysieren (Levy und Futerman 2010b). Die CerS2 bevorzugt für die Katalyse sehr langkettige Acyl-CoA-Moleküle zur Bildung von Cer d18:1/22:0 bis hin zu 
Cer d18:1/26:0 (Laviad et al. 2008; Pewzner-Jung et al. 2010). Menschliche Nieren zeigen ein ähnliches Expressionsmuster mit CerS2 als die am stärksten exprimierte Ceramidsynthase und geringer Expression von CerS4-6 (Uhlén et al. 2015). In unserer Studie konnten wir auf mRNA-Ebene keine Unterschiede in der Expression von CerS2, CerS5 und CerS6 in den Nierengeweben aus den erkrankten im Vergleich zu den gesunden Mäusen messen. Die mRNA-Expression spiegelt jedoch nicht die Translation und Aktivität der Ceramidsynthasen wider, welche durch Dimerisierung, Bindung von S1P, BAK oder miRNAs beeinflusst werden kann (Siskind et al. 2010; Matanes et al. 2019). So wurde gezeigt, dass die Aktivität von CerS2 von der Bildung von Heterodimeren mit CerS4, CerS5 oder CerS6 abhängt (Laviad et al. 2012). Zudem ist CerS2 die einzige Ceramidsynthase, bei der eine Bindestelle für S1P nachgewiesen worden ist, welche zur Inhibierung des Enzyms führt (Laviad et al. 2008). Deshalb ist es möglich, dass die beobachteten Unterschiede in den Ceramiden auf die Ceramidsynthasen zurückzuführen sind, obwohl sowohl die mRNA- als auch die Proteinexpression der CerS2 in den AN Mäusen nicht geringer war im Vergleich zu den gesunden Kontrollen. Die zugehörigen sehr langkettigen Dihydroceramide, welche ebenfalls durch die Ceramidsynthasen gebildet werden, wiesen keinen Unterschied zwischen den kranken und den gesunden Nierenbiopsien auf. Es gilt jedoch zu beachten, dass die Dihydroceramide in deutlich geringerer Konzentration als die sehr langkettigen Ceramide in der Niere vorliegen und sie lediglich im ER als Zwischenschritt zur Ceramidsynthese aus Sphinganin und Acyl-CoA entstehen (Rother et al. 1992). Die Ceramide hingegen sind zudem noch im Golgi-Apparat, in der Plasmamembran, insbesondere in ceramidreichen Plattformen, und in Lysosomen zu finden und können neben der de novo-Synthese im ER aus den Dihydroceramiden auch noch über die Ceramidsynthasen aus Sphingosin und Acyl-CoA oder aus der Spaltung von Sphingomylein gebildet werden (Grösch et al. 2012). Somit können die Veränderungen in den Ceramiden durch unterschiedliche Enzyme in verschiedenen Organellen bedingt sein.

Besonders interessant für diese Studie ist, dass langkettige Ceramide (C12-C18) generell als proapoptotisch angesehen werden, während sehr langkettige Ceramide (C20-C26) Apoptose verhindern können (Grösch et al. 2012). Da Apoptose ein stets auftretendes Phänomen bei Hydronephrose und Pyelonephritis darstellt, steht der Verlust von sehr langkettigen Ceramiden in der Niere in den Biopsien der Patienten im Einklang 
mit ihren antiapoptotischen Eigenschaften (Sung et al. 2000; Yoo et al. 2006). In diesem Zusammenhang wäre es interessant herauszufinden, ob und wie sich der Verlauf einer renalen Fibrose in Ceramidsynthase-Knockout-Mäusen in einem Tiermodell gegenüber Wildtyp-Tieren ändert.

Wir konnten zeigen, dass sehr langkettige Ceramide in der Niere von Menschen und Mäusen höher konzentriert sind als langkettige Ceramide. Die Mediane von Cer d18:1/24:0 und Cer d18:1/24:1 waren in menschlichen Nieren 4-mal höher in der Nierenrinde und 2-mal höher im Nierenmark im Vergleich zu dem am häufigsten vorkommenden langkettigen Ceramid Cer d18:1/16:0. Nur in Mäusen zeigte Cer d18:1/16:0 vergleichbar hohe Werte wie Cer d18:1/24:0. In den Messungen von Laviad et al. war Cer d18:1/16:0 sogar das häufigste Ceramid in den Mäusenieren (Laviad et al. 2008). Im Gegensatz zu den Gegebenheiten im menschlichen Nierengewebe war Cer d18:1/16:0 auch in fibrotischen Mäusenieren im Vergleich zu den gesunden signifikant reduziert. Dieser Unterschied ist also eventuell bedingt durch die stark unterschiedlichen Konzentrationen von Cer d18:1/16:0 im humanen und murinen Nierengewebe.

Im Gegensatz zur Reduktion von bestimmten Ceramiden in fibrotischem Nierengewebe, wie wir es in unserer Studie beobachtet haben, wurde andererseits gezeigt, dass ein Cisplatin-induzierter akuter Nierenschaden zu einem Anstieg der Konzentrationen von einigen langkettigen und sehr langkettigen Ceramiden (Cer d18:1/16:0, Cer d18:1/20:0, Cer d18:1/24:1, Cer d18:1/26:0) und deren zugehörigen Hexosylceramiden in der Nierenrinde von C57BL/6J Mäusen führte (Dupre et al. 2017). Des Weiteren vermuteten die Autoren, dass eine Unterbindung der Bildung von Hexosylceramiden aus Ceramiden Gewebeschaden, Inflammation und Apoptose verstärkte. Eine Unterscheidung zwischen der Akkumulation von langkettigen im Verhältnis zu sehr langkettigen Ceramiden wurde in der Studie nicht weiter erörtert. Es ist aber wahrscheinlich, dass der Anstieg des proapoptotischen Cer d18:1/16:0 den Krankheitsverlauf stärker beeinflussen konnte als jener, der sehr langkettigen antiapoptotischen Ceramide. Zudem ist bekannt, dass Cisplatin den Anstieg von Ceramiden in direkter Weise bewirkt, wohingegen in unserem Modell die Veränderungen der Ceramide intrinsisch durch den Krankheitsverlauf bedingt wurden (Noda et al. 2001; Rebillard et al. 2007). 
Da wir in unserer Studie Gesamtnierenhomogenisate der Maus verarbeitet haben, war eine Differenzierung zwischen Nierenkortex und Nierenmark, wie es bei den humanen Biopsien gegeben war, nicht möglich. Auffallend war, dass die Ceramidspiegel sich im fibrotischen gegenüber dem gesunden humanen Nierenmarkgewebe nicht unterschieden. Es wurde jedoch auch kein signifikanter Anstieg von fibrotischen Markern in den Nierenmarkproben gemessen, selbst wenn diese fibrotischen Marker in den zugehörigen Proben aus dem Bereich der Nierenrinde signifikant exprimiert waren im Vergleich zu den Kontrollproben. Ob der Abfall der sehr langkettigen Ceramide ein spezifisches Phänomen in der Nierenrinde darstellt, bleibt daher offen. Hinzu kommt, dass die Konzentrationen der sehr langkettigen Ceramide in den Proben aus gesundem Nierenmark viel geringer waren als in den Proben aus gesunder Nierenrinde. Es ist daher davon auszugehen, dass bestimmte Zellen aus der Nierenrinde, zum Beispiel Mesangiumzellen aus den Glomerula, in besonderem Maße Ceramide akkumulieren.

Zusammengefasst konnten wir in dieser Studie zeigen, dass ein Abfall der Konzentrationen von sehr langkettigen Ceramiden mit renaler Fibrose in Menschen und Mäusen einhergeht. Somit ist davon auszugehen, dass in beiden Spezies ähnliche Mechanismen ablaufen und folglich Mausmodelle ein geeignetes Mittel zur Untersuchung von Ceramiden im Hinblick auf die involvierten Enzyme im Kontext von Nierenerkrankungen darstellen. Die Studie wirft interessante Fragen hinsichtlich der Funktion und der Folgen einer Manipulation der Enzyme des Ceramidstoffwechsels auf, welche in weiteren Studien untersucht werden sollten.

\subsection{Die Rolle des Sphingosin-1-Phosphat-Transporters Spns2 im Kontext der Nierenfibrose}

Die Stimulation von Spns2--- und Spns2 $2^{+/+}-m M C$ mit TFG- $\beta_{2}$ zeigte, dass Spns2 die Expression von CTGF über einen längeren Zeitraum aufrechterhält. Diese Wirkung wurde auch durch eine RNAi-vermittelte Herunterregulation von Spns2 in einer humanen proximalen Tubuluszelllinie nachgewiesen, welche zur verminderten Expression von CTGF und Fibronektin nach Stimulation mit TFG- $\beta_{2}$ führte (Blanchard et al. 2018). In den ersten Stunden nach der Stimulation mit TFG- $\beta_{2}$ war die Expression von CTGF in den hier verwendeten mMC beider Genotypen gleich. Dies erscheint 
schlüssig, da TFG- $\beta_{2}$ über Smads direkt die Expression von CTGF induziert (Meng et al. 2016). Darüber hinaus induziert der Wachstumsfaktor aber auch die Expression der SK-1 (Yamanaka et al. 2004). Über die SK-1 wird vermehrt S1P gebildet, welches über den Transporter Spns2 aus der Zelle geschleust werden kann (Hisano et al. 2012). Dadurch kann S1P autokrin und auch parakrin die S1P-Rezeptoren in den Zellmembranen aktivieren, was ebenfalls zur Expression von CTGF führen kann (Li et al. 2008; Cheng et al. 2018). Wird das gebildete S1P jedoch nicht ausgeschleust, kann es im Zellkern die Expression von CTGF hemmen (Ren et al. 2009). Dieser Effekt war in den durchgeführten Versuchen nach 24 Stunden zu erkennen und besonders deutlich nach 48 Stunden. Eine erhöhte intrazelluläre Konzentration von S1P konnte mittels Massenspektrometrie nicht festgestellt werden. Es scheint somit nicht ausschlaggebend zu sein, dass besonders hohe Mengen an S1P akkumulieren. Maßgeblich ist vermutlich eher die subzelluläre Lokalisation, die darüber entscheidet, ob S1P im Zellkern oder auf der Plasmamembran aktiv werden kann. S1P bewegt sich nicht frei im Zellkulturmedium, sondern ist an Proteinen wie Albumin (im Zellkulturmedium an BSA) gebunden (Adamson et al. 2014). Hohe Konzentrationen an S1P in der Zelle würden sich wohl auch deshalb bei fehlendem Transport nicht bilden, da es mehrere enzymatische Wege über Phosphatasen und die S1P-Lyase zum Abbau dieses Lipids gibt, deren Genexpression auch in den hier verwendeten mMC gemessen werden konnten (Pyne et al. 2005; Bektas et al. 2010). Zudem wurde auch die Genexpression des Transportproteins MRP1 in den mMC mittels RT-qPCR gemessen, welches ebenfalls in der Lage ist S1P zu transportieren. Extrazelluläre Konzentrationen von S1P im Zellkulturmedium waren unter dem Detektionslimit des verfügbaren Verfahrens zur massenspektrometrischen Analyse, weshalb eine Quantifizierung des Exports von S1P nicht überprüft werden konnte. Bestätigt wurde diese Problematik in einer Studie, in welcher sogar extrazellulär zugefügtes S1P auf einem S1P-Lyase-unabhängigen Weg von allen getesteten Zelltypen innerhalb von 30 Minuten abgebaut wurde (Peest et al. 2008). 


\section{Ausblick}

In der vorliegenden Arbeit wurden sowohl die Rolle von $\mathrm{S}_{1} \mathrm{P}_{5}$ in einem Mausmodell für tubulointerstitielle Fibrose, die Konzentrationsänderungen von spezifischen Ceramiden in fibrotischen Nieren aus dem Menschen und der Maus als auch die Rolle von Spns2 im Kontext der Nierenfibrose in vitro untersucht.

Es wurde festgestellt, dass $\mathrm{S}_{1} \mathrm{P}_{5}^{-/-}$-Mäuse einen milderen Krankheitsverlauf bei der AN gegenüber Wildtypen zeigen. So waren die Schäden im Gewebe, die Entzündungsreaktionen und auch die fibrotischen Prozesse nach 7 und 14 Tagen deutlich geringer in den $\mathrm{S}_{1} \mathrm{P}_{5}^{-/-}$-Mäusen. Es konnte jedoch noch nicht geklärt werden, welche Zellen für diesen Unterschied verantwortlich sind, da sowohl residente Zellen der Niere als auch infiltrierende Immunzellen eine Rolle spielen könnten. Durch die falschpositiven Signale für die Expression von $\mathrm{S}_{1} \mathrm{P}_{5}$ mit der verwendeten $\mathrm{TaqMan}^{\Theta_{-}}$ Sonde war die Identifikation der relevanten Zelltypen bisher nicht möglich. In nachfolgenden Studien sollten daher Zellen aus der Niere und Immunzellen aus den $\mathrm{S}_{1} \mathrm{P}_{5}{ }^{-/}-$Mäusen in Experimenten im Vergleich zu Zellen aus Wildtypen untersucht werden. Zukünftige Untersuchungen können zudem mit dem S1P5-spezifischen Antagonisten A-971432 im Vergleich zu dem S1P1- und S1P5-antagonisierenden Siponimod durchgeführt werden. Hierdurch könnten die spezifischen Effekte der Modulation von $\mathrm{S}_{1} \mathrm{P}_{5}$ sowohl in vitro als auch in vivo weiter herausgearbeitet werden. Daraus könnten weitere Indikationen für die therapeutische Verwendung dieser Wirkstoffe als auch mögliche Kontraindikationen für das bereits zugelassene Medikament Siponimod abgeleitet werden.

In den fibrotischen Nierenrindengeweben aus Patienten und den fibrotischen Nierengeweben aus Mäusen wurden geringere Konzentrationen von sehr langkettigen Ceramiden im Vergleich zu gesunden Nierengewebeproben gefunden. Die Ursache dieser Änderungen scheint somit durch Zellen verursacht zu werden, die hauptsächlich oder ausschließlich in der Nierenrinde zu finden sind. Es wäre daher interessant, Zellen aus der Nierenrinde zu isolieren und ihre Konzentrationen an Ceramiden in Abhängigkeit von profibrotischen und proentzündlichen Faktoren zu vergleichen. Zudem könnten CerS2 ${ }^{-/-}$-Mäuse in einem Modell zur Nierenfibrose, induziert durch UUO oder Adenin, untersucht werden, um den Einfluss der sehr langkettigen Ceramide in der Niere im Krankheitsverlauf zu analysieren. 
Die Zellkulturversuche mit Spns2 $2^{-{ }^{-}}$- und Spns2 $^{+/+}$-mMC zeigten, dass Spns2 die Expression von CTGF fördert. Mit Hilfe eines GFP-markierten S1P-Rezeptors könnte untersucht werden, ob in Abwesenheit von Spns2 die Rezeptoraktivierung vermindert ist. Zudem könnte die extrazelluläre Konzentration von S1P in Spns2 ${ }^{-I_{-}}$- und Spns2 ${ }^{+++}$$\mathrm{mMC}$ durch Stimulation mit caged-S1P oder Sphingosin in den messbaren Bereich der Massenspektrometrie gesteigert werden. Caged-S1P ist hydrophob und kann in die Zellen diffundieren. Über UV-Licht wird es gespalten, wodurch S1P intrazellulär freigesetzt werden kann (Meyer zu Heringdorf et al. 2003). Eine Stimulation mit dem membrangängigen Sphingosin führt über die Aktivität der Sphingosinkinasen ebenfalls zu einer Erhöhung der intrazellulären S1P-Konzentrationen (unveröffentlichte Daten). Der rasche Abbau von S1P kann durch die Verwendung des Phosphatase-Inhibitors Natriumorthovanadat verhindert werden (Peest et al. 2008). Um den möglichen Export von S1P durch MRP1 zu unterbinden, können MRP1-Inhibitoren wie MK-571 oder Reversan in den Versuchen miteinbezogen werden. Darüber hinaus könnte der Einfluss von Spns2 auch unter der Verwendung der Spns2 ${ }^{-I^{-}}$- und Spns2 $2^{+/+}$-Mäuse in einem Modell zur Nierenfibrose wie dem Adenin-Modell oder der UUO analysiert werden. 


\section{Zusammenfassung}

Es ist bekannt, dass die Aktivierung von S1P-Rezeptoren die Expression von profibrotischen Mediatoren, wie dem Bindegewebswachstumsfaktor CTGF, induzieren und deshalb auch eine Rolle bei der Entstehung der Nierenfibrose spielen kann. In diesem Kontext konnte unsere Arbeitsgruppe zeigen, dass die Aktivierung von $\mathrm{S}_{1} \mathrm{P}_{5}$ zur TGF- $\beta_{2}$-induzierten CTGF-Expression in humanen glomerulären Mesangiumzellen beiträgt (Wünsche et al. 2015). Im Rahmen dieser Doktorarbeit wurde deshalb die Rolle von $\mathrm{S}_{1} \mathrm{P}_{5}$ in einem in vivo-Modell zur Nierenfibrose untersucht. Männliche S1 $15^{-1-}$-Mäuse und Wildtypmäuse mit C57BL/6J-Hintergrund wurden mit einer adeninreichen Diät für jeweils 7 und 14 Tage gefüttert, um eine tubulointerstitielle Fibrose hervorzurufen. Die Nieren von unbehandelten Mäusen des jeweiligen Genotyps dienten als Kontrolle. Die Ergebnisse zeigen, dass $\mathrm{S}_{1} \mathrm{P}_{5}{ }^{-/}$-Mäuse geringere Kreatininplasmaspiegel und weniger Schäden im Nierengewebe gegenüber Wildtypen zeigten. Darüber hinaus wurde festgestellt, dass die mRNA-Expression von mehreren Fibrosemarkern und proinflammatorischen Zytokinen in den $\mathrm{S}_{1} \mathrm{P}_{5}{ }^{--}$-Mäusen schwächer war als in den Wildtypen. Die Auswertung von histochemischen Färbungen und Western Blots bestätigte diese Beobachtung. Zusammengefasst kann festgehalten werden, dass $\mathrm{S}_{1} \mathrm{P}_{5}$ eine wichtige Rolle bei der Entstehung von Adenininduzierter Entzündung in der Niere und nachfolgender Pathogenese wie Gewebeschäden und Fibrose spielt.

Ceramide sind ein Bestandteil der Lipiddoppelschicht, in allen eukaryotischen Zellen vorhanden und zentrale Moleküle des Sphingolipidstoffwechsels. Die Synthese und der Abbau der Ceramide werden von vielen verschiedenen Enzymen reguliert. Neben ihrer Aufgabe als strukturelle Elemente der Zellmembranen wurde herausgefunden, dass Ceramide auch in verschiedenen Signalwegen involviert sind, die auch bei Nierenerkrankungen eine Rolle spielen. In Bezug auf die Kettenlänge der angehängten Fettsäure können so genannte kurz- und langkettige Ceramide Apoptose induzieren, wohingegen sehr langkettige Ceramide Zellproliferation fördern. In mehreren Studien wurden bereits Konzentrationsänderungen von kettenlängenspezifischen Ceramiden im Plasma und Serum von Patienten gemessen, die zu diesem Zeitpunkt an einer Nierenerkrankung litten. In dieser Arbeit wurde daher untersucht, ob solche Konzentrationsänderungen auch im Nierengewebe von Patienten und Mäusen mit 
einer Nierenfibrose, dem Kennzeichen nahezu aller chronischen Nierenerkrankungen, zu sehen sind. Zu diesem Zwecke wurden Biopsien der Nierenrinde und des Nierenmarks von fibrotischen Nieren aus Patienten, die an Hydronephrose und/oder Pyelonephritis litten, und von gesunden Gewebeproben untersucht. Letztere wurden durch Nephrektomien zur Behandlung von Nierenkarzinomen gewonnen und dienten als nichtfibrotische Kontrolle. Zum Vergleich mit fibrotischen Nieren aus Mäusen wurden männliche Mäuse der Linie C57BL/6J mit einer adeninreichen Diät für 14 Tage gefüttert. Die Konzentrationen der Sphingolipide wurden mittels Massenspektrometrie gemessen und die Level der fibrotischen Marker wurden mit Hilfe von RT-qPCR und histologischen Färbungen analysiert. Die Ergebnisse zeigen, dass die sehr langkettigen Ceramide Cer d18:1/24:0 und Cer d18:1/24:1 sowohl in fibrotischen Nierenrindenproben der Patienten als auch in fibrotischen Nieren der Mäuse im Vergleich zu den jeweiligen Kontrollproben signifikant geringer konzentriert waren. Diese Effekte korrelieren mit der Hochregulation der Fibrosemarker COL1a1, COL3a1 und aSMA in den fibrotischen Nieren. Es konnte gezeigt werden, dass nur bestimmte Ceramide in fibrotischem Nierengewebe in ihrer Konzentration verändert sind, was interessante Fragen hinsichtlich der Ursache dieser Veränderungen, ihrer funktionellen Aufgabe und zu möglichen Effekten einer Manipulation des Ceramidstoffwechsels mit dem Ziel der Behandlung der Nierenfibrose oder der Entdeckung neuer Biomarker aufwirft. Die hier präsentierten Ergebnisse zeigen zudem die Eignung von in vivo-Mausmodellen als translationalen Ansatz für das Verständnis der Beteiligung von Ceramiden in menschlichen Nierenerkrankungen.

Die in vitro-Untersuchungen zu der Rolle des S1P-Transporters Spns2 haben gezeigt, dass Spns2 die Expression von CTGF nach Stimulation von Mausmesangiumzellen mit TFG- $\beta_{2}$ verstärkt. 24 Stunden nach Stimulation war im Zellkulturüberstand von Spns2 $2^{-/-m M C ~ i m ~ G e g e n s a t z ~ z u ~ S p n s 2 ~}{ }^{+/+}-\mathrm{mMC}$ keine Akkumulation des profibrotischen Zytokins CTGF gegenüber der unstimulierten Kontrolle detektierbar. Nach 48 Stunden Stimulation mit TFG- $\beta_{2}$ war die Menge an CTGF im Zelllysat als auch im Zellkulturüberstand von Spns2---mMC genauso hoch wie in der unstimulierten Kontrolle. Im Zelllysat und im Überstand der Spns $2^{-1-}$-mMC war die Expression von CTGF weiterhin deutlich höher im Vergleich zu den Proben der unstimulierten Zellen. Die basale und TFG- $\beta_{2}$-induzierte Genexpression von S1P-synthetisierenden und 
S1P-degradierenden Enzymen, sowie die Konzentrationen an S1P und Sphingosin in den Zellen unterschieden sich zwischen Spns2 ${ }^{-/-}-\mathrm{mMC}$ und Spns2 ${ }^{+/+}-\mathrm{mMC}$ nicht. 


\section{Summary}

$\mathrm{S} 1 \mathrm{P}$ receptor activation is known to induce the expression of profibrotic mediators such as CTGF and thus might play a role in the progression of renal fibrosis. In this context, we previously showed that $\mathrm{S}_{1} \mathrm{P}_{5}$ activation contributes to the TGF- $\beta_{2}$-induced CTGF expression in human glomerular mesangial cells (Wünsche et al. 2015). In this thesis, the role of $\mathrm{S} \mathrm{P}_{5}$ was investigated in an in vivo model of renal fibrosis. Male S1P5 knockout mice and wildtype mice on C57BL/6J background were fed with an adenine-

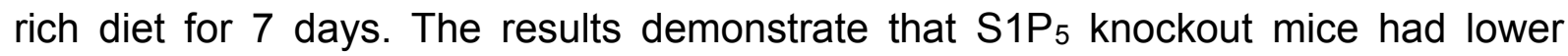
plasma creatinine levels and less tissue damage compared to wildtype mice. Further, the mRNA expression of several fibrotic markers and inflammatory cytokines was diminished in kidneys of $\mathrm{S}_{1} \mathrm{P}_{5}$ knockout mice compared to wildtype mice. Histochemistry and Western Blot analyses of fibrotic markers confirmed these results. Taken together, S1 $\mathrm{P}_{5}$ seems to play an essential role in the onset of adenine-induced renal inflammation, damage and progression of renal fibrosis and might be a promising target for future pharmacological treatment.

Ceramides are a part of the lipid bilayer in all eukaryotic cells and represent central molecules of the sphingolipid metabolism. Ceramide synthesis and degradation are regulated by numerous enzymes. Besides serving as structural elements in cell membranes, ceramides are also known to influence various signaling events involved in the progression of renal diseases. Depending on the chain length of the attached fatty acid, so called short- and long-chain ceramides induce apoptosis whereas very long-chain ceramides promote cell proliferation. In addition, several studies reveal alterations of chain-length specific ceramides in plasma and serum of patients suffering from renal diseases. In this thesis, it was investigated whether such alterations also occur in kidney tissue samples from patients and mice suffering from renal fibrosis, as a hallmark of chronic kidney diseases. For this purpose, human fibrotic kidney samples from renal cortex and renal medulla were collected from nephrectomy specimens with hydronephrosis and/or pyelonephritis. Healthy parts from tumor nephrectomies served as nonfibrotic controls. Mouse fibrotic kidney samples were collected from male C57BL/6J mice treated with an adenine-rich diet for 14 days or were subjected to 7 days of UUO. Kidneys of untreated mice and contralateral kidneys (UUO) served as respective controls. Sphingolipid levels were detected by LC-ESI-MS/MS and 
expression levels of fibrotic markers were analyzed by real-time PCR and histological stains. Very long-chain ceramides Cer d18:1/24:0 and Cer d18:1/24:1 were significantly downregulated in both fibrotic human kidney cortex and fibrotic murine kidney compared to respective control samples. These effects correlate with upregulation of COL1 1 1, COL3a1 and aSMA expression in fibrotic human kidney cortex and fibrotic mouse kidney. The results show that specific ceramides are altered in renal fibrosis, which raises interesting questions about their functional role and putative effects of ceramide metabolism manipulations in order to find new treatment strategies for renal fibrosis and potential biomarkers of chronic kidney disease. These findings also support the use of in vivo murine models as appropriate translational means to understand the involvement of ceramides in human kidney diseases.

The in vitro studies about the role of S1P transporter Spns2 in the context of renal fibrosis showed that Spns2 augments CTGF expression after stimulation with TFG- $\beta_{2}$ in renal mesangial cells. There was no accumulation of the profibrotic cytokine CTGF in supernatant of Spns2 $2^{-/}-$mMC detectable compared to Spns2 $2^{+/+}$-mMC after 24 hours of stimulation. 48 hours after stimulation with TFG- $\beta_{2}$, the amount of CTGF in the cell lysate as well as in the supernatant of Spns2-- $2^{-1}$ mC was as high as in samples from unstimulated control cells. Basal and TFG- $\beta_{2}$-induced gene expression of enzymes for S1P generation and degradation as well as levels of S1P and sphingosine in mesangial cells did not show any difference between Spns2 $2^{-{ }_{-}-\mathrm{mMC}}$ und Spns2 $2^{+/+}-\mathrm{mMC}$. 


\section{Anhang}

\subsection{Abkürzungsverzeichnis}

\begin{tabular}{|c|c|}
\hline Abb. & Abbildung \\
\hline ABC-Transporter & Adenosine triphosphate binding cassette-Transporter \\
\hline AN & Adenin-induzierte Nephropathie \\
\hline aSMA & anti-smooth muscle actin \\
\hline APS & Ammoniumpersulfat \\
\hline ATP/CTP & Adenosintriphosphat/Cytidintriphosphat/ \\
\hline GTP/TTP & Guanosintriphosphat/Thymidintriphosphat \\
\hline BAK & Bcl-2 homologous antagonist/killer \\
\hline BSA & Bovines Serumalbumin \\
\hline Bzw. & Beziehungsweise \\
\hline C & Kohlenstoff \\
\hline $\mathrm{Ccl} 2 / \mathrm{MCP}-1$ & C-C Chemokinligand 2/ monocyte chemotactic protein-1 \\
\hline CerS & Ceramidsynthase \\
\hline Cftr & cystic fibrosis transmembrane conductance regulator gene \\
\hline CoA & Coenzym A \\
\hline Col1a1 & Kollagen Typ I alpha 1 \\
\hline Col3a1 & Kollagen Typ III alpha 1 \\
\hline cDNA & complementary DNA \\
\hline CTGF & connective tissue growth factor \\
\hline $\mathrm{DAB}$ & 3, 3-Diaminobenzidin \\
\hline
\end{tabular}


DAG Diacylglycerin

DEPC Diethylpyrocarbonat

DMEM/F12 Dulbecco's Modified Eagle Medium

DN diabetische Nephropathie

DNA deoxyribonucleic acid

DMSO Dimethylsulfoxid

DPBS Dulbecco's Phosphate Buffered Saline

dNTP 2 -Desoxynucleosidtriphosphat

DTT Dithiothreitol

EDTA Ethylendiamintetraacetat

EDG endothelial differentiation gene

EGTA Ethylenglycol-bis-( 3 -aminoethylether)-N-N-N'-N'-tetraessigsäure

ELISA enzyme-linked immunosorbent assay

EMT Epithelial-mesenchymale Transition

ER Endoplasmatisches Retikulum

FDA Food and Drug Administration, USA

FKS Fötales Kälberserum

FN1 Fibronektin 1

$\mathrm{g} / \mathrm{kg} / \mathrm{mg} / \mathrm{hg} / \mathrm{ng} \quad$ Gramm/Kilogramm/Milligramm/Mikrogramm/Nanogramm

$\mathrm{G}_{12 / 13} / \mathrm{G}_{\mathrm{i} / \mathrm{o}} / \mathrm{G}_{\mathrm{q}} \quad$ G-Protein $\mathrm{G}_{12 / 13} / \mathrm{G}_{\mathrm{i} / \mathrm{o}} / \mathrm{G}_{\mathrm{q}}$

GAPDH Glycerinaldehyd-3-Phosphat-Dehydrogenase

h/Min/s Stunde/Minute/Sekunde

$\mathrm{H}_{2} \mathrm{O} / \mathrm{ddH}_{2} \mathrm{O}$ / Wasser/double distilled water (bidestilliertes Wasser)/ 


$\begin{array}{ll}\text { VE- } \mathrm{H}_{2} \mathrm{O} & \text { vollentsalztes (destilliertes) Wasser } \\ \mathrm{HCl} & \text { Salzsäure } \\ \mathrm{HEPES} & \text { 2-(4-(2-Hydroxyethyl)-1-piperazinyl)-ethansulfonsäure } \\ \mathrm{HN} & \text { Hydronephrose } \\ \mathrm{HRP} & \text { horseradish peroxidase (Meerrettichperoxidase) } \\ \mathrm{IgG} & \text { Immunglobulin G } \\ \mathrm{IL}-6 & \text { Interleukin-6 } \\ \mathrm{IL}-1 \beta & \text { Interleukin-1-beta } \\ \mathrm{KCl} & \text { Kaliumchlorid } \\ \mathrm{kDa} & \text { kilo Dalton / atomare Masseneinheit } \\ \mathrm{KIM}-1 & \text { kidney injury molecule-1 } \\ \mathrm{L} / \mathrm{\mu L} / \mathrm{mL} & \text { Liter/Mikroliter/Milliliter } \\ \mathrm{LN} & \text { Lupus-Nephritis }\end{array}$

LC-ESI-MS/MS Liquid chromatography with electrospray ionization coupled with tandem mass spectrometry / Flüssigchromatographie mit Elektrosprayionisation und Tandem-MassenspektrometrieKopplung

Mfsd2b major facilitator superfamily domain containing $2 b$

$\mathrm{MgCl}_{2} \quad$ Magnesiumchlorid

$\mathrm{mm} / \mathrm{cm} \quad$ Millimeter/Zentimeter

$\mathrm{M} / \mathrm{mM} / \mu \mathrm{M} / \mathrm{nM} \quad$ Molar/Millimolar/Mikromolar/Nanomolar

$\mathrm{mMC} \quad$ renale Mesangiumzellen aus der Maus

MRP1 multidrug resistance-associated protein 1

MS Massenspektrometrie 
number (hier: Anzahl der Versuchsproben)

$\mathrm{NaCl}$

Natriumchlorid

$\mathrm{NaOH}$

Natriumhydroxid

$\mathrm{Na}_{3} \mathrm{VO}_{4}$

Natriumorthovanadat

$\mathrm{NaF}$

Natriumflourid

NF-KB

nuclear factor kappa $B$

NGAL

neutrophil gelatinase-associated lipocalin

NLRP3

nucleotide-binding oligomerization domain, leucine-rich repeat and pyrin domain-containing 3 gene

NP40

Nonidet-P40

PAS

periodic acid-Schiff reaction

PAl-1

Plasminogen-Aktivator-Inhibitor-1

PAGE

Polyacrylamid-Gelelektrophorese

PBS

phosphate-buffered saline

PBST

phosphate-buffered saline tween

PCR

polymerase chain reaction / Polymerasekettenreaktion

PDGF

platelet-derived growth factor

PIC

Protease Inhibitor Cocktail

PMSF

Phenylmethylsulfonylfluorid

PN

Pyelonephritis

Rac

kleine GTPase der Proteinfamilie Rac, Subfamilie Rho

Ras

kleine GTPase der Proteinsuperfamilie Ras

Rho

kleine GTPase der Proteinfamilie Rho, Subfamilie Ras 


\begin{tabular}{|c|c|}
\hline RNA/mRNA/ & ribonucleic acid/messenger-RNA \\
\hline rRNA/RNAi/miRN & ribosomal-RNA/RNA interference/microRNA \\
\hline RPMI & Roswell Park Memorial Institute \\
\hline RT & Raumtemperatur \\
\hline RT-PCR & reverse transcriptase-polymerase chain reaction \\
\hline RT-qPCR & reverse transcriptase-quantitative polymerase chain reaction \\
\hline S1P & Sphingosin-1-Phosphat \\
\hline $\mathrm{S} 1 \mathrm{P}_{1-5}$ & Sphingosin-1-Phosphat-Rezeptor-1 bis 5 \\
\hline SD & Standard deviation / Standardabweichung \\
\hline SDS & sodium dodecylsulfate / Natriumdodecylsulfat \\
\hline SEM & standard error of the mean / Standardfehler \\
\hline Smad & mothers against decapentaplegic homolog \\
\hline S1P $5^{-1-}-$ Mäuse & S1P5-defiziente Mäuse \\
\hline Spns2-/-Mäuse & Spns2-defiziente Mäuse \\
\hline Spns2 $2^{+/+}$-Mäuse & Spns2-exprimierende Mäuse \\
\hline SGPP1 & Sphingosin-1-Phosphat-Phosphatase-1/2 \\
\hline SK-1 & Sphingosinkinase-1 \\
\hline SK-2 & Sphingosinkinase-2 \\
\hline Spns2 & Spinster homolog 2 \\
\hline SLE & Systemischer Lupus erythematodes \\
\hline TBS & Tris-gepufferte Saline \\
\hline TEMED & Tetramethylethylendiamin \\
\hline TGF- $\beta_{2}$ & transforming growth factor- $\beta 2$ \\
\hline
\end{tabular}


TNFa

TRIS

Upm

UUO

UV

V/V

${ }^{\circ} \mathrm{C}$ tumor-necrosis factor-alpha

Tris(hydroxymethyl)-aminomethan

Umdrehungen pro Minute

unilaterale Ureterobstruktion

Ultraviolett

Volumen/Volumen

Grad Celsius 


\subsection{Tabellenverzeichnis}

$\begin{array}{lll}\text { Tabelle 1: } & \text { Zellen } & 26\end{array}$

Tabelle 2: $\quad$ Kulturmedien und Zusätze 26

Tabelle 3: $\quad$ Zusammensetzung des Wachstumsmediums 27

Tabelle 4: $\quad$ Zusammensetzung anderer Medien 27

Tabelle 5: $\quad$ Geräte 28

Tabelle 6: $\quad$ Chemikalien $29 f$

Tabelle 7: $\quad$ Proteine und Reagenzien 31

Tabelle 8: $\quad$ Antikörper für Western Blot 32

Tabelle 9: $\quad$ Kits 33

Tabelle 10: $\quad$ Angesetzte Lösungen 34

Tabelle 11: $\quad$ Puffer 34

Tabelle 12: $\quad$ TaqMan $^{\circledR}$-Sonden $\quad 35$

Tabelle 13: $\quad$ Primer für die Genotypisierungen 36

Tabelle 14: $\quad$ Software 36

$\begin{array}{lll}\text { Tabelle 15: } \quad \text { Verbrauchsmaterialien } & 37\end{array}$

Tabelle 16: Zusammensetzung der Trenngellösungen für 2 Gele $\quad 52$

Tabelle 17: Zusammensetzung der Sammelgellösung für 2 Gele $\quad$ Z2 


\subsection{Abbildungsverzeichnis}

Abbildung 1: $\quad$ Schematischer Aufbau der Niere 2

Abbildung 2: $\quad$ Schematischer Aufbau eines Nephrons 3

Abbildung 3 Histologischer Schnitt durch eine fibrotische Niere 6

Abbildung 4: $\quad$ Übersicht über die Lokalisation und Stoffwechselwege der $\quad 9$ Sphingolipide inklusive der beteiligten Enzyme in den verschiedenen Zellkompartimenten

Abbildung 5: Strukturformeln der wichtigsten Vertreter der Sphingolipide

Abbildung 6: Schema des Metabolismus von S1P und der direkte Einfluss auf 15 renale Fibrose

Abbildung 7: Schema der S1P-Rezeptoren und der gekoppelten G-Proteine sowie deren Einfluss auf nachgeschaltete Signalwege nach

Abbildung 8: Die Substratspezifität der sechs bekannten Ceramidsynthasen

Abbildung 9: $\quad$ Schema der Herstellung des Spns2-- mittels des Kassettenaustausch-verfahrens

Abbildung 10: Stoffwechselweg für den Abbau von Adenin und die Folgen einer Übersättigung für die Niere

Abbildung 11: Genexpression von $\mathrm{S} \mathrm{P}_{5}$ in humanen Nierenbiopsien

Abbildung 12: Kreatininkonzentrationen im Plasma der Mäuse

Abbildung 13: Untersuchung auf Gewebeschäden in den Nieren

Abbildung 14: Expression von Nierenschädigungsmarkern

Abbildung 15: Genexpression proinflammatorischer Zytokine

Abbildung 16: Untersuchung der Nieren auf mononukleäre Phagozyten

Abbildung 17: Genexpression von Fibrosemarkern in den Nieren

Abbildung 18: Proteinexpression von Fibrosemarkern in den Nieren 
Abbildung 20: Genexpression der Sphingosinkinasen und des S1P-

Transporters Spns2 in den Nieren der gesunden und nierenkranken Mäuse

Abbildung 21: Genexpression der S1P-Rezeptoren

Abbildung 22: Plasmaspiegel von S1P und Sphingosin in gesunden und Nierenkranken Mäusen

Abbildung 23: Ergebnis der Real-Time PCR zur Bestimmung der mRNA-

Expression in den fibrotischen und gesunden Kortexgewebeproben

Abbildung 24: Immunhistochemische Färbungen des humanen Nierenkortex

Abbildung 25: Konzentration von Ceramiden bestimmter Kettenlänge im menschlichen Nierenkortex

Abbildung 26: Ergebnis der Real-Time PCR zur Bestimmung der mRNA-

Expression in den fibrotischen und gesunden Kortexgewebeproben

Abbildung 27: Ergebnis der Real-Time PCR zur Bestimmung der mRNA-

Expression in den fibrotischen und gesunden Nierenmarkgewebeproben

Abbildung 28: Immunhistochemische Färbungen des humanen Nierenmarks

Abbildung 29: Konzentration von Ceramiden bestimmter Kettenlänge im menschlichen Nierenmark

Abbildung 30: Ergebnis der Real-Time PCR zur Bestimmung der mRNAExpression in den fibrotischen und gesunden Nierenmarkgewebeproben

Abbildung 31: Konzentration von Ceramiden bestimmter Kettenlänge in menschlichen Nierenkortex und Nierenrinde

Abbildung 32: Ergebnis der Real-Time PCR zur Bestimmung der mRNA

Expression in den fibrotischen und gesunden Kortexgewebeproben

Abbildung 33: Histochemische Färbungen von Nierenschnitten aus der Maus

Abbildung 34: Konzentration von Ceramiden bestimmter Kettenlänge in Mausnieren 
Abbildung 35: Ergebnis der Real-Time PCR und des Western Blots zur Bestimmung der Expression der Ceramidsynthasen in den fibrotischen und gesunden Nierenproben

Abbildung 36: Genexpression von SK-1, Spns2 und S1P-Lyase in mMC

Abbildung 37: S1P und Sphingosinkonzentration in $\mathrm{mMC}$

Abbildung 38: CTGF-Expression von renalen Mesangiumzellen aus Spns2 $2^{-1-}$ und Spns2 $2^{++}$-Mäusen 


\subsection{Literaturverzeichnis}

Adamson, R. H., J. F. Clark, M. Radeva, A. Kheirolomoom, K. W. Ferrara, and F. E. Curry. 2014. "Albumin Modulates S1P Delivery from Red Blood Cells in Perfused Microvessels: Mechanism of the Protein Effect." American Journal of Physiology-Heart and Circulatory Physiology 306 (7): H1011-17. https://doi.org/10.1152/ajpheart.00829.2013.

Alemany, Regina, Chris J. van Koppen, Kerstin Danneberg, Michael ter Braak, and Dagmar Meyer zu Heringdorf. 2007. "Regulation and Functional Roles of Sphingosine Kinases." Naunyn-Schmiedeberg's Archives of Pharmacology 374 (5): 413-28. https://doi.org/10.1007/s00210-007-0132-3.

Allende, Maria L., Galina Tuymetova, Bridgin G. Lee, Eliana Bonifacino, Yun-Ping Wu, and Richard L. Proia. 2010. "S1P1 Receptor Directs the Release of Immature B Cells from Bone Marrow into Blood." Journal of Experimental Medicine 207 (5): 1113-24. https://doi.org/10.1084/jem.20092210.

Almaani, Salem, Alexa Meara, and Brad H. Rovin. 2017. "Update on Lupus Nephritis." Clinical Journal of the American Society of Nephrology 12 (5): 82535. https://doi.org/10.2215/CJN.05780616.

Alperovich, G, I Rama, N Lloberas, M Franquesa, R Poveda, M Gomà, I HerreroFresneda, et al. 2007. "New Immunosuppresor Strategies in the Treatment of Murine Lupus Nephritis." Lupus 16 (1): 18-24.

https://doi.org/10.1177/0961203306073136.

Al-Salama, Zaina T. 2019. "Siponimod: First Global Approval.” Drugs, May. https://doi.org/10.1007/s40265-019-01140-x.

An, Shuxian, Xiujuan Zang, Weijie Yuan, Yifeng Zhuge, and Qing Yu. 2013.

"Neutrophil Gelatinase-Associated Lipocalin (NGAL) May Play a Protective Role Against Rats Ischemia/Reperfusion Renal Injury via Inhibiting Tubular Epithelial Cell Apoptosis." Renal Failure 35 (1): 143-49. https://doi.org/10.3109/0886022X.2012.741877.

Ando, Seiichiro, Hirofumi Amano, Eri Amano, Kentaro Minowa, Takashi Watanabe, Soichiro Nakano, Yutaka Nakiri, et al. 2010. "FTY720 Exerts a Survival Advantage through the Prevention of End-Stage Glomerular Inflammation in Lupus-Prone BXSB Mice." Biochemical and Biophysical Research Communications 394 (3): 804-10. https://doi.org/10.1016/j.bbrc.2010.03.078. 
Anjos Cassado, Alexandra dos. 2017. "F4/80 as a Major Macrophage Marker: The Case of the Peritoneum and Spleen." In Macrophages: Origin, Functions and Biointervention, edited by Malgorzata Kloc, 161-79. Results and Problems in Cell Differentiation. Cham: Springer International Publishing. https://doi.org/10.1007/978-3-319-54090-0_7.

Arango Duque, Guillermo, and Albert Descoteaux. 2014. "Macrophage Cytokines: Involvement in Immunity and Infectious Diseases." Frontiers in Immunology 5 (October). https://doi.org/10.3389/fimmu.2014.00491.

Awad, Alaa S., Michael D. Rouse, Konstantine Khutsishvili, Liping Huang, W. Kline Bolton, Kevin R. Lynch, and Mark D. Okusa. 2011. "Chronic Sphingosine 1Phosphate 1 Receptor Activation Attenuates Early-Stage Diabetic Nephropathy Independent of Lymphocytes." Kidney International 79 (10): 1090-98. https://doi.org/10.1038/ki.2010.544.

Bajwa, Amandeep, Liping Huang, Elvira Kurmaeva, Joseph C. Gigliotti, Hong Ye, Jacqueline Miller, Diane L. Rosin, Peter I. Lobo, and Mark D. Okusa. 2016. "Sphingosine 1-Phosphate Receptor 3-Deficient Dendritic Cells Modulate Splenic Responses to Ischemia-Reperfusion Injury." Journal of the American Society of Nephrology: JASN 27 (4): 1076-90. https://doi.org/10.1681/ASN.2015010095.

Bajwa, Amandeep, Sang-Kyung Jo, Hong Ye, Liping Huang, Krishna R. Dondeti, Diane L. Rosin, Volker H. Haase, Timothy L. Macdonald, Kevin R. Lynch, and Mark D. Okusa. 2010. "Activation of Sphingosine-1-Phosphate 1 Receptor in the Proximal Tubule Protects Against Ischemia-Reperfusion Injury." Journal of the American Society of Nephrology 21 (6): 955-65.

https://doi.org/10.1681/ASN.2009060662.

Bajwa, Amandeep, Diane L. Rosin, Piotr Chroscicki, Sangju Lee, Krishna Dondeti, Hong Ye, Gilbert R. Kinsey, et al. 2015. "Sphingosine 1-Phosphate Receptor-1 Enhances Mitochondrial Function and Reduces Cisplatin-Induced Tubule Injury." Journal of the American Society of Nephrology 26 (4): 908-25. https://doi.org/10.1681/ASN.2013121351.

Barnawi, Jameel, Hubertus Jersmann, Rainer Haberberger, Sandra Hodge, and Robyn Meech. 2017. "Reduced DNA Methylation of Sphingosine-1 Phosphate Receptor 5 in Alveolar Macrophages in COPD: A Potential Link to Failed Efferocytosis." Respirology 22 (2): 315-21. https://doi.org/10.1111/resp.12949. 
Barnawi, Jameel, Hai Tran, Hubertus Jersmann, Stuart Pitson, Eugene Roscioli, Greg Hodge, Robyn Meech, Rainer Haberberger, and Sandra Hodge. 2015. "Potential Link between the Sphingosine-1-Phosphate (S1P) System and Defective Alveolar Macrophage Phagocytic Function in Chronic Obstructive Pulmonary Disease (COPD)." PLOS ONE 10 (10): e0122771. https://doi.org/10.1371/journal.pone.0122771.

Bazarganipour, Sarah, Johannes Hausmann, Stephanie Oertel, Khadija El-Hindi, Sebastian Brachtendorf, Irina Blumenstein, Alica Kubesch, et al. 2019. "The Lipid Status in Patients with Ulcerative Colitis: Sphingolipids Are DiseaseDependent Regulated." Journal of Clinical Medicine 8 (7). https://doi.org/10.3390/jcm8070971.

Bekpinar, S., G. Yenidunya, F. Gurdol, Y. Unlucerci, E. Aycan-Ustyol, and N. Dinccag. 2015. "The Effect of Nephropathy on Plasma Sphingosine 1Phosphate Concentrations in Patients with Type 2 Diabetes." Clinical Biochemistry 48 (18): 1264-67. https://doi.org/10.1016/j.clinbiochem.2015.08.001.

Bektas, Meryem, Maria Laura Allende, Bridgin G. Lee, Weiping Chen, Marcelo J. Amar, Alan T. Remaley, Julie D. Saba, and Richard L. Proia. 2010. "Sphingosine 1-Phosphate Lyase Deficiency Disrupts Lipid Homeostasis in Liver." The Journal of Biological Chemistry 285 (14): 10880-89. https://doi.org/10.1074/jbc.M109.081489.

Benito, S., A. Sánchez-Ortega, N. Unceta, F. Andrade, L. Aldámiz-Echevarria, M. A. Goicolea, and R. J. Barrio. 2018. "Untargeted Metabolomics for Plasma Biomarker Discovery for Early Chronic Kidney Disease Diagnosis in Pediatric Patients Using LC-QTOF-MS." Analyst 143 (18): 4448-58. https://doi.org/10.1039/C8AN00864G.

Blanchard, Olivier, Bisera Stepanovska, Manuel Starck, Martin Erhardt, Isolde Römer, Dagmar Meyer zu Heringdorf, Josef Pfeilschifter, Uwe ZangemeisterWittke, and Andrea Huwiler. 2018. "Downregulation of the S1P Transporter Spinster Homology Protein 2 (Spns2) Exerts an Anti-Fibrotic and AntiInflammatory Effect in Human Renal Proximal Tubular Epithelial Cells." International Journal of Molecular Sciences 19 (5): 1498. https://doi.org/10.3390/ijms19051498.

Bolignano, Davide, Valentina Donato, Giuseppe Coppolino, Susanna Campo, Antoine Buemi, Antonio Lacquaniti, and Michele Buemi. 2008. "Neutrophil Gelatinase-Associated Lipocalin (NGAL) as a Marker of Kidney Damage." American Journal of Kidney Diseases 52 (3): 595-605. https://doi.org/10.1053/j.ajkd.2008.01.020. 
Bradford, Marion M. 1976. "A Rapid and Sensitive Method for the Quantitation of Microgram Quantities of Protein Utilizing the Principle of Protein-Dye Binding." Analytical Biochemistry 72 (1): 248-54. https://doi.org/10.1016/00032697(76)90527-3.

Brinkmann, Volker. 2007. "Sphingosine 1-Phosphate Receptors in Health and Disease: Mechanistic Insights from Gene Deletion Studies and Reverse Pharmacology." Pharmacology \& Therapeutics 115 (1): 84-105. https://doi.org/10.1016/j.pharmthera.2007.04.006.

Brinkmann, Volker, Jason G. Cyster, and Timothy Hla. 2004. "FTY720: Sphingosine 1-Phosphate Receptor-1 in the Control of Lymphocyte Egress and Endothelial Barrier Function." American Journal of Transplantation: Official Journal of the American Society of Transplantation and the American Society of Transplant Surgeons 4 (7): 1019-25. https://doi.org/10.1111/j.1600-6143.2004.00476.x.

Brodlie, Malcolm, Michael C. McKean, Gail E. Johnson, Joe Gray, Andrew J. Fisher, Paul A. Corris, James L. Lordan, and Christopher Ward. 2010. "Ceramide Is Increased in the Lower Airway Epithelium of People with Advanced Cystic Fibrosis Lung Disease." American Journal of Respiratory and Critical Care Medicine 182 (3): 369-75. https://doi.org/10.1164/rccm.200905-07990C.

Brunkhorst, R., F. Friedlaender, N. Ferreirós, S. Schwalm, A. Koch, G. Grammatikos, S. Toennes, C. Foerch, J. Pfeilschifter, and W. Pfeilschifter. 2015. "Alterations of the Ceramide Metabolism in the Peri-Infarct Cortex Are Independent of the Sphingomyelinase Pathway and Not Influenced by the Acid Sphingomyelinase Inhibitor Fluoxetine." Neural Plasticity 2015: 503079.

https://doi.org/10.1155/2015/503079.

Brunkhorst, Robert, Waltraud Pfeilschifter, Sammy Patyna, Stefan Büttner, Timon Eckes, Sandra Trautmann, Dominique Thomas, Josef Pfeilschifter, and Alexander Koch. 2018. "Preanalytical Biases in the Measurement of Human Blood Sphingolipids." International Journal of Molecular Sciences 19 (5). https://doi.org/10.3390/ijms19051390.

Cao, Qi, Yiping Wang, Xin Maggie Wang, Junyu Lu, Vincent W. S. Lee, Qianling Ye, Hanh Nguyen, et al. 2015. "Renal F4/80+CD11C+ Mononuclear Phagocytes Display Phenotypic and Functional Characteristics of Macrophages in Health and in Adriamycin Nephropathy." Journal of the American Society of Nephrology 26 (2): 349-63. https://doi.org/10.1681/ASN.2013121336.

Cartwright, Tara A., Christopher R. Campos, Ronald E. Cannon, and David S. Miller. 2013. "Mrp1 Is Essential for Sphingolipid Signaling to P-Glycoprotein in Mouse Blood-Brain and Blood-Spinal Cord Barriers." Journal of Cerebral Blood Flow \& Metabolism 33 (3): 381-388. 
Chang, Chi-Lun, Ming-Chih Ho, Po-Huang Lee, Chi-Yen Hsu, Wei-Pang Huang, and Hsinyu Lee. 2009. "S1P5 Is Required for Sphingosine 1-Phosphate-Induced Autophagy in Human Prostate Cancer PC-3 Cells." American Journal of Physiology-Cell Physiology 297 (2): C451-58. https://doi.org/10.1152/ajpcell.00586.2008.

Checa, A, H Idborg, A Zandian, D Garcia Sar, I Surowiec, J Trygg, E Svenungsson, et al. 2017. "Dysregulations in Circulating Sphingolipids Associate with Disease Activity Indices in Female Patients with Systemic Lupus Erythematosus: A Cross-Sectional Study." Lupus 26 (10): 1023-33. https://doi.org/10.1177/0961203316686707.

Chen, Jing, Neil Ingham, John Kelly, Shalini Jadeja, David Goulding, Johanna Pass, Vinit B. Mahajan, et al. 2014. "Spinster Homolog 2 (Spns2) Deficiency Causes Early Onset Progressive Hearing Loss." PLOS Genetics 10 (10): e1004688. https://doi.org/10.1371/journal.pgen.1004688.

Cheng, Jung-Chien, Evan Y. Wang, Yuyin Yi, Avinash Thakur, Shu-Huei Tsai, and Pamela A. Hoodless. 2018. "S1P Stimulates Proliferation by Upregulating CTGF Expression through S1PR2-Mediated YAP Activation." Molecular Cancer Research 16 (10): 1543-55. https://doi.org/10.1158/1541-7786.MCR17-0681.

Chun, Jerold, and Hans-Peter Hartung. 2010. "Mechanism of Action of Oral Fingolimod (FTY720) in Multiple Sclerosis." Clinical Neuropharmacology 33 (2): 91-101. https://doi.org/10.1097/WNF.0b013e3181cbf825.

Cutler, Roy G., Jeremiah Kelly, Kristin Storie, Ward A. Pedersen, Anita Tammara, Kimmo Hatanpaa, Juan C. Troncoso, and Mark P. Mattson. 2004. "Involvement of Oxidative Stress-Induced Abnormalities in Ceramide and Cholesterol Metabolism in Brain Aging and Alzheimer's Disease." Proceedings of the National Academy of Sciences of the United States of America 101 (7): 2070-75. https://doi.org/10.1073/pnas.0305799101.

Cuvillier, O., G. Pirianov, B. Kleuser, P. G. Vanek, O. A. Coso, S. Gutkind, and S. Spiegel. 1996. "Suppression of Ceramide-Mediated Programmed Cell Death by Sphingosine-1-Phosphate." Nature 381 (6585): 800-803. https://doi.org/10.1038/381800a0.

Daha, M. R., and C. van Kooten. 2000. "Is the Proximal Tubular Cell a Proinflammatory Cell?" Nephrology, Dialysis, Transplantation: Official Publication of the European Dialysis and Transplant Association - European Renal Association 15 Suppl 6: 41-43. 
Debien, Emilie, Katia Mayol, Vincent Biajoux, Cécile Daussy, Mercedes Gomez De Aguero, Morgan Taillardet, Nicolas Dagany, et al. 2013. "S1PR5 Is Pivotal for the Homeostasis of Patrolling Monocytes." European Journal of Immunology 43 (6): 1667-75. https://doi.org/10.1002/eji.201343312.

Denic, Aleksandar, Richard J. Glassock, and Andrew D. Rule. 2016. "Structural and Functional Changes With the Aging Kidney." Advances in Chronic Kidney Disease, CKD and the Elderly, 23 (1): 19-28. https://doi.org/10.1053/j.ackd.2015.08.004.

Di Pardo, Alba, Salvatore Castaldo, Enrico Amico, Giuseppe Pepe, Federico Marracino, Luca Capocci, Alfredo Giovannelli, et al. 2018. "Stimulation of S1PR5 with A-971432, a Selective Agonist, Preserves Blood-Brain Barrier Integrity and Exerts Therapeutic Effect in an Animal Model of Huntington's Disease." Human Molecular Genetics 27 (14): 2490-2501. https://doi.org/10.1093/hmg/ddy153.

Donoviel, Michael S., Nitai C. Hait, Subramaniam Ramachandran, Michael Maceyka, Kazuaki Takabe, Sheldon Milstien, Tamas Oravecz, and Sarah Spiegel. 2015. "Spinster 2, a Sphingosine-1-Phosphate Transporter, Plays a Critical Role in Inflammatory and Autoimmune Diseases." The FASEB Journal 29 (12): 5018 28. https://doi.org/10.1096/fj.15-274936.

Drouillard, Annabelle, Anne-Laure Mathieu, Antoine Marçais, Alexandre Belot, Sébastien Viel, Michaël Mingueneau, Kevin Guckian, and Thierry Walzer. 2018. "S1PR5 Is Essential for Human Natural Killer Cell Migration toward Sphingosine-1 Phosphate." Journal of Allergy and Clinical Immunology 141 (6): 2265-2268.e1. https://doi.org/10.1016/j.jaci.2017.11.022.

Du, Chunyang, Yunzhuo Ren, Fang Yao, Jialiang Duan, Hui'er Zhao, Yunxia Du, Xia Xiao, Huijun Duan, and Yonghong Shi. 2017. "Sphingosine Kinase 1 Protects Renal Tubular Epithelial Cells from Renal Fibrosis via Induction of Autophagy." The International Journal of Biochemistry \& Cell Biology 90 (July): 17-28. https://doi.org/10.1016/j.biocel.2017.07.011.

Duffield, Jeremy S. 2010. "Macrophages and Immunologic Inflammation of the Kidney." Seminars in Nephrology 30 (3): 234-54. https://doi.org/10.1016/j.semnephrol.2010.03.003.

Duong, Chinh Quoc, Salim Maa Bared, Ahmad Abu-Khader, Christa Buechler, Anna Schmitz, and Gerd Schmitz. 2004. "Expression of the Lysophospholipid Receptor Family and Investigation of Lysophospholipid-Mediated Responses in Human Macrophages." Biochimica Et Biophysica Acta 1682 (1-3): 112-19. https://doi.org/10.1016/j.bbalip.2004.03.002. 
Dupre, Tess V., Mark A. Doll, Parag P. Shah, Cierra N. Sharp, Deanna Siow, Judit Megyesi, James Shayman, et al. 2017. "Inhibiting Glucosylceramide Synthase Exacerbates Cisplatin-Induced Acute Kidney Injury." Journal of Lipid Research, jlr-M076745.

Eardley, K. S., D. Zehnder, M. Quinkler, J. Lepenies, R. L. Bates, C. O. Savage, A. J. Howie, D. Adu, and P. Cockwell. 2006. "The Relationship between Albuminuria, MCP-1/CCL2, and Interstitial Macrophages in Chronic Kidney Disease." Kidney International 69 (7): 1189-97. https://doi.org/10.1038/sj.ki.5000212.

Edsall, L. C., O. Cuvillier, S. Twitty, S. Spiegel, and S. Milstien. 2001. "Sphingosine Kinase Expression Regulates Apoptosis and Caspase Activation in PC12 Cells." Journal of Neurochemistry 76 (5): 1573-84. https://doi.org/10.1046/j.1471-4159.2001.00164.x.

Esteban, Vanesa, Oscar Lorenzo, Mónica Rupérez, Yusuke Suzuki, Sergio Mezzano, Julia Blanco, Mathias Kretzler, Takeshi Sugaya, Jesús Egido, and Marta RuizOrtega. 2004. "Angiotensin II, via AT1 and AT2 Receptors and NF-KB Pathway, Regulates the Inflammatory Response in Unilateral Ureteral Obstruction." Journal of the American Society of Nephrology 15 (6): 1514-29. https://doi.org/10.1097/01.ASN.0000130564.75008.F5.

Eum, Jung Yong, Jong Cheol Lee, Sun Shin Yi, II Yong Kim, Je Kyung Seong, and Myeong Hee Moon. 2020. "Aging-Related Lipidomic Changes in Mouse Serum, Kidney, and Heart by Nanoflow Ultrahigh-Performance Liquid Chromatography-Tandem Mass Spectrometry." Journal of Chromatography A, January, 460849. https://doi.org/10.1016/j.chroma.2020.460849.

Fagerberg, Linn, Björn M. Hallström, Per Oksvold, Caroline Kampf, Dijana Djureinovic, Jacob Odeberg, Masato Habuka, et al. 2014. "Analysis of the Human Tissue-Specific Expression by Genome-Wide Integration of Transcriptomics and Antibody-Based Proteomics." Molecular \& Cellular Proteomics: MCP 13 (2): 397-406. https://doi.org/10.1074/mcp.M113.035600.

Fang, Chao, Ganlan Bian, Pan Ren, Jie Xiang, Jun Song, Caiyong Yu, Qian Zhang, et al. 2018. "S1P Transporter SPNS2 Regulates Proper Postnatal Retinal Morphogenesis." The FASEB Journal 32 (7): 3597-3613. https://doi.org/10.1096/fj.201701116R.

Futerman, Anthony H., and Yusuf A. Hannun. 2004. "The Complex Life of Simple Sphingolipids." EMBO Reports 5 (8): 777-82. https://doi.org/10.1038/sj.embor.7400208. 
Galadari, Sehamuddin, Anees Rahman, Siraj Pallichankandy, Alaa Galadari, and Faisal Thayyullathil. 2013. "Role of Ceramide in Diabetes Mellitus: Evidence and Mechanisms." Lipids in Health and Disease 12 (July): 98. https://doi.org/10.1186/1476-511X-12-98.

Garić, Dušan, Juan B. De Sanctis, Gabriella Wojewodka, Daniel Houle, Shanon Cupri, Asmahan Abu-Arish, John W. Hanrahan, Marian Hajduch, Elias Matouk, and Danuta Radzioch. 2017. "Fenretinide Differentially Modulates the Levels of Long- and Very Long-Chain Ceramides by Downregulating Cers5 Enzyme: Evidence from Bench to Bedside." Journal of Molecular Medicine (Berlin, Germany) 95 (10): 1053-64. https://doi.org/10.1007/s00109-017-1564y.

Geissmann, Frederic, Steffen Jung, and Dan R. Littman. 2003. "Blood Monocytes Consist of Two Principal Subsets with Distinct Migratory Properties." Immunity 19 (1): 71-82.

Genovese, Federica, Alba A. Manresa, Diana Julie Leeming, Morten Asser Karsdal, and Peter Boor. 2014. "The Extracellular Matrix in the Kidney: A Source of Novel Non-Invasive Biomarkers of Kidney Fibrosis?" Fibrogenesis \& Tissue Repair 7 (1): 4. https://doi.org/10.1186/1755-1536-7-4.

Glaenzel, Ulrike, Yi Jin, Robert Nufer, Wenkui Li, Kirsten Schroer, Sylvie AdamStitah, Sjoerd Peter van Marle, et al. 2018. "Metabolism and Disposition of Siponimod, a Novel Selective S1P1/S1P5 Agonist, in Healthy Volunteers and In Vitro Identification of Human Cytochrome P450 Enzymes Involved in Its Oxidative Metabolism." Drug Metabolism and Disposition: The Biological Fate of Chemicals 46 (7): 1001-13. https://doi.org/10.1124/dmd.117.079574.

Golfier, Sven, Shinichi Kondo, Tobias Schulze, Tomomi Takeuchi, Galya Vassileva, Ariel H. Achtman, Markus H. Gräler, et al. 2010. "Shaping of Terminal Megakaryocyte Differentiation and Proplatelet Development by Sphingosine-1Phosphate Receptor S1P4." FASEB Journal: Official Publication of the Federation of American Societies for Experimental Biology 24 (12): 4701-10. https://doi.org/10.1096/fj.09-141473.

Gomez, Ivan G., Deidre A. MacKenna, Bryce G. Johnson, Vivek Kaimal, Allie M. Roach, Shuyu Ren, Naoki Nakagawa, et al. 2015. "Anti-MicroRNA-21 Oligonucleotides Prevent Alport Nephropathy Progression by Stimulating Metabolic Pathways." The Journal of Clinical Investigation 125 (1): 141-56. https://doi.org/10.1172/JCI75852.

Gottschalk, Catherine, and Christian Kurts. 2015. "The Debate about Dendritic Cells and Macrophages in the Kidney." Frontiers in Immunology 6. https://doi.org/10.3389/fimmu.2015.00435. 
Gräler, Markus H., Günter Bernhardt, and Martin Lipp. 1998. "EDG6, a Novel GProtein-Coupled Receptor Related to Receptors for Bioactive Lysophospholipids, Is Specifically Expressed in Lymphoid Tissue." Genomics 53 (2): 164-69. https://doi.org/10.1006/geno.1998.5491.

Gräler, Markus H., Robert Grosse, Angelika Kusch, Elisabeth Kremmer, Thomas Gudermann, and Martin Lipp. 2003. "The Sphingosine 1-Phosphate Receptor S1P4 Regulates Cell Shape and Motility via Coupling to Gi and G12/13." Journal of Cellular Biochemistry 89 (3): 507-19. https://doi.org/10.1002/jcb.10537.

Grammatikos, Georgios, Niklas Schoell, Nerea Ferreirós, Dimitra Bon, Eva Herrmann, Harald Farnik, Verena Köberle, et al. 2016. "Serum Sphingolipidomic Analyses Reveal an Upregulation of C16-Ceramide and Sphingosine-1-Phosphate in Hepatocellular Carcinoma." Oncotarget 7 (14): 18095-105. https://doi.org/10.18632/oncotarget.7741.

Grande, M. Teresa, Berta Sánchez-Laorden, Cristina López-Blau, Cristina A. De Frutos, Agnès Boutet, Miguel Arévalo, R. Grant Rowe, Stephen J. Weiss, José M. López-Novoa, and M. Angela Nieto. 2015. "Snail1-Induced Partial Epithelial-to-Mesenchymal Transition Drives Renal Fibrosis in Mice and Can Be Targeted to Reverse Established Disease." Nature Medicine 21 (9): 989_ 97. https://doi.org/10.1038/nm.3901.

Grösch, Sabine, Susanne Schiffmann, and Gerd Geisslinger. 2012. "Chain LengthSpecific Properties of Ceramides." Progress in Lipid Research 51 (1): 50-62. https://doi.org/10.1016/j.plipres.2011.11.001.

Grupp, Clemens, Ilka Troche, Carmen Klass, Matthias Köhler, and Gerhard Anton Müller. 2001. "A Novel Model to Study Renal Myofibroblast Formation in Vitro." Kidney International 59 (2): 543-53. https://doi.org/10.1046/j.15231755.2001.059002543.x.

Guilbault, Claudine, Juan B. De Sanctis, Gabriella Wojewodka, Zienab Saeed, Claude Lachance, Thomas A. A. Skinner, Regina M. Vilela, et al. 2008. "Fenretinide Corrects Newly Found Ceramide Deficiency in Cystic Fibrosis." American Journal of Respiratory Cell and Molecular Biology 38 (1): 47-56. https://doi.org/10.1165/rcmb.2007-0036OC.

Han, Mei, Ying Li, Di Wen, Maodong Liu, Yuteng Ma, and Bin Cong. 2018. "NGAL Protects against Endotoxin-Induced Renal Tubular Cell Damage by Suppressing Apoptosis." BMC Nephrology 19 (1): 168. https://doi.org/10.1186/s12882-018-0977-3. 
Han, W. K., S. S. Waikar, A. Johnson, R. A. Betensky, C. L. Dent, P. Devarajan, and J. V. Bonventre. 2008. "Urinary Biomarkers in the Early Diagnosis of Acute Kidney Injury." Kidney International 73 (7): 863-69.

https://doi.org/10.1038/sj.ki.5002715.

Han, Won K., Veronique Bailly, Rekha Abichandani, Ravi Thadhani, and Joseph V. Bonventre. 2002. "Kidney Injury Molecule-1 (KIM-1): A Novel Biomarker for Human Renal Proximal Tubule Injury." Kidney International 62 (1): 237-44. https://doi.org/10.1046/j.1523-1755.2002.00433.x.

Hanada, Kentaro, Keigo Kumagai, Satoshi Yasuda, Yukiko Miura, Miyuki Kawano, Masayoshi Fukasawa, and Masahiro Nishijima. 2003. "Molecular Machinery for Non-Vesicular Trafficking of Ceramide." Nature 426 (6968): 803-9. https://doi.org/10.1038/nature02188.

Hänel, Petra, Paul Andréani, and Markus H. Gräler. 2007. "Erythrocytes Store and Release Sphingosine 1-Phosphate in Blood." The FASEB Journal 21 (4): 1202-9. https://doi.org/10.1096/fj.06-7433com.

Hannun, Y. A., and R. M. Bell. 1989. "Functions of Sphingolipids and Sphingolipid Breakdown Products in Cellular Regulation." Science 243 (4890): 500-507. https://doi.org/10.1126/science.2643164.

Hanson, Michael A., and Robert Peach. 2014. "Structural Biology of the S1P1 Receptor." Current Topics in Microbiology and Immunology 378: 23-53. https://doi.org/10.1007/978-3-319-05879-5_2.

Hartmann, Daniela, Marthe-Susanna Wegner, Ruth Anna Wanger, Nerea Ferreirós, Yannick Schreiber, Jessica Lucks, Susanne Schiffmann, Gerd Geisslinger, and Sabine Grösch. 2013. "The Equilibrium between Long and Very Long Chain Ceramides Is Important for the Fate of the Cell and Can Be Influenced by Co-Expression of CerS." The International Journal of Biochemistry \& Cell Biology 45 (7): 1195-1203. https://doi.org/10.1016/j.biocel.2013.03.012.

Haus, Jacob M., Sangeeta R. Kashyap, Takhar Kasumov, Renliang Zhang, Karen R. Kelly, Ralph A. Defronzo, and John P. Kirwan. 2009. "Plasma Ceramides Are Elevated in Obese Subjects with Type 2 Diabetes and Correlate with the Severity of Insulin Resistance." Diabetes 58 (2): 337-43. https://doi.org/10.2337/db08-1228.

Havulinna, Aki S., Marko Sysi-Aho, Mika Hilvo, Dimple Kauhanen, Reini Hurme, Kim Ekroos, Veikko Salomaa, and Reijo Laaksonen. 2016. "Circulating Ceramides Predict Cardiovascular Outcomes in the Population-Based FINRISK 2002 Cohort." Arteriosclerosis, Thrombosis, and Vascular Biology 36 (12): 2424-30. https://doi.org/10.1161/ATVBAHA.116.307497. 
Hermann, Viktoria, Anastas Batalov, Svetlana Smakotina, Pierre-Eric Juif, and Peter Cornelisse. 2019. "First Use of Cenerimod, a Selective S1P1 Receptor Modulator, for the Treatment of SLE: A Double-Blind, Randomised, PlaceboControlled, Proof-of-Concept Study." Lupus Science \& Medicine 6 (1): e000354. https://doi.org/10.1136/lupus-2019-000354.

Hewitson, Tim D. 2012. "Fibrosis in the Kidney: Is a Problem Shared a Problem Halved?" Fibrogenesis \& Tissue Repair 5 (Suppl 1): S14. https://doi.org/10.1186/1755-1536-5-S1-S14.

Hisano, Yu, Naoki Kobayashi, Atsuo Kawahara, Akihito Yamaguchi, and Tsuyoshi Nishi. 2011. "The Sphingosine 1-Phosphate Transporter, SPNS2, Functions as a Transporter of the Phosphorylated Form of the Immunomodulating Agent FTY720." Journal of Biological Chemistry 286 (3): 1758-66. https://doi.org/10.1074/jbc.M110.171116.

Hisano, Yu, Naoki Kobayashi, Akihito Yamaguchi, and Tsuyoshi Nishi. 2012. "Mouse SPNS2 Functions as a Sphingosine-1-Phosphate Transporter in Vascular Endothelial Cells." Edited by David Holowka. PLoS ONE 7 (6): e38941. https://doi.org/10.1371/journal.pone.0038941.

Hoerger, Thomas J., John S. Wittenborn, Joel E. Segel, Nilka R. Burrows, Kumiko Imai, Paul Eggers, Meda E. Pavkov, et al. 2010. "A Health Policy Model of CKD: 1. Model Construction, Assumptions, and Validation of Health Consequences." American Journal of Kidney Diseases 55 (3): 452-62. https://doi.org/10.1053/j.ajkd.2009.11.016.

Huwiler, Andrea, and Josef Pfeilschifter. 2018. "Sphingolipid Signaling in Renal Fibrosis." Matrix Biology, SI : Fibrosis - Mechanisms and Translational Aspects, 68-69 (August): 230-47. https://doi.org/10.1016/j.matbio.2018.01.006.

Huwiler, A., T. Kolter, J. Pfeilschifter, and K. Sandhoff. 2000. "Physiology and Pathophysiology of Sphingolipid Metabolism and Signaling." Biochimica Et Biophysica Acta 1485 (2-3): 63-99. https://doi.org/10.1016/s13881981(00)00042-1.

Igarashi, Nobuaki, Taro Okada, Shun Hayashi, Toshitada Fujita, Saleem Jahangeer, and Shun-ichi Nakamura. 2003. "Sphingosine Kinase 2 Is a Nuclear Protein and Inhibits DNA Synthesis." Journal of Biological Chemistry 278 (47): 4683239. https://doi.org/10.1074/jbc.M306577200. 
Ikeda, Hitoshi, Naoko Watanabe, Isao Ishii, Tatsuo Shimosawa, Yukio Kume, Tomoaki Tomiya, Yukiko Inoue, et al. 2009. "Sphingosine 1-Phosphate Regulates Regeneration and Fibrosis after Liver Injury via Sphingosine 1Phosphate Receptor 2." Journal of Lipid Research 50 (3): 556-64. https://doi.org/10.1194/jlr.M800496-JLR200.

Im, D. S., C. E. Heise, N. Ancellin, B. F. O’Dowd, G. J. Shei, R. P. Heavens, M. R. Rigby, et al. 2000. "Characterization of a Novel Sphingosine 1-Phosphate Receptor, Edg-8." The Journal of Biological Chemistry 275 (19): 14281-86. https://doi.org/10.1074/jbc.275.19.14281.

Imeri, Faik, Olivier Blanchard, Aurelio Jenni, Stephanie Schwalm, Christin Wünsche, Aleksandra Zivkovic, Holger Stark, Josef Pfeilschifter, and Andrea Huwiler. 2015. "FTY720 and Two Novel Butterfly Derivatives Exert a General AntiInflammatory Potential by Reducing Immune Cell Adhesion to Endothelial Cells through Activation of S1P(3) and Phosphoinositide 3-Kinase." NaunynSchmiedeberg's Archives of Pharmacology 388 (12): 1283-92. https://doi.org/10.1007/s00210-015-1159-5.

Imran, Tasnim F., Frederick Yick, Suneet Verma, Christopher Estiverne, Chinonye Ogbonnaya-Odor, Srikanth Thiruvarudsothy, Alluru S. Reddi, and Neil Kothari. 2016. "Lupus Nephritis: An Update." Clinical and Experimental Nephrology 20 (1): 1-13. https://doi.org/10.1007/s10157-015-1179-y.

Ishii, Isao, Beth Friedman, Xiaoqin Ye, Shuji Kawamura, Christine McGiffert, James J. A. Contos, Marcy A. Kingsbury, Guangfa Zhang, Joan Heller Brown, and Jerold Chun. 2001. "Selective Loss of Sphingosine 1-Phosphate Signaling with No Obvious Phenotypic Abnormality in Mice Lacking Its G Protein-Coupled Receptor, LPB3/EDG-3." Journal of Biological Chemistry 276 (36): 33697704. https://doi.org/10.1074/jbc.M104441200.

Ishizawa, Sho, Junko Takahashi-Fujigasaki, Yasushi Kanazawa, Keiichiro Matoba, Daiji Kawanami, Tamotsu Yokota, Takeo Iwamoto, Naoko Tajima, Yoshinobu Manome, and Kazunori Utsunomiya. 2014. "Sphingosine-1-Phosphate Induces Differentiation of Cultured Renal Tubular Epithelial Cells under Rho Kinase Activation via the S1P2 Receptor." Clinical and Experimental Nephrology 18 (6): 844-52. https://doi.org/10.1007/s10157-014-0933-x.

Jarman, Kate E., Paul A. B. Moretti, Julia R. Zebol, and Stuart M. Pitson. 2010. "Translocation of Sphingosine Kinase 1 to the Plasma Membrane Is Mediated by Calcium- and Integrin-Binding Protein 1." The Journal of Biological Chemistry 285 (1): 483-92. https://doi.org/10.1074/jbc.M109.068395. 
Jenne, Craig N., Anselm Enders, Richard Rivera, Susan R. Watson, Alexander J. Bankovich, Joao P. Pereira, Ying Xu, et al. 2009. "T-Bet-Dependent S1P5 Expression in NK Cells Promotes Egress from Lymph Nodes and Bone Marrow." Journal of Experimental Medicine 206 (11): 2469-81. https://doi.org/10.1084/jem.20090525.

Jia, Ting, Hannes Olauson, Karolina Lindberg, Risul Amin, Karin Edvardsson, Bengt Lindholm, Göran Andersson, et al. 2013. "A Novel Model of Adenine-Induced Tubulointerstitial Nephropathy in Mice.” BMC Nephrology 14 (May): 116. https://doi.org/10.1186/1471-2369-14-116.

Jo, Sang-Kyung, Amandeep Bajwa, Hong Ye, Amy L. Vergis, Alaa S. Awad, Yugesh Kharel, Kevin R. Lynch, and Mark D. Okusa. 2009. "Divergent Roles of Sphingosine Kinases in Kidney Ischemia-Reperfusion Injury." Kidney International 75 (2): 167-175.

Kajander, Kajsa, Eveliina Myllyluoma, Sinikka Kyrönpalo, Martin Rasmussen, Pentti Sipponen, Ismo Mattila, Tuulikki Seppänen-Laakso, Heikki Vapaatalo, Matej Oresic, and Riitta Korpela. 2009. "Elevated Pro-Inflammatory and Lipotoxic Mucosal Lipids Characterise Irritable Bowel Syndrome." World Journal of Gastroenterology 15 (48): 6068-74. https://doi.org/10.3748/wjg.15.6068.

Kang, Hyun Mi, Seon Ho Ahn, Peter Choi, Yi-An Ko, Seung Hyeok Han, Frank Chinga, Ae Seo Deok Park, et al. 2015. "Defective Fatty Acid Oxidation in Renal Tubular Epithelial Cells Has a Key Role in Kidney Fibrosis Development." Nature Medicine 21 (1): 37-46. https://doi.org/10.1038/nm.3762.

Kanzler, Stephan, Ansgar W. Lohse, Andrea Keil, Jürgen Henninger, Hans P. Dienes, Peter Schirmacher, Stefan Rose-John, Karl H. Meyer Zum Büschenfelde, and Manfred Blessing. 1999. "TGF-B1 in Liver Fibrosis: An Inducible Transgenic Mouse Model to Study Liver Fibrogenesis." American Journal of Physiology-Gastrointestinal and Liver Physiology 276 (4): G105968. https://doi.org/10.1152/ajpgi.1999.276.4.G1059.

Kawahara, Atsuo, Tsuyoshi Nishi, Yu Hisano, Hajime Fukui, Akihito Yamaguchi, and Naoki Mochizuki. 2009. "The Sphingolipid Transporter Spns2 Functions in Migration of Zebrafish Myocardial Precursors." Science 323 (5913): 524-27. https://doi.org/10.1126/science.1167449.

“KDOQI Clinical Practice Guideline for Diabetes and CKD: 2012 Update." 2012. American Journal of Kidney Diseases 60 (5): 850-86. https://doi.org/10.1053/j.ajkd.2012.07.005. 
Ke, Po-Yuan, and Steve S.-L. Chen. 2012. "Hepatitis C Virus and Cellular Stress Response: Implications to Molecular Pathogenesis of Liver Diseases." Viruses 4 (10): 2251-90. https://doi.org/10.3390/v4102251.

Kendig, Derek M., Alec K. Matsumoto, and Robert S. Moreland. 2013. "Sphingosine1-Phosphate Induced Contraction of Bladder Smooth Muscle." European Journal of Pharmacology 720 (0). https://doi.org/10.1016/j.ejphar.2013.10.004.

Khayrullin, Andrew, Priyanka Krishnan, Luis Martinez-Nater, Bharati Mendhe, Sadanand Fulzele, Yutao Liu, Julie A. Mattison, and Mark W. Hamrick. 2019. "Very Long-Chain C24:1 Ceramide Is Increased in Serum Extracellular Vesicles with Aging and Can Induce Senescence in Bone-Derived Mesenchymal Stem Cells." Cells 8 (1). https://doi.org/10.3390/cells8010037.

Kim, Su-Mi, Sang-Ho Lee, Yang-Gyun Kim, Se-Yun Kim, Jung-Woo Seo, YoungWook Choi, Dong-Jin Kim, et al. 2015. "Hyperuricemia-Induced NLRP3 Activation of Macrophages Contributes to the Progression of Diabetic Nephropathy." American Journal of Physiology-Renal Physiology 308 (9): F993-1003. https://doi.org/10.1152/ajprenal.00637.2014.

Klessens, Celine Q. F., Malu Zandbergen, Ron Wolterbeek, Jan A. Bruijn, Ton J. Rabelink, Ingeborg M. Bajema, and Daphne H. T. IJpelaar. 2017. "Macrophages in Diabetic Nephropathy in Patients with Type 2 Diabetes." Nephrology, Dialysis, Transplantation: Official Publication of the European Dialysis and Transplant Association - European Renal Association 32 (8): 1322-29. https://doi.org/10.1093/ndt/gfw260.

Klingele, Matthias, and Doreen Brodmann, eds. 2017. Einführung in die Nephrologie und Nierenersatzverfahren. Berlin, Heidelberg: Springer Berlin Heidelberg. https://doi.org/10.1007/978-3-662-54583-6.

Koch, Alexander, Josef Pfeilschifter, and Andrea Huwiler. 2013. "Sphingosine 1Phosphate in Renal Diseases." Cellular Physiology and Biochemistry 31 (6): 745-60. https://doi.org/10.1159/000350093.

Kong, Ping, Panagiota Christia, and Nikolaos G. Frangogiannis. 2014. "The Pathogenesis of Cardiac Fibrosis." Cellular and Molecular Life Sciences 71 (4): 549-74. https://doi.org/10.1007/s00018-013-1349-6.

Kono, Mari, Inna A. Belyantseva, Athanasia Skoura, Gregory I. Frolenkov, Matthew F. Starost, Jennifer L. Dreier, Darcy Lidington, et al. 2007. "Deafness and Stria Vascularis Defects in S1P2 Receptor-Null Mice." The Journal of Biological Chemistry 282 (14): 10690-96. https://doi.org/10.1074/jbc.M700370200. 
Kuć, Kamil, Paweł Kiciński, Sylwia Przybylska-Kuć, Jerzy Mosiewicz, and Wojciech Myśliński. 2010. "[Serum creatinine level and eGFR as the indices of renal function in present-day clinical practice]." Przeglad Lekarski 67 (7): 491-95.

LaBach, J. P., and D. C. White. 1969. "Identification of Ceramide Phosphorylethanolamine and Ceramide Phosphorylglycerol in the Lipids of an Anaerobic Bacterium." Journal of Lipid Research 10 (5): 528-34.

Laemmli, U. K. 1970. "Cleavage of Structural Proteins during the Assembly of the Head of Bacteriophage T4.” Nature 227 (5259): 680-85. https://doi.org/10.1038/227680a0.

Lai, Li-Wen, K. C. Yong, S. Igarashi, and Y.-Hh Lien. 2007. "A Sphingosine-1Phosphate Type 1 Receptor Agonist Inhibits the Early T-Cell Transient Following Renal Ischemia-Reperfusion Injury." Kidney International 71 (12): 1223-1231.

Larsen, Reinhard. 2016. Anästhesie und Intensivmedizin für die Fachpflege. 9th ed. Berlin Heidelberg: Springer-Verlag. https://doi.org/10.1007/978-3-662-504444.

Laviad, Elad L., Lee Albee, Irene Pankova-Kholmyansky, Sharon Epstein, Hyejung Park, Alfred H. Merrill, and Anthony H. Futerman. 2008. "Characterization of Ceramide Synthase 2 TISSUE DISTRIBUTION, SUBSTRATE SPECIFICITY, AND INHIBITION BY SPHINGOSINE 1-PHOSPHATE." Journal of Biological Chemistry 283 (9): 5677-84. https://doi.org/10.1074/jbc.M707386200.

Laviad, Elad L., Samuel Kelly, Alfred H. Merrill, and Anthony H. Futerman. 2012. "Modulation of Ceramide Synthase Activity via Dimerization." Journal of Biological Chemistry 287 (25): 21025-33. https://doi.org/10.1074/jbc.M112.363580.

Lee, Hyun Soon. 2011. "Role of TGF-ß in Mesangial Matrix Accumulation in Chronic Progressive Glomerular Disease." An Update on Glomerulopathies - Etiology and Pathogenesis, September. https://doi.org/10.5772/21988.

Lee, M. J., J. R. Van Brocklyn, S. Thangada, C. H. Liu, A. R. Hand, R. Menzeleev, S. Spiegel, and T. Hla. 1998. "Sphingosine-1-Phosphate as a Ligand for the $G$ Protein-Coupled Receptor EDG-1." Science (New York, N.Y.) 279 (5356): 1552-55. https://doi.org/10.1126/science.279.5356.1552.

Lee, Su-Yeon, Jung Ran Kim, Yunying Hu, Raffay Khan, Su-Jung Kim, Kalyani G. Bharadwaj, Mercy M. Davidson, et al. 2012. "Cardiomyocyte Specific Deficiency of Serine Palmitoyltransferase Subunit 2 Reduces Ceramide but Leads to Cardiac Dysfunction." Journal of Biological Chemistry 287 (22): 18429-39. https://doi.org/10.1074/jbc.M111.296947. 
Lei, Lei, Liang Ping Li, Zhen Zeng, Jing Xi Mu, Xue Yang, Chao Zhou, Zhi Lan Wang, and Hu Zhang. 2018. "Value of Urinary KIM-1 and NGAL Combined with Serum Cys C for Predicting Acute Kidney Injury Secondary to Decompensated Cirrhosis." Scientific Reports 8 (1): 7962. https://doi.org/10.1038/s41598-01826226-6.

Lemaitre Rozenn N., Jensen Paul N., Hoofnagle Andrew, McKnight Barbara, Fretts Amanda M., King Irena B., Siscovick David S., et al. 2019. "Plasma Ceramides and Sphingomyelins in Relation to Heart Failure Risk." Circulation: Heart Failure 12 (7): e005708.

https://doi.org/10.1161/CIRCHEARTFAILURE.118.005708.

Leonard, Edward J, and Teizo Yoshimura. 1990. "Human Monocyte Chemoattractant Protein-1 (MCP-1)." Immunology Today 11 (January): 97-101. https://doi.org/10.1016/0167-5699(90)90035-8.

Lepley, Denise, Ji-Hye Paik, Timothy Hla, and Fernando Ferrer. 2005. "The G Protein-Coupled Receptor S1P2 Regulates Rho/Rho Kinase Pathway to Inhibit Tumor Cell Migration." Cancer Research 65 (9): 3788-95. https://doi.org/10.1158/0008-5472.CAN-04-2311.

Levy, Michal, and Anthony H. Futerman. 2010a. "Mammalian Ceramide Synthases." IUBMB Life 62 (5): 347-56. https://doi.org/10.1002/iub.319. 2010b. "Mammalian Ceramide Synthases." IUBMB Life 62 (5): 347-56. https://doi.org/10.1002/iub.319.

Li, Jin H., Xiao R. Huang, Hong-Jian Zhu, Richard Johnson, and Hui Y. Lan. 2003. "Role of TGF- $\beta$ Signaling in Extracellular Matrix Production under High Glucose Conditions." Kidney International 63 (6): 2010-19. https://doi.org/10.1046/j.1523-1755.2003.00016.x.

Li, Mei-Hong, Teresa Sanchez, Anna Pappalardo, Kevin R. Lynch, Timothy Hla, and Fernando Ferrer. 2008. "Induction of Antiproliferative Connective Tissue Growth Factor Expression in Wilms' Tumor Cells by Sphingosine-1-Phosphate Receptor 2." Molecular Cancer Research 6 (10): 1649-56. https://doi.org/10.1158/1541-7786.MCR-07-2048.

Liu, H., M. Sugiura, V. E. Nava, L. C. Edsall, K. Kono, S. Poulton, S. Milstien, T. Kohama, and S. Spiegel. 2000. "Molecular Cloning and Functional Characterization of a Novel Mammalian Sphingosine Kinase Type 2 Isoform." The Journal of Biological Chemistry 275 (26): 19513-20. https://doi.org/10.1074/jbc.M002759200. 
Liu, Hong, Rachelle E. Toman, Sravan K. Goparaju, Michael Maceyka, Victor E. Nava, Heidi Sankala, Shawn G. Payne, et al. 2003. "Sphingosine Kinase Type 2 Is a Putative BH3-Only Protein That Induces Apoptosis." Journal of Biological Chemistry 278 (41): 40330-36. https://doi.org/10.1074/jbc.M304455200.

Liu, Xing, Kun Ren, Rong Suo, Sheng-Lin Xiong, Qing-Hai Zhang, Zhong-Cheng Mo, Zhen-Li Tang, Yue Jiang, Xiao-Shan Peng, and Guang-Hui Yi. 2016. "ApoA-I Induces S1P Release from Endothelial Cells through ABCA1 and SR-BI in a Positive Feedback Manner." Journal of Physiology and Biochemistry, July. https://doi.org/10.1007/s13105-016-0504-6.

Liu, Y., R. Wada, T. Yamashita, Y. Mi, C. X. Deng, J. P. Hobson, H. M. Rosenfeldt, et al. 2000. "Edg-1, the G Protein-Coupled Receptor for Sphingosine-1Phosphate, Is Essential for Vascular Maturation." The Journal of Clinical Investigation 106 (8): 951-61. https://doi.org/10.1172/JCI10905.

Lott, Dominik, Pierre-Eric Juif, Jasper Dingemanse, and Andreas Krause. 2020. "Modelling Pharmacokinetics and Pharmacodynamics of the Selective S1P1 Receptor Modulator Cenerimod in Healthy Subjects and Systemic Lupus Erythematosus Patients." British Journal of Clinical Pharmacology 86 (4): 791800. https://doi.org/10.1111/bcp.14182.

Lovisa, Sara, Valerie S. LeBleu, Björn Tampe, Hikaru Sugimoto, Komal Vadnagara, Julienne L. Carstens, Chia-Chin Wu, et al. 2015. "Epithelial-to-Mesenchymal Transition Induces Cell Cycle Arrest and Parenchymal Damage in Renal Fibrosis." Nature Medicine 21 (9): 998-1009. https://doi.org/10.1038/nm.3902.

Ludwig-Portugall, Isis, Eva Bartok, Ermanila Dhana, Beatrix D. G. Evers, Michael J. Primiano, J. Perry Hall, Bernardo S. Franklin, et al. 2016. "An NLRP3-Specific Inflammasome Inhibitor Attenuates Crystal-Induced Kidney Fibrosis in Mice." Kidney International 90 (3): 525-39. https://doi.org/10.1016/j.kint.2016.03.035.

Maceyka, Michael, Kuzhuvelil B. Harikumar, Sheldon Milstien, and Sarah Spiegel. 2012. "Sphingosine-1-Phosphate Signaling and Its Role in Disease." Trends in Cell Biology 22 (1): 50-60. https://doi.org/10.1016/j.tcb.2011.09.003.

MacLennan, A. J., P. R. Carney, W. J. Zhu, A. H. Chaves, J. Garcia, J. R. Grimes, K. J. Anderson, S. N. Roper, and N. Lee. 2001. "An Essential Role for the H218/AGR16/Edg-5/LP(B2) Sphingosine 1-Phosphate Receptor in Neuronal Excitability." The European Journal of Neuroscience 14 (2): 203-9. https://doi.org/10.1046/j.0953-816x.2001.01634.x. 
Malchinkhuu, Enkhzol, Koichi Sato, Tomohiko Maehama, Chihiro Mogi, Hideaki Tomura, Shogo Ishiuchi, Yuhei Yoshimoto, Hitoshi Kurose, and Fumikazu Okajima. 2008. "S1P2 Receptors Mediate Inhibition of Glioma Cell Migration through Rho Signaling Pathways Independent of PTEN." Biochemical and Biophysical Research Communications 366 (4): 963-68. https://doi.org/10.1016/j.bbrc.2007.12.054.

Martini, Sebastian, Stephanie Krämer, Tanja Loof, Yingrui Wang-Rosenke, Ute Daig, Klemens Budde, Hans-H. Neumayer, and Harm Peters. 2007. "S1P Modulator FTY720 Limits Matrix Expansion in Acute Anti-Thy1 Mesangioproliferative Glomerulonephritis." American Journal of Physiology. Renal Physiology 292 (6): F1761-1770. https://doi.org/10.1152/ajprenal.00253.2006.

Matanes, Faris, Waleed O. Twal, and Samar M. Hammad. 2019. "Sphingolipids as Biomarkers of Disease." In Bioactive Ceramides in Health and Disease: Intertwined Roles of Enigmatic Lipids, edited by Johnny Stiban, 109-38. Advances in Experimental Medicine and Biology. Cham: Springer International Publishing. https://doi.org/10.1007/978-3-030-21162-2_7.

Matloubian, Mehrdad, Charles G. Lo, Guy Cinamon, Matthew J. Lesneski, Ying Xu, Volker Brinkmann, Maria L. Allende, Richard L. Proia, and Jason G. Cyster. 2004. "Lymphocyte Egress from Thymus and Peripheral Lymphoid Organs Is Dependent on S1P Receptor 1." Nature 427 (6972): 355-60. https://doi.org/10.1038/nature02284.

Mayol, Katia, Vincent Biajoux, Jacqueline Marvel, Karl Balabanian, and Thierry Walzer. 2011. "Sequential Desensitization of CXCR4 and S1P5 Controls Natural Killer Cell Trafficking." Blood 118 (18): 4863-71.

https://doi.org/10.1182/blood-2011-06-362574.

Meeusen, Jeffrey W., Leslie J. Donato, Sandra C. Bryant, Linnea M. Baudhuin, Peter B. Berger, and Allan S. Jaffe. 2018. "Plasma Ceramides." Arteriosclerosis, Thrombosis, and Vascular Biology 38 (8): 1933-39. https://doi.org/10.1161/ATVBAHA.118.311199.

Mendoza, Alejandra, Béatrice Bréart, Willy D. Ramos-Perez, Lauren A. Pitt, Michael Gobert, Manjula Sunkara, Juan J. Lafaille, Andrew J. Morris, and Susan R. Schwab. 2012. "The Transporter Spns2 Is Required for Secretion of Lymph but Not Plasma Sphingosine-1-Phosphate." Cell Reports 2 (5): 1104-10. https://doi.org/10.1016/j.celrep.2012.09.021.

Meng, Xiao-Ming, David J. Nikolic-Paterson, and Hui Yao Lan. 2016. "TGF-ß: The Master Regulator of Fibrosis." Nature Reviews. Nephrology 12 (6): 325-38. https://doi.org/10.1038/nrneph.2016.48. 
Mesicek, Judith, Hyunmi Lee, Taya Feldman, Xuejun Jiang, Anastasia Skobeleva, Evgeny V. Berdyshev, Adriana Haimovitz-Friedman, Zvi Fuks, and Richard Kolesnick. 2010. "Ceramide Synthases 2, 5, and 6 Confer Distinct Roles in Radiation-Induced Apoptosis in HeLa Cells." Cellular Signalling 22 (9): 13001307. https://doi.org/10.1016/j.cellsig.2010.04.006.

Meyer zu Heringdorf, Dagmar, Karoly Liliom, Michael Schaefer, Kerstin Danneberg, Jonathan H. Jaggar, Gabor Tigyi, and Karl H. Jakobs. 2003. "Photolysis of Intracellular Caged Sphingosine-1-Phosphate Causes Ca2+ Mobilization Independently of G-Protein-Coupled Receptors." FEBS Letters 554 (3): 44349. https://doi.org/10.1016/S0014-5793(03)01219-5.

Mishra, Jaya, Kiyoshi Mori, Qing Ma, Caitlin Kelly, Jun Yang, Mark Mitsnefes, Jonathan Barasch, and Prasad Devarajan. 2004. "Amelioration of Ischemic Acute Renal Injury by Neutrophil Gelatinase-Associated Lipocalin." Journal of the American Society of Nephrology 15 (12): 3073-82. https://doi.org/10.1097/01.ASN.0000145013.44578.45.

Mitra, Poulami, Carole A. Oskeritzian, Shawn G. Payne, Michael A. Beaven, Sheldon Milstien, and Sarah Spiegel. 2006. "Role of ABCC1 in Export of Sphingosine1-Phosphate from Mast Cells." Proceedings of the National Academy of Sciences 103 (44): 16394-16399.

Mitsnefes, Mark, Philipp E. Scherer, Lisa Aronson Friedman, Ruth Gordillo, Susan Furth, Bradley A. Warady, and CKiD study group. 2014. "Ceramides and Cardiac Function in Children with Chronic Kidney Disease." Pediatric Nephrology (Berlin, Germany) 29 (3): 415-22. https://doi.org/10.1007/s00467013-2642-1.

Mizugishi, Kiyomi, Tadashi Yamashita, Ana Olivera, Georgina F. Miller, Sarah Spiegel, and Richard L. Proia. 2005. "Essential Role for Sphingosine Kinases in Neural and Vascular Development." Molecular and Cellular Biology 25 (24): 11113-21. https://doi.org/10.1128/MCB.25.24.11113-11121.2005.

Nagahashi, M., E. Y. Kim, A. Yamada, S. Ramachandran, J. C. Allegood, N. C. Hait, M. Maceyka, S. Milstien, K. Takabe, and S. Spiegel. 2013. "Spns2, a Transporter of Phosphorylated Sphingoid Bases, Regulates Their Blood and Lymph Levels, and the Lymphatic Network." The FASEB Journal 27 (3): 100111. https://doi.org/10.1096/fj.12-219618.

Nagahashi, Masayuki, Kazuaki Takabe, Krista P. Terracina, Daiki Soma, Yuki Hirose, Takashi Kobayashi, Yasunobu Matsuda, and Toshifumi Wakai. 2014. "Sphingosine-1-Phosphate Transporters as Targets for Cancer Therapy." BioMed Research International 2014: 651727. https://doi.org/10.1155/2014/651727. 
Nakano, Yoshiro, Kazuko Fujitani, Joyce Kurihara, Janet Ragan, Kazue Usui-Aoki, Lori Shimoda, Tamas Lukacsovich, et al. 2001. "Mutations in the Novel Membrane Protein Spinster Interfere with Programmed Cell Death and Cause Neural Degeneration InDrosophila Melanogaster." Molecular and Cellular Biology 21 (11): 3775-88. https://doi.org/10.1128/MCB.21.11.37753788.2001.

Nava, Victor E., Emanuela Lacana', Samantha Poulton, Hong Liu, Masako Sugiura, Keita Kono, Sheldon Milstien, Takafumi Kohama, and Sarah Spiegel. 2000. "Functional Characterization of Human Sphingosine Kinase-1." FEBS Letters 473 (1): 81-84. https://doi.org/10.1016/S0014-5793(00)01510-6.

Neubauer, Heidi A., Duyen H. Pham, Julia R. Zebol, Paul A.B. Moretti, Amanda L. Peterson, Tamara M. Leclercq, Huasheng Chan, et al. 2016. "An Oncogenic Role for Sphingosine Kinase 2." Oncotarget 7 (40): 64886-99. https://doi.org/10.18632/oncotarget.11714.

Ni, Hai-Feng, Jun-Feng Chen, Ming-Hui Zhang, Ming-Ming Pan, Jian-Dong Zhang, Hong Liu, Ri-Ning Tang, Kun-Ling Ma, and Bi-Cheng Liu. 2013. "FTY720 Attenuates Tubulointerstitial Inflammation and Fibrosis in Subtotally Nephrectomized Rats." Renal Failure 35 (7): 996-1004. https://doi.org/10.3109/0886022X.2013.809006.

Nickolas, Thomas L., Matthew J. O'Rourke, Jun Yang, Meghan E. Sise, Pietro A. Canetta, Nicholas Barasch, Charles Buchen, et al. 2008. "Sensitivity and Specificity of a Single Emergency Department Measurement of Urinary Neutrophil Gelatinase-Associated Lipocalin for Diagnosing Acute Kidney Injury." Annals of Internal Medicine 148 (11): 810-19.

Nieuwenhuis, Barbara, Anja Lüth, Jerold Chun, Andrea Huwiler, Josef Pfeilschifter, Monika Schäfer-Korting, and Burkhard Kleuser. 2009. "Involvement of the ABC-Transporter ABCC1 and the Sphingosine 1-Phosphate Receptor Subtype $\mathrm{S} 1 \mathrm{P}(3)$ in the Cytoprotection of Human Fibroblasts by the Glucocorticoid Dexamethasone." Journal of Molecular Medicine (Berlin, Germany) 87 (6): 645-57. https://doi.org/10.1007/s00109-009-0468-x.

Nishi, Tsuyoshi, Naoki Kobayashi, Yu Hisano, Atsuo Kawahara, and Akihito Yamaguchi. 2014. "Molecular and Physiological Functions of Sphingosine 1Phosphate Transporters." Biochimica et Biophysica Acta (BBA) - Molecular and Cell Biology of Lipids 1841 (5): 759-65. https://doi.org/10.1016/j.bbalip.2013.07.012. 
Noda, Shinji, Shin-ichi Yoshimura, Motoshi Sawada, Takashi Naganawa, Toru Iwama, Shigeru Nakashima, and Noboru Sakai. 2001. "Role of Ceramide During Cisplatin-Induced Apoptosis in C6 Glioma Cells." Journal of NeuroOncology 52 (1): 11-21. https://doi.org/10.1023/A:1010624823158.

Nowack, Rainer, Rainer Birck, and Thomas Weinreich, eds. 2009. Dialyse und Nephrologie für Fachpersonal. 3rd ed. Berlin Heidelberg: Springer-Verlag. https://doi.org/10.1007/978-3-540-72323-3.

Nowling, Tamara K., Andrew R. Mather, Thirumagal Thiyagarajan, María José Hernández-Corbacho, Thomas W. Powers, E. Ellen Jones, Ashley J. Snider, Jim C. Oates, Richard R. Drake, and Leah J. Siskind. 2015. "Renal Glycosphingolipid Metabolism Is Dysfunctional in Lupus Nephritis." Journal of the American Society of Nephrology: JASN 26 (6): 1402-13. https://doi.org/10.1681/ASN.2014050508.

Obeid, L. M., C. M. Linardic, L. A. Karolak, and Y. A. Hannun. 1993. "Programmed Cell Death Induced by Ceramide." Science (New York, N.Y.) 259 (5102): 1769-71. https://doi.org/10.1126/science.8456305.

Ohmori, Tsukasa, Yutaka Yatomi, Makoto Osada, Fuminori Kazama, Toshiro Takafuta, Hitoshi Ikeda, and Yukio Ozaki. 2003. "Sphingosine 1-Phosphate Induces Contraction of Coronary Artery Smooth Muscle Cells via S1P2." Cardiovascular Research 58 (1): 170-77. https://doi.org/10.1016/s00086363(03)00260-8.

Okamoto, Hiroyuki, Noriko Takuwa, Takehiko Yokomizo, Naotoshi Sugimoto, Soutaro Sakurada, Hiroshi Shigematsu, and Yoh Takuwa. 2000. "Inhibitory Regulation of Rac Activation, Membrane Ruffling, and Cell Migration by the G ProteinCoupled Sphingosine-1-Phosphate Receptor EDG5 but Not EDG1 or EDG3." Molecular and Cellular Biology 20 (24): 9247-61. https://doi.org/10.1128/MCB.20.24.9247-9261.2000.

Okazaki, Hitoaki, Daisuke Hirata, Takeshi Kamimura, Hidetomo Sato, Masahiro Iwamoto, Taku Yoshio, Junichi Masuyama, et al. 2002. "Effects of FTY720 in MRL-Lpr/Lpr Mice: Therapeutic Potential in Systemic Lupus Erythematosus." The Journal of Rheumatology 29 (4): 707-16.

Olivera, A., T. Kohama, L. Edsall, V. Nava, O. Cuvillier, S. Poulton, and S. Spiegel. 1999. "Sphingosine Kinase Expression Increases Intracellular Sphingosine-1Phosphate and Promotes Cell Growth and Survival." The Journal of Cell Biology 147 (3): 545-58. https://doi.org/10.1083/jcb.147.3.545. 
Olivera, A., and S. Spiegel. 1993. "Sphingosine-1-Phosphate as Second Messenger in Cell Proliferation Induced by PDGF and FCS Mitogens." Nature 365 (6446): 557-60. https://doi.org/10.1038/365557a0.

Osborne, Nick, Koroboshka Brand-Arzamendi, Elke A. Ober, Suk-Won Jin, Heather Verkade, Nathalia Glickman Holtzman, Deborah Yelon, and Didier Y. R. Stainier. 2008. "The Spinster Homolog, Two of Hearts, Is Required for Sphingosine 1-Phosphate Signaling in Zebrafish." Current Biology 18 (23): 1882-88. https://doi.org/10.1016/j.cub.2008.10.061.

Paik, Ji H., Sung-suk Chae, Menq-Jer Lee, Shobha Thangada, and Timothy Hla. 2001. "Sphingosine 1-Phosphate-Induced Endothelial Cell Migration Requires the Expression of EDG-1 and EDG-3 Receptors and Rho-Dependent Activation of Avß3- and B1-Containing Integrins." Journal of Biological Chemistry 276 (15): 11830-37. https://doi.org/10.1074/jbc.M009422200.

Panzer, Ulf, Oliver M. Steinmetz, Jan-Eric Turner, Catherine Meyer-Schwesinger, Claudia von Ruffer, Tobias N. Meyer, Gunther Zahner, et al. 2009. "Resolution of Renal Inflammation: A New Role for NF-KB1 (P50) in Inflammatory Kidney Diseases." American Journal of Physiology-Renal Physiology 297 (2): F429_ 39. https://doi.org/10.1152/ajprenal.90435.2008.

Paradis, Valerie, Gabriel Perlemuter, Franck Bonvoust, Delphine Dargere, Beatrice Parfait, Michel Vidaud, Marc Conti, et al. 2001. "High Glucose and Hyperinsulinemia Stimulate Connective Tissue Growth Factor Expression: A Potential Mechanism Involved in Progression to Fibrosis in Nonalcoholic Steatohepatitis." Hepatology 34 (4): 738-44. https://doi.org/10.1053/jhep.2001.28055.

Parrill, Abby L., Santiago Lima, and Sarah Spiegel. 2012. "Structure of the First Sphingosine 1-Phosphate Receptor." Science Signaling 5 (225): pe23. https://doi.org/10.1126/scisignal.2003160.

Patyna, Sammy, Stefan Büttner, Timon Eckes, Nicholas Obermüller, Christine Bartel, Axel Braner, Sandra Trautmann, et al. 2019. "Blood Ceramides as Novel Markers for Renal Impairment in Systemic Lupus Erythematosus." Prostaglandins \& Other Lipid Mediators 144 (October): 106348. https://doi.org/10.1016/j.prostaglandins.2019.106348.

Peest, Ulrike, Sven-Christian Sensken, Paul Andréani, Petra Hänel, Paul P. Van Veldhoven, and Markus H. Gräler. 2008. "S1P-Lyase Independent Clearance of Extracellular Sphingosine 1-Phosphate after Dephosphorylation and Cellular Uptake." Journal of Cellular Biochemistry 104 (3): 756-72. https://doi.org/10.1002/jcb.21665. 
Peters, Harm, Sebastian Martini, Yingrui Wang, Fuijo Shimizu, Hiroshi Kawachi, Stephanie Krämer, and Hans-H. Neumayer. 2004. "Selective Lymphocyte Inhibition by FTY720 Slows the Progressive Course of Chronic Anti-Thy 1 Glomerulosclerosis." Kidney International 66 (4): 1434-43. https://doi.org/10.1111/j.1523-1755.2004.00906.x.

Petrache, Irina, Krzysztof Kamocki, Christophe Poirier, Yael Pewzner-Jung, Elad L. Laviad, Kelly S. Schweitzer, Mary Van Demark, Matthew J. Justice, Walter C. Hubbard, and Anthony H. Futerman. 2013. "Ceramide Synthases Expression and Role of Ceramide Synthase-2 in the Lung: Insight from Human Lung Cells and Mouse Models." PLOS ONE 8 (5): e62968. https://doi.org/10.1371/journal.pone.0062968.

Pewzner-Jung, Yael, Hyejung Park, Elad L. Laviad, Liana C. Silva, Sujoy Lahiri, Johnny Stiban, Racheli Erez-Roman, et al. 2010. "A Critical Role for Ceramide Synthase 2 in Liver Homeostasis." The Journal of Biological Chemistry 285 (14): 10902-10. https://doi.org/10.1074/jbc.M109.077594.

Prozialeck, Walter C., Joshua R. Edwards, Peter C. Lamar, Jie Liu, Vishal S. Vaidya, and Joseph V. Bonventre. 2009. "Expression of Kidney Injury Molecule-1 (Kim-1) in Relation to Necrosis and Apoptosis during the Early Stages of CdInduced Proximal Tubule Injury." Toxicology and Applied Pharmacology, New Insights into the Mechanisms of Cadmium Toxicity, 238 (3): 306-14. https://doi.org/10.1016/j.taap.2009.01.016.

Pyne, S., J. S. Long, N. T. Ktistakis, and N. J. Pyne. 2005. "Lipid Phosphate Phosphatases and Lipid Phosphate Signalling." Biochemical Society Transactions 33 (Pt 6): 1370-74. https://doi.org/10.1042/BST20051370.

Rajamäki, Kristiina, Jani Lappalainen, Katariina Öörni, Elina Välimäki, Sampsa Matikainen, Petri T. Kovanen, and Kari K. Eklund. 2010. "Cholesterol Crystals Activate the NLRP3 Inflammasome in Human Macrophages: A Novel Link between Cholesterol Metabolism and Inflammation." PLOS ONE 5 (7): e11765. https://doi.org/10.1371/journal.pone.0011765.

Rebillard, Amélie, Xavier Tekpli, Olivier Meurette, Odile Sergent, Gwenaëlle LeMoigne-Muller, Laurent Vernhet, Morgane Gorria, et al. 2007. "CisplatinInduced Apoptosis Involves Membrane Fluidification via Inhibition of NHE1 in Human Colon Cancer Cells." Cancer Research 67 (16): 7865-74. https://doi.org/10.1158/0008-5472.CAN-07-0353. 
Rees, Frances, Michael Doherty, Matthew J. Grainge, Peter Lanyon, and Weiya Zhang. 2017. "The Worldwide Incidence and Prevalence of Systemic Lupus Erythematosus: A Systematic Review of Epidemiological Studies." Rheumatology 56 (11): 1945-61. https://doi.org/10.1093/rheumatology/kex260.

Ren, Shuyu, Andrea Babelova, Kristin Moreth, Cuiyan Xin, Wolfgang Eberhardt, Anke Doller, Hermann Pavenstädt, Liliana Schaefer, Josef Pfeilschifter, and Andrea Huwiler. 2009. "Transforming Growth Factor-B2 Upregulates Sphingosine Kinase-1 Activity, Which in Turn Attenuates the Fibrotic Response to TGF-B2 by Impeding CTGF Expression." Kidney International 76 (8): 857-67. https://doi.org/10.1038/ki.2009.297.

Rother, Jürgen, Gerhild van Echten, Günter Schwarzmann, and Konrad Sandhoff. 1992. "Biosynthesis of Sphingolipids: Dihydroceramide and Not Sphinganine Is Desaturated by Cultured Cells." Biochemical and Biophysical Research Communications 189 (1): 14-20. https://doi.org/10.1016/0006291X(92)91518-U.

Saeedi, Pouya, Inga Petersohn, Paraskevi Salpea, Belma Malanda, Suvi Karuranga, Nigel Unwin, Stephen Colagiuri, et al. 2019. "Global and Regional Diabetes Prevalence Estimates for 2019 and Projections for 2030 and 2045: Results from the International Diabetes Federation Diabetes Atlas, 9th Edition." Diabetes Research and Clinical Practice 157 (November): 107843. https://doi.org/10.1016/j.diabres.2019.107843.

Saran, Rajiv, Bruce Robinson, Kevin C. Abbott, Lawrence Y. C. Agodoa, Jennifer Bragg-Gresham, Rajesh Balkrishnan, Nicole Bhave, et al. 2019. "US Renal Data System 2018 Annual Data Report: Epidemiology of Kidney Disease in the United States." American Journal of Kidney Diseases 73 (3): A7-8. https://doi.org/10.1053/j.ajkd.2019.01.001.

Saran, Rajiv, Bruce Robinson, Kevin C. Abbott, Jennifer Bragg-Gresham, Xiaoying Chen, Debbie Gipson, Haoyu Gu, et al. 2020. "US Renal Data System 2019 Annual Data Report: Epidemiology of Kidney Disease in the United States." American Journal of Kidney Diseases: The Official Journal of the National Kidney Foundation 75 (1S1): A6-7. https://doi.org/10.1053/j.ajkd.2019.09.003.

Schwalm, Stephanie, Sandra Beyer, Helena Frey, Riad Haceni, Georgios Grammatikos, Dominique Thomas, Gerd Geisslinger, Liliana Schaefer, Andrea Huwiler, and Josef Pfeilschifter. 2017. "Sphingosine Kinase-2 Deficiency Ameliorates Kidney Fibrosis by up-Regulating Smad7 in a Mouse Model of Unilateral Ureteral Obstruction." The American Journal of Pathology, August. https://doi.org/10.1016/j.ajpath.2017.06.017. 
Schwalm, Stephanie, Josef Pfeilschifter, and Andrea Huwiler. 2013. "Sphingosine-1Phosphate: A Janus-Faced Mediator of Fibrotic Diseases.” Biochimica Et Biophysica Acta 1831 (1): 239-50.

https://doi.org/10.1016/j.bbalip.2012.07.022.

Serriere-Lanneau, Valérie, Fatima Teixeira-Clerc, Liying Li, Marlies Schippers, Willie de Wries, Boris Julien, Jeanne Tran-Van-Nhieu, et al. 2007. "The Sphingosine 1-Phosphate Receptor S1P2 Triggers Hepatic Wound Healing." The FASEB Journal 21 (9): 2005-13. https://doi.org/10.1096/fj.06-6889com.

Sharma, Sushil, A G Mathur, Sapna Pradhan, D B Singh, and Sparsh Gupta. 2011. "Fingolimod (FTY720): First Approved Oral Therapy for Multiple Sclerosis." Journal of Pharmacology \& Pharmacotherapeutics 2 (1): 49-51. https://doi.org/10.4103/0976-500X.77118.

Shlipak, Michael G., Ronit Katz, Bryan Kestenbaum, Linda F. Fried, Anne B. Newman, David S. Siscovick, Lesley Stevens, and Mark J. Sarnak. 2009. "Rate of Kidney Function Decline in Older Adults: A Comparison Using Creatinine and Cystatin C." American Journal of Nephrology 30 (3): 171-78. https://doi.org/10.1159/000212381.

Siskind, Leah J., Thomas D. Mullen, Kimberly Romero Rosales, Christopher J. Clarke, María José Hernandez-Corbacho, Aimee L. Edinger, and Lina M. Obeid. 2010. "The BCL-2 Protein BAK Is Required for Long-Chain Ceramide Generation during Apoptosis." The Journal of Biological Chemistry 285 (16): 11818-26. https://doi.org/10.1074/jbc.M109.078121.

Sjöstedt, Evelina, Wen Zhong, Linn Fagerberg, Max Karlsson, Nicholas Mitsios, Csaba Adori, Per Oksvold, et al. 2020. "An Atlas of the Protein-Coding Genes in the Human, Pig, and Mouse Brain." Science 367 (6482). https://doi.org/10.1126/science.aay5947.

Spiegel, Sarah, and Sheldon Milstien. 2000. "Sphingosine-1-Phosphate: Signaling inside and Out." FEBS Letters 476 (1-2): 55-57. https://doi.org/10.1016/S0014-5793(00)01670-7. 2003. "Sphingosine-1-Phosphate: An Enigmatic Signalling Lipid." Nature Reviews. Molecular Cell Biology 4 (5): 397-407. https://doi.org/10.1038/nrm1103.

Stiban, Johnny, and Meenu Perera. 2015. "Very Long Chain Ceramides Interfere with C16-Ceramide-Induced Channel Formation: A Plausible Mechanism for Regulating the Initiation of Intrinsic Apoptosis." Biochimica et Biophysica Acta (BBA) - Biomembranes 1848 (2): 561-67. https://doi.org/10.1016/j.bbamem.2014.11.018. 
Sui, Manshu, Jin Zhou, Rujuan Xie, Xiaogang Liu, Suhong Mu, Xibei Jia, Jing Ma, and Hongchi Wu. 2012. "The Sphingosine-1-Phosphate Receptor Agonist FTY720 Prevents the Development of Anti-Glomerular Basement Membrane Glomerulonephritis." Molecular Biology Reports 39 (1): 389-97. https://doi.org/10.1007/s11033-011-0750-1.

Sun, Xiao-Jing, Chen Wang, Lu-Xia Zhang, Feng Yu, Min Chen, and Ming-Hui Zhao. 2017. "Sphingosine-1-Phosphate and Its Receptors in Anti-Neutrophil Cytoplasmic Antibody-Associated Vasculitis." Nephrology, Dialysis, Transplantation: Official Publication of the European Dialysis and Transplant Association - European Renal Association 32 (8): 1313-22. https://doi.org/10.1093/ndt/gfw427.

Sung, Sun Hee, Soyoun Woo, and Seung Joo Lee. 2000. "Correlation between Renal Growth Retardation and Apoptosis of Cortical Tubules in Experimentally Induced Acute Ascending Pyelonephritis in Infant Rat." Korean J Pathol 34 (12): 1001.

Takabe, Kazuaki, Steven W. Paugh, Sheldon Milstien, and Sarah Spiegel. 2008. "'Inside-out' Signaling of Sphingosine-1-Phosphate: Therapeutic Targets." Pharmacological Reviews 60 (2): 181-95. https://doi.org/10.1124/pr.107.07113.

Tashiro, Koichiro, Satoshi Tamada, Nobuyuki Kuwabara, Toshiyuki Komiya, Kaori Takekida, Toshihiro Asai, Hiroshi Iwao, et al. 2003. "Attenuation of Renal Fibrosis by Proteasome Inhibition in Rat Obstructive Nephropathy: Possible Role of Nuclear Factor KB." International Journal of Molecular Medicine 12 (4): 587-92. https://doi.org/10.3892/ijmm.12.4.587.

Thangada Shobha, Shapiro Linda H., Silva Cynthia, Yamase Harold, Hla Timothy, and Ferrer Fernando A. 2014. "Treatment with the Immunomodulator FTY720 (Fingolimod) Significantly Reduces Renal Inflammation in Murine Unilateral Ureteral Obstruction." Journal of Urology 191 (5S): 1508-16. https://doi.org/10.1016/j.juro.2013.10.072.

Uhlén, Mathias, Linn Fagerberg, Björn M. Hallström, Cecilia Lindskog, Per Oksvold, Adil Mardinoglu, Åsa Sivertsson, et al. 2015. "Tissue-Based Map of the Human Proteome." Science 347 (6220). https://doi.org/10.1126/science.1260419.

Uhlén, Mathias, Max J. Karlsson, Andreas Hober, Anne-Sophie Svensson, Julia Scheffel, David Kotol, Wen Zhong, et al. 2019. "The Human Secretome." Science Signaling 12 (609). https://doi.org/10.1126/scisignal.aaz0274. 
Uhlen, Mathias, Max J. Karlsson, Wen Zhong, Abdellah Tebani, Christian Pou, Jaromir Mikes, Tadepally Lakshmikanth, et al. 2019. "A Genome-Wide Transcriptomic Analysis of Protein-Coding Genes in Human Blood Cells." Science (New York, N.Y.) 366 (6472). https://doi.org/10.1126/science.aax9198.

Van Brocklyn, James R., Catherine A. Jackson, Dennis K. Pearl, Mark S. Kotur, Pamela J. Snyder, and Thomas W. Prior. 2005. "Sphingosine Kinase-1 Expression Correlates with Poor Survival of Patients with Glioblastoma Multiforme: Roles of Sphingosine Kinase Isoforms in Growth of Glioblastoma Cell Lines." Journal of Neuropathology and Experimental Neurology 64 (8): 695-705. https://doi.org/10.1097/01.jnen.0000175329.59092.2c.

Vu, Thiet M., Ayako-Nakamura Ishizu, Juat Chin Foo, Xiu Ru Toh, Fangyu Zhang, Ding Ming Whee, Federico Torta, et al. 2017. "Mfsd2b Is Essential for the Sphingosine-1-Phosphate Export in Erythrocytes and Platelets." Nature advance online publication (October). https://doi.org/10.1038/nature24053.

Wahab, Nadia Abdel, Katherine Harper, and Roger M. Mason. 1996. "Expression of Extracellular Matrix Molecules in Human Mesangial Cells in Response to Prolonged Hyperglycaemia." Biochemical Journal 316 (3): 985-92. https://doi.org/10.1042/bj3160985.

Walzer, Thierry, Laura Chiossone, Julie Chaix, Andrew Calver, Claude Carozzo, Laure Garrigue-Antar, Yannick Jacques, Myriam Baratin, Elena Tomasello, and Eric Vivier. 2007. "Natural Killer Cell Trafficking in Vivo Requires a Dedicated Sphingosine 1-Phosphate Receptor." Nature Immunology 8 (12): 1337-44. https://doi.org/10.1038/ni1523.

Wang, De-an, Zsolt Lorincz, Debra L. Bautista, Karoly Liliom, Gabor Tigyi, and Abby L. Parrill. 2001. "A Single Amino Acid Determines Lysophospholipid Specificity of the S1P1 (EDG1) and LPA1 (EDG2) Phospholipid Growth Factor Receptors." Journal of Biological Chemistry 276 (52): 49213-20. https://doi.org/10.1074/jbc.M107301200.

Wang, Yan, Minghao Nie, Yanhong Lu, Rui Wang, Jin Li, Bin Yang, Mingyang Xia, Haiyang Zhang, and Xiurong Li. 2015. "Fucoidan Exerts Protective Effects against Diabetic Nephropathy Related to Spontaneous Diabetes through the NF-KB Signaling Pathway in Vivo and in Vitro." International Journal of Molecular Medicine 35 (4): 1067-73.

Watson, L., K. Tullus, S. D. Marks, R. C. L. Holt, C. Pilkington, and M. W. Beresford. 2012. "Increased Serum Concentration of Sphingosine-1-Phosphate in Juvenile-Onset Systemic Lupus Erythematosus." Journal of Clinical Immunology 32 (5): 1019-25. https://doi.org/10.1007/s10875-012-9710-3. 
Weber, Karl T., Yao Sun, Syamal K. Bhattacharya, Robert A. Ahokas, and Ivan C. Gerling. 2013. "Myofibroblast-Mediated Mechanisms of Pathological Remodelling of the Heart." Nature Reviews Cardiology 10 (1): 15-26. https://doi.org/10.1038/nrcardio.2012.158.

Weigert, Andreas, Susanne Schiffmann, Divya Sekar, Stephanie Ley, Heidi Menrad, Christian Werno, Sabine Grosch, Gerd Geisslinger, and Bernhard Brüne. 2009. "Sphingosine Kinase 2 Deficient Tumor Xenografts Show Impaired Growth and Fail to Polarize Macrophages towards an Anti-Inflammatory Phenotype." International Journal of Cancer 125 (9): 2114-21. https://doi.org/10.1002/ijc.24594.

Weisheit, Christina K., Daniel R. Engel, and Christian Kurts. 2015. "Dendritic Cells and Macrophages: Sentinels in the Kidney." Clinical Journal of the American Society of Nephrology 10 (10): 1841-51. https://doi.org/10.2215/CJN.07100714.

Windh, Rolf T., Menq-Jer Lee, Timothy Hla, Songzhu An, Alastair J. Barr, and David R. Manning. 1999. "Differential Coupling of the Sphingosine 1-Phosphate Receptors Edg-1, Edg-3, and H218/Edg-5 to the Gi, Gq, and G12 Families of Heterotrimeric G Proteins." Journal of Biological Chemistry 274 (39): 2735158. https://doi.org/10.1074/jbc.274.39.27351.

Won Park, S., M. Kim, K. M. Brown, V. D. D'Agati, and H. T. Lee. 2012. "Inhibition of Sphingosine 1-Phosphate Receptor 2 Protects against Renal IschemiaReperfusion Injury." Journal of the American Society of Nephrology 23 (2): 266-80. https://doi.org/10.1681/ASN.2011050503.

Wu, J. M., A. M. DiPietrantonio, and T.-C. Hsieh. 2001. "Mechanism of Fenretinide (4-HPR)-Induced Cell Death.” Apoptosis 6 (5): 377-88. https://doi.org/10.1023/A:1011342220621.

Wünsche, Christin, Alexander Koch, Roel Goldschmeding, Stephanie Schwalm, Dagmar Meyer zu Heringdorf, Andrea Huwiler, and Josef Pfeilschifter. 2015. "Transforming Growth Factor B2 (TGF-B2)-Induced Connective Tissue Growth Factor (CTGF) Expression Requires Sphingosine 1-Phosphate Receptor 5 (S1P5) in Human Mesangial Cells." Biochimica et Biophysica Acta (BBA) Molecular and Cell Biology of Lipids 1851 (5): 519-26. https://doi.org/10.1016/j.bbalip.2015.01.003. 
Wynn, T. A. 2008. "Cellular and Molecular Mechanisms of Fibrosis." The Journal of Pathology 214 (2): 199-210. https://doi.org/10.1002/path.2277.

Wynn, Thomas A. 2011. "Integrating Mechanisms of Pulmonary Fibrosis." Journal of Experimental Medicine 208 (7): 1339-50. https://doi.org/10.1084/jem.20110551.

Xia, P., J. R. Gamble, L. Wang, S. M. Pitson, P. A. Moretti, B. W. Wattenberg, R. J. D'Andrea, and M. A. Vadas. 2000. "An Oncogenic Role of Sphingosine Kinase." Current Biology: CB 10 (23): 1527-30. https://doi.org/10.1016/s09609822(00)00834-4.

Xin, Cuiyan, Shuyu Ren, Burkhardt Kleuser, Soheyla Shabahang, Wolfgang Eberhardt, Heinfried Radeke, Monika Schäfer-Korting, Josef Pfeilschifter, and Andrea Huwiler. 2004. "Sphingosine 1-Phosphate Cross-Activates the Smad Signaling Cascade and Mimics Transforming Growth Factor- $\beta$-Induced Cell Responses." Journal of Biological Chemistry 279 (34): 35255-62. https://doi.org/10.1074/jbc.M312091200.

Xu, Min, Dan Liu, Li-hong Ding, Kun-ling Ma, Min Wu, Lin-li Lv, Yi Wen, Hong Liu, Rining Tang, and Bi-cheng Liu. 2014. "FTY720 Inhibits Tubulointerstitial Inflammation in Albumin Overload-Induced Nephropathy of Rats via the Sphk1 Pathway." Acta Pharmacologica Sinica 35 (12): 1537-45. https://doi.org/10.1038/aps.2014.100.

Yamada, Akimitsu, Masayuki Nagahashi, Tomoyoshi Aoyagi, Wei-Ching Huang, Santiago Lima, Nitai C. Hait, Aparna Maiti, et al. 2018. "ABCC1-Exported Sphingosine-1-Phosphate, Produced by Sphingosine Kinase 1 Shortens Survival of Mice and Patients with Breast Cancer." Molecular Cancer Research, January, molcanres.0353.2017. https://doi.org/10.1158/15417786.MCR-17-0353.

Yamanaka, Masayoshi, Daniel Shegogue, Heuping Pei, Shizhong Bu, Alicja Bielawska, Jacek Bielawski, Benjamin Pettus, Yusuf A. Hannun, Lina Obeid, and Maria Trojanowska. 2004. "Sphingosine Kinase 1 (SPHK1) Is Induced by Transforming Growth Factor- $\beta$ and Mediates TIMP-1 Up-Regulation." Journal of Biological Chemistry 279 (52): 53994-1. https://doi.org/10.1074/jbc.M410144200.

Yanagawa, Y, Y Masubuchi, and K Chiba. 1998. "FTY720, a Novel Immunosuppressant, Induces Sequestration of Circulating Mature Lymphocytes by Acceleration of Lymphocyte Homing in Rats, III. Increase in Frequency of CD62L-Positive T Cells in Peyer's Patches by FTY720-Induced Lymphocyte Homing." Immunology 95 (4): 591-94. 
Yang, Li, Benjamin D. Humphreys, and Joseph V. Bonventre. 2011. "Pathophysiology of Acute Kidney Injury to Chronic Kidney Disease: Maladaptive Repair." Controversies in Acute Kidney Injury 174: 149-55. https://doi.org/10.1159/000329385.

Yang, N., N. M. Isbel, D. J. Nikolic-Paterson, Y. Li, R. Ye, R. C. Atkins, and H. Y. Lan. 1998. "Local Macrophage Proliferation in Human Glomerulonephritis." Kidney International 54 (1): 143-51. https://doi.org/10.1046/j.15231755.1998.00978.x.

Yazdani, Saleh, Ryanne S. Hijmans, Fariba Poosti, Wendy Dam, Gerjan Navis, Harry van Goor, and Jacob van den Born. 2015. "Targeting Tubulointerstitial Remodeling in Proteinuric Nephropathy in Rats." Disease Models \& Mechanisms 8 (8): 919-30. https://doi.org/10.1242/dmm.018580.

Yoo, K. H., B. A. Thornhill, M. S. Forbes, C. M. Coleman, E. S. Marcinko, L. Liaw, and R. L. Chevalier. 2006. "Osteopontin Regulates Renal Apoptosis and Interstitial Fibrosis in Neonatal Chronic Unilateral Ureteral Obstruction." Kidney International 70 (10): 1735-41. https://doi.org/10.1038/sj.ki.5000357.

Young, Nicholas, and James R. Van Brocklyn. 2007. "Roles of Sphingosine-1Phosphate (S1P) Receptors in Malignant Behavior of Glioma Cells. Differential Effects of S1P2 on Cell Migration and Invasiveness." Experimental Cell Research 313 (8): 1615-27. https://doi.org/10.1016/j.yexcr.2007.02.009.

Zaidan, Mohamad, Runolfur Palsson, Emilie Cornec-Le Gall, Antoine Garstka, Umberto Maggiore, Patrice Deteix, Michele Battista, et al. 2014. "Recurrent 2,8-Dihydroxyadenine Nephropathy: A Rare but Preventable Cause of Renal Allograft Failure." American Journal of Transplantation : Official Journal of the American Society of Transplantation and the American Society of Transplant Surgeons 14 (11): 2623-32. https://doi.org/10.1111/ajt.12926.

Zhang, H., N. N. Desai, A. Olivera, T. Seki, G. Brooker, and S. Spiegel. 1991. "Sphingosine-1-Phosphate, a Novel Lipid, Involved in Cellular Proliferation." The Journal of Cell Biology 114 (1): 155-67. https://doi.org/10.1083/jcb.114.1.155.

Zhou, Dong, and Youhua Liu. 2016. "Renal Fibrosis in 2015: Understanding the Mechanisms of Kidney Fibrosis." Nature Reviews. Nephrology 12 (2): 68-70. https://doi.org/10.1038/nrneph.2015.215.

Zhou, Huijun, Xianli Yin, Fei Bai, Wu Liu, Shaofeng Jiang, and Jinfeng Zhao. 2020. "The Role and Mechanism of S1PR5 in Colon Cancer." Cancer Management and Research 12 (June): 4759-75. https://doi.org/10.2147/CMAR.S239118. 


\section{Kooperationspartner}

Die Extraktion, Bestimmung und Quantifizierung der Sphingolipide mit Hilfe von Flüssigchromatographie mit Elektrosprayionisation-Massenspektrometrie-Kopplung und anschließender Tandem-Massenspektrometrie (LC-ESI-MS/MS) wurden von Sandra Trautmann und Dr. Dominique Thomas aus dem Institut für Klinische Pharmakologie des Universitätsklinikums Frankfurt am Main unter der Leitung von Prof. Dr. Dr. Gerd Geißlinger durchgeführt. Die Abbildungen 22, 25, 29, 31, 34 und 37 sind auf Grundlage dieser Kooperation entstanden.

Dr. Sonja Djudjaj und Prof. Dr. Peter Boor aus dem Institut für Pathologie des Universitätsklinikums der RWTH Aachen haben die Gewebeproben der Patienten zur Verfügung gestellt und histologische Färbungen durchgeführt. Die Abbildungen 24 und 28 wurden im Rahmen dieser Zusammenarbeit zur Verfügung gestellt.

Die histologischen Färbungen zur Fibrose in den Mausgeweben wurden von Dr. Stefan Gauer aus der Abteilung für Nephrologie des Universitätsklinikums Frankfurt am Main durchgeführt. Im Rahmen dieser Kooperation wurden die Abbildungen 19 und 33 zur Verfügung gestellt.

Prof. Dr. H. J. Gröne, Leiter der Abteilung für Zelluläre und Molekulare Pathologie am DKFZ in Heidelberg, stellte die Abbildung $11 \mathrm{~B}$ zur Verfügung, welche eine semiquantitative RT-PCR zur Bestimmung der Expression von $\mathrm{S} \mathrm{P}_{5}$ in der humanen Niere und ihren Bestandteilen auf mRNA-Ebene zeigt. 


\section{Erklärung}

Hiermit versichere ich, dass die vorliegende Arbeit von mir eigenständig und nur mit den angegebenen Mitteln, sowie unter Beachtung der Grundsätze der guten wissenschaftlichen Praxis, angefertigt wurde. Daten, die von Koooperationpartner zur Verfügung gestellt wurden, sind entsprechend ausgewiesen und zusätzlich explizit auf Seite 148 aufgelistet.

Die Daten aus dem Abschnitt 3.2 mit den Abbildungen 23, 24 ,25 , 27, 28, 29, 31, 32, 33, 34 und 35B wurden bereits in dem wissenschaftlichen Artikel "Consistent Alteration of Chain Length-Specific Ceramides in Human and Mouse Fibrotic Kidneys" in Biochimica Et Biophysica Acta Molecular and Cell Biology of Lipids; Band 1866, Ausgabe 1, Januar 2021 veröffentlicht.

Für Abbildungen, die aus externen Quellen stammen oder bereits publiziert sind, wurde die Erlaubnis zur Verwendung eingeholt.

Frankfurt am Main, den 18.01.2021

Timon Sebastian Eckes 